
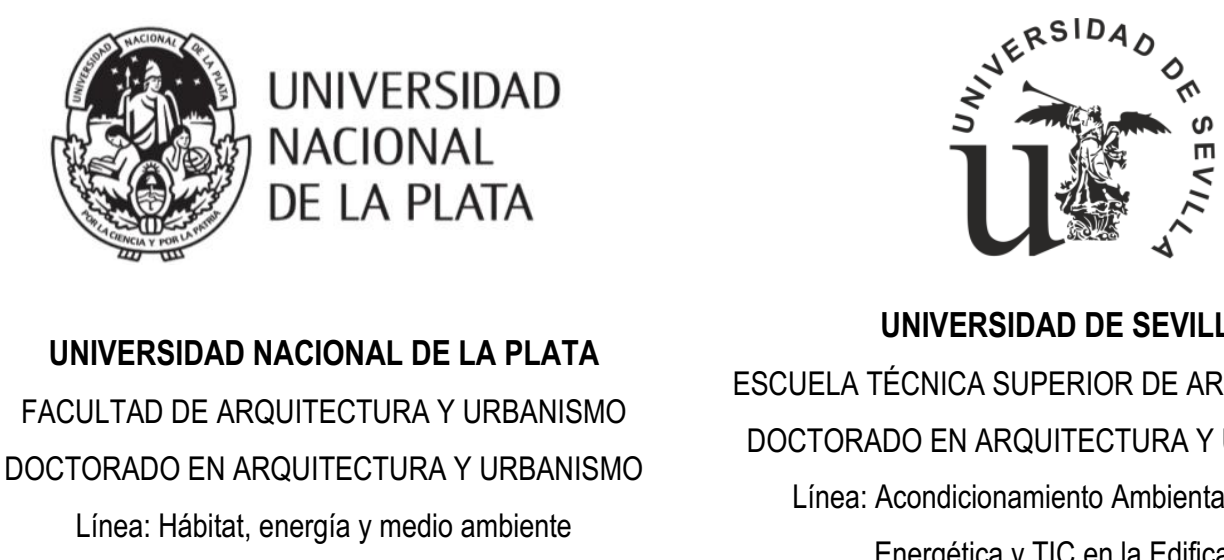

UNIVERSIDAD DE SEVILLA

ESCUELA TÉCNICA SUPERIOR DE ARQUITECTURA DOCTORADO EN ARQUITECTURA Y URBANISMO

Línea: Acondicionamiento Ambiental, Eficiencia

Energética y TIC en la Edificación

\title{
METODOLOGÍA DE CÁLCULO SIMPLIFICADO PARA EL CONSUMO ENERGÉTICO EN ACONDICIONAMIENTO DE EDIFICIOS RESIDENCIALES EN CLIMA TEMPLADO
}

TOMO I

Tesis doctoral presentada por

GABRIELA REUS NETTO

ante la Facultad de Arquitectura y Urbanismo de la Universidad Nacional de La Plata y la Universidad de Sevilla

para acceder al grado académico de

DOCTOR EN ARQUITECTURA Y URBANISMO

Dirección de tesis en cotutela:

Director: Dr. Ing. Arq. Jorge Daniel Czajkowski - UNLP

Codirectora: Dra. María del Pilar Mercader Moyano - US 


Únicamente el que hace, aprende. Friedrich Nietzsche 


\section{Agradecimientos}

La presente tesis es el resultado de una experiencia iniciada hace ocho años, aún como alumna oyente en el curso de Arquitectura y Hábitat Sustentable de la Facultad de Arquitectura y Urbanismo de la Universidad Nacional de La Plata - FAU UNLP, continuó posteriormente como alumna de la Maestría de Arquitectura y Hábitat Sustentable de la FAU UNLP, y actualmente como alumna del Doctorado en Arquitectura y Urbanismo de la FAU UNLP en cotutela con la Escuela Técnica Superior de Arquitectura de la Universidad de Sevilla - ETSA US.

Este trabajo pudo realizarse gracias al soporte económico de una beca de postgrado CONICET con sede en el Laboratorio de Arquitectura y Hábitat Sustentable - LAyHS FAU UNLP, una beca de estadías cortas para miembros de instituciones de ciencia y tecnología en el exterior del Programa BEC.AR con sede en el Departamento de Construcciones Arquitectónicas I de la ETSA US, y una Ayuda para Movilidad Internacional de Estudiantes de Doctorado para el Desarrollo de Tesis Co-Tuteladas de la Universidad de Sevilla, las cuales permitieron mi dedicación exclusiva a las tareas de investigación.

A lo largo de estos años, muchas personas dentro del ámbito académico, y también por fuera de ello, dedicaron su tiempo a enseñarme y a apoyarme.

Jorge despertó en mí el interés por el confort térmico y la eficiencia energética en la arquitectura, primero como alumna y luego como becaria parte del equipo de trabajo en el LAyHS. Depositó su confianza en mí, alentando mis ideas, despejando mis inquietudes e indicando el camino para materializar este trabajo.

Analía demostró gran capacidad y practicidad al proponer soluciones, organizar datos y eventos, aspectos que poco a poco busqué incorporar en mi proceso de investigación.

Pilar me permitió analizar la investigación desde otra perspectiva. Generó discusiones y aportes valiosos que contribuyeron a delimitar la problemática y el ámbito del trabajo, para que su materialización fuera posible. 
Santiago me presentó, con tamaña generosidad, el mundo de la simulación energética. Hizo con que fuera sencillo comprender y manejar los diferentes procesos de construcción de los modelos energéticos, motivando la definición de los programas computacionales empleadas en este trabajo.

Ana María me introdujo al análisis de datos cuantitativos. Me llamaba la arquitecta debido a mi dificultad en comprender los términos y las inferencias utilizadas en clase. Su experiencia, convicción, y capacidad de transmitir el conocimiento, despertaron en mí el entusiasmo por la comprobación de los datos, motivando la definición de los métodos estadísticos empleados en esta investigación.

Todos los momentos compartidos con compañeros de clase, y docentes de los cursos de postgrado a los que asistí durante los años dedicados al avance de esta investigación, permitieron reforzar mis ideales de que si bien todavía hay mucho por hacer, estamos en el camino correcto.

Sara, Gustavo y Juan me dieron el espacio para construir y compartir mi pasión con el equipo docente del taller Vertical de Arquitectura. Una experiencia humana e inspiradora, que me permitió superar los momentos críticos de la investigación.

Juan, Estela, Cristina, Antonio, y Carmen, así como el personal administrativo del departamento de Postgrado de la FAU UNLP, y el departamento de Doctorado de la US, brindaron atención y paciencia para responder a mis inquietudes y auxiliar en cada procedimiento necesario.

Paz me regaló consejos, ejemplos, abrazos y alegrías. Me invitó a participar de su vida, y se integró a la mía.

David me acompañó a escribir emails, en los caminos del trabajo a casa, y en las inúmeras historias de la vida.

Patri me enseñó que la capacidad, la simplicidad, y la generosidad pueden caminar de la mano.

Roberto me ayudó desde mi primer día en La Plata, tanto en los procesos para cebar un mate, como en las mudanzas de hogar.

Walter y Vivi me hicieron sentir identificada con las diferencias existentes entre Argentina, Brasil y Colombia. Posibilitaron que la experiencia de insertarse en otra cultura sea más enriquecedora, menos desafiante, $\mathrm{y}$ brindaron una amistad sin fronteras.

Las chicas me ofrecieron una silla para ocupar y quedarme. Me involucraron como si me conocieran desde años, me escucharon y ayudaron en cada situación, con compañerismo, alegría y amor.

Laura estuvo presente a cualquier hora, en cualquier situación, todo el tiempo. Meu presente argentino, exemplo de capacidade e fortaleza.

Ale me acompañó en todas las etapas, desde el principio de esta larga jornada. Me enseñó la belleza de verse a uno mismo, y el poder de mirar el mundo con otros ojos.

Tami me demostró que la distancia es solo física.

Elen estuvo presente durante toda mi estancia en Sevilla, brindando apoyo, amor y alegría ante cada situación. 
Lizia me escuchó y alentó en cada momento, me hizo sentir acompañada aunque tuviera un océano de por medio.

Mis padres me incentivaron a creer en mis habilidades y a buscar mis sueños, sin cuestionar cuales eran o donde estaban.

Mis hermanas fueron mi motor y despertaron mi mejor versión.

Agradezco profundamente la atención, la paciencia, y el cariño de cada uno. Cada persona fue parte de mi formación, dividiendo momentos fundamentales para la conclusión de este trabajo. 



\section{Contenido}

RESUMEN

XII

ABSTRACT

XIII

INTRODUCCIÓN | 15

1. CONSIDERACIONES PREVIAS

1.1 ACERCA Del ESTADO de LA CUESTIÓN 16

1.2 OBJETIVOS 18

1.3 Metodología y CONTENIDO de LA TESIS

2. ESTADO DE LA CUESTIÓN

2.1 SISTEMAS DE CALIFICACIÓN EDILICIA EN CLIMA TEMPLADO

2.1.1 CONTEXTO DE IMPLEMENTACIÓN Y APLICACIÓN 24

2.1.2 MÉTODOS Y CRITERIOS DE EVALUACIÓN 31

2.2 MODELOS DE PREDICCIÓN DE CONSUMO ENERGÉTICO EDILICIO 32 34

2.2.1 CONTEXTO DE IMPLEMENTACIÓN Y APLICACIÓN 38

2.2.2 OBJETIVOS Y VARIABLES DE ENTRADA 39

2.2.3 TÉCNICAS DE AGRUPAMIENTO DE DATOS 40

2.3 CONCLUSIONES 43

3. OBJETIVOS Y METODOLOGÍA 45 


\section{PARTE I - DELIMITACIÓN DEL ÁMBITO DE LA INVESTIGACIÓN | 51}

4. CARACTERÍSTICAS CONSTRUCTIVAS

OBJETIVO

4.1 SELECCIÓN DE LOS SISTEMAS DE CALIFICACIÓN EDILICIA E INDICADORES DE ESTUDIO

4.1.1 ARGENTINA

4.1.2 BRASIL

4.1.3 CHILE 62

4.1.4 MÉXICO 65

4.1.5 DEFINICIÓN DE LOS SISTEMAS DE CALIFICACIÓN EDILICIA

4.1.6 DEFINICIÓN DE LOS INDICADORES DE ESTUDIO

4.2 SeleCCIÓN DE LOS EDIFICIOS CASOS DE ESTUdiO

4.3 DEFINICIÓN DE LOS ESCENARIOS DE CÁLCULO

4.3.1 ARGENTINA

4.3.2 BRASIL

4.3.3 CHILE

4.3.4 ESPAÑA

4.3.5 MÉXICO

4.3.6 DEFINICIÓN DE LAS SOLUCIONES CONSTRUCTIVAS

$\begin{array}{ll}\text { CONCLUSIONES } & 94\end{array}$

5. CARACTERÍSTICAS CLIMÁTICAS 96

OBJETIVO $\quad 96$

5.1 SELECCIÓN DE LAS LOCALIDADES DE APLICACIÓN

5.1.1 DEFINICIÓN DE LAS VARIABLES CLIMÁTICAS 98

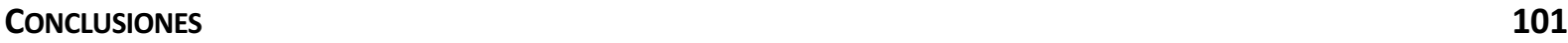

6. CARACTERÍSTICAS DE USO Y OCUPACIÓN 102

OBJETIVO $\quad 102$

6.1 APLICACIÓN DE LAS ENCUESTAS A LOS USUARIOS

6.1.1 DELIMITACIÓN DEL UNIVERSO DE ANÁLISIS Y PLANIFICACIÓN DEL MUESTREO 103

6.1.2 ELECCIÓN Y CONSTRUCCIÓN DE LAS TÉCNICAS DE OBSERVACIÓN 103

6.1.3 INTERPRETACIÓN DE LOS RESULTADOS 105

6.2 REALIZACIÓN DEL MONITOREO ENERGÉTICO

6.2.1. CARACTERÍSTICAS DEL CLIMA

6.2.2. PROCEDIMIENTO DE MEDICIÓN

6.2.3 CONDICIONES DEL AMBIENTE INTERIOR 116

$\begin{array}{ll}\text { CONCLUSIONES } & 119\end{array}$ 
PARTE II - CUANTIFICACIÓN DEL CONSUMO ENERGÉTICO | 121

7. MODELO ENERGÉTICO

OBJetivo

123

7.1 CONSTRUCCIÓN DEL MODELO ENERGÉTICO

7.1.1 MODELADO DE LOS EDIFICIOS

$\begin{array}{ll}7.2 \text { VALIDACIÓN DEL MODELO ENERGÉTICO } & 127\end{array}$

7.2.1 ANÁLISIS DE INCERTIDUMBRE 128

7.3 CUANTIFICACIÓN DEL CONSUMO ENERGÉTICO

$\begin{array}{ll}\text { CONCLUSIONES } & 137\end{array}$

8. MODELO ESTADÍSTICO

OBJEtIVO

141

8.1 ANÁLISIS DE REGRESIÓN LINEAL MÚLTIPLE

8.1.1 MUESTRA DE ESTUDIO 142

$\begin{array}{ll}\text { 8.1.2 VARIABLE PRINCIPAL } & 147\end{array}$

$\begin{array}{ll}\text { 8.1.3 VARIABLES SECUNDARIAS } & 149\end{array}$

8.1.4 DEFINICIÓN DE LAS ECUACIONES 152

8.1.5 CompaRACIÓN CON LOS MÉTOdOS DE CÁlCULO DE BRASIL, CHILE, Y ESPAÑa 154

$\begin{array}{ll}\text { CONCLUSIONES } & 163\end{array}$

9. MODELO DE EFICIENCIA ENERGÉTICA

OBJeTIVO $\quad 165$

9.1 AHORROS ENERGÉTICOS 167

9.2 AHORROS EN EMISIONES DE CO2 169

9.3 DEFINICIÓN DE LOS ESTÁNDARES DE AHORRO

$\begin{array}{ll}\text { CONCLUSIONES } & 174\end{array}$

10. CONSIDERACIONES FINALES

BIBLIOGRAFIA

181

LISTA DE FIGURAS

LISTA DE TABLAS

LISTA DE ECUACIONES 199 


\section{Resumen}

Las regulaciones y certificaciones edilicias surgieron como un instrumento para minimizar el consumo de energía y de emisiones de gases contaminantes, mejorar la eficiencia energética, y promover una mayor transparencia con respecto al uso de energía en las edificaciones. En América Latina, más del $80 \%$ de las iniciativas existentes evalúan el rendimiento edilicio a partir de la demanda energética y del cumplimiento de valores admisibles para indicadores, mientras el $20 \%$ evalúa el rendimiento edilicio a partir del consumo energético. Entretanto, la evaluación del rendimiento edilicio a partir de la demanda y de indicadores, como por ejemplo la transmitancia térmica y el factor solar, no permiten realizar una evaluación integral de la edificación. El objetivo principal de esta investigación es desarrollar un método de cálculo simplificado para evaluar el consumo energético de edificios multifamiliares, aplicable al contexto socioeconómico de Latinoamérica. Se propone un método integral basado en la variación de las condiciones climáticas, de uso y ocupación, de las características constructivas del edificio y sus sistemas (HVAC y ACS). La metodología del trabajo se divide en tres partes, en primer lugar se delimitan las características necesarias para la elaboración del modelo energético, en seguida se cuantifica el consumo del modelo energético aplicado a 42 localidades situadas en Argentina, Brasil, Chile, España y México considerando diferentes escenarios constructivos, y en tercer lugar se construyen los modelos de cálculo simplificado y se establecen los ahorros potenciales en energía y emisiones de CO2. Los resultados muestran una confiabilidad muy alta en la predicción de los modelos estadísticos elaborados. El coeficiente de determinación es $R^{2}=0.92$ para el consumo de energía en refrigeración y $\mathrm{R}^{2}=0.94$ para calefacción. Mediante el cumplimiento de los valores mínimos de $\mathrm{U}$ para muros exteriores y techos definidos por cada país, sería posible reducir más del $20 \%$ en consumo energético y el $30 \%$ en las emisiones de CO2. En función del contexto sociocultural Latinoamericano, se estima que el método simplificado propuesto tiene una mayor posibilidad de aceptación y aplicación en comparación con los métodos de simulación, lo que permite fomentar el desarrollo y aumentar la implementación de iniciativas de eficiencia energética edilicia para mitigación del cambio climático.

Palabras clave: método de cálculo simplificado, consumo energético para refrigeración y calefacción, edificio residencial plurifamiliar, clima templado, América Latina 


\begin{abstract}
Building regulations and certifications emerged as instruments to minimize energy consumption and Greenhouse Gas Emissions, to improve energy efficiency, and to promote a transparent energy use in buildings. In Latin America, more than $80 \%$ of existing initiatives evaluates building performance based on energy demand and compliance with admissible values indicators, while $20 \%$ assesses building performance based on energy consumption. However, building performance based on energy demand and indicators, such as thermal transmittance and solar factor, does not allow a comprehensive understanding of the whole process. The main objective of this research is to develop a simplified calculation methodology to evaluate energy consumption in multi-family housing blocks to be applied in Latin America socio-economic context. An integrated method it proposes, bases on the variation of the climatic conditions, use and occupancy standards, and building constructive characteristics and systems (HVAC and DHW). The methodology has three steps: the first defines the characteristics required for the energy model, the second quantifies the energy model consumption applied to 42 cities located in Argentina, Brazil, Chile, Spain and Mexico, considering different construction scenarios, and the third builds simplified calculation models and establishes the potential energy saving in energy and $\mathrm{CO}_{2}$ emissions reduction. Results show a very high confidence in the prediction of the elaborated statistical models. The coefficient of determination is $R^{2}=0.92$ for cooling energy consumption and $R^{2}=0.94$ for heating. By means of the compliance of minimum $U$ values for exterior walls and ceilings defined by each country, it would be possible to reduce over $20 \%$ of the energy consumption and $30 \%$ of the $\mathrm{CO}_{2}$ emissions. Due to the Latin America sociocultural context, the proposed simplified method has a greater possibility of acceptance and implementation, than simulation methods, promoting development and increasing the application of energy efficiency initiatives of buildings for Climate Change mitigation.
\end{abstract}

Keywords: simplified calculation method, cooling and heating energy consumption, multi-family buildings, temperate climate, Latin America. 



\section{INTRODUCCIÓN}

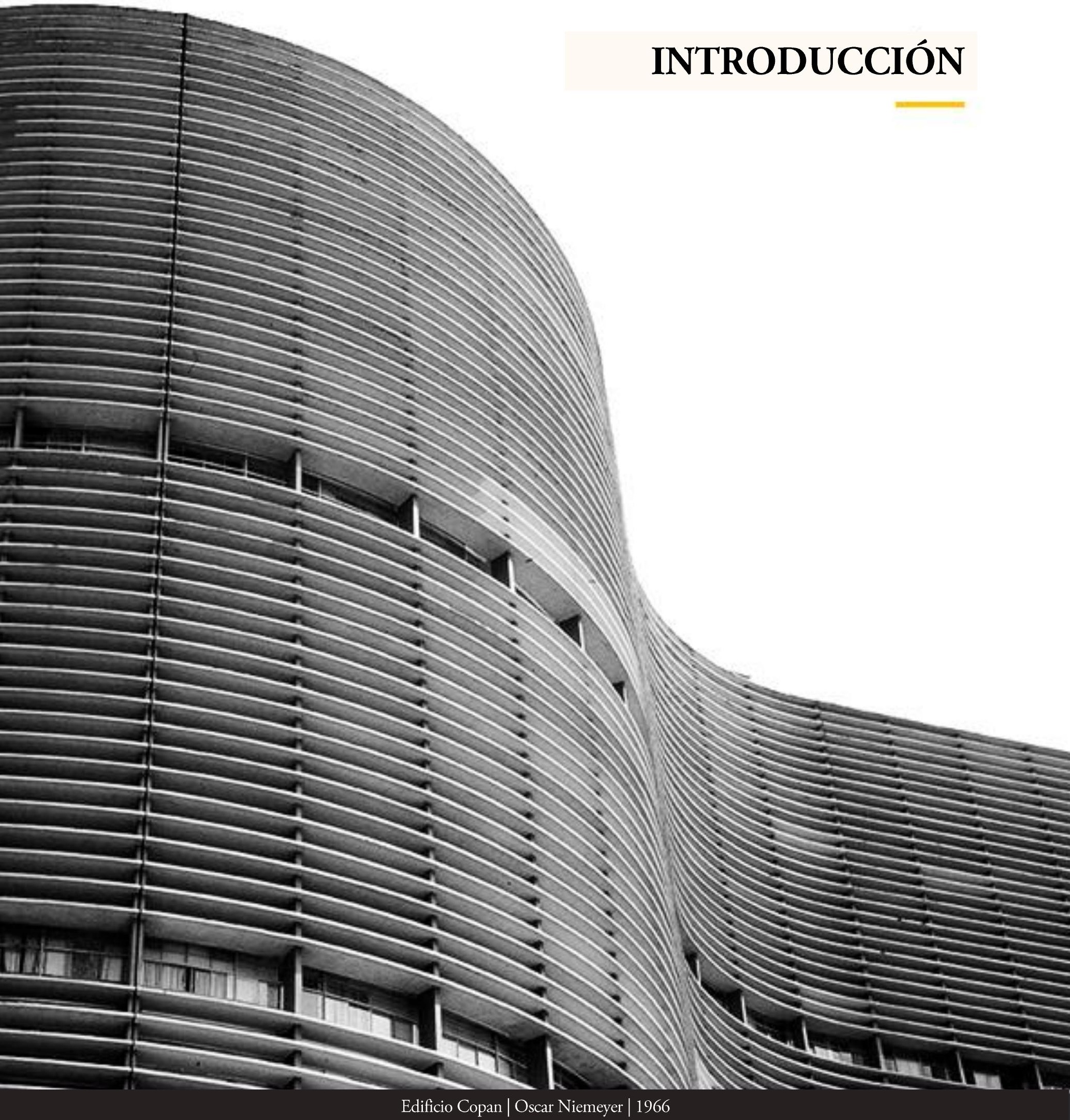




\section{Consideraciones previas}

\subsection{Acerca del estado de la cuestión}

El crecimiento continuo de la demanda energética a nivel global, sus consecuencias económicas y ambientales, han sido posiblemente una de las temáticas más discutidas en las últimas décadas.

La construcción civil es responsable por el desarrollo de una cadena de empresas vinculadas a la producción de insumos y servicios, haciendo con que desde el proceso de construcción hasta la etapa de operación, la actividad de la construcción consuma elevadas cantidades de energía, agua y materiales, y produzca importantes impactos ambientales.

En la década del 90, el mayor tiempo ocupado por los usuarios dentro de las edificaciones, y la creciente mejora en los niveles de comodidad y de vida útil de los edificios, resultaron en el incremento del consumo energético del sector de la construcción civil (Janda 2009). A finales de la década de 90, la tasa de crecimiento en el consumo de energía del sector edilicio en Europa, Asia y América había superado al sector industrial y al de transporte. Y las emisiones de $\mathrm{CO} 2$ en virtud de la actividad de la construcción civil, representaron más de un tercio de las emisiones totales del mundo (Ürge Vorsatz e Novikova 2008).

Frente a este contexto, la Agencia Internacional de Energía - AIE desarrolló en 2011, un conjunto de 25 recomendaciones de eficiencia energética para mejorar la política energética nacional de sus países miembros (International Energy Agency 2011). Dichas estrategias se centraron en siete áreas principales: intersectorial, transporte, edificios, industria, electrodomésticos y equipo, utilidades de energía, e iluminación.

Desde el punto de vista de las recomendaciones propuestas para el sector edilicio, la AIE indica que los actores gubernamentales deben: (I) aplicar un código de construcción de cumplimiento obligatorio, así como establecer estándares mínimos de rendimiento energético, (II) apoyar y fomentar la construcción de edificios con consumo energético cero, mediante el uso de un modelo de referencia para nuevas edificaciones a partir de 2020, (III) mejorar la eficiencia energéticas de 
edificios existentes, a través del fomento de programas de financiación para la implementación de medidas de ahorro, programas de auditoría energética, (IV) implementar etiquetas y certificados de eficiencia energética edilicia, y (V) establecer políticas para mejorar el rendimiento energético de los componentes críticos del edificio, tales como ventanas, sistemas de calefacción, ventilación y refrigeración (International Energy Agency 2011).

Se observa que la totalidad de las medidas establecidas para el ámbito de la construcción civil se centran en reducir el consumo de energía mediante la definición de estándares de desempeño mínimo, y soluciones para mejorar, evaluar y calificar el desempeño energético de las edificaciones.

Los principales instrumentos destinados a disminuir los consumos energéticos y minimizar el impacto ambiental edilicio son las regulaciones y las certificaciones (Casals 2006). El principal objetivo de dichas herramientas consiste en definir pautas constructivas que permitan disminuir los consumos energéticos del edificio (Triana, Lamberts e Sassi 2018). Usualmente evalúan el rendimiento térmico del edificio para proporcionar condiciones de confort, y clasifican el desempeño alcanzado a partir del cumplimiento de requerimientos prescriptivos, mediante simulaciones computacionales, o a través de mediciones in situ (Pérez-Lombard, Ortiz, et al. 2009).

En un trabajo previo realizado, se ha podido verificar que la aplicabilidad de las regulaciones y certificaciones en Latinoamérica efectivamente no se cumplen (Reus Netto 2017). Aunque existan incentivos financieros, cursos de capacitación profesional, y las exigencias de cumplimiento obligatorio se hayan postergado en diversos casos, la adopción de dichas iniciativas es reducida, ya sea por el incremento en el coste de la obra, por la complejidad de aplicación de los criterios o por falta de control por parte de las autoridades.

En la investigación llevada a cabo en la presente tesis, y detallada a continuación, se observa que el método de evaluación empleado por las regulaciones y certificaciones en Latinoamérica es predominantemente simplificado. De la misma forma en que más del $90 \%$ de las herramientas analizadas evalúan el atendimiento de criterios prescriptivos y de demanda energética. Cuando en los demás países del mundo con clima templado, más del $80 \%$ evalúa el consumo energético edilicio mediante el empleo de programas de simulación computacional.

Este trabajo busca promover el desarrollo de las regulaciones y certificaciones, incorporando el análisis de los consumos energéticos como principal indicador del desempeño térmico del edificio. Para ello, se centra en elaborar un método de cálculo simplificado, de forma que sea coherente con el contexto socioeconómico de las estrategias de eficiencia energética edilicia en Latinoamérica.

En función del método de cálculo elaborado, establece los ahorros potenciales en consumo energético y en emisiones de dióxido de carbono resultante del cumplimiento de valores mínimos de transmitancia térmica para muros y techos, lo que permite definir las bases para la construcción de un modelo de eficiencia energética para edificios residenciales en Latinoamérica. 


\subsection{Objetivos}

El objetivo de este trabajo consiste en definir una metodología de cálculo simplificado capaz de predecir el consumo energético en acondicionamiento térmico para viviendas unifamiliares y multifamiliares situadas en clima templado, con el fin de tender hacia un modelo energético ambiental basado en el análisis múltiple, que fomente el desarrollo y aumente la aplicación de iniciativas de eficiencia energética edilicia para la mitigación del cambio climático.

Este estudio busca llenar el vacío encontrado en la literatura utilizando un método integrado, fundamentado en la variación de las características climáticas, de los estándares de uso y ocupación, además de las características constructivas, morfológicas, y de las instalaciones del edificio.

Para ello, se plantean los siguientes objetivos específicos:

1 - Delimitar el enfoque de la construcción del modelo estadístico, especificando las características del clima, de uso y ocupación, del edificio, y de sus instalaciones.

2 - Construir los modelos energéticos y cuantificar los consumos en acondicionamiento.

3 - Determinar el modelo estadístico y cuantificar los ahorros potenciales en consumo energético y en emisiones de $\mathrm{CO} 2$.

Se espera que este trabajo contribuya al mejoramiento de las iniciativas de calificación edilicia ya existentes, sirviendo para disminuir las barreras encontradas en su aplicación y reforzar la importancia de investigaciones en esta temática. A largo plazo se estima poder contribuir a la creación de regulaciones y certificaciones en aquellos países con clima templado que actualmente no disponen de dichos instrumentos. De forma inmediata, se elevarán los resultados obtenidos a las reuniones del subcomité de Eficiencia Energética del Instituto Argentino de Normalización y Certificación.

\subsection{Metodología y contenido de la tesis}

Para la ejecución de este trabajo se ha simulado la aplicación de dos edificios residenciales a diferentes localidades con clima templado, con el fin de estimar su consumo energético en acondicionamiento térmico. A continuación, mediante un análisis de regresión lineal se ha analizado la correlación entre los resultados obtenidos con las características climáticas de las diferentes ciudades, permitiendo encontrar un modelo estadístico final. Finalmente se han estimado los ahorros en energía y en emisiones de $\mathrm{CO} 2$, posibilitando definir las pautas para la creación de un modelo de eficiencia energética en Latinoamérica.

Las tareas desarrolladas para concretar el objetivo propuesto se estructuraron en 3 partes principales, la cuales se subdividen en diferentes etapas interrelacionadas en el cuerpo de la tesis (Figura 1). 


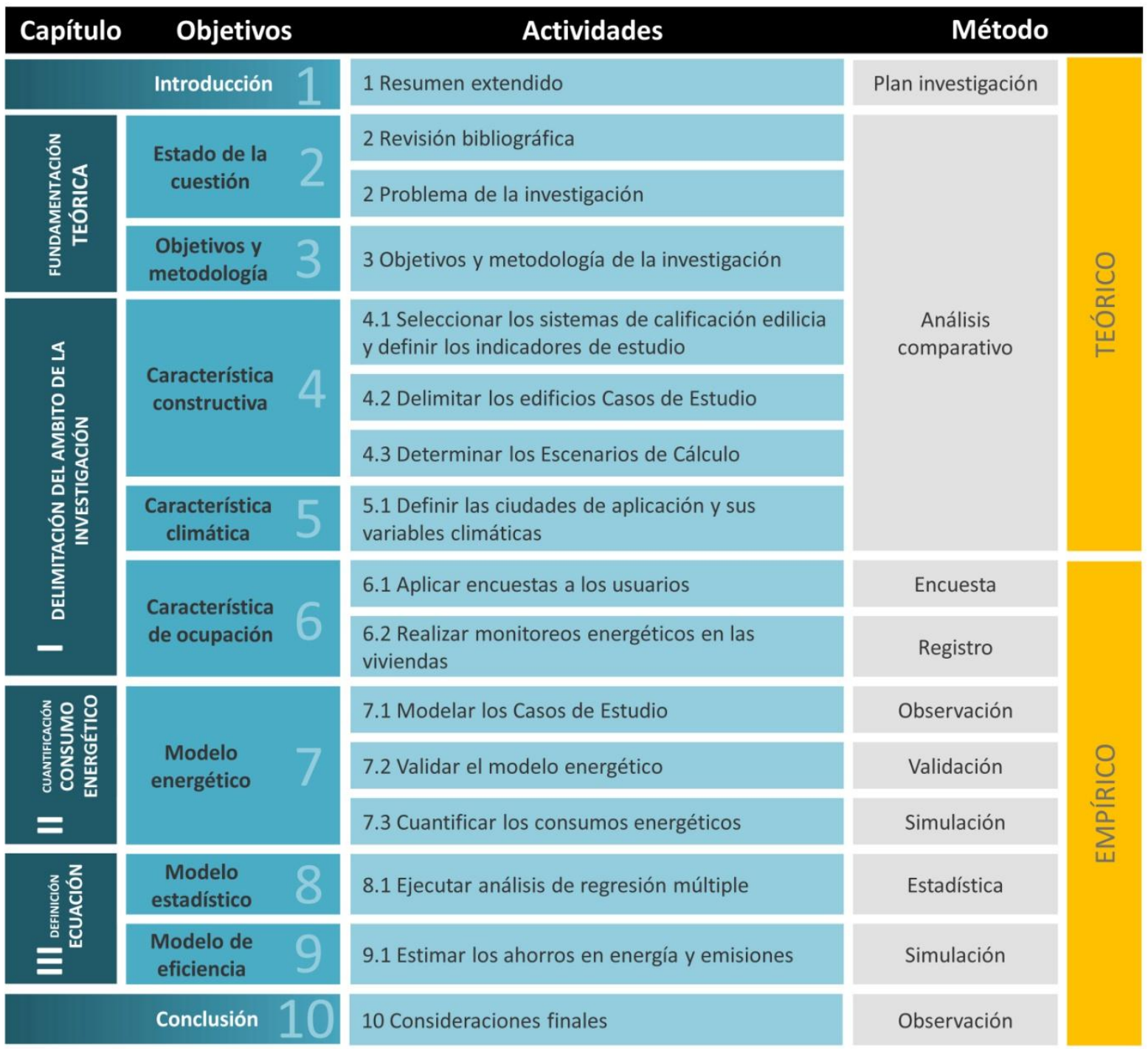

Figura 1: Metodología propuesta para el desarrollo del objetivo principal propuesto. Elaboración propia.

El contenido de la presente tesis se organiza en 6 capítulos (Figura 1):
i. El presente capítulo, denominado Introducción,
ii. Fundamentación teórica,
iii. Parte I - Delimitación del ámbito de la investigación,
iv. Parte II - Cuantificación del consumo energético,
v. Parte III - Definición de la ecuación, y
vi. Conclusión.

\section{FUNDAMENTACIÓN TEÓRICA}

El segundo capítulo construye y delimita el problema de la investigación a partir de la revisión bibliográfica de las iniciativas enfocadas en la calificación edilicia existentes en los países con clima templado. Su universo de análisis se centra en las iniciativas de certificación ambiental y energética, en los etiquetados de eficiencia energéticas y normativas que se destinen a calificar el desempeño térmico y o energético de edificios. 


\section{PARTE I - DELIMITACIÓN DEL ÁMBITO DE LA INVESTIGACIÓN}

El tercer capítulo establece la estructura en la cual se fundamenta el trabajo. Delimita las características constructivas, climáticas, de uso y ocupación, y de las instalaciones ejecutando las actividades necesarias para la materialización del objetivo secundario 1.

Los parámetros constructivos se determinan a partir de la selección de los sistemas de calificación y del análisis de sus parámetros de estudio, de la definición de los escenarios de cálculo en función de los estándares exigidos por cada sistema, y de la selección de los edificios Casos de Estudio. Su universo de análisis se fundamenta en considerar los sistemas que establezcan indicadores de confort térmico y de eficiencia energéticas que influencien las características constructivas de la envolvente, con valores objetivos. Para los Casos de Estudio el universo de análisis se fundamenta en la tipología de edificios residenciales usualmente empleados en la construcción civil Regional.

Las variables climáticas se definen a partir de la selección de las localidades de aplicación empleadas en el trabajo. Su universo de análisis se centra en considerar los países en donde se aplican los sistemas seleccionados y elegir ciudades representativas del clima templado para cada país.

Las características de uso y ocupación se establecen mediante la aplicación de encuestas a los usuarios y monitoreos en las viviendas de los Casos de Estudio seleccionados.

Las características de las instalaciones se fundamentan en el confort adaptativo y en los estándares definidos por el Código Técnico de la Edificación de España, el cual se toma como ejemplo modelo.

\section{PARTE II - CUANTIFICACIÓN DEL CONSUMO ENERGÉTICO}

El cuarto capítulo construye y valida el modelo energético a partir de los datos de uso y ocupación. A continuación realiza las simulaciones energéticas considerando los diferentes escenarios de cálculo y localidades de aplicación, ejecutando el objetivo secundario 2.

\section{PARTE III - DEFINICIÓN DE LA ECUACIÓN}

El quinto capítulo define los modelos estadísticos a partir de los análisis de regresión lineal múltiple, y estima los ahorros potenciales de alcanzar con la aplicación de los estándares de transmitancia térmica mínimos definidos para muros y techos por los países analizados en el trabajo.

Así mismo propone la elaboración de un modelo de eficiencia energética considerando los resultados de la presente investigación como estructuradores de la propuesta, lo que ejecuta el objetivo secundario 3 , y materializa el objeto principal de esta investigación. 



\section{FUNDAMENTACIÓN TEÓRICA}

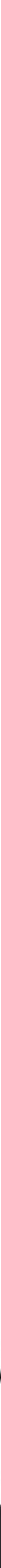




\section{Estado de la cuestión}

Las certificaciones energéticas de edificios y los requisitos normativos mínimos de aislamiento, control solar y rendimiento de las instalaciones térmicas surgieron como un método esencial para minimizar el consumo de energía y las emisiones de gases contaminantes, mejorar la eficiencia energética, y promover una mayor transparencia con respecto al uso de energía en las edificaciones (Pérez-Lombard, Ortiz, et al. 2009).

El consumo energético de los edificios se establece mediante la relación entre la demanda energética y el rendimiento de los sistemas térmicos. La demanda energética varía según las condiciones climáticas, las características de la envolvente y las condiciones operacionales y de funcionamiento del edificio ocupación, hábitos del uso de electrodomésticos, equipos e iluminación (Figura 2).

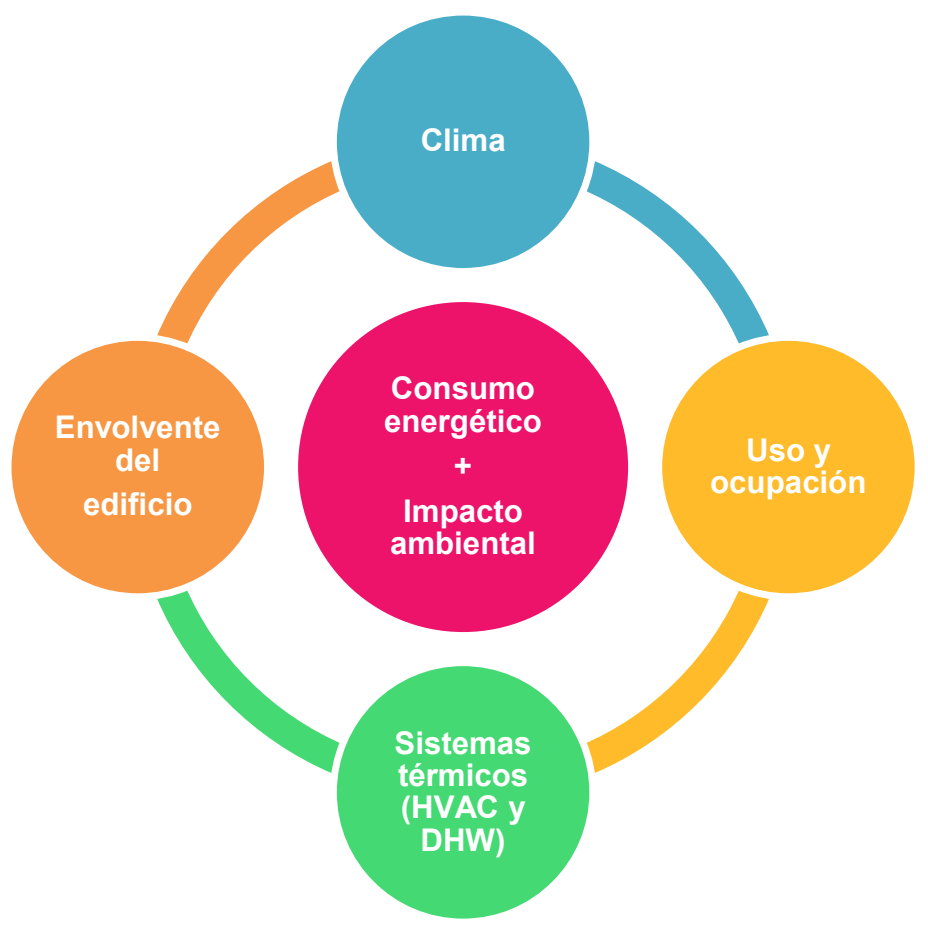

Figura 2: Relación entre las características del clima, de la envolvente, de uso y ocupación, y de las instalaciones en la determinación del consumo energético y del impacto ambiental de la edificación. Elaboración propia. 
La regulación posee un carácter normativo prescriptivo usualmente obligatorio, donde establece los criterios y los valores que deben ser atendidos para garantizar una condición mínima. La certificación se orienta al mercado de la construcción civil y consiste en una herramienta para evaluar, calificar y certificar el desempeño del edificio en relación al atendimiento de las condiciones mínimas. Con una aplicabilidad generalmente voluntaria, la certificación promueve estándares de rendimiento más elevados que las regulaciones y permite la comparación directa entre diferentes edificios (Casals 2006).

Las primeras regulaciones de eficiencia energética de edificios surgieron en la década de 50, en Francia, Suiza y Alemania debido a la preocupación de las entidades gubernamentales en disminuir el elevado consumo en calefacción de las edificaciones (Walsh, Cóstola e Chebel Labaki 2017).

Las iniciativas de calificación, surgieron en la década de 90 en Reino Unido, Alemania, y Canadá, con el objetivo de evaluar la eficiencia energética y las emisiones de CO2 de edificios (Baldwin, y otros 1990) (Feist 2006) (Cole, Rousseau e Theaker 1993). Actualmente, tanto las regulaciones como las certificaciones, se encuentran ampliamente desarrollados en el marco regulatorio de la mayor parte de los países en el mundo (Walsh, Cóstola e Chebel Labaki 2017).

\subsection{Sistemas de calificación edilicia en clima templado}

En este trabajo se han revisado 47 iniciativas de regulación y certificación de edificios, distribuidas entre 27 países de todo el mundo, con la presencia de localidades con clima templado (Tabla 1), debido a que las regiones con clima templado representan la posibilidad de trabajar con la mayor extensión territorial del mundo, la mayor densidad poblacional, y consecuentemente los mayores consumos energéticos. Los países en donde se aplican los sistemas analizados cubren el $57 \%$ de la población mundial y son responsables de consumir el $68 \%$ de la energía primaria total del mundo (U.S. Energy Information Administration 2017).

El Clima Templado (C, según la clasificación de Köppen) (Figura 3) se caracteriza por tener cuatro estaciones definidas durante el año, siendo usualmente un verano cálido con temperatura media del mes más cálido superior a $10{ }^{\circ} \mathrm{C}$, un invierno frío con temperatura media del mes más frío menor a $18{ }^{\circ} \mathrm{C}$ y superior a $-3{ }^{\circ} \mathrm{C}$, y otoño y primavera con temperaturas gradualmente más frías y calurosas respectivamente, a medida que pasan los días (Ministerio de Vivienda y Urbanismo 2016).

Se consideraron las iniciativas que disponían de información suficiente para permitir la comprensión integral de su estructura, permitiendo identificar el año de su implementación, los actores responsables por su institución, su alcance y carácter de aplicación, a qué tipo de edificio se destina, la estructura en que se encuadra, su método de evaluación y los criterios requeridos para su atendimiento. 


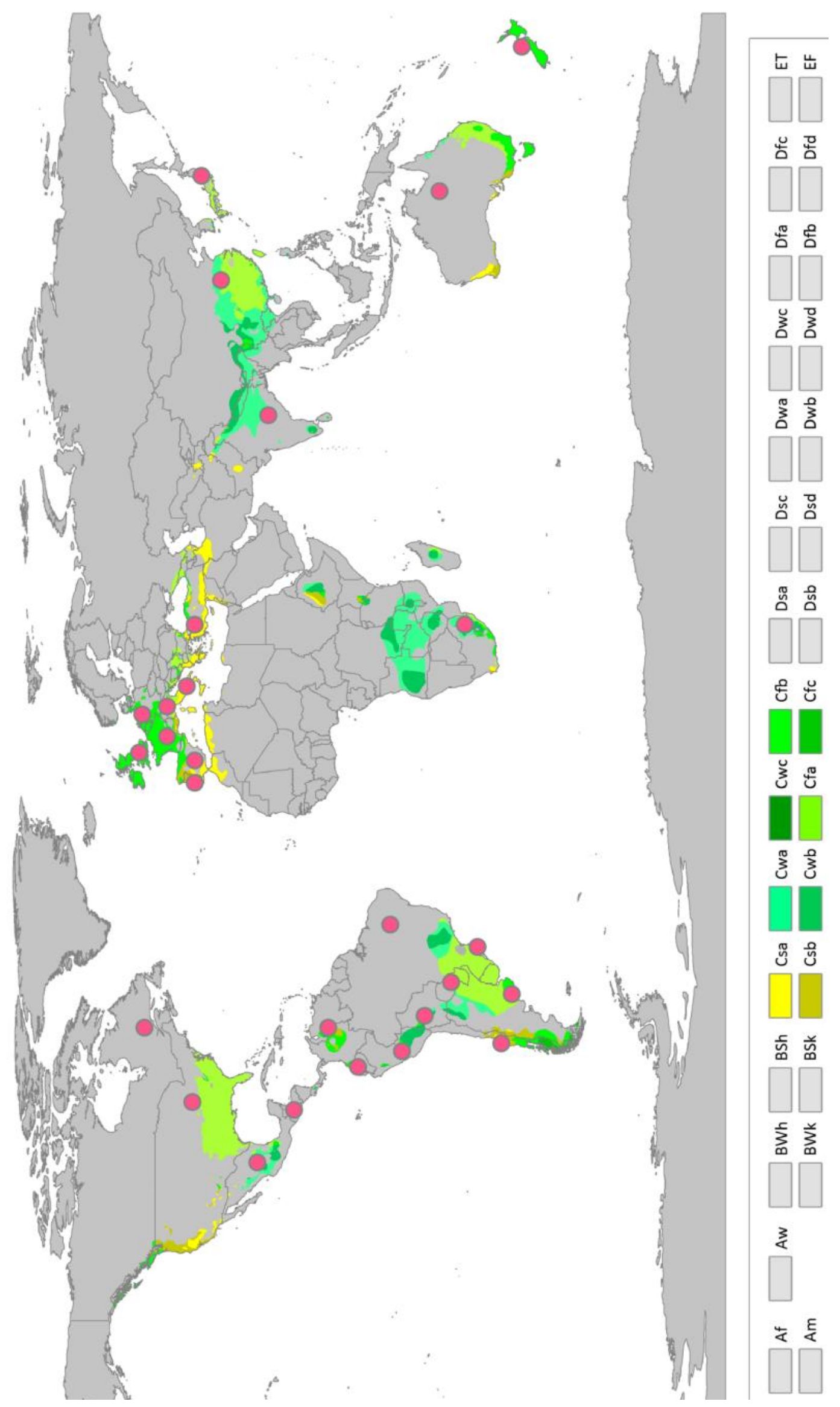

Figura 3: Países con presencia de clima templado analizados. Elaboración propia adaptada de la clasificación climática Köppen-Geiger (Ministerio de Vivienda y Urbanismo 2016). 


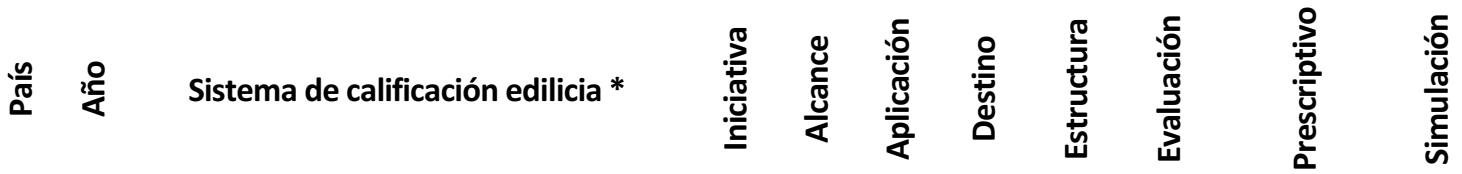

\begin{tabular}{|c|c|c|c|c|c|c|c|c|c|c|}
\hline 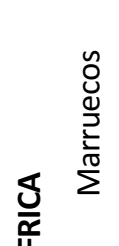 & $\stackrel{m}{\stackrel{n}{\sigma}}$ & $\begin{array}{c}\text { Thermal Regulation of Construction in } \\
\text { Morocco - RTCM (Agence Nationale } \\
\text { pour le Développement des Energies } \\
\text { Renouvelables et de I'Efficacité } \\
\text { Energétique 2013) }\end{array}$ & $\mathrm{Pu}$ & $\mathrm{N}$ & 0 & G & $\mathrm{Re}$ & $\begin{array}{c}P+S \\
+A\end{array}$ & $\begin{array}{c}\text { U, R, Rov, } \\
\text { Fs }\end{array}$ & C \\
\hline 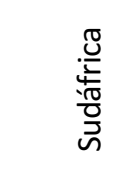 & 공 & $\begin{array}{l}\text { Energy efficiency in buildings - SANS } \\
204 \text { (South African Bureau of Standards } \\
\text { 2011) }\end{array}$ & $\mathrm{Pu}$ & $\mathrm{N}$ & 0 & G & $\mathrm{Re}$ & $\mathrm{P}+\mathrm{S}$ & $\begin{array}{l}\text { U, R, I, } \\
\text { SHGC, Pt, } \\
\text { WWR, T, } \\
\text { HR, O, D }\end{array}$ & C \\
\hline
\end{tabular}

Evaluation standard for green building

(American Society of Heating,

Refrigerating, and Air - Conditioning

$\begin{array}{llllll}\text { Pu N } & \text { Pu, } & \text { R } & \text { C }\end{array}$

Engineers 2011)

\section{Code for acceptance of energy efficient \\ building construction}

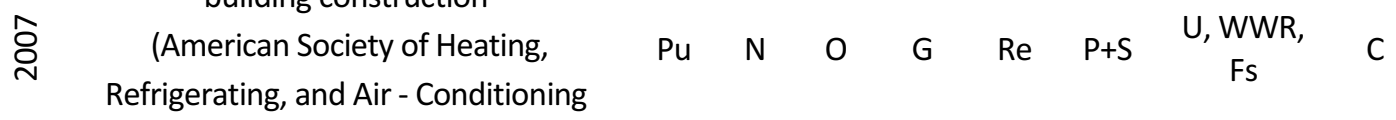
Engineers 2011)

\begin{tabular}{|c|c|c|c|c|c|c|c|c|c|c|}
\hline \multirow{2}{*}{$\stackrel{\frac{\pi}{0}}{\underline{\underline{O}}}$} & চ্ণ & $\begin{array}{l}\text { Energy conservation building code - } \\
\text { ECBC (USAID ECO-III 2009) }\end{array}$ & $\mathrm{Pu}$ & $\mathrm{N}$ & V & $C$ & $\mathrm{Re}$ & $\mathrm{P}+\mathrm{S}$ & $\begin{array}{l}\text { U, R, } \varepsilon, \alpha, \\
\rho, F s, \\
\text { SHGC, } \\
\text { VTL, } \\
\text { WWR. }\end{array}$ & C \\
\hline & ঠิ & $\begin{array}{l}\text { Green rating integrated habitat } \\
\text { Assessment - GRIHA } \\
\text { (The Energy and Resources Institute } \\
\text { 2017) }\end{array}$ & $\mathrm{Pu}$ & $\mathrm{N}$ & V & G & $\mathrm{Ce}$ & $\mathrm{P}+\mathrm{S}$ & $\mathrm{T}, \mathrm{HR}$ & C \\
\hline
\end{tabular}

\begin{tabular}{|c|c|c|c|c|c|c|c|c|c|c|}
\hline \multirow{2}{*}{$\begin{array}{l}\frac{1}{0} \\
\frac{0}{0}\end{array}$} & Яั & $\begin{array}{l}\text { Design and Construction Guidelines on } \\
\text { the Rationalization of Energy Use for } \\
\text { Houses - DCGREUH (Ministry of } \\
\text { construction 1990) }\end{array}$ & $\mathrm{Pu}$ & $\mathrm{N}$ & 0 & $\mathrm{R}$ & $\operatorname{Re}$ & $P$ & $\begin{array}{c}\mathrm{U}, \mathrm{R}, \mathrm{Rc} \\
\mathrm{Pt}\end{array}$ & - \\
\hline & ণิ & $\begin{array}{l}\text { Comprehensive Assessment System for } \\
\text { Built Environment Efficiency - CASBEE } \\
\text { (Institute for Building Environment and } \\
\text { Energy Conservation 2014) }\end{array}$ & $M$ & $\mathrm{~N}$ & V & G & $\mathrm{Ce}$ & $\begin{array}{l}P+S \\
+A\end{array}$ & $\begin{array}{l}\mathrm{T}, \mathrm{HR}, \mathrm{Ra}, \\
\mathrm{U}, \mathrm{WWR},\end{array}$ & $\begin{array}{l}\text { D, } \\
\text { C }\end{array}$ \\
\hline 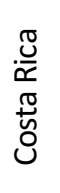 & 궁 & $\begin{array}{c}\text { Requisitos para Edificaciones } \\
\text { Sostenibles en el Trópico - RESET } \\
\text { (Instituto de Normas Técnicas de Costa } \\
\text { Rica 2012) }\end{array}$ & $M$ & $\mathrm{~N}$ & V & G & $\operatorname{Re}$ & $P$ & $\begin{array}{l}\text { U, HR, I, } \\
\text { Fs, SHGC, } \\
\text { VTL, } \\
\text { WWR }\end{array}$ & - \\
\hline
\end{tabular}




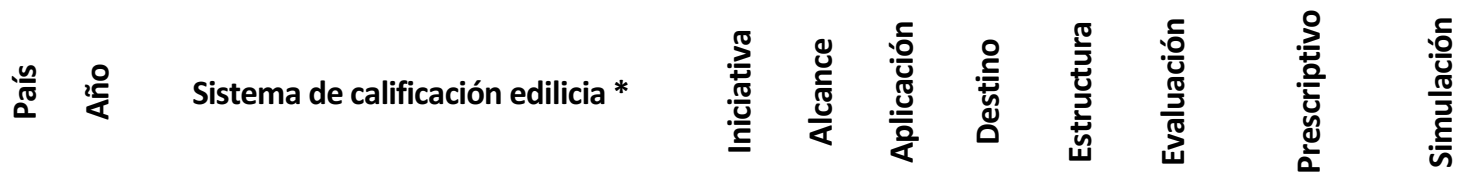

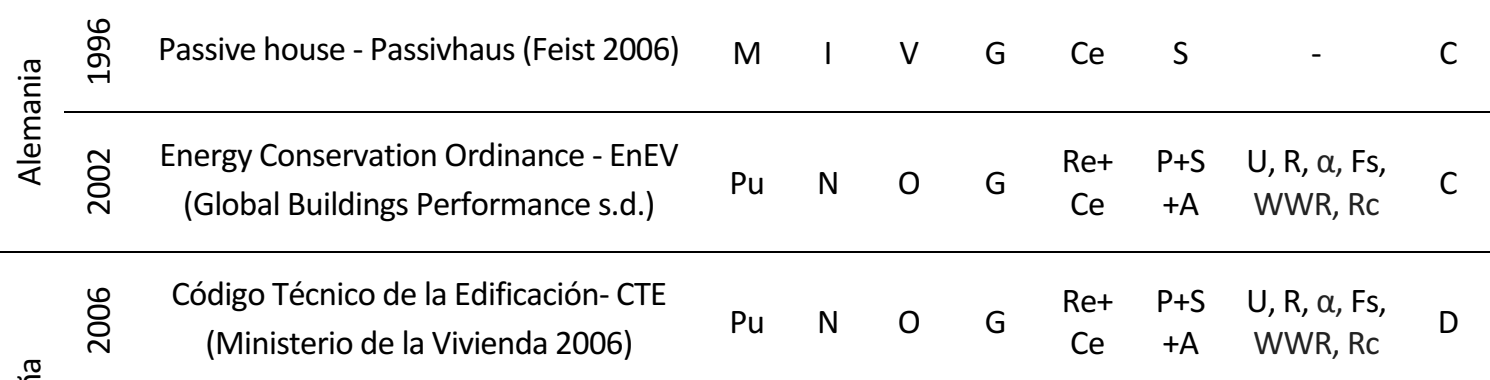

ํㅗㄴ

Certificación de eficiencia energética de

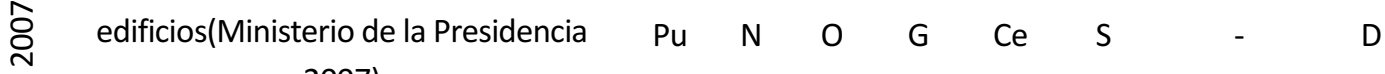

2007)

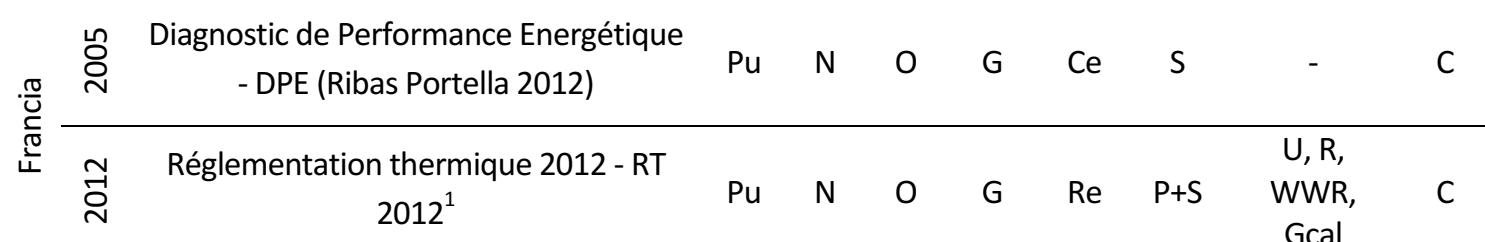

\begin{tabular}{|c|c|c|c|c|c|c|c|c|c|}
\hline$\frac{\frac{\pi}{\pi}}{ \pm}$ & ํㅛㅇ & $\begin{array}{l}\text { Rendimento energetico nell'edilizia - } \\
\text { Decreto } 192 \text { (Presidente della } \\
\text { repubblica 2005) }\end{array}$ & $\mathrm{Pu}$ & $\mathrm{N}$ & 0 & $\mathrm{G}$ & $\begin{array}{c}\mathrm{Re}+ \\
\mathrm{Ce}\end{array}$ & $\begin{array}{c}\mathrm{P}+\mathrm{S} \\
+\mathrm{A}\end{array}$ & $\begin{array}{l}\text { U, WWR, } \\
\text { Gcal Ra, } \\
\text { Pt, O, Fs, } \\
\text { VN }\end{array}$ \\
\hline
\end{tabular}

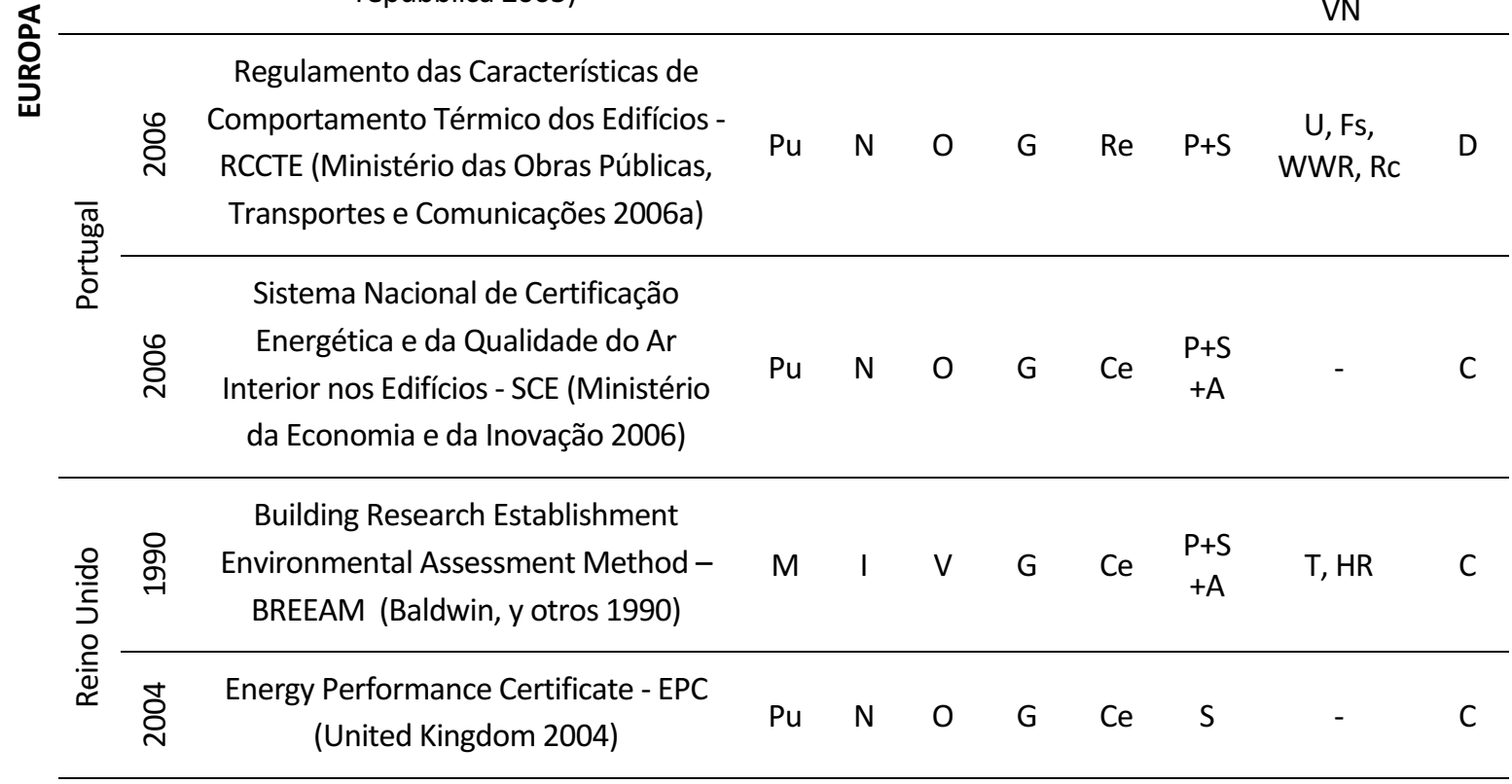

Standard of thermal energy in building

\begin{tabular}{|c|c|c|c|c|c|c|c|c|c|}
\hline $\begin{array}{l}\infty \\
\infty \\
\stackrel{్}{\sim}\end{array}$ & $\begin{array}{c}\text { construction - SIA380/1 } \\
\text { (Swiss Society of Engineers and } \\
\text { Architects 2009) }\end{array}$ & $M$ & $\mathrm{~N}$ & 0 & G & $\operatorname{Re}$ & $\mathrm{P}+\mathrm{S}$ & $\begin{array}{l}\text { U, R, } \\
\text { WWR, Fs } \\
\text { Gcal }\end{array}$ & $D$ \\
\hline જి & $\begin{array}{l}\text { Sustainable building standard - } \\
\text { MINERGIE (Lange 2017) }\end{array}$ & $M$ & $\mathrm{~N}$ & $\mathrm{~V}$ & G & $\mathrm{Ce}$ & $\begin{array}{c}\mathrm{P}+\mathrm{S} \\
+\mathrm{A}\end{array}$ & - & C \\
\hline
\end{tabular}

.continua

\footnotetext{
${ }^{1}$ Información extraída de la página web de la Regulación Térmica de https://www.rt-batiment.fr/. Acceso 19/02/18

${ }^{2}$ Información incorporada mediante la participación en el Grupo de Trabajo de Estrategias Pasivas del Subcomité de Eficiencia
} 


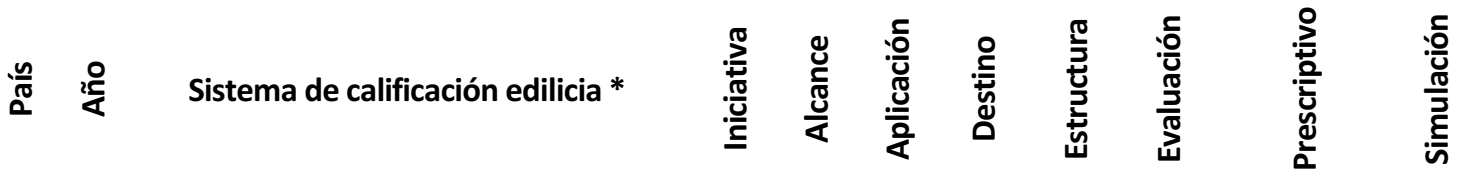

\begin{tabular}{|c|c|c|c|c|c|c|c|c|c|c|c|}
\hline \multirow{2}{*}{ 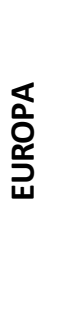 } & \multirow{2}{*}{$\frac{\sqrt[0]{\frac{0}{7}}}{\frac{0}{5}}$} & बু & $\begin{array}{c}\text { Thermal insulation requirements for } \\
\text { buildings TS825 (Turkish Standards } \\
\text { Institute 2008) }\end{array}$ & $M$ & $\mathrm{~N}$ & 0 & $\mathrm{G}$ & $\operatorname{Re}$ & $\begin{array}{l}P+S \\
+A\end{array}$ & $\begin{array}{l}\text { U, R, Pt, } \\
\text { Rc, Ra, } \\
\text { Gcal, } \\
\text { WWR, Fs }\end{array}$ & C \\
\hline & & 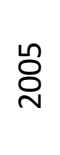 & $\begin{array}{c}\text { Energy Performance Certificates } \\
\text { (United Nations Development } \\
\text { Programme Turkey 2010) }\end{array}$ & $M$ & $\mathrm{~N}$ & 0 & $\mathrm{G}$ & $\mathrm{Ce}$ & $\begin{array}{l}P+S \\
+A\end{array}$ & - & C \\
\hline \multirow{6}{*}{ 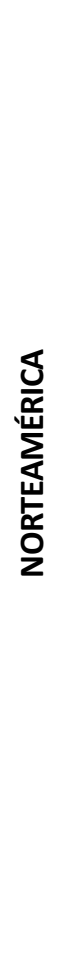 } & \multirow{2}{*}{$\begin{array}{l}\frac{\pi}{0} \\
\frac{\pi}{0} \\
\frac{\pi}{10} \\
ن\end{array}$} & $\stackrel{\text { }}{\text { ğ }}$ & $\begin{array}{c}\text { Building Environmental Performance } \\
\text { Assessment Criteria - BEPAC } \\
\text { (Cole, Rousseau e Theaker 1993) }\end{array}$ & $\mathrm{Pu}$ & $\mathrm{N}$ & V & C & $\mathrm{Ce}$ & $\begin{array}{l}P+S \\
+A\end{array}$ & - & C \\
\hline & & ڤ̆ & $\begin{array}{l}\text { Green Building Challenge - GBC (Cole e } \\
\text { Larsson 2000) }\end{array}$ & $M$ & I & $\mathrm{V}$ & G & $\mathrm{Ce}$ & $\begin{array}{l}P+S \\
+A\end{array}$ & - & $C$ \\
\hline & \multirow{2}{*}{ 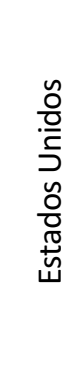 } & ஓे & $\begin{array}{l}\text { Leadership in Energy \& Environmental } \\
\text { Design - LEED (US Green Building } \\
\text { Council 2000) }\end{array}$ & $\mathrm{Pu}$ & I & $\mathrm{V}$ & $\mathrm{G}$ & $\mathrm{Ce}$ & $\begin{array}{l}P+S \\
+A\end{array}$ & - & C \\
\hline & & ஓ्̀ & $\begin{array}{l}\text { Building energy quotient - bEQ } \\
\text { (American Society of Heating, } \\
\text { Refrigerating, and Air - Conditioning } \\
\text { Engineers 2011) }\end{array}$ & $\mathrm{Pu}$ & $\mathrm{N}$ & $\mathrm{V}$ & $C$ & $\mathrm{Ce}$ & $\mathrm{S}+$ & - & C \\
\hline & \multirow{2}{*}{ 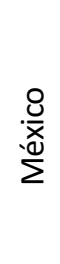 } & $\stackrel{\infty}{\stackrel{\infty}{\sim}}$ & $\begin{array}{c}\text { Programa de Certificación de } \\
\text { Edificaciones Sustentables - PCES } \\
\text { (Secretaría del Medio Ambiente 2012) }\end{array}$ & $\mathrm{Pu}$ & $\mathrm{R}$ & $\mathrm{V}$ & $\begin{array}{c}\mathrm{R}+ \\
\mathrm{S}\end{array}$ & $\mathrm{Ce}$ & $\begin{array}{l}P+S \\
+A\end{array}$ & $\begin{array}{l}\text { Gcal, } \\
\text { Gref, C, } \\
\text { VN }\end{array}$ & C \\
\hline & & $\stackrel{m}{\stackrel{n}{\sim}}$ & $\begin{array}{l}\text { Edificación Sustentable - NMX-AA-164- } \\
\text { SCFI (Secretaría de Economía 2013) }\end{array}$ & $\mathrm{Pu}$ & $\mathrm{N}$ & $\mathrm{V}$ & $\mathrm{G}$ & $\begin{array}{c}\mathrm{Re}+ \\
\mathrm{Ce}\end{array}$ & $\mathrm{S}+$ & $\begin{array}{l}\text { T, Vn, } \\
\text { Gref, U }\end{array}$ & $D$ \\
\hline
\end{tabular}

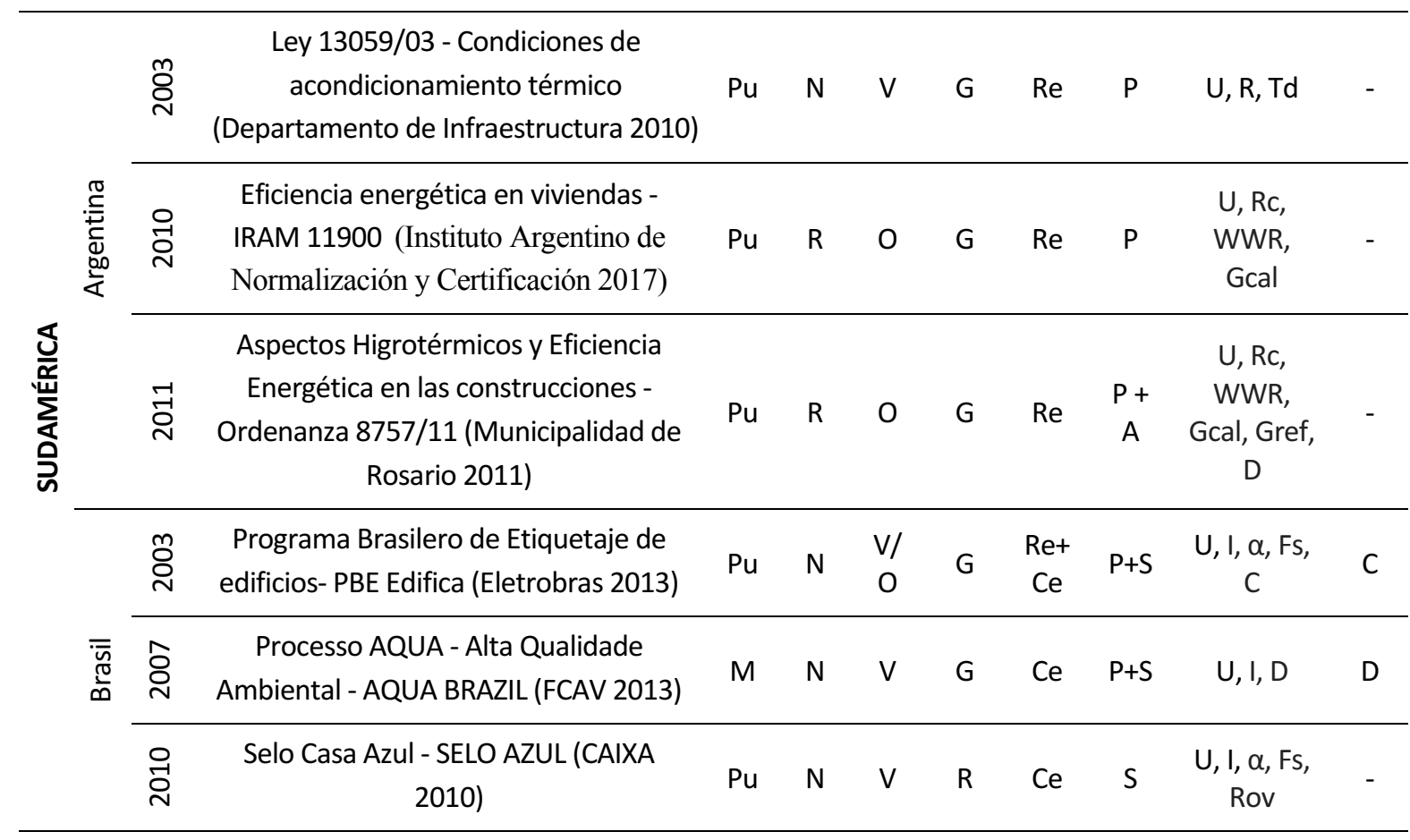




\begin{tabular}{|c|c|c|c|c|c|c|c|c|c|c|c|}
\hline & $\frac{n}{\pi}$ & 足 & Sistema de calificación edilicia * & 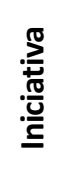 & 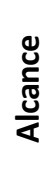 & 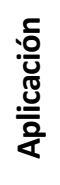 & 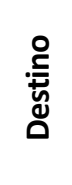 & 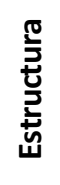 & 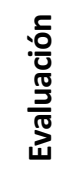 & 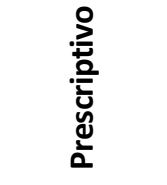 & $\frac{\text { 을 }}{\frac{\pi}{5}}$ \\
\hline \multirow{7}{*}{ 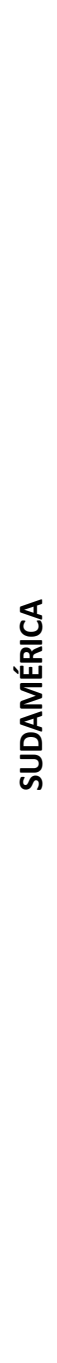 } & \multirow[b]{2}{*}{$\frac{\mathscr{U}}{\frac{\underline{\tau}}{U}}$} & $\stackrel{m}{\stackrel{一}{\sim}}$ & $\begin{array}{c}\text { Calificación Energética de Viviendas - } \\
\text { CEV (Ministerio de Vivienda y } \\
\text { Urbanismo 2016) }\end{array}$ & $\mathrm{Pu}$ & $\mathrm{N}$ & V & $\mathrm{R}$ & $\mathrm{Ce}$ & $\mathrm{P}+\mathrm{S}$ & $\begin{array}{l}\text { U, O,Fs, } \\
\text { WWR,FA, } \\
\text { FAV, FAR, } \\
\text { C }\end{array}$ & C \\
\hline & & 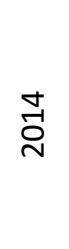 & $\begin{array}{l}\text { Sistema Nacional de Certificación de } \\
\text { Calidad Ambiental y Eficiencia } \\
\text { Energética para Edificios de Uso Público } \\
\text { - CES (Instituto de la Construcción } \\
\text { 2014) }\end{array}$ & M & $\mathrm{N}$ & V & $\mathrm{Pu}$ & $\mathrm{Ce}$ & $\mathrm{P}+\mathrm{S}$ & $\begin{array}{l}\text { U, Fs, Ra, } \\
\text { WWR, D }\end{array}$ & $\mathrm{D}$ \\
\hline & $\frac{\frac{\pi}{0}}{\frac{0}{0}}$ & 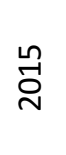 & $\begin{array}{l}\text { Reglamento Técnico de Construcción } \\
\text { Sostenible (Ministerio de Vivienda, } \\
\text { Ciudad y Territorio 2015b) }\end{array}$ & $\mathrm{Pu}$ & $\mathrm{N}$ & $\mathrm{O}$ & G & $\operatorname{Re}$ & $\mathrm{S}$ & $\begin{array}{l}\text { Rov, } \\
\text { SHGC, O, } \\
\text { F, Vn, Fs. }\end{array}$ & - \\
\hline & 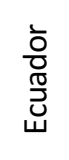 & $\stackrel{-7}{\stackrel{ }{*}}$ & $\begin{array}{c}\text { Norma Ecuatoriana de la Construcción } \\
\text { (Ministerios de Desarrollo Urbano y } \\
\text { Vivienda 2011). }\end{array}$ & $\mathrm{Pu}$ & $\mathrm{N}$ & $\mathrm{O}$ & G & $\operatorname{Re}$ & $S$ & $\begin{array}{l}\text { U, O, Fs, } \\
\text { VN, D }\end{array}$ & - \\
\hline & 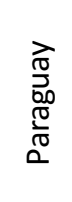 & 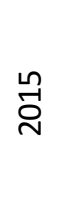 & $\begin{array}{c}\text { Norma Paraguaya de Instalaciones de } \\
\text { aire acondicionado- NP } 4901715 \\
\text { (Instituto Nacional de Tecnología, } \\
\text { Normalización y Metrología 2015b). }\end{array}$ & $\mathrm{Pu}$ & $\mathrm{N}$ & $\mathrm{O}$ & G & $\operatorname{Re}$ & A & $\mathrm{T}, \mathrm{HR}, \mathrm{VN}$ & - \\
\hline & $\frac{2}{20}$ & 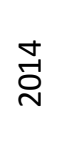 & $\begin{array}{l}\text { Reglamento Nacional de Edificaciones - } \\
\text { EM.110 (Ministerio de Vivienda, } \\
\text { Construcción y Saneamiento 2014) }\end{array}$ & $\mathrm{Pu}$ & $\mathrm{N}$ & $\mathrm{O}$ & G & $\operatorname{Re}$ & $\mathrm{S}$ & U, Ra, Rc & - \\
\hline & 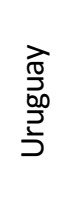 & ஓ्̀ & $\begin{array}{l}\text { Reducción de la demanda de energía } \\
\text { para acondicionamiento térmico - } \\
\text { Resolución n²928/09 (Intendencia de } \\
\text { Montevideo 2009) }\end{array}$ & $\mathrm{Pu}$ & $\mathrm{R}$ & $\mathrm{O}$ & $\mathrm{R}$ & $\operatorname{Re}$ & $S$ & $\begin{array}{l}\text { U, O, Fs, } \\
\text { Rov }\end{array}$ & - \\
\hline \multirow{4}{*}{ 离 } & \multirow{3}{*}{ 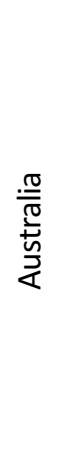 } & $\stackrel{m}{\check{\nu}}$ & $\begin{array}{l}\text { Building Codes of Australia (Australian } \\
\text { Building Codes Board 2015) }\end{array}$ & $\mathrm{Pu}$ & $\mathrm{N}$ & $\mathrm{O}$ & $\begin{array}{c}\mathrm{R}+ \\
\mathrm{C}\end{array}$ & $\operatorname{Re}$ & $\begin{array}{l}P+S \\
+A\end{array}$ & U, SHGC & C \\
\hline & & $\stackrel{m}{\check{\nu}}$ & $\begin{array}{l}\text { National Australian Built Environment } \\
\text { Rating System - NABERS (Office of } \\
\text { Environment and Heritage, 2018) }\end{array}$ & $\mathrm{Pu}$ & $\mathrm{N}$ & $\mathrm{V}$ & $\begin{array}{l}\mathrm{C}+\mathrm{S} \\
+\mathrm{Pu}\end{array}$ & $\mathrm{Ce}$ & $S$ & - & $C$ \\
\hline & & $\stackrel{m}{\check{\nu}}$ & $\begin{array}{l}\text { Nationwide house energy rating } \\
\text { scheme - NatHERS } \\
\text { (Australian Greenhouse Office s.d.) }\end{array}$ & $\mathrm{Pu}$ & $\mathrm{N}$ & $\mathrm{V}$ & $\mathrm{R}$ & $\mathrm{Ce}$ & $S$ & - & $C$ \\
\hline & 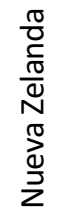 & ริ & $\begin{array}{l}\text { New Zealand Building Code - NZBC } \\
\text { (Ministry of Business, Innovation and } \\
\text { Employment 2016) }\end{array}$ & $\mathrm{Pu}$ & $\mathrm{N}$ & 0 & $\mathrm{G}$ & $\operatorname{Re}$ & $\begin{array}{l}P+S \\
+A\end{array}$ & $\begin{array}{l}\text { R, Rc, Rov, } \\
\text { WWR, } \\
\text { SHGC }\end{array}$ & $C$ \\
\hline
\end{tabular}

Tabla 1: Sistemas de calificación edilicia implementados en países con clima templado (* Ver leyenda). Elaboración propia. 
Leyenda

\begin{tabular}{|c|c|}
\hline País & Países con localidades en clima templado \\
\hline Año & Año de implementación \\
\hline Sistema & Sistema de calificación edilicia elaborado para el contexto del país \\
\hline Iniciativa & M - Mixta | Privada - P | Pública - Pu (gobierno nacional) | \\
\hline Alcance & I - Internacional | N - Nacional | R - Regional | \\
\hline Aplicación & O - Obligatoria | V - Voluntaria| \\
\hline Destino & C - Comercial | G - Edificios en general| Pu - Público | R - Residencial | S - Servicio | \\
\hline Estructura & Ce - Certificación | Re - Regulación | Re+Ce - Mixta | \\
\hline Evaluación & A - Auditoría | P - Prescriptivo | S - Simulación computacional | \\
\hline \multirow{28}{*}{ Prescriptivo } & Parámetros de cumplimiento \\
\hline & C - Consumo \\
\hline & D - Demanda \\
\hline & I - Inercia térmica \\
\hline & F - Forma \\
\hline & FA - Coeficiente de accesibilidad de la ventana \\
\hline & FAR - Factor de accesibilidad respecto a elementos de sombra remotos \\
\hline & FAV - Factor de accesibilidad respecto a elementos de sombra cercanos \\
\hline & Fs - Factor de sombra \\
\hline & Gcal - Coeficiente volumétrico de pérdida de calor \\
\hline & Gref - Coeficiente volumétrico de refrigeración \\
\hline & HR - Humedad relativa \\
\hline & O - Orientación \\
\hline & Pt - Puentes térmicos \\
\hline & $\mathrm{R}$ - Resistencia térmica (m2K/W) \\
\hline & Ra - Renovación de aire \\
\hline & Rc - Riesgo de Condensación \\
\hline & Rov - Relación opaco x vidriado \\
\hline & SHGC - Coeficiente de ganancia solar \\
\hline & T - Temperatura \\
\hline & Td - Temperatura de diseño \\
\hline & U - Transmitancia térmica (W/m2K) \\
\hline & VN - Ventilación Natural \\
\hline & VTL - Transmitancia de luz visible \\
\hline & WWR - Infiltración de aire \\
\hline & $\alpha$ - Coeficiente de absortividad \\
\hline & $\varepsilon$ - Coeficiente de emisividad \\
\hline & $\rho$ - Coeficiente de reflectividad \\
\hline \multirow{3}{*}{ Simulación } & Parámetros de cumplimiento \\
\hline & C - Consumo \\
\hline & D - Demanda \\
\hline- & No corresponde \\
\hline
\end{tabular}




\subsubsection{Contexto de implementación y aplicación}

Más del 70\% de los instrumentos estudiados surgieron en los últimos 15 años, a partir de la iniciativa del gobierno de cada país, demostrando que la implementación de estas iniciativas está cada vez más presente en las políticas energéticas nacionales.

De las 47 iniciativas, el $48 \%$ son de cumplimiento obligatorio y se aplican en todo el territorio nacional. Se observa que mientras todos los países desarrollados estudiados presentan regulaciones y certificaciones energéticas de los edificios, no todos los países emergentes disponen de un instrumento destinado a evaluar la eficiencia energética de la edificación. Del análisis de la aplicación de las regulaciones y certificaciones en el ámbito de la construcción, se destacan dos contextos bastante diferenciados, el de Europa y el de Latinoamérica.

En Europa, las políticas y estrategias de cada país están dirigidas por las Directivas Europeas, las cuales establecen las líneas estructurales que deben ser adoptadas por sus países miembros. Cada país posee la libertad de construir su propio marco regulatorio, siempre y cuando no comprometa el atendimiento ni la jerarquía establecida en las directivas.

En el ámbito de la eficiencia energética de la edificación, la Comisión Europea publicó en 2002 la Directiva 2002/91/CE sobre eficiencia energética de la edificación, la cual introdujo los certificados de eficiencia energética de los edificios de cumplimiento obligatorio en todos los países miembros (European Council 2002). Así mismo, estableció los requisitos mínimos de eficiencia energética y una metodología de cálculo que debería ser atendida por los edificios nuevos, y aquellos existentes que fueran objeto de grandes reformas.

En 2010, se publica la Directiva 2010/31/UE que refunde la del 2002/91/CE y estable nuevos objetivos para el periodo 2010-2020 en relación con los requisitos mínimos de eficiencia energética, certificación energética e inspección periódica de las instalaciones térmicas de los edificios. Introduce una metodología de cálculo de los requisitos mínimos, establecidos conforme un marco metodológico comparativo común y en base a un nivel óptimo de rentabilidad (Mercader-Moyano e Claro-Ponce 2017).

En Latinoamérica, cada país desarrolla e implementa las políticas y estrategias en su territorio, así como el marco regulatorio de la edificación. No todos los países poseen instrumentos reguladores enfocados en la evaluación energética y eficiencia energética de la edificación, así mismo como muchas regulaciones y certificaciones presentan carácter de cumplimiento voluntario (Reus Netto 2017).

Entre las iniciativas obligatorias, destacan el caso del Programa Brasilero de Etiquetagem de Edificios (PBE Edifica), que, para permitir la construcción de edificios con uso público, requiere el nivel $\mathrm{A}$ de eficiencia, y el caso de la ciudad de Rosario en Argentina, que para acceder al permiso de obra para la construcción de nuevos edificios es necesario atender a los criterios de transmitancia térmica, riesgo de condensación, permeabilidad del aire y carga térmica para refrigeración y calefacción, establecidos en la Ordenanza 8757/11 (Reus Netto 2017). 
Las principales dificultades relatadas por los actores involucrados en el desarrollo de estos instrumentos consistieron en lograr capacitar a los profesionales para entender los criterios y garantizar su correcta ejecución en la obra, aumentar el personal responsable por el control de las obras, y promover la actualización del mercado para mejorar la calidad de los productos. Estos factores dilatan los procesos de implementación e incrementan el valor final de la obra, lo que explica la baja aceptación del mercado y la dificultad de la aplicación efectiva de dichos instrumentos en Latinoamérica.

Estas consideraciones marcan los diferentes contextos en que se desarrollan los sistemas de calificación de los edificios en Europa y Latinoamérica e indican las pautas a seguir para alcanzar mejores resultados a nivel regional.

\subsubsection{Métodos y criterios de evaluación}

El enfoque principal de las 47 iniciativas estudiadas es variado, abordando las temáticas de eficiencia en acondicionamiento, estrategias pasivas, desempeño térmico, eficiencia energética, reducción del consumo energético, de recursos y de emisiones, calidad ambiental, sustentabilidad, entre otros.

Se observa que el $61 \%$ de las herramientas, se centran en definir criterios de eficiencia energética para edificios con uso general y residencial. Las demás se centran principalmente en el desempeño ambiental, en la calidad del ambiente interior, y se destinan a edificios públicos, comerciales o de servicio.

En cuanto al análisis de los criterios requeridos por las 47 iniciativas estudiadas, se observa que en Latinoamérica el $62 \%$ evalúa el cumplimiento de requisitos mínimos de la envolvente térmica, el $19 \%$ analiza la demanda y $19 \%$ restante el consumo. En Europa, así como entre las iniciativas implementadas en los países con clima templado de demás regiones del mundo, esta relación es inversa. En Europa el $73 \%$ de las iniciativas evalúa la edificación a partir de su consumo energético, y el $27 \%$ evalúa la demanda. En las demás regiones del mundo los porcentajes son de $86 \%$ y de $6 \%$ respectivamente (Figura 4).

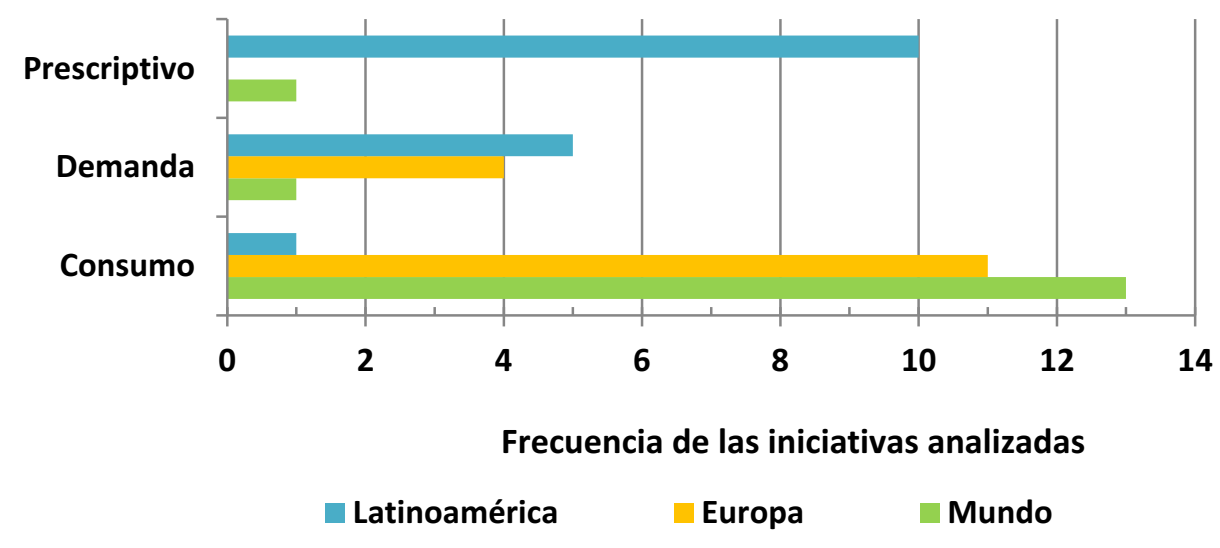

Figura 4: Criterios de evaluación de regulaciones y certificaciones en países con presencia de clima templado. Elaboración propia.

Se registraron 27 criterios requeridos por las 47 herramientas analizadas. La transmitancia térmica y el consumo energético son solicitados por 27 iniciativas, la infiltración de aire y el factor de sombra por 17, y la demanda energética por 13 iniciativas (Figura 5). 


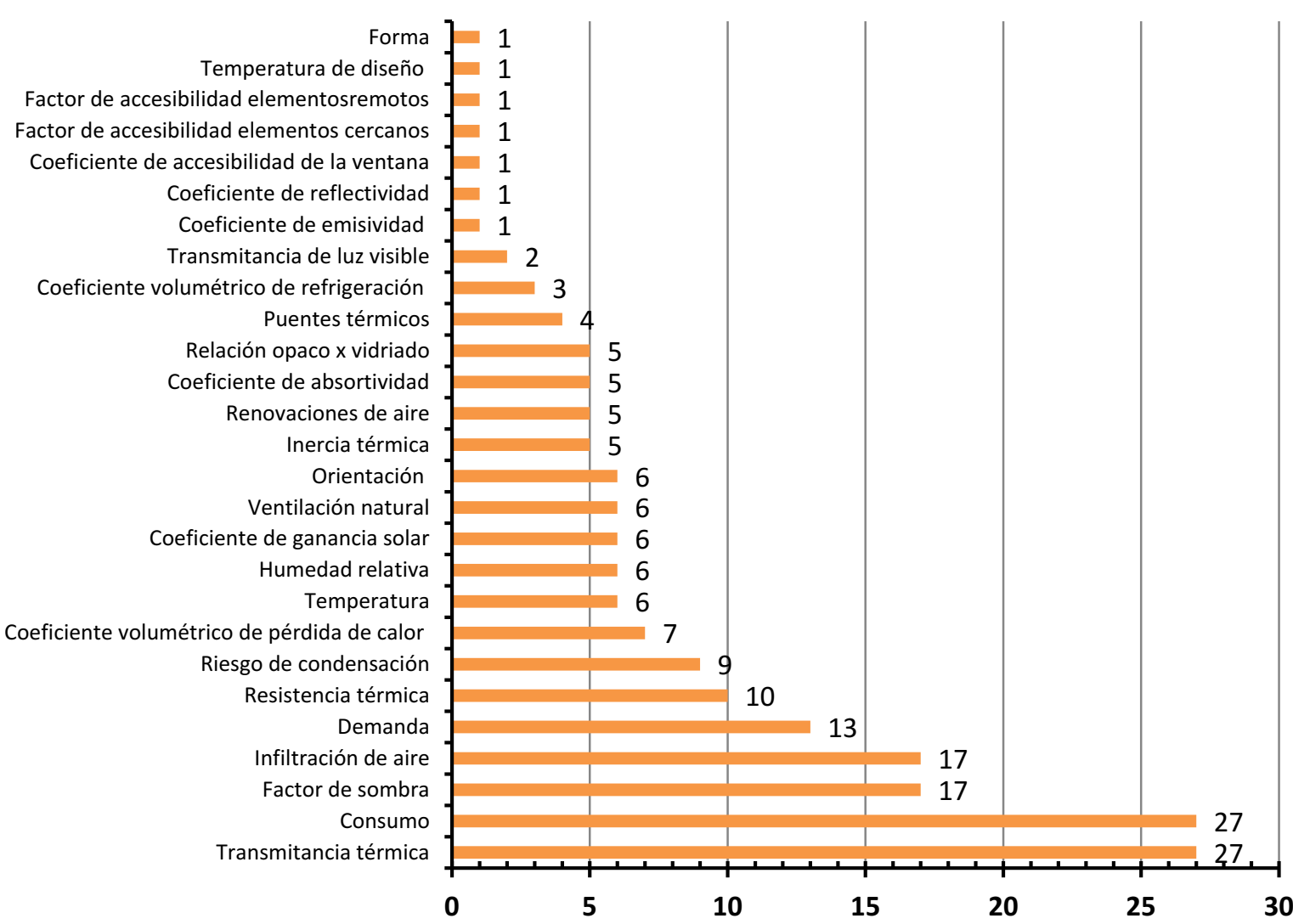

Figura 5: Frecuencia de los criterios requeridos por las iniciativas analizadas. Elaboración propia.

Las herramientas de evaluación se clasifican en métodos de cálculo general y métodos de cálculo simplificado. Los métodos de cálculo simplificado, como por ejemplo la comparación con valores límite y el uso de ecuaciones simples o planillas Excel, requieren de menor tiempo dedicado al ingreso de la información que los métodos generales (A. P. Melo 2012). Esto ha permitido que muchas iniciativas implementadas a nivel nacional en Latinoamérica hagan uso de este método para evaluar la edificación, ya que posibilita la optimización de la gestión de los proyectos en municipalidades y otros órganos de control. De hecho, en Latinoamérica, más del $80 \%$ de las iniciativas emplean métodos simplificados y se centran en la limitación de la demanda térmica o en el establecimiento de unas características mínimas de la envolvente térmica. Sin embargo, la aplicación de estas herramientas es reducida.

Cabe señalar además que esta evaluación energética en base a la demanda o a las características de la envolvente térmica, no integra todos los procesos de intercambio de calor presentes en el edificio, ni permite establecer una relación con el consumo energético ni las emisiones de gases de efecto invernadero, ya que no incorpora el funcionamiento ni rendimiento de las instalaciones térmicas.

El empleo de métodos de cálculo general, simulación energética basada en motores de cálculo como DOE 2 o EnergyPlus, permiten analizar el comportamiento energético del edificio así como considerar las múltiples interacciones que suceden entre el proyecto y los sistemas térmicos (Crawley 2008). Sin embargo, su manejo exige una inversión de tiempo y de recursos importante, además de la elevada curva de aprendizaje que el profesional tiene que enfrentarse, en comparación con la aplicación de los métodos simplificados (Melo, et al. 2012). 
Estos datos indican que la evaluación del consumo energético de las edificaciones frente a la verificación del cumplimiento de los indicadores de desempeño, no solo es lo más adecuado para representar el desempeño térmico integral del edificio, sino que es una tendencia mundial. Viendo la baja aplicación de las herramientas simplificadas en Latinoamérica, la implementación de métodos de evaluación más complejos, como la simulación energética, reduciría aún más el porcentaje de edificios con evaluación energética en este territorio.

En este contexto es importante desarrollar un método simplificado para predecir el consumo energético de las edificaciones en Latinoamérica por dos motivos. El primero consiste en poder realizar una evaluación integral de la edificación analizada incluyendo el análisis del impacto medio ambiental, cuestión que no es posible analizar con sistemas basados en la evaluación de la demanda. El segundo guarda relación con el contexto socioeconómico latinoamericano, de forma que un método simplificado tendría una mayor posibilidad de aceptación y aplicación, aumentando de esta forma el número de edificios con evaluación energética.

\subsection{Modelos de predicción de consumo energético edilicio}

El Programa Energía en Edificios y Comunidades -EBC de la Agencia Internacional de la Energía - IEA, tiene la misión de desarrollar a través de la innovación y la investigación, la integración de tecnologías y procesos para la eficiencia energética y la conservación en edificios y comunidades saludables, con bajas emisiones y sostenibles (International Energy Agency 2013).

En el marco del EBC, se publicó el Anexo 53 fundamentado en comprender y fortalecer mejor el conocimiento sobre la predicción del uso total de energía en los edificios, permitiendo evaluar las medidas, políticas y técnicas de ahorro de energía. Según el documento, el consumo de energía del edificio está influenciado principalmente por factores relacionados al clima, a la envolvente del edificio, a los equipos de climatización, y al comportamiento de los usuarios durante la etapa de operación del edificio (International Energy Agency 2013).

Este trabajo ha podido revisar más de 100 modelos de predicción para edificios, publicados desde la década de 90 hasta el presente (Tabla 2). Dentro de las disciplinas analíticas, un modelo predictivo consiste en un método de cálculo creado para describir un comportamiento futuro. Su desarrollo se fundamenta en el análisis de un conjunto de datos usualmente reales, los cuales son agrupados en función de determinadas reglas de asociación, posibilitando predecir el resultado final caso se modifique una o más variables.

Se registraron las principales características de cada modelo, su objetivo, las variables de entrada consideradas, el algoritmo empleado para el análisis, el ámbito de aplicación, los autores y año de publicación de la investigación. 


\begin{tabular}{|c|c|c|c|c|c|c|}
\hline 宅 & 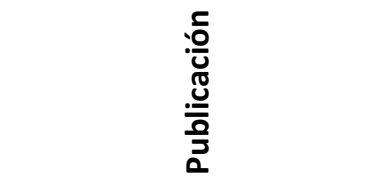 & 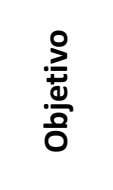 & $\begin{array}{l}\frac{y}{0} \\
\frac{0}{\frac{0}{0}} \\
\frac{10}{5}\end{array}$ & 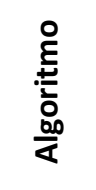 & 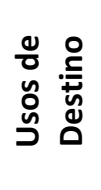 & 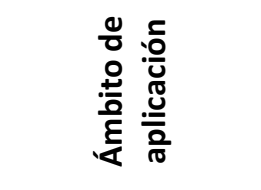 \\
\hline 2005 & Ansari & D ref & $\mathrm{EE}+\mathrm{O}$ & $E$ & $\mathrm{R}$ & - \\
\hline 2012 & Aranda & C & $E+C+E q$ & $E$ & S & España \\
\hline 2017 & Arregi & D cal & $E+O+E q$ & $E$ & No $R$ & Europa \\
\hline 2014 & Asadi & C & $\mathrm{EE}+\mathrm{T}$ & $E$ & C & Houston \\
\hline 2003 & Aydinalp et al. & C elec & $\mathrm{Eq}+\mathrm{P}$ & RNA & $\mathrm{V}$ & Canadá \\
\hline 2008 & Aydinalp-Koksal y Ugursal & C elec & 0 & E & $\mathrm{V}$ & Canadá \\
\hline 1991 & Bartels y Fiebig & C & $\mathrm{CH}$ & $E$ & V & Australia \\
\hline 2000 & Bartels y Fiebig & EM & $\mathrm{O}+\mathrm{M}$ & $\mathrm{E}$ & $\mathrm{V}$ & - \\
\hline 1998 & Bauer y Scartezzini & $\mathrm{D}$ & $E+O$ & $E$ & $\mathrm{~S}$ & Delémont \\
\hline 2014 & Braun & $\mathrm{C}$ & $\mathrm{CH}$ & $E$ & $\mathrm{C}$ & Reino Unido \\
\hline 2008 & Caldera & D cal & $\mathrm{E}$ & $E$ & $\mathrm{R}$ & Torino \\
\hline 2017 & Camporeale & Di & $E+C$ & RNA & G & Clima Templado \\
\hline 1994 & Capaso et al. & $\mathrm{Cl}$ & 0 & $\mathrm{~S}$ & V & Italia \\
\hline 2008 & Carlo & $\mathrm{EE}$ & $E+T$ & $E$ & No $R$ & Brasil \\
\hline 2003 & Carlo et al. & $\mathrm{T}$ & $\mathrm{CH}$ & $\mathrm{S}$ & C & Brasil \\
\hline 2013 & Catalina & D cal & I & $\mathrm{E}$ & $\mathrm{R}$ & Rumania \\
\hline 1987 & Caves et al. & C elec & $\mathrm{CH}$ & $E$ & V & Los Ángeles \\
\hline 2012 & Che et al. & C elec & DE & MVS & - & New South Wales \\
\hline 2008 & Clarke y col. & $\mathrm{Cl}$ & $E$ & $S$ & G & Escocia \\
\hline 2000 & Czajkowski & G cal & $C+E$ & $\mathrm{E}$ & $\mathrm{R}$ & Argentina \\
\hline 2009 & Czajkowski & G ref & $C+E+O$ & $E$ & G & Argentina \\
\hline 1999 & Dhar et al. & D & C & $E$ & $\mathrm{C}$ & Texas \\
\hline 2017 & Diao & $\mathrm{Cl}$ & $\mathrm{O}$ & $A$ & $\mathrm{R}$ & Nueva york \\
\hline 2017 & Diulio & $\mathrm{Cft}$ & $E+O$ & E & $\mathrm{S}$ & Argentina \\
\hline 2010 & Ekici & D cal & E & RNA & - & - \\
\hline 2011 & Escriva-Escriva et al. & C & $\mathrm{CH}$ & RNA & $\mathrm{S}$ & Valencia \\
\hline 2014 & Fan & $\mathrm{C}$ & $\mathrm{C}$ & $\mathrm{H}$ & No $R$ & Hong Kong \\
\hline 2016 & Fang & D cal & $\mathrm{C}+\mathrm{CH}$ & $E$ & - & Espoo \\
\hline 1998 & Farahbakhsh et al. & C & $E+O$ & $\mathrm{~S}$ & $\mathrm{~V}$ & Canadá \\
\hline 2015 & Farzan & $\mathrm{D}$ & $\mathrm{O}+\mathrm{CH}$ & $\mathrm{H}$ & $\mathrm{R}$ & - \\
\hline 2014 & Farzana & $\mathrm{C}$ & $\mathrm{C}+\mathrm{O}$ & RNA & $\mathrm{R}$ & China \\
\hline 2013 & Filippín & C cal & $\mathrm{CH}+\mathrm{M}$ & A & $\mathrm{R}$ & Santa Rosa \\
\hline 2010 & Fumo & C & $\mathrm{CH}$ & $E$ & - & Atlanta \\
\hline 2015 & Fumo & C elec & $\mathrm{C}$ & $E$ & $\mathrm{R}$ & - \\
\hline 1999 & Fung et al. & C cal & $\begin{array}{c}E+C+E q+P+ \\
P E\end{array}$ & $E$ & V & Canadá \\
\hline 2001 & Givoni y Vecchia & $\mathrm{TI}$ & $\mathrm{C}+\mathrm{O}$ & $E$ & V & Descalvado \\
\hline 2008 & Guler et al. & $E$ & $\mathrm{CH}$ & $\mathrm{S}$ & V & Canadá \\
\hline 1986 & Hirst et al. & C cal & $\mathrm{C}+\mathrm{CH}$ & $\mathrm{E}$ & $\mathrm{V}$ & Estados Unidos \\
\hline 1995 & Hsiao et al. & C & $\mathrm{O}+\mathrm{CH}$ & $E$ & V & - \\
\hline 2009 & $\mathrm{Hu}$ & $\% \mathrm{C}$ & $C+E$ & $E$ & $\mathrm{~S}$ & Wuhan \\
\hline 2000 & Huang y Broderick & $\mathrm{D}$ & C & $\mathrm{S}$ & $\mathrm{R}$ & Estados Unidos \\
\hline 1996 & Jaccard and Baille & C & $\mathrm{CH}$ & S & $\mathrm{R}$ & Canadá \\
\hline 2014 & Jain & C & $\mathrm{C}$ & MVS & $\mathrm{R}$ & Nueva york \\
\hline 2014 & Johnson & $\mathrm{C}$ & $\mathrm{O}$ & E & $\mathrm{R}$ & Estados unidos \\
\hline 2007 & Kadian et al. & $\mathrm{C}$ & $\mathrm{CH}$ & $S$ & $\mathrm{R}$ & Delhi \\
\hline 2000 & Kalogirou y Bojic & $\mathrm{C}$ & $C+E E$ & RNA & V & Vivienda \\
\hline 2011 & Kavaklioglu & C elec & $P+S$ & MVS & - & Turquía \\
\hline 1997 & Kohler et al. & $\mathrm{Ci}$ & $\mathrm{E}$ & $\mathrm{S}$ & - & Alemania \\
\hline 2013 & Korolija & C & $E+T$ & $\mathrm{H}$ & $\mathrm{S}$ & Reino Unido \\
\hline 1995 & Kreider et al. & $\mathrm{C}$ & $\mathrm{C}+\mathrm{CH}$ & RNA & $\mathrm{S}$ & College Station \\
\hline
\end{tabular}




\begin{tabular}{|c|c|c|c|c|c|c|}
\hline 突 & 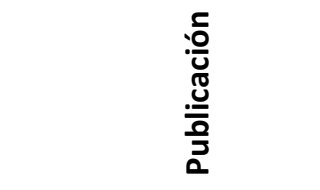 & $\begin{array}{l}\frac{0}{2} \\
\frac{1}{2} \\
\frac{0}{0}\end{array}$ & $\begin{array}{l}\frac{y}{0} \\
\frac{0}{0} \\
\frac{\pi}{\frac{\pi}{\pi}}\end{array}$ & 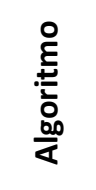 & 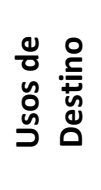 & 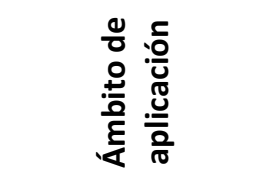 \\
\hline 2004 & Krüger Givoni & $\mathrm{TI}$ & $E+O$ & $E$ & $\mathrm{~V}$ & Curitiba \\
\hline 2011 & Kwok & D ref & $C+O$ & RNA & $\mathrm{S}$ & Hong Kong \\
\hline 1994 & LaFrance y Perron & C & $C+E q+P$ & E & $\mathrm{V}$ & Quebec \\
\hline 2012 & Lai et al. & C elec & $\mathrm{M}+\mathrm{CH}$ & MVS & $\mathrm{R}$ & Tohoku - Japón \\
\hline 2010 & Lam & $\mathrm{C}$ & $E+O+E q$ & RNA & $\mathrm{C}$ & China \\
\hline 1997 & Larsen y Nesbakken & $\mathrm{T}$ & E & $\mathrm{S}$ & $\mathrm{V}$ & Noruega \\
\hline 2010 & $\mathrm{Li}$ & $\mathrm{C}$ & $\mathrm{E}$ & MVS & $\mathrm{R}$ & China \\
\hline 2002 & Lins et al. & $\mathrm{C}$ & $\mathrm{CH}$ & $E$ & V & Brasil \\
\hline 2013 & Liu & C elec & $\mathrm{C}+\mathrm{O}$ & MVS & No $R$ & - \\
\hline 2010 & Ma et al. & C elec & $\mathrm{CH}$ & $\mathrm{E}$ & $\mathrm{S}$ & $\mathrm{Xi} \mathrm{Na}$ \\
\hline 1993 & MacGregor et al. & $\mathrm{Al}$ & 0 & $E$ & $\mathrm{R}$ & Escocia \\
\hline 2014 & Mastrucci & $\% \mathrm{C}$ & $E+P$ & $E$ & $\mathrm{~V}$ & Rotterdam \\
\hline 2012 & Melo & $\mathrm{C}$ & $E+T$ & RNA & $\mathrm{C}$ & Brasil \\
\hline 2014 & Mena & $\mathrm{C}$ & C & RNA & $\mathrm{S}$ & España \\
\hline 2002 & Mihalakakou et al. & $\mathrm{C}$ & $\mathrm{C}$ & RNA & $\mathrm{V}$ & Grecia \\
\hline 2010 & Min etal. & $\mathrm{C}$ & $\mathrm{O}+\mathrm{CH}$ & $\mathrm{S}$ & $\mathrm{R}$ & Estados Unidos \\
\hline 2010 & Newsham y Birt & $\mathrm{D}$ & $\mathrm{C}+\mathrm{O}$ & $E$ & $\mathrm{~S}$ & Ontario \\
\hline 2006 & Nishio y Asano & $\mathrm{T}$ & $\mathrm{C}+\mathrm{O}$ & $\mathrm{S}$ & V & Japón \\
\hline 1998 & Olofsson & D cal & $\mathrm{CH}+\mathrm{M}$ & RNA & $\mathrm{R}$ & Suecia \\
\hline 2005 & Ozturk et al. & C elec & DE & G & I & Turquía \\
\hline 2011 & Paniagua-Tineo et al. & TE & $\mathrm{C}$ & MVS & - & Europa \\
\hline 2005 & Parekh & $\mathrm{C}+\mathrm{Eu}$ & $E+O$ & $\mathrm{E}$ & G & - \\
\hline 1980 & Parti y Parti & $\mathrm{Da}$ & $\mathrm{O}+\mathrm{CH}$ & $E$ & V & San Diego \\
\hline 2006 & Petersdorff y col. & $\mathrm{C}$ & $C+T$ & $\mathrm{~S}$ & $\mathrm{R}$ & Unión Europea \\
\hline 2005 & Pfafferott & TI & $\mathrm{M}$ & $E$ & $\mathrm{~S}$ & Creuzburg \\
\hline 2017 & Pino-Mejías & $C+D$ & $\mathrm{EE}$ & RNA & $\mathrm{S}$ & Chile \\
\hline 2016 & Pulido-Arcas & $C+E$ & $\mathrm{EE}+\mathrm{Eq}$ & $\mathrm{H}$ & $\mathrm{S}$ & Chile \\
\hline 2007 & Raffio et al. & C & $\mathrm{C}+\mathrm{CH}$ & $E$ & $\mathrm{~V}$ & - \\
\hline 2005 & Ramirez et al. & $E$ & $\mathrm{C}+\mathrm{E}+\mathrm{O}+\mathrm{CH}$ & $\mathrm{S}$ & C & California \\
\hline 2018 & Ran Yoon & $\mathrm{C}$ & 0 & RNA & $\mathrm{S}$ y $\mathrm{C}$ & Seúl \\
\hline 1987 & Rosenfeld & G cal & $C+E$ & $E$ & G & Argentina \\
\hline 2011 & Sadeghi et al. & C elec & $\mathrm{CH}$ & G & $\mathrm{R}$ & Irán \\
\hline 2007 & Saidur et al. & $\mathrm{Cl}$ & $\mathrm{Eq}$ & $\mathrm{S}$ & $\mathrm{R}$ & Malasia \\
\hline 2015 & Salvetti & $\mathrm{C}$ & $E+O$ & $E$ & $\mathrm{R}$ y $\mathrm{S}$ & Buenos Aires \\
\hline 2018 & Serrano-Guerrero & C elec & 0 & $E$ & - & España \\
\hline 2015 & Shams Amiri & C & $\mathrm{EE}+\mathrm{T}+\mathrm{O}$ & $E$ & $\mathrm{C}$ & Estados Unidos \\
\hline 2004 & Shimoda et al. & C & 0 & $\mathrm{~S}$ & $\mathrm{R}$ & Osaka \\
\hline 2002 & Shipley et al. & $C+E$ & $\mathrm{E}+\mathrm{CH}$ & $\mathrm{S}$ & $\mathrm{S}$ & Canadá \\
\hline 2016 & Silva & $\mathrm{De}$ & $E+O$ & $\mathrm{E}$ & $\mathrm{C}$ & Florianópolis \\
\hline 2008 & Swan et al. & $\mathrm{C}$ & E & RNA & $\mathrm{R}$ & Canadá \\
\hline 1988 & Tonn y White & $\mathrm{Cl}$ & 0 & E & $\mathrm{V}$ & - \\
\hline 2015 & Versage & D ref & $E+O$ & $\mathrm{E}$ & $\mathrm{C}$ & Florianópolis \\
\hline 2004 & Wan y Yik & GS & $\mathrm{E}$ & $\mathrm{S}$ & $\mathrm{R}$ & Hong Kong \\
\hline 2017 & Wang & D cal & 0 & $E$ & $\mathrm{R}$ & China \\
\hline 2010 & Wong et al. & C & $C+E E$ & RNA & $\mathrm{S}$ & Clima subtropical \\
\hline 2005 & Yalcintas et al. & Cref & $C+M$ & RNA & $\mathrm{C}$ & Clima tropical \\
\hline 2010 & Yan y Yao & D & $C+E E$ & RNA & - & - \\
\hline 2005 & Yao y Steemers & $\mathrm{D}$ & $\mathrm{CH}$ & $\mathrm{S}$ & $\mathrm{V}$ & Reino Unido \\
\hline 2009 & Yokoyama & D ref & $M$ & RNA & - & - \\
\hline 2002 & Zhai & D & $E$ & $\mathrm{~S}$ & $\mathrm{~S}$ & - \\
\hline 2013 & Zhou S., Zhu N & $\mathrm{C}$ & $C+E E$ & $\mathrm{~S}$ & $\mathrm{~S}$ & China \\
\hline
\end{tabular}

Tabla 2: Frecuencia de los criterios requeridos por las iniciativas analizadas (* Ver leyenda). Elaboración propia. 


\section{Leyenda}

\begin{tabular}{|c|c|}
\hline Año & Año de publicación de la investigación \\
\hline Publicación & Referencia bibliográfica de la investigación \\
\hline \multirow[t]{2}{*}{ Objetivo } & $\begin{array}{l}\text { Finalidad del modelo de predicción. Definir: } \\
\text { Al - Aislamiento e infiltraciones } \\
\text { C - Consumo } \\
\text { C cal - Consumo en calefacción } \\
\text { C elec - Consumo eléctrico } \\
\text { C ref - Consumo en refrigeración } \\
\text { Cft - Confort } \\
\text { Cl - Perfil de cargas internas } \\
\text { D - Demanda } \\
\text { Da - Demanda de artefactos } \\
\text { De - Desempeño } \\
\text { Di - Diseño } \\
\text { D cal - Demanda en calefacción } \\
\text { D ref - Demanda en refrigeración } \\
\text { G cal - Coeficiente de calefacción } \\
\text { G ref - Coeficiente de refrigeración } \\
\text { GS - Ganancias solares } \\
\text { E - Emisiones } \\
\text { EE - Eficiencia energética } \\
\text { EM - Eficiencia en la medición } \\
\text { T- Tipología edilicia } \\
\text { TE - Temperatura exterior } \\
\text { TI - Temperatura interior } \\
\text { \%C - Ahorro en consumo }\end{array}$ \\
\hline & $\begin{array}{l}\text { Variables de entrada empleadas para construir la matriz de datos del modelo: } \\
\text { C - Clima } \\
\text { CH - Consumos históricos } \\
\text { Cl - Carga interna } \\
\text { DE - Demanda eléctrica } \\
\text { E - Edificio } \\
\text { EE - Envolvente edilicia } \\
\text { Eq - Eficiencia equipos } \\
\text { I - Indicadores de desempeño } \\
\text { M - Medidos } \\
\text { O - Ocupación } \\
\text { P - Densidad demográfica } \\
\text { PE - Precio de la energía eléctrica } \\
\text { S - Socioeconómicos } \\
\text { T - Tipologías }\end{array}$ \\
\hline Algoritmo & $\begin{array}{l}\text { Método empleado para construir el modelo de predicción. } \\
\text { Estadística } \\
\text { R - Regresión } \\
\text { Inteligencia Artificial ( A - Agrupamiento | G - Genético | RNA - Red neural | SVM - } \\
\text { Máquina de soporte vectorial ) } \\
\text { H -Híbrida } \\
\text { I - Ingeniería }\end{array}$ \\
\hline Usos de destino & Comercial- C | G - General| I - Industrial | R - Residencial | Servicio - S |V - Viviendas | \\
\hline Ámbito de Aplicación & Localidad, país, o región de aplicación del modelo. \\
\hline- & No corresponde \\
\hline
\end{tabular}




\subsubsection{Contexto de implementación y aplicación}

La publicación de estos trabajos ha evolucionado significativamente a partir de la década de 90, de forma similar a la implementación de los sistemas de calificación edilicia en clima templado (Figura 6). Ambas iniciativas coinciden con la realización de las Conferencias y Convenciones de las Naciones Unidas sobre Medio Ambiente Humano, Medio Ambiente y Desarrollo, y Cambio Climático, demostrando el aumento de la consciencia respecto la preservación de los recursos y el ahorro energético en el mundo.

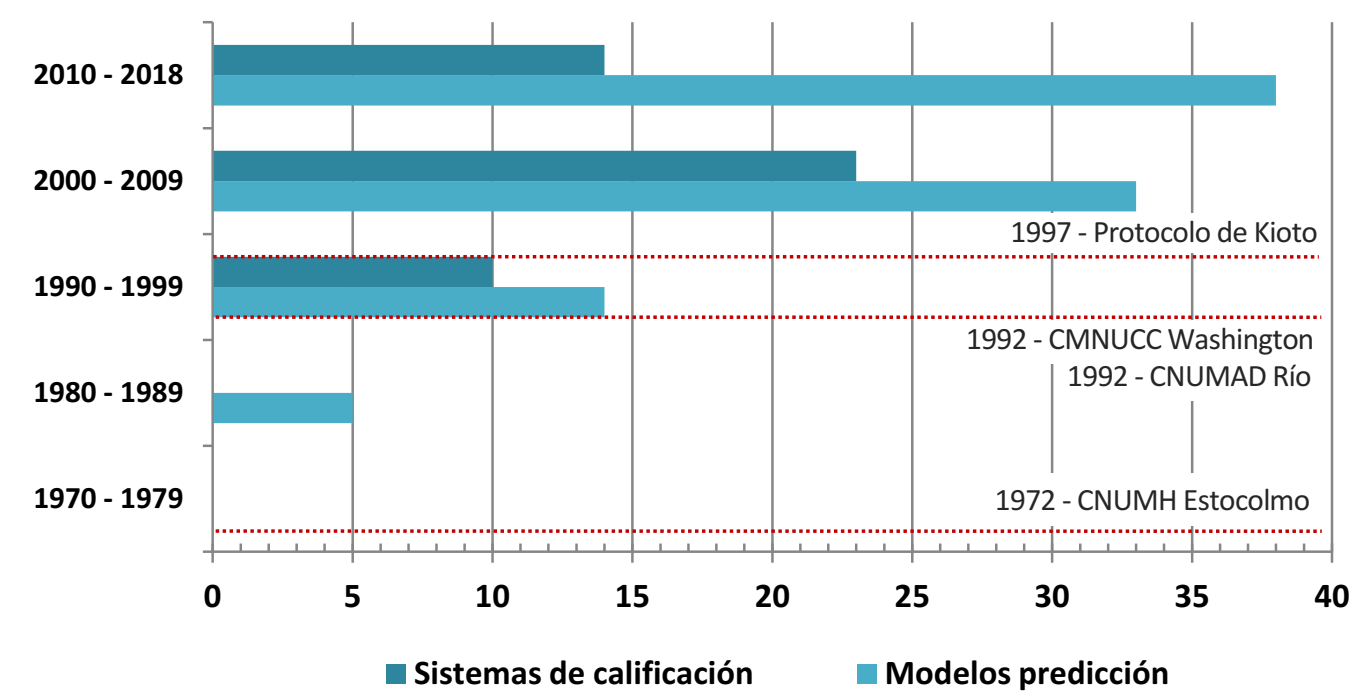

Figura 6: Evolución del modelo predictivo edilicio y de los sistemas de calificación edilicia en clima templado. Elaboración propia.

\section{Uso residencial en clima templado}

El 50\% de los modelos analizados se destinan al cálculo de aspectos vinculados a edificios con uso residencial y exclusivo de viviendas, en cuanto el $42 \%$ se centra en edificios comerciales, de servicio, y uso general (Figura 7). Los edificios residenciales consisten en las tipologías más representativas en los países con clima templado, así como son los edificios que mayores consumos requieren durante su vida útil (Mercader Moyano, Olivares Santiago e Ramirez de Arellano Agudo 2012).

El $47 \%$ de los trabajos construyen modelos para predecir resultados a todo el país, en cuanto el $33 \%$ se centra en las localidades de donde se recogieron los datos de entrada, y el $6 \%$ se aplican a grandes regiones, como es el caso de modelos elaborados para Europa, clima tropical y mediterráneo.

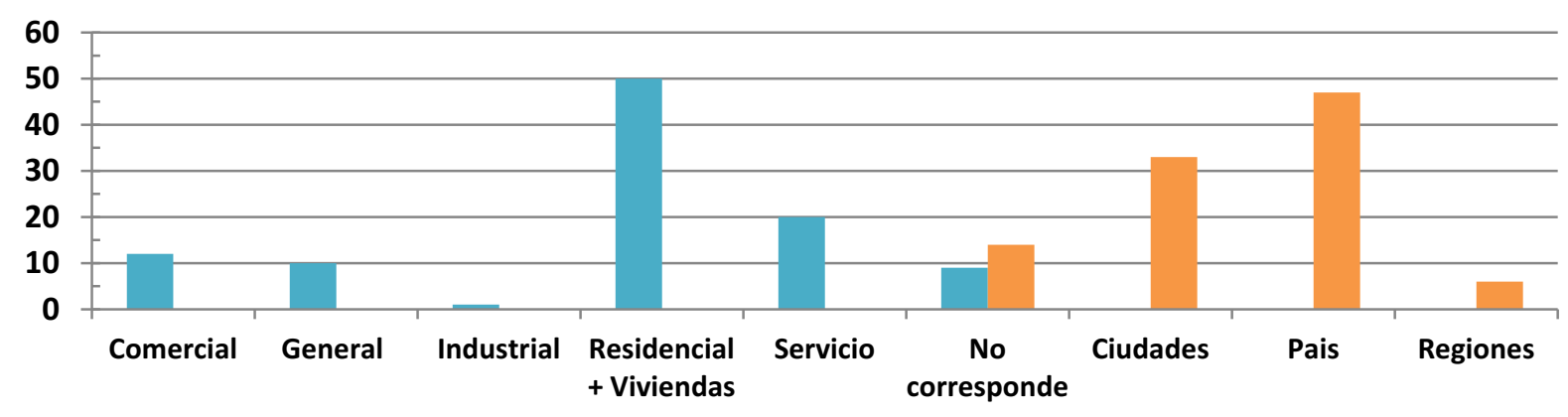

Usos del edificio Ambito de la aplicación

Figura 7: Ámbito de aplicación de los modelos de predicción revisados. Elaboración propia. 


\subsubsection{Objetivos y variables de entrada}

Los modelos de predicción revisados poseen objetivos y datos de entrada muy variados. El $60 \%$ de las investigaciones se centran en estimar el consumo energético, el consumo eléctrico, la demanda en calefacción y el perfil de ocupación de los usuarios.

Los datos de entrada utilizados para construir la matriz de datos son heterogéneos, entretanto existe una predominancia entre los modelos creados a partir del consumo histórico de los edificios, de las características climáticas, de la variación entre las tipologías, las características de la envolvente edilicia, y los perfiles de los usuarios.

Se encontraron 24 variables empleadas para construir la matriz del modelo, las cuales muchas veces son combinadas entre sí, resultando en un total de 34 conjuntos de datos. Las principales variables utilizadas para modelos de consumo energético, han sido los consumos históricos, ya sean eléctricos o en gas natural y las características climáticas de donde el edificio se inserta (Figura 8).

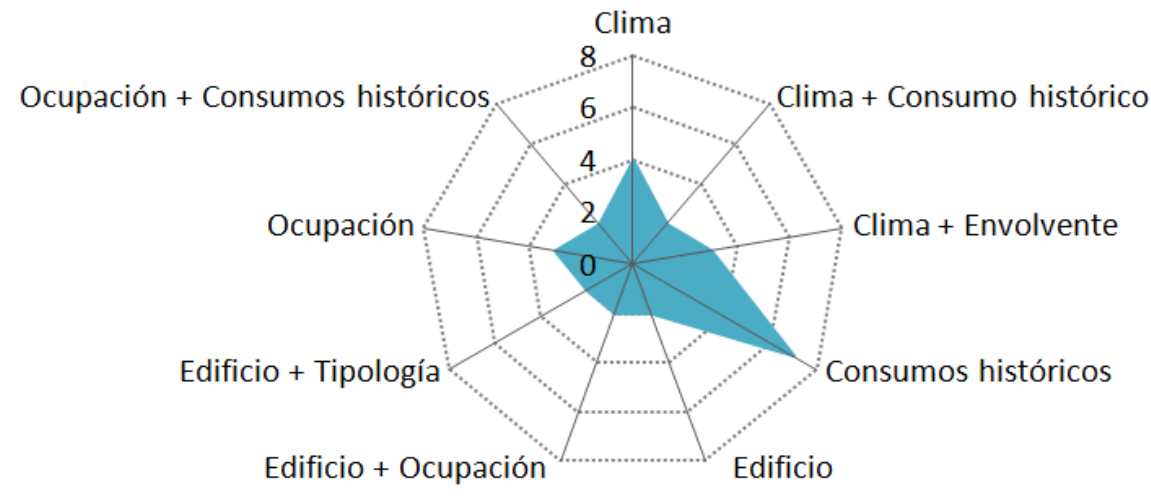

Modelos de predicción de consumo energético

Figura 8: Variables de entrada utilizadas para la construcción de modelos de predicción de consumo energético. Elaboración propia.

Entre los modelos creados para grandes regiones, Petersdorff, Boermans y Harnisch (2006) elaboraron un modelo para predecir el consumo en calefacción en base a cinco tipologías de edificios con ocho niveles diferentes de aislamiento térmico para la envolvente del edificio, simulados en tres regiones climáticas de Europa - fría, moderada, cálida.

Wong, Wan and Lam (2010) propusieron un modelo para predecir el consumo de energía para edificios de oficinas con control de iluminación diurna en climas subtropicales, considerando cuatro variables climáticas - temperatura promedio diaria del bulbo seco, temperatura promedio diaria del bulbo húmedo, radiación solar global diaria e índice de claridad promedio diario, cuatro variables de la envolvente del edificio - apertura solar, apertura de luz diurna, proyecciones sobresalientes y de aletas laterales, y el día de la semana - sábado, domingo y entre semana.

Korolija, et al. (2013) desarrollaron un modelo para predecir el consumo en HVAC de edificios de oficinas en Reino Unido, a partir de cuatro tipologías de edificios de oficinas, siete variables de la envolvente del edificio - orientación, forma, reflective y \% de superficie vidriada, protección solar, control 
de la luz natural, y cinco niveles de aislamiento para la envolvente edilicia -, cinco variables de sistemas de HVAC - VAV, CAV, sistema de fan-coil con aire dedicado, y dos sistemas de techo frío con aire dedicado Aire, calefacción del radiador y tubos embebidos o paneles de aluminio expuestos -, y cinco variables de ocupación - temperatura de setpoint, tasa de infiltración, densidad ocupacional y tasa metabólica, y ganancias de calor interno.

Nath y Lamberts (2018) establecieron un modelo simplificado para estimar el consumo energético en refrigeración para un edificio de oficinas simulando su aplicación a 18 zonas climáticas de Brasil. Los autores emplearon 15 variables del edificio, 12 variables del sistema HVAC, y 3 variables de uso y ocupación. Para representar las características del clima de las diferentes zonas climáticas, construyeron un indicador de grados horas a partir de la entalpía - CEH, el cual sirvió como parámetro para sectorizar 407 ciudades brasileñas en 18 grupos. Para cada grupo eligieron una ciudad de referencia para representar las características climáticas de cada zona.

No se ha encontrado un modelo de predicción del consumo que se base en las características de la envolvente edilicia, de uso y ocupación, de las instalaciones, y del clima de ciudades situadas en clima templado. Los resultados encontrados coinciden con la revisión realizada por Yoon y Moon (2018), donde los autores resaltan que la mayoría de los modelos energéticos se basan en el análisis de las condiciones relacionadas al clima y al tipo de construcción, indicando la falta de modelos energéticos construidos a partir de los estándares de uso y ocupación.

\subsubsection{Técnicas de agrupamiento de datos}

Al presente, son diversas las técnicas utilizadas para agrupar la información en el análisis predictivo (Figura 9). Usualmente se clasifican entre caja blanca a la técnicas que suponen el conocimiento de todas las características del edificio permitiendo describir con precisión los mecanismos físicos, caja negra a los métodos que requieren de gran cantidad de datos, entregando resultados con enfoque estadístico que dificultan la interpretación de los mecanismos físicos en el edificio, y caja gris a las técnicas híbridas (Espino Timón 2017).

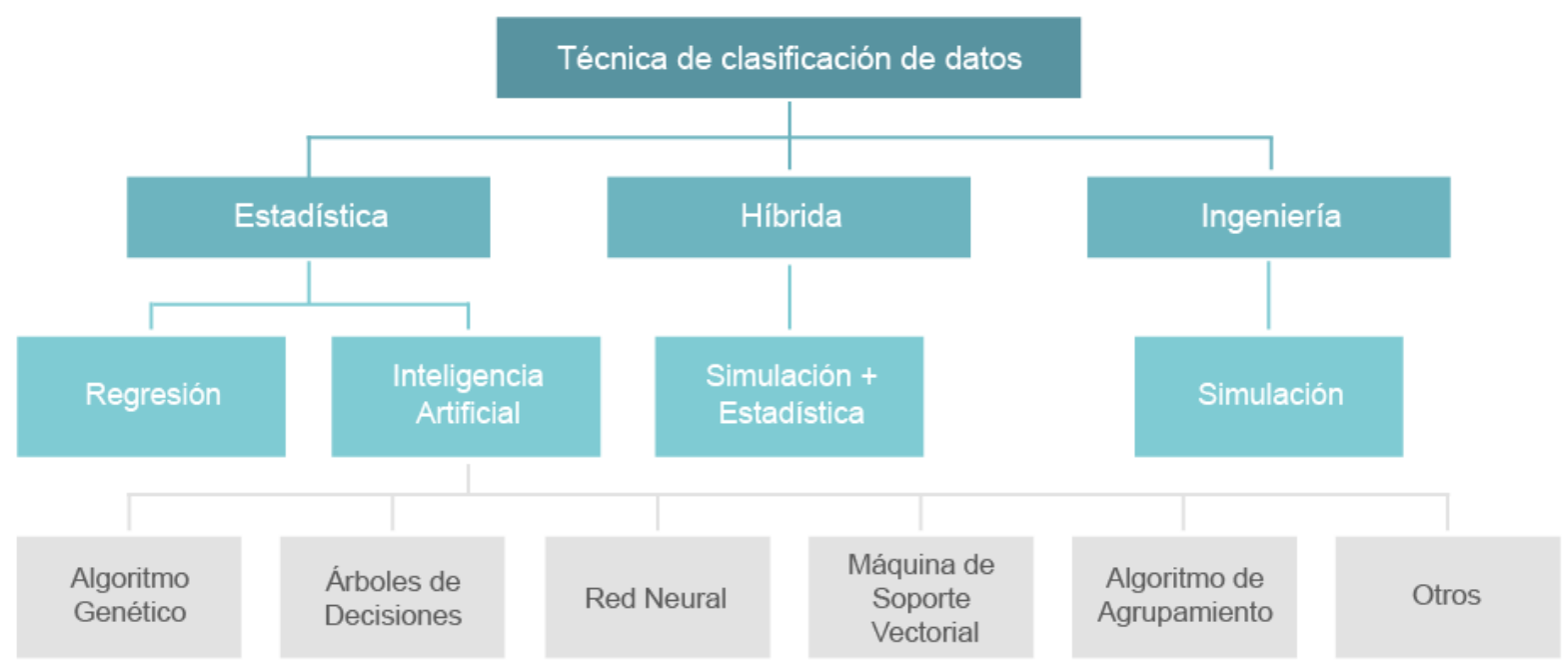

Figura 9: Técnicas utilizadas para el agrupamiento de datos en modelos de predicción. Elaboración propia. 


\subsubsection{Ingeniería}

Las técnicas de ingeniería se basan en la resolución de ecuaciones fundamentadas en las leyes de termodinámica, lo que permite describir el comportamiento físico de la transferencia de calor y luego el comportamiento térmico del edificio. De forma general, la formulación física requiere de una descripción detallada de los mecanismos que ocurren dentro y fuera de la geometría del edificio, lo que implica un elevado tiempo de cálculo necesario para construir el modelo energético.

Para resolver estos problemas físicos se emplea una variedad de programas numéricos, como los softwares de simulación computacional Energy Plus, Design Builder, Transys, entre otros. En la interfaz del programa se construye el modelo energético asignando parámetros de entrada como datos meteorológicos, geométricos, características termofísicas, de uso y ocupación y de encendido y eficiencia de los equipos. Estos parámetros siempre expresan cierta incertidumbre asociada a los datos de entrada y a las suposiciones para estimar el comportamiento del edificio, estableciendo una dificultad para evaluar la precisión de ajuste del modelo creado (Foucquier, et al. 2013).

\section{Confort adaptativo}

Entre los trabajos que utilizan simulación computacional para generar datos de consumo de los edificios, se encontraron escasos casos de modelos energéticos que se basan en el confort adaptativo.

El confort adaptativo se basa en que la percepción del confort térmico es relativa, dado que distintos usuarios expuestos a un ambiente con parámetros ambientales iguales (temperatura del aire, temperatura radiante media, velocidad del aire y humedad relativa) tendrán diferente percepción del confort (Fanger 1970).

En términos fisiológicos un individuo se encuentra en confort cuando su cuerpo realiza el menor esfuerzo posible para regular la temperatura interna, involucrando diversos factores, como la edad, el sexo, la contextura física, la tasa metabólica correspondiente a la actividad física que se realice entre otros. Así mismo, para auxiliar en la regulación de la temperatura corporal, el individuo utiliza diversas estrategias para alcanzar el confort térmico, que varían desde la modificación de la vestimenta puesta y la apertura de las ventanas, hasta el encendido de artefactos como el ventilador y el aire acondicionado.

Estas medidas cuantificadas a gran escala como sería el caso de un edificio, o del parque edilicio de una ciudad, son importantes para poder estimar valores de consumo energético aproximados a los reales. Por lo que un modelo energético para edificios residenciales que no lleve en consideración el confort adaptativo, posiblemente hará estimaciones de consumos energéticos distantes de la realizad, haciendo con que las decisiones tomadas sean poco eficientes (Escandón, Suárez e Sendra 2017).

En la bibliografía, diversas investigaciones demuestran que usuarios en todo el mundo hacen uso de diferentes medidas para alcanzar niveles de confort térmico mínimo (Melo, et al. 2012) (Ruiz e Correa 2015) (Trebilcock, et al. 2017) (Li, et al. 2018) (Rijal, et al. 2013) (Barbadilla Martín, et al. 2017).

En los últimos años los conceptos de confort térmico adaptativo han sido integrados en diversos instrumentos regulatorios de desempeño. En Alemania, China, Europa y Estados Unidos se han 
implementado normativas basadas en la adaptación de los usuarios para evaluar la calidad de los ambientes térmico (Carlucci, et al. 2018).

En Latinoamérica, el confort adaptativo también es una práctica común entre los usuarios aunque no se encuentre reglamentado (Pérez Fargallo, et al. 2018) (Filippín, Flores Larsen e Marek 2015) (Ganem, Coch e Esteves 2008), por lo que su consideración en la construcción de los modelos energéticos es necesaria para promover la creación de estándares y estrategias de eficiencia acorde a la realidad.

\subsubsection{Estadísticos}

Las técnicas estadísticas se basan en construir reglas para describir el comportamiento de un sistema a partir de la muestra de datos ingresada. Soporta una gran variedad de datos de entrada, realizando el cálculo de inúmeros escenarios en un corto intervalo de tiempo, y con elevada precisión.

A diferencia de las técnicas de ingeniería, se puede aplicar el método estadístico también cuando no se conocen las características físicas del edificio, ya que no requieren de parámetros físicos o geométricos del modelo. Las principales diferencias entre las técnicas de regresión y de inteligencia artificial - Al es que para la primera la relación entre las variables debe ser lineal y no se requiere una base de datos relevante, en cuanto para la segunda no es necesario identificar una colinealidad entre ellas, pero usualmente se requiere una muestra con datos representativos y completos. Además, la red neural permite definir reglas de agrupamiento a partir de la relación entre diferentes variables sin ningún supuesto asociado al modelo (Foucquier, et al. 2013).

\subsubsection{Híbrido}

Tanto las técnicas estadísticas como las de ingeniería poseen cualidades y limitaciones en su empleo. La técnica híbrida consiste en un método que une dos dominios científicos distintos, acoplando el método estadístico y el modelo físico con el fin de optimizar los procesos. Existen varias estrategias híbridas disponibles, pero se observan dos estructuras principales. La primera se centra en utilizar el aprendizaje automático para generar reglas de agrupamiento y mantener el significado físico, en cuanto la segunda utiliza el método estadístico para implementar un modelo de aprendizaje que describa el comportamiento del edificio.

Las principales ventajas del método híbrido residen en poder considerar una muestra con datos reducida, realizar una descripción aproximada de las características del edificio, y obtener una respuesta con mayor precisión que permita realizar una interpretación física.

Según la revisión de la literatura no existe una estructura única para la clasificación de la información disponible, sino que todas son válidas según el problema de cada investigación (Fumo 2014) (Amasyali e El-Gohary 2018) (Foucquier, et al. 2013).

Con respecto a las técnicas utilizadas para el agrupamiento de datos en los modelos analizados, el método estadístico consiste en la técnica predominante, debido a la mayor precisión en la predicción y a la reducción del tiempo cuando comparados con modelos de ingeniería. La regresión lineal es aplicada en $44 \%$ de los casos muchas veces asociada al análisis de los consumos históricos asignados en los datos de 
entrada, en cuanto el análisis con técnicas de inteligencia artificial se utiliza en $31 \%$ de los casos, principalmente en trabajos con muestras construidas a partir de una extensa cantidad de variables y situaciones posibles (Figura 10).

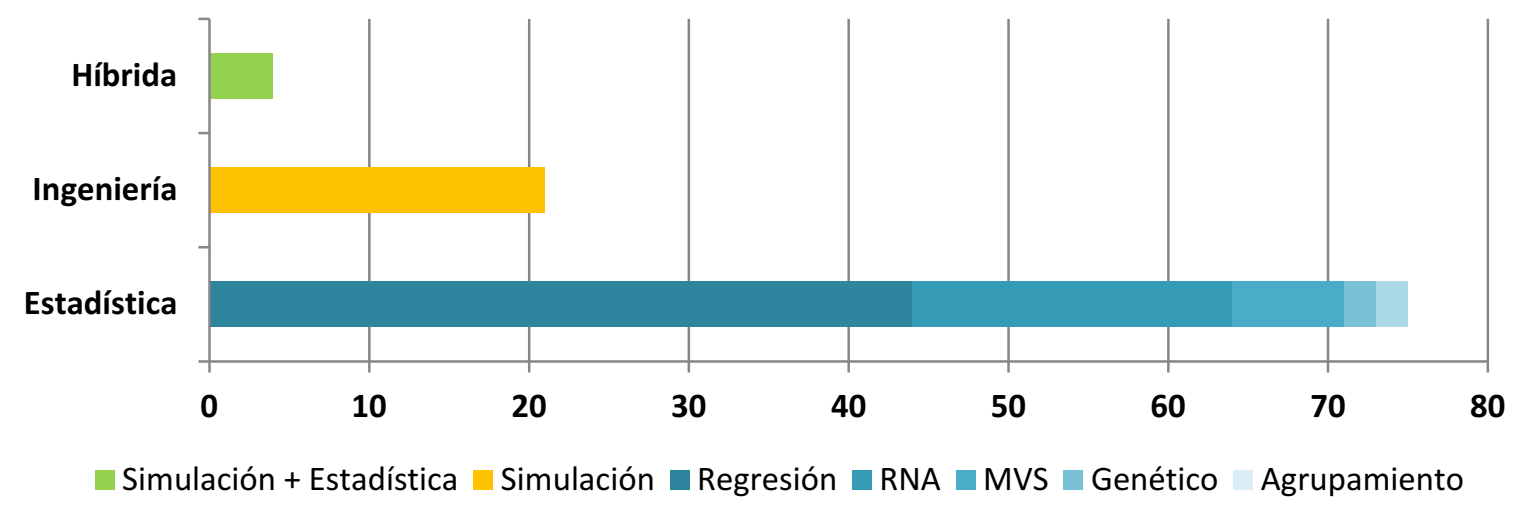

Figura 10: Frecuencia de las técnicas de agrupamiento de datos empleadas en los modelos de predicción revisados. Elaboración propia.

\subsection{Conclusiones}

En función de lo expuesto en este capítulo, se ha definido que la implementación de regulaciones y certificaciones de desempeño térmico edilicio contribuye a la generación de consciencia y promueve la preservación de los recursos y la disminución del impacto ambiental en el ámbito de la construcción civil.

La aplicación de estas iniciativas es obligatoria desde 2006 para todos los estados miembros de la Unión Europea, lo que ha llevado la Comunidad a alcanzar importantes ahorros en consumo energético y en emisiones. En Latinoamérica no todos los países poseen instrumentos reguladores del desempeño térmico para edificios, así como no todas las iniciativas existentes se aplican efectivamente. Lo que torna la experiencia europea un modelo de referencia para investigaciones centradas en la promoción de estrategias de eficiencia energética en Latinoamérica.

Entre las regulaciones y certificaciones existentes en clima templado, el consumo energético consiste en el principal criterio evaluado, con excepción de Latinoamérica donde el atendimiento de la demanda energética e indicadores son predominantes.

Se definió que el análisis del consumo energético permite el análisis integral del desempeño del edificio, entregando resultados adecuados para estimar la eficiencia energética de un edificio a nivel local, bien como del parque edilicio para aproximaciones a nivel regional. Las políticas energéticas fundamentadas en resultados de estudios que consideran la demanda energética son poco eficientes, por lo que se deduce necesario que las iniciativas en Latinoamérica se basen en el consumo energético.

Una de las limitaciones encontradas en la introducción del análisis del consumo energético en lugar de criterios que se pueden verificar de manera simplificada, consiste en aumentar la dificultad de entendimiento de la herramienta, sus procesos de cálculo y control, lo que sugiere que esta modificación incrementaría el problema de implementación de las iniciativas en Latinoamérica. 
Dado este contexto se define la importancia de la creación de un método de cálculo simplificado para estimar el consumo energético de edificios en clima templado, actualmente inexistente en la bibliografía revisada. De esta forma será posible introducir el consumo energético en los sistemas de calificación edilicia de Latinoamérica manteniendo la facilidad en el entendimiento y aplicación de la herramienta y la practicidad en los procesos de evaluación y control. El método desarrollado será posible de aplicar a diferentes países en Latinoamérica, y considerando el modelo europeo como referencia, permitirá verificar si es posible de estimar y generalizar el rendimiento de edificios situados en localidades de Latinoamérica con clima templado, a demás localidades del mundo con clima templado.

Para el desarrollo del modelo propuesto, se revisaron las características de los modelos de predicción para edificios buscando identificar su estructura principal.

Se constató que la mayor parte de los estudios buscan estimar el consumo eléctrico o energético para edificios residenciales, dado que son grandes consumidores de energía principalmente durante la etapa de uso y ocupación. Se decidió que el modelo creado se destinará a edificios de vivienda unifamiliar y multifamiliar, con el fin de que la herramienta desarrollada auxilie en la implementación de iniciativas capaces de promover mayor ahorro energético y de emisiones.

Se definió que las variables de entrada necesarias para construir el modelo de predicción de consumo energético deben incluir aspectos del clima, de la envolvente del edificio, de uso y ocupación y de instalaciones. Entre los modelos revisados no se encontraron casos que se fundamenten en los cuatro pilares citados, así como casos que se apliquen a diferentes localidades con clima templado, lo que otorga las principales diferencias entre los modelos existentes.

Para la técnica de agrupamiento de datos utilizada en la construcción del modelo se eligió el método híbrido dada la posibilidad de construir modelos energéticos con informaciones reales y utilizar los consumos provenientes de la simulación en la matriz de datos para el análisis estadístico. Los modelos energéticos contemplaran los principios del confort adaptativo conforme la realidad de los usuarios. 


\section{Objetivos y metodología}

Este trabajo se centra en promover la introducción del análisis del consumo energético como principal indicador del desempeño térmico del edificio, a partir de la elaboración de un método de cálculo de fácil aplicación, coherente con el contexto de las estrategias de eficiencia energética edilicia en Latinoamérica. Para ello, propone un método simplificado integrador fundamentado en la variación de las condiciones climáticas, de los estándares de uso y ocupación, de las características constructivas y morfologías del edificio y de sus instalaciones (Figura 11).

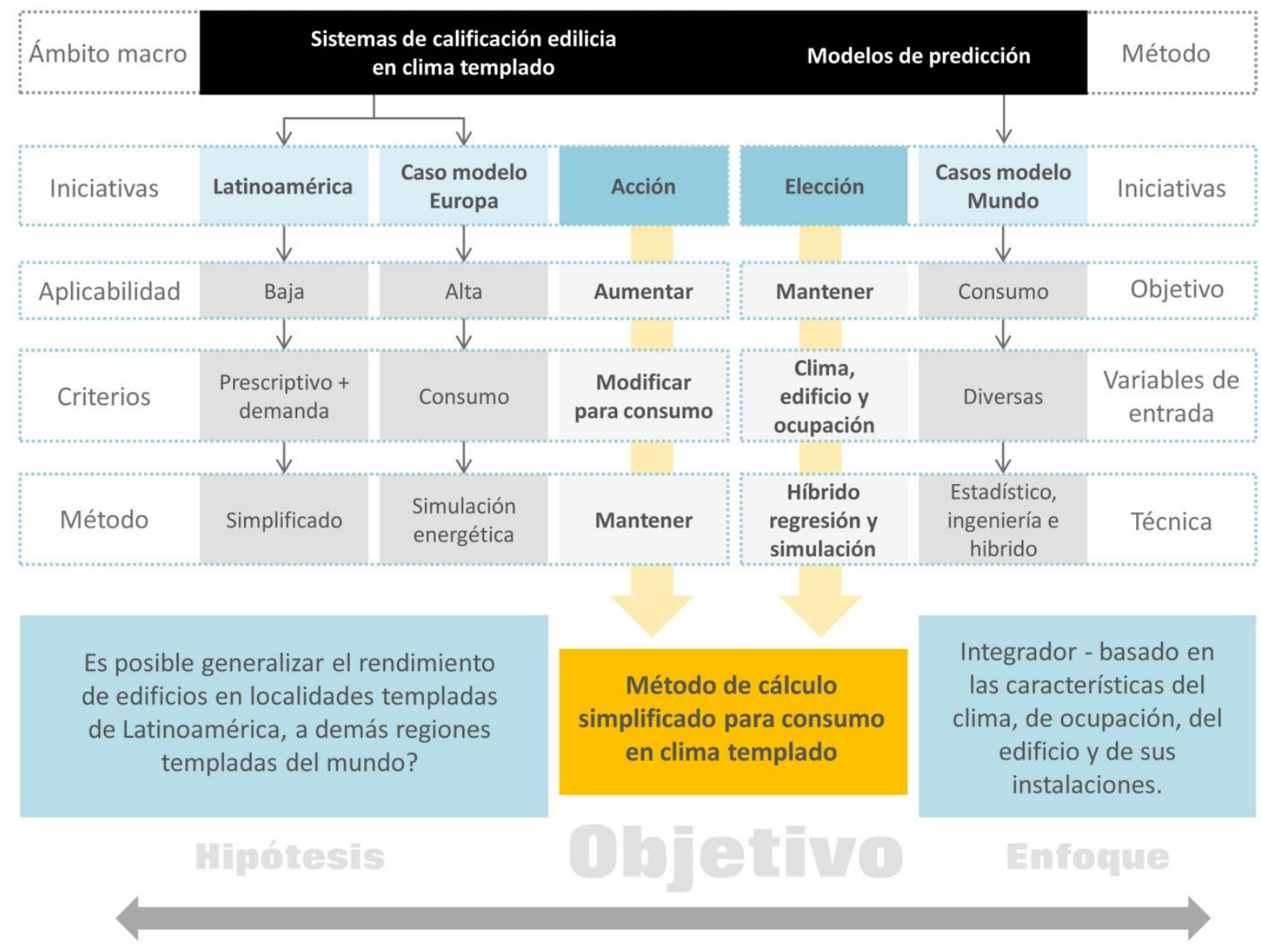

Figura 11: Construcción del objetivo de la investigación. Elaboración propia. 


\section{Objetivo principal}

El objetivo principal de la presente tesis es definir una metodología de cálculo simplificado capaz de predecir el consumo energético en acondicionamiento térmico para viviendas unifamiliares y multifamiliares situadas en clima templado, con el fin de tender hacia un modelo energético ambiental basado en análisis múltiple que fomente el desarrollo y aumente la aplicación de iniciativas de eficiencia energética edilicia para mitigación del cambio climático.

\section{Objetivos secundarios}

Para alcanzar el objetivo propuesto se establecieron 3 objetivos secundarios, los cuales se subdividen en 6 etapas y pueden ser agrupadas en 3 niveles jerárquicos. Estos niveles jerárquicos se vinculan con los objetivos propuestos y se denominan Parte I, Parte II, y Parte III (Figura 12).

El objetivo en la Parte I - Delimitación del ámbito de la investigación es definir las características del clima, de uso y ocupación, del edificio y sus instalaciones, necesarias para la ejecución de la Parte II y III.

En la Parte II - Cuantificación del consumo energético se pretende construir los modelos energéticos y cuantificar los consumos en acondicionamiento para los Casos de Estudio aplicados a distintas localidades con clima templado, considerando diferentes escenarios de cálculo.

En la Parte III - Definición de la ecuación el objetivo es determinar los modelos estadísticos que mejor representan la correlación entre los consumos y las características climáticas de las diferentes localidades de aplicación, así como establecer los rangos de ahorro para la creación de la base del modelo energético ambiental para edificios residenciales situados en clima templado de Latinoamérica.

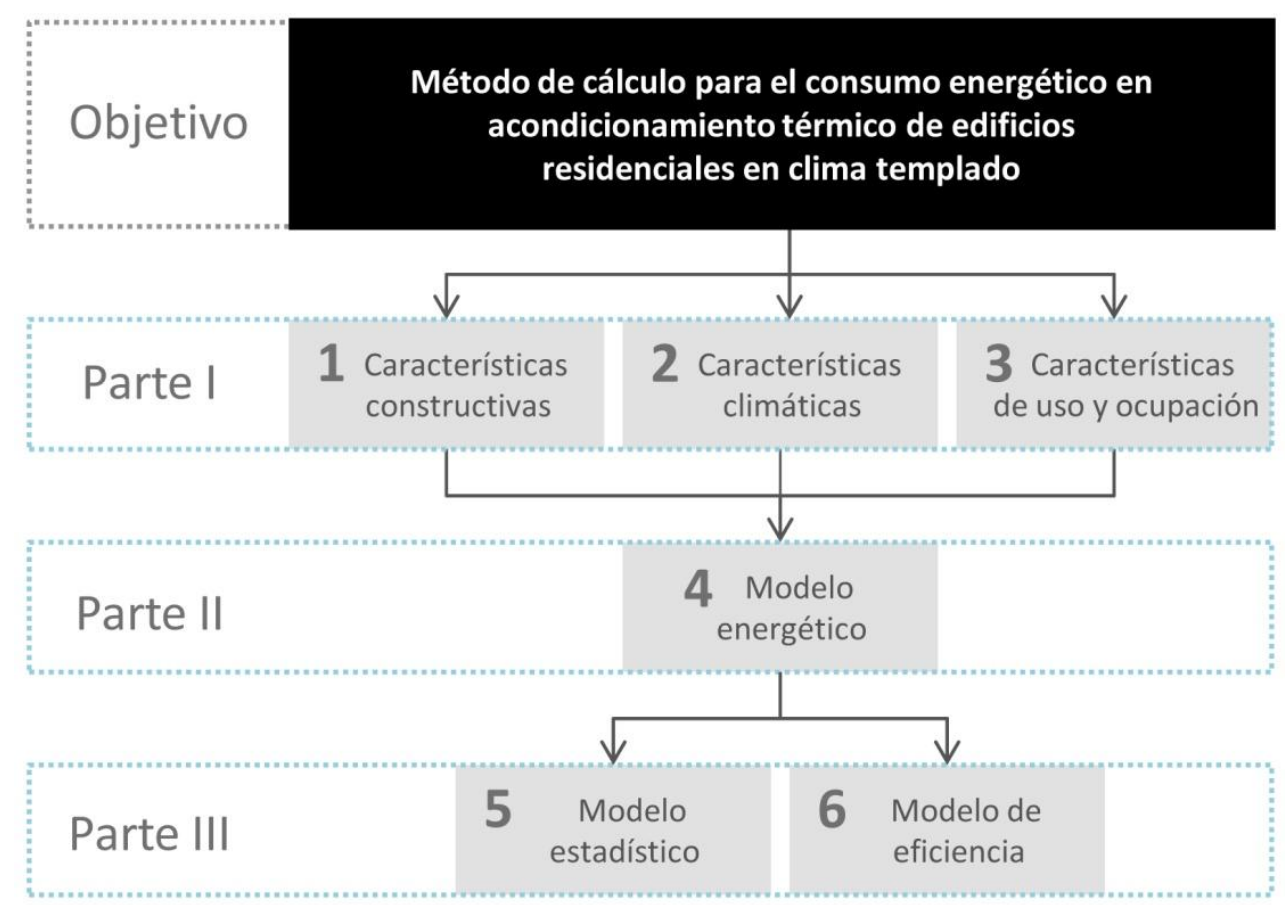

Figura 12: Jerarquía para la estructuración de los objetivos de la investigación. Elaboración propia. 


\section{Metodología}

En función de la estructura jerárquica de objetivos, se establece un plan de actividades necesarias para alcanzar las metas propuestas, partiendo del principio de que el objetivo principal se obtendrá mediante la construcción de un modelo predictivo de consumo energético integrado (Figura 13).

Para ello se estima el consumo energético en acondicionamiento térmico de dos edificios de vivienda, simulando su aplicación a diferentes localidades con clima templado. En seguida, mediante un análisis de regresión lineal múltiple se estudia la correlación entre los resultados obtenidos con las características climáticas de las diferentes ciudades, lo que permite definir el modelo estadístico final. A continuación se determinan los porcentajes de ahorro posibles de alcanzar en consumo energético y en emisiones de dióxido de carbono, y se estructura la base para la creación del modelo energético ambiental.

\begin{tabular}{|c|c|c|c|c|}
\hline Capítulo & Objetivos & Actividades & Método & \\
\hline & Introducción & 1 Resumen extendido & Plan investigación & \multirow{8}{*}{$\begin{array}{l}\text { 엄 } \\
\text { 음 } \\
\text { 맘 }\end{array}$} \\
\hline \multirow{3}{*}{ 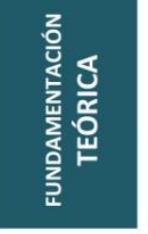 } & \multirow{2}{*}{$\begin{array}{l}\text { Estado de la } \\
\text { cuestión }\end{array}$} & 2 Revisión bibliográfica & \multirow{2}{*}{$\begin{array}{l}\text { Análisis } \\
\text { comparativo }\end{array}$} & \\
\hline & & 2 Problema de la investigación & & \\
\hline & $\begin{array}{l}\text { Objetivos y } \\
\text { metodología }\end{array}$ & 3 Objetivos y metodología de la investigación & \multirow{5}{*}{$\begin{array}{l}\text { Análisis } \\
\text { comparativo }\end{array}$} & \\
\hline \multirow{6}{*}{ 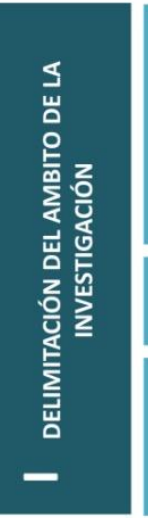 } & \multirow{3}{*}{$\begin{array}{l}\text { Característica } \\
\text { constructiva }\end{array}$} & $\begin{array}{l}\text { 4.1 Seleccionar los sistemas de calificación edilicia } \\
\text { y definir los indicadores de estudio }\end{array}$ & & \\
\hline & & 4.2 Delimitar los edificios Casos de Estudio & & \\
\hline & & 4.3 Determinar los Escenarios de Cálculo & & \\
\hline & $\begin{array}{l}\text { Característica } \\
\text { climática }\end{array}$ & $\begin{array}{l}5.1 \text { Definir las ciudades de aplicación y sus } \\
\text { variables climáticas }\end{array}$ & & \\
\hline & \multirow{2}{*}{$\begin{array}{l}\text { Característica } \\
\text { de ocupación }\end{array}$} & 6.1 Aplicar encuestas a los usuarios & Encuesta & \multirow{8}{*}{$\frac{\mathrm{S}}{\sim}$} \\
\hline & & $\begin{array}{l}6.2 \text { Realizar monitoreos energéticos en las } \\
\text { viviendas }\end{array}$ & Registro & \\
\hline \multirow{3}{*}{ 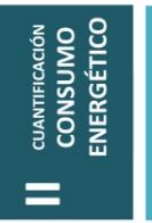 } & \multirow{3}{*}{$\begin{array}{l}\text { Modelo } \\
\text { energético }\end{array}$} & 7.1 Modelar los Casos de Estudio & Observación & \\
\hline & & 7.2 Validar el modelo energético & Validación & \\
\hline & & 7.3 Cuantificar los consumos energéticos & Simulación & \\
\hline \multirow{3}{*}{ 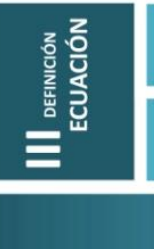 } & $\begin{array}{c}\text { Modelo } \\
\text { estadístico }\end{array}$ & 8.1 Ejecutar análisis de regresión múltiple & Estadística & \\
\hline & $\begin{array}{l}\text { Modelo de } \\
\text { eficiencia }\end{array}$ & 9.1 Estimar los ahorros en energía y emisiones & Simulación & \\
\hline & Conclusión & 10 Consideraciones finales & Observación & \\
\hline
\end{tabular}

Figura 13: Metodología propuesta para el desarrollo del método de cálculo simplificado. Elaboración propia. 


\section{PARTE I - DELIMITACIÓN DEL ÁMBITO DE LA INVESTIGACIÓN}

\section{Etapa 1: Delimitar las características constructivas}

Para delimitar las características constructivas necesarias para asignar al modelo energético se seleccionarán los sistemas de calificación edilicia en Latinoamérica empleados en el trabajo, y un caso de Europa como modelo de referencia. Así mismo se identificarán cuales son los indicadores requeridos por cada iniciativa que permiten la comparación de los estándares mínimos propuestos por cada país. A partir de la definición de los indicadores, se construirán diferentes escenarios constructivos atendiendo a los estándares mínimos definidos por cada iniciativa, los cuales serán asignados al modelo energético según la localidad en que se simule su aplicación.

Para definir los Casos de Estudio trabajados se delimitarán tipologías de edificios residenciales tradicionales construidos en Latinoamérica, con el fin de que los resultados encontrados sean representativos del parque edilicio regional.

\section{Etapa 2: Determinar las características climáticas}

Para determinar las variables climáticas que servirán de base para la matriz de datos utilizada en la construcción del modelo estadístico, se delimitarán las localidades con clima templado encontradas en los países correspondientes a los sistemas de calificación seleccionados anteriormente. Así mismo, en la simulación energética se utilizará el archivo de datos con extensión EPW para asignar al modelo y estimar su consumo en cada localidad seleccionada.

\section{Etapa 3: Fijar las características de uso y ocupación}

Para establecer las características de uso y ocupación necesarias para asignar al modelo energético, se aplicarán encuestas a los habitantes de los Casos de Estudio seleccionados buscando identificar el perfil del usuario. Así mismo se ejecutarán monitoreos energéticos con el fin de registrar datos para la interpretación de las encuestas recogidas, bien como validar el modelo energético.

Para definir las características de los sistemas de climatización se fundamentarán en los principios del confort adaptativo y en las especificaciones del CTE. Estos parámetros de detallan en la construcción del modelo energético en la etapa de simulación.

\section{PARTE II - CUANTIFICACIÓN DEL CONSUMO ENERGÉTICO}

\section{Etapa 4: Construir los modelos energéticos}

Para la construcción de los modelos energéticos primeramente se realizará el modelado detallado de los Casos de Estudio asignando las características constructivas establecidas en los Escenarios de Cálculo, las cargas de ocupación recogidas de las encuestas, las características del sistema de acondicionamiento y el archivo climático correspondiente. Se procederá a la validación del modelo teniendo como base los registros del monitoreo energético, y a continuación se ejecutarán las simulaciones para obtener los consumos necesarios para emplear en la matriz de datos para la elaboración del modelo estadístico. 
PARTE III - DEFINICIÓN DE LA ECUACIÓN

\section{Etapa 5: Establecer los modelos estadísticos}

Para construir los modelos estadísticos se aplicará el análisis de regresión múltiple considerando los consumos en la variable dependiente y las variables climáticas en las variables secundarias. Se pondrán a prueba los coeficientes resultantes, se identificarán las variables influyentes y se definirá un modelo final.

\section{Etapa 6: Definir los ahorros energéticos y en emisiones para el modelo de eficiencia}

Una vez obtenida la ecuación se estimarán los ahorros potenciales resultantes de la aplicación de los estándares mínimos definidos por cada país, así como los ahorros en emisiones de $\mathrm{CO} 2$ provenientes de la diferencia entre la construcción tradicional y la aplicación de los estándares. 



\section{PARTE I}

\section{delimitación del ámbito de la investigación}

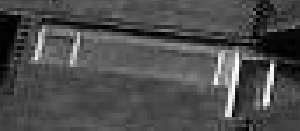




\section{Objetivo del capítulo}

En este capítulo se ejecutarán las actividades necesarias para delimitar las características constructivas y las localidades aplicadas en la etapa de simulación energética, las características climáticas empleadas en la etapa de creación del modelo estadístico, y la información de uso y ocupación requerida para la etapa de simulación energética (Figura 14).

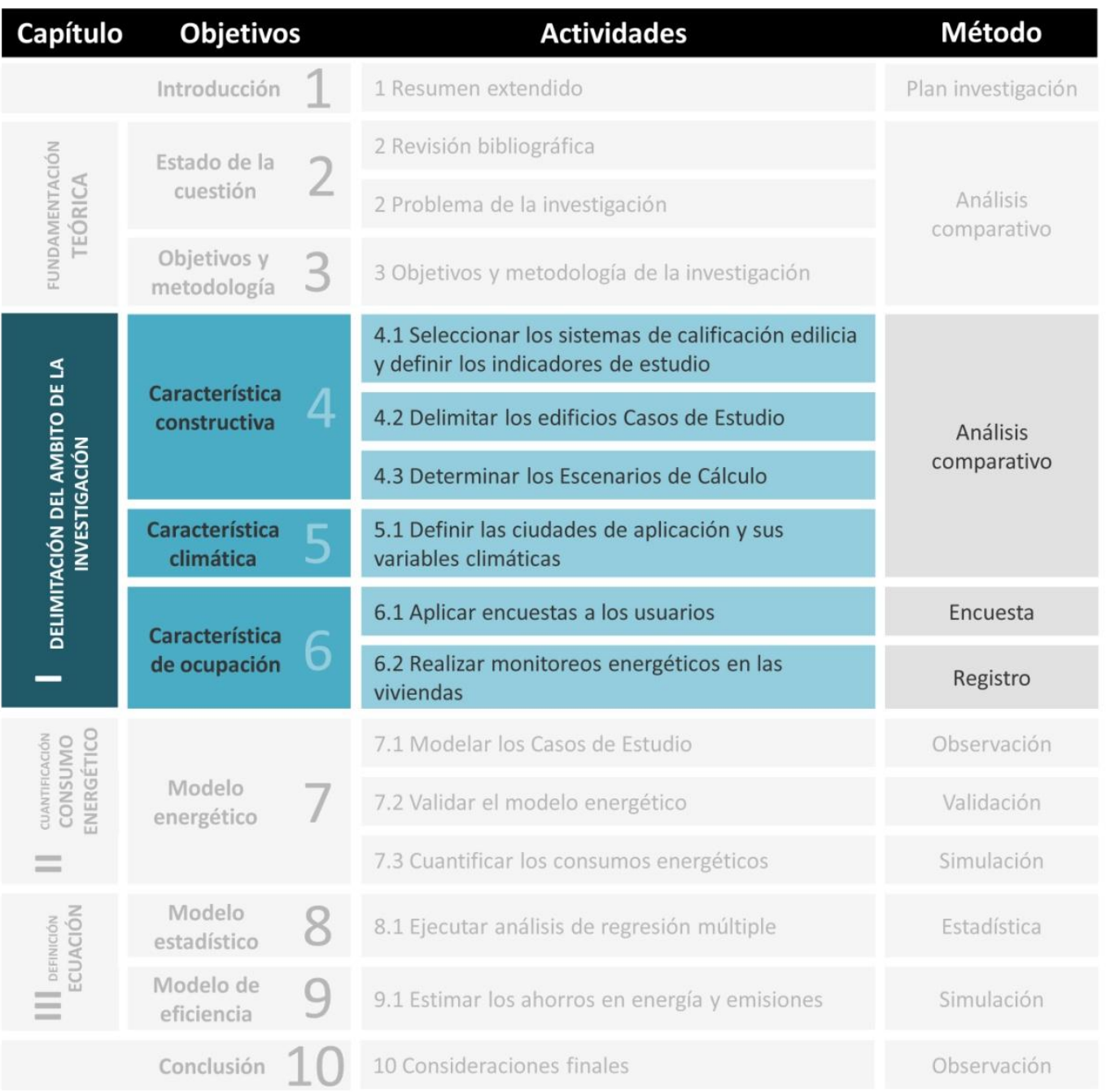

Figura 14: Esquema metodológico Parte I-Delimitación del ámbito de la cuestión. Elaboración propia. 


\section{Características Constructivas}

\section{Objetivo}

En esta etapa se profundizarán los estudios sobre los criterios de confort térmico y de eficiencia energética establecidos en los sistemas de calificación edilicia existentes en Latinoamérica, con el propósito de definir los casos de aplicación y los parámetros de análisis utilizados en la investigación.

Se definirán las tipologías estándares de edificios residenciales definidos por el Programa Minha Casa Minha Vida, con el fin de seleccionar casos posibles de acceder para la realización del monitoreo energético y la aplicación de las encuestas. A estos casos se los denominarán Casos de Estudio.

Se identificarán los valores mínimos admisibles para la transmitancia térmica - $U$ de los cerramientos opacos establecidos por cada uno de los sistemas de calificación edilicia seleccionados, con el propósito de construir los diferentes escenarios de cálculos necesarios para ejecutar la etapa de simulación energética. Este apartado se vincula con 5.1 Selección de las localidades ya que para asignar los valores de U correspondientes, se deben conocer primeramente las localidades en donde se aplican. 


\subsection{Selección de los sistemas de calificación edilicia e indicadores de estudio}

En el apartado 2.1 Sistemas de calificación edilicia se expuso brevemente el contexto de las iniciativas de calificación edilicia implementadas en los países con clima templado. Se observó que cada caso posee un enfoque particular, sugiriendo que sus universos de análisis y criterios, también son diferentes.

Estos factores dificultan la realización de un análisis homogéneo capaz de representar la individualidad de cada sistema, a la vez que permita obtener una comprensión conjunta de ellos.

Para poder comparar los requerimientos definidos por cada sistema con un criterio único, se realizó la reestructuración de las metodologías originales, simplificando los términos y nomenclaturas, sin la modificación del contenido y de la información relevante (Figura 15).

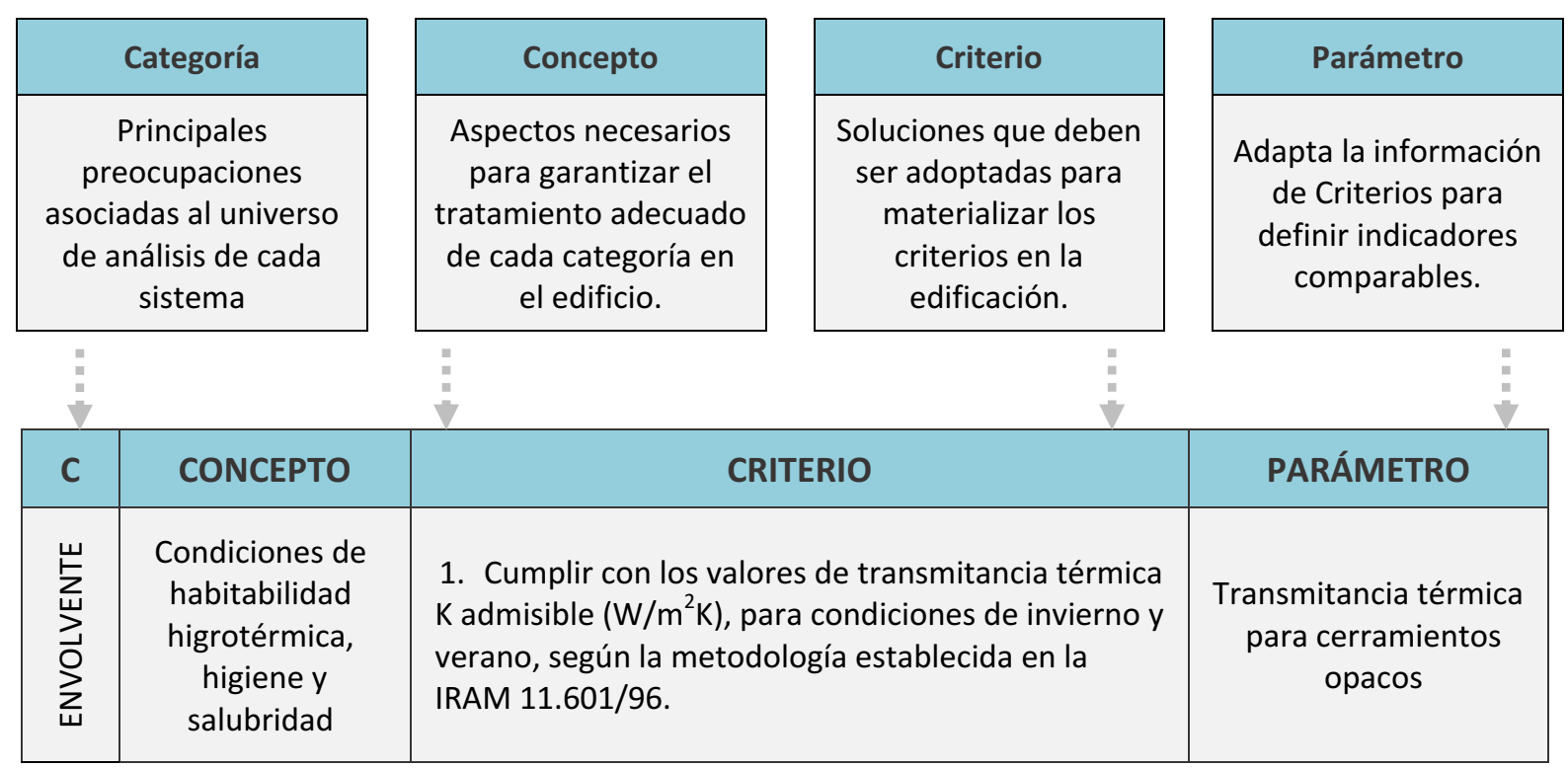

Figura 15: Reestructuración de los requerimientos establecidos en los sistemas de calificación edilicia estudiados. Modelo de ejemplo: caso Ley $n^{\circ}$ 13.059/03. Elaboración propia.

Se denominó Categoría a las principales preocupaciones asociadas al universo de análisis de cada sistema, Concepto a la definición de los aspectos necesarios para garantizar el tratamiento adecuado de cada categoría en el edificio, Criterio a la especificación de las soluciones que deben ser adoptadas para visualizar la materialización de los criterios en la edificación, y Parámetros a los indicadores de confort térmico y eficiencia energética definidos, siguiendo una nomenclatura estandarizada.

Con el objetivo de realizar una comparación objetiva, la selección de los sistemas de calificación edilicia aplicables en este estudio se fundamentó en elegir las iniciativas destinadas a edificios residenciales, con criterios de confort térmico y eficiencia energética objetivos, es decir que tengan valores e indicadores específicos, y que pudiesen ser empleadas en al menos 5 localidades del país con disponibilidad de archivos climáticos en formato EPW, ya que no cumplir con este factor dificultaría la realización de simulaciones energéticas empleando una base de datos climáticos homogénea.

La selección de los criterios de confort térmico y eficiencia energética se basó en dos aspectos. El primero se centró en priorizar los criterios que estaban directamente relacionados con el confort térmico 
percibido por los usuarios. El segundo se centró en elegir los criterios de eficiencia energética que representasen una solución proyectual, es decir, que incidiera en las decisiones de diseño del edificio y en las características constructivas de su envolvente. Se desconsideraron las medidas para la reducción de la demanda a partir de la potencia de los artefactos, del rendimiento de los equipos y similares.

Dado que Colombia, Costa Rica, Ecuador, Paraguay, Perú, y Uruguay solamente disponen de archivos climáticos en formato EPW para las ciudades de Bogotá, Quito, Asunción, Arequipa, Cuzco, Lima, y Montevideo, resulta inviable la comparación de estos países en igualdad de condiciones con los demás, por lo que se decide dar continuidad al estudio considerando los sistemas de Argentina, Brasil, Chile y México.

\subsubsection{Argentina}

\subsubsection{Etiquetado de eficiencia energética}

La Etiqueta de eficiencia energética de calefacción para edificios conocida como Norma IRAM 11.900 (Instituto Argentino de Normalización y Certificación 2010) ha sido publicada con el objetivo de establecer valores máximos de consumo energético para invierno, e informar a los usuarios la eficiencia térmica de la envolvente del edificio analizado. Se destina a toda edificación susceptible de ser calefaccionada, presenta carácter de cumplimiento voluntario, y su método de evaluación se basa en Cumplir con los valores máximos del indicador Tau - tm (Tabla 3).

\begin{tabular}{|c|c|c|c|}
\hline C & CONCEPTOS & CRITERIOS & PARÁMETRO \\
\hline 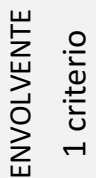 & $\begin{array}{l}\text { Establecer índices } \\
\text { máximos de } \\
\text { consumo } \\
\text { energético }\end{array}$ & $\begin{array}{l}\text { 1. Cumplir con los valores máximos de variación } \\
\text { media ponderada entre la temperatura de la } \\
\text { superficie interior del muro y la temperatura interior } \\
\text { de diseño. }\end{array}$ & Indicador Tau \\
\hline
\end{tabular}

Tabla 3: Criterios de evaluación de la Etiqueta de eficiencia energética de calefacción para edificios. Elaboración propia adaptada de (Instituto Argentino de Normalización y Certificación 2010).

Este indicador define la variación media ponderada entre la temperatura de la superficie interior del muro y la temperatura interior de diseño, considerada por defecto $20^{\circ} \mathrm{C}$ (Instituto Argentino de Normalización y Certificación 2010). El método de cálculo analiza la resistencia térmica superficial interior y total, la transmitancia térmica de cada una de las componentes de la envolvente, y la diferencia de temperatura de diseño interior y exterior, como se describe en la Ecuación 1. El nivel de eficiencia energética alcanzado puede ser clasificado entre ocho niveles, variando entre la letra A hasta la $\mathrm{H}$.

$$
\tau_{m}=\frac{\Sigma\left(\tau_{i} \cdot S_{i}\right)}{\Sigma S_{i}}
$$

Ecuación 1: Indicador Tau. Fuente: (Instituto Argentino de Normalización y Certificación 2010). 
Donde:

$\tau_{i}=0,13 \frac{m^{2} \cdot k}{W} \cdot K_{i} \cdot \Delta \mathrm{t}$

$0,13 \frac{m^{2} . k}{W}$ - la resistencia térmica superficial interior, en ${ }^{\circ} \mathrm{C}$,

$\mathrm{K}$ - la transmitancia térmica $\left(\mathrm{m}^{20} \mathrm{~K}\right) \frac{1}{\mathrm{Rt}}$

$R t$ - resistencia térmica superficial total $\left(\mathrm{m}^{2 \circ} \mathrm{K} / \mathrm{W}\right)$,

$\mathrm{Ki}$ - la transmitancia térmica de cada una de los componentes de la envolvente $\left(\mathrm{Wm}^{2 \circ} \mathrm{K}\right)$,

$\Delta \mathrm{t}$ - la diferencia de temperatura de diseño interior y exterior $\left({ }^{\circ} \mathrm{C}\right), \mathrm{y}$

$\mathrm{Si}$ - la superficie de cada una de las componentes de la envolvente $\left(\mathrm{m}^{2}\right)$

Desde mediados de 2016, la IRAM 11.900 se encuentra en proceso de revisión con el objetivo de desarrollar un etiquetado de eficiencia energética para viviendas².

Publicada en diciembre de 2017 como objeto de estudio bajo el nombre de Prestaciones energéticas en viviendas, la IRAM 11.900/17 corresponde a un instrumento de aplicación voluntario, destinado a viviendas nuevas y existentes construidas en territorio nacional (Instituto Argentino de Normalización y Certificación 2017). La principal diferencia entre la IRAM 11.900/10 y la nueva versión, consiste en que se deja de evaluar la eficiencia de la envolvente de edificios en general y se empieza a considerar la eficiencia de los sistemas de edificios de vivienda.

Los criterios analizados se organizan entre las temáticas de estrategias pasivas, calefacción y refrigeración, iluminación, agua calienta sanitaria, y aporte de energías renovables. La clasificación final de la eficiencia energética del edificio se obtiene en función de la evaluación parcial de cada sistema, dónde para la temática de estrategias pasivas la evaluación es cualitativa, mediante un sistema de puntos. Para las demás temáticas la evaluación es cuantitativa, a partir de resultados de consumo de energía primaria y de emisiones de dióxido de carbono (Instituto Argentino de Normalización y Certificación 2017).

\subsubsection{Ley $n^{\circ}$ 13.059/03 - Condiciones de Acondicionamiento Térmico}

La Ley 13.059 se ha implementado en 2003, con el fin de definir las condiciones de acondicionamiento térmico exigibles en la construcción de todos los edificios públicos y privados localizados en la Provincia de Buenos Aires. Consiste en el instrumento legal base para la elaboración de la norma IRAM 11.900/10 y de la Ordenanza ${ }^{\circ}$ 8.757/11 de la ciudad de Rosario, razón por la cual se detalla en este trabajo.

La regulación presenta carácter de cumplimiento obligatorio, y define que toda obra debe atender a los siguientes requisitos: (I) cumplir con los valores de transmitancia térmica admisible $\left(\mathrm{W} / \mathrm{m}^{2} \mathrm{~K}\right)$, para condiciones de invierno y verano, según la metodología establecida en la IRAM 11.601/1996, (II) verificar el Riesgo de Condensación superficial e intersticial para paños centrales y singulares, según la metodología establecida en la IRAM $11.625 / 2000$ y 11.630/2000, (III) comprobar el valor del Coeficiente

\footnotetext{
${ }^{2}$ Información incorporada mediante la participación en el Grupo de Trabajo de Estrategias Pasivas del Subcomité de Eficiencia Energética de IRAM, para la elaboración del futuro certificado de eficiencia energética para viviendas.
} 
Gadm para calefacción, según indica la IRAM 11.604/2001, (IV) verificar los valores de calidad térmica K en vidriados, según indica la IRAM 11.507/2001, y (V) cumplir con la calidad de infiltración en carpinterías, según indica la IRAM 11.507/2001 (Tabla 4).

\begin{tabular}{|c|c|c|c|c|}
\hline C & & CONCEPTOS & CRITERIOS & PARÁMETRO \\
\hline \multirow{6}{*}{\multicolumn{2}{|c|}{ 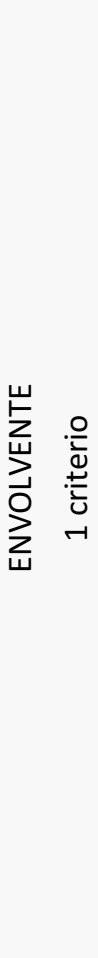 }} & \multirow{6}{*}{$\begin{array}{l}\text { Condiciones de } \\
\text { habitabilidad } \\
\text { higrotérmica, de } \\
\text { higiene, y de } \\
\text { salubridad } \\
5 \text { subcriterios }\end{array}$} & $\begin{array}{l}\text { 1. Cumplir con los valores de transmitancia térmica } \\
\mathrm{K} \text { admisible }(\mathrm{W} / \mathrm{m} 2 \mathrm{~K}) \text {, para condiciones de invierno } \\
\text { y verano, según la metodología establecida en la } \\
\text { IRAM } 11.601 / 96 \text {. }\end{array}$ & $\begin{array}{c}\text { Transmitancia } \\
\text { térmica para } \\
\text { cerramientos opacos }\end{array}$ \\
\hline & & & $\begin{array}{l}\text { 2. Verificar las condiciones higrotérmicas de los } \\
\text { paños centrales, riesgo de condensación superficial } \\
\text { e intersticial, según la metodología establecida en la } \\
\text { IRAM } 11.625 / 00 \text {. }\end{array}$ & $\begin{array}{l}\text { Riesgo de } \\
\text { condensación }\end{array}$ \\
\hline & & & $\begin{array}{l}\text { 3. Verificar las condiciones higrotérmicas de puntos } \\
\text { singulares, riesgo de condensación superficial e } \\
\text { intersticial, según la metodología establecida en la } \\
\text { IRAM } 11.630 / 00 \text {. }\end{array}$ & $\begin{array}{l}\text { Riesgo de } \\
\text { condensación }\end{array}$ \\
\hline & & & $\begin{array}{l}\text { 4. Verificar el coeficiente Gcal admisible, según la } \\
\text { metodología establecida en la IRAM 11.604/01. }\end{array}$ & $\begin{array}{l}\text { Demanda de } \\
\text { calefacción }\end{array}$ \\
\hline & & & \multirow{2}{*}{$\begin{array}{l}\text { 5. Verificar los valores de calidad térmica K en } \\
\text { vidriados, según indica la IRAM } 11.507 / 2001, \text { y } \\
\text { cumplir con la calidad de infiltración en carpinterías, } \\
\text { según indica la IRAM } 11.507 / 2001 \text {. }\end{array}$} & $\begin{array}{l}\text { Calidad térmica } \\
\text { carpinterías }\end{array}$ \\
\hline & & & & $\begin{array}{l}\text { Coeficiente de } \\
\text { infiltración de aire }\end{array}$ \\
\hline
\end{tabular}

Tabla 4: Criterios de evaluación de la Ley sobre Condiciones de Acondicionamiento Térmico. Elaboración propia adaptada de (Senado y Cámara de Diputados, 2003).

\subsubsection{Ordenanza no 8.757 - Aspectos Higrotérmicos y Demanda Energética de las}

\section{Construcciones}

La Ordenanza n 8.757 ha sido publicada en 2011 con el objetivo de garantizar condiciones mínimas de habitabilidad higrotérmica a través de la definición de parámetros constructivos para la envolvente de edificios ubicados en la ciudad de Rosario.

Se destina a nuevos edificios públicos y privados, y a edificios existentes con una superficie mayor a $500 \mathrm{~m}^{2}$, o que presenten más del $25 \%$ del total de sus cerramientos renovados (Municipalidad de Rosario, 2013). Presenta carácter de cumplimiento obligatorio en función de una gradualidad en su aplicación, entendiendo que el sector de la construcción civil necesita un periodo de adaptación, tanto para profesionales y entidades reguladoras, como para las empresas fabricantes (Bordachar, Furno, \& Lattuca, 2016).

Los criterios exigidos varían en función del año de aplicabilidad en que se encuentra la norma, y el procedimiento de verificación se realiza en dos instancias, la primera en la fase de proyecto y la segunda durante la construcción del edificio. En los dos primeros años de vigencia de la Ordenanza se requerirá la conformidad con los parámetros de (I) transmitancia térmica y (II) de riesgo de condensación, en cuanto a 
partir del tercer año, se complementará con los criterios de (III) permeabilidad del aire y (IV) demanda energética para calefacción y (V) refrigeración (Tabla 5).

\begin{tabular}{|c|c|c|c|}
\hline C & CONCEPTOS & CRITERIOS & PARÁMETRO \\
\hline \multirow{5}{*}{ 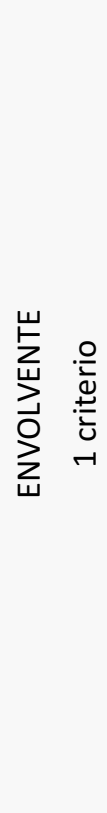 } & \multirow{5}{*}{$\begin{array}{l}\text { Condiciones } \\
\text { mínimas de } \\
\text { habitabilidad } \\
\text { higrotérmica }\end{array}$} & $\begin{array}{l}\text { 1. Controlar las condiciones de habitabilidad } \\
\text { mediante la limitación de los parámetros } \\
\text { característicos de los cerramientos y particiones } \\
\text { interiores que componen su envolvente térmica, } \\
\text { según limita la IRAM } 11.605 / 2001 \text {. }\end{array}$ & $\begin{array}{l}\text { Transmitancia } \\
\text { térmica para } \\
\text { cerramientos opacos }\end{array}$ \\
\hline & & $\begin{array}{l}\text { 2. Limitar la presencia de condensaciones en la } \\
\text { superficie y en el interior de los cerramientos, según } \\
\text { indica la IRAM } 11.625 / 00 \text { y la IRAM } 11.630 / 00 \text {. }\end{array}$ & $\begin{array}{l}\text { Riesgo de } \\
\text { condensación }\end{array}$ \\
\hline & & $\begin{array}{l}\text { 3. Limitar la permeabilidad del aire según indica la } \\
\text { IRAM } 11.507 / 2001\end{array}$ & $\begin{array}{l}\text { Coeficiente de } \\
\text { infiltración de aire }\end{array}$ \\
\hline & & $\begin{array}{l}\text { 4. Controlar la Demanda Energética de calefacción, } \\
\text { mediante la limitación del parámetro Gcal, según } \\
\text { establece la IRAM } 11.604 / 01 .\end{array}$ & $\begin{array}{l}\text { Demanda de } \\
\text { calefacción }\end{array}$ \\
\hline & & $\begin{array}{l}\text { 5. Controlar la Demanda Energética de } \\
\text { refrigeración, mediante la limitación del parámetro } \\
\text { Gref, según establece la IRAM 11.659/07. }\end{array}$ & $\begin{array}{l}\text { Demanda de } \\
\text { refrigeración }\end{array}$ \\
\hline
\end{tabular}

Tabla 5: Criterios de evaluación de la Ordenanza sobre Aspectos Higrotérmicos y Demanda Energética de las Construcciones. Elaboración propia adaptada de (Municipalidad de Rosario 2011).

\subsubsection{Brasil}

\subsubsection{Programa Brasileiro de Etiquetagem de Edifícios - PBE Edifica}

El PBE Edifica consiste en un programa de etiquetado de eficiencia energética, instituido en 2003 para promover la concientización, mejorar el confort térmico y disminuir el consumo energético edilicio. Posee carácter de cumplimiento voluntario para edificios de uso residencial y comercial, y cumplimiento obligatorio para toda edificación construida y reformada con recurso federal, con una superficie superior a $500 \mathrm{~m}^{2}$, debiendo además alcanzar el nivel A de eficiencia energética (Ministério Do Planejamento, Orçamento e Gestão, 2014).

El Programa evalúa el desempeño de la edificación en función del desempeño de sus sistemas y posibilita obtener una clasificación de forma integral o parcial. La etiqueta general evalúa el desempeño del conjunto de los sistemas, en cuanto la etiqueta parcial analiza cada sistema aisladamente.

Para edificios de uso residencial, establece criterios vinculados a la envolvente y el sistema de calentamiento de agua, en cuanto para edificaciones con uso comercial, de servicio y público define criterios para la envolvente, sistema de iluminación y acondicionamiento del aire (Eletrobras 2013).

Los prerrequisitos para el análisis de la envolvente se relacionan con los parámetros térmicos de (I) absortancia solar, (II) transmitancia y (III) capacidad térmica de las superficies, bien como las características físicas relacionadas a ventilación natural e iluminación (Tabla 6). 


\begin{tabular}{|c|c|c|c|}
\hline C & CONCEPTOS & CRITERIOS & PARÁMETRO \\
\hline \multirow{10}{*}{ 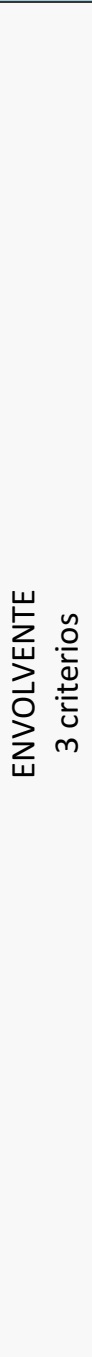 } & \multirow{3}{*}{$\begin{array}{l}\text { Transmitancia } \\
\text { térmica } \\
\text { capacidad } \\
\text { térmica y } \\
\text { absortancia solar }\end{array}$} & \multirow{3}{*}{$\begin{array}{l}\text { 1. Atender a los valores máximos de transmitancia } \\
\text { térmica, capacidad térmica y absortancia solar para } \\
\text { los cerramientos opacos exteriores de los ambientes } \\
\text { de primera, según establece la Guía. }\end{array}$} & $\begin{array}{l}\text { Transmitancia térmica } \\
\text { para cerramientos } \\
\text { opacos }\end{array}$ \\
\hline & & & $\begin{array}{l}\text { Capacidad térmica } \\
\text { para cerramientos } \\
\text { opacos }\end{array}$ \\
\hline & & & $\begin{array}{l}\text { Absortancia solar para } \\
\text { cerramientos opacos }\end{array}$ \\
\hline & \multirow{6}{*}{$\begin{array}{l}\text { Ventilación } \\
\text { natural } \\
4 \text { subcriterios }\end{array}$} & \multirow{2}{*}{$\begin{array}{l}\text { 2. Cumplir con los valores mínimos de superficies } \\
\text { de ventilación para los ambientes de primera, según } \\
\text { establece la Guía. } \\
\text { Permitir el cerramiento de las aperturas durante la } \\
\text { noche para ciudades con temperatura media } \\
\text { mensual por debajo de los } 20^{\circ} \mathrm{C} \text {. }\end{array}$} & $\begin{array}{l}\text { Factor de proporción } \\
\text { superficies vidriadas }\end{array}$ \\
\hline & & & $\begin{array}{l}\text { Factor de ventilación } \\
\text { natural }\end{array}$ \\
\hline & & \multirow{2}{*}{$\begin{array}{l}\text { 3. Permitir la ventilación cruzada en edificios } \\
\text { ubicados entre las zonas bioclimáticas } 2 \text { y } 8 \text {, } \\
\text { respetando la proporción: } A 2 / A 1 \geq 0,25 \text { de salida de } \\
\text { aire entre dos aperturas de distintas fachadas. } \\
\text { Donde } A 1 \text { es la sumatoria de las superficies efectivas } \\
\text { de la fachada con mayor apertura para ventilación y } \\
\text { A2 para las demás orientaciones. }\end{array}$} & $\begin{array}{l}\text { Factor de proporción } \\
\text { superficies vidriadas }\end{array}$ \\
\hline & & & $\begin{array}{l}\text { Factor de ventilación } \\
\text { natural }\end{array}$ \\
\hline & & $\begin{array}{l}\text { 4. Permitir que el } 50 \% \text { de los baños existentes en la } \\
\text { unidad habitacional presenten ventilación natural. }\end{array}$ & $\begin{array}{l}\text { Factor de ventilación } \\
\text { natural }\end{array}$ \\
\hline & & $\begin{array}{l}\text { 5. Atender a la porosidad mínima de } 20 \% \text { en dos } \\
\text { fachadas con orientación diferenciada. }\end{array}$ & $\begin{array}{l}\text { Factor de proporción } \\
\text { superficies vidriadas }\end{array}$ \\
\hline & $\begin{array}{l}\text { Iluminación } \\
\text { natural }\end{array}$ & $\begin{array}{l}\text { 6. Garantizar que las superficies de apertura para } \\
\text { iluminación natural cumplan con el } 12,5 \% \text { del área } \\
\text { útil del ambiente. }\end{array}$ & $\begin{array}{l}\text { Factor de proporción } \\
\text { superficies vidriadas }\end{array}$ \\
\hline
\end{tabular}

Tabla 6: Criterios de evaluación del PBE Edifica para edificaciones residenciales. Elaboración propia adaptada de (Eletrobras 2013).

Los valores para los aspectos térmicos mencionados anteriormente - i, ii y iii, deben ser atendidos en función de la zona bioclimática que se encuentra la edificación, según indica la NBR 15.220. Los criterios para garantizar la adecuada ventilación natural (IV) deben respetar el porcentual de superficie mínima de apertura en relación al área útil del ambiente, establecido para cada zona bioclimática en la NBR 15.575. En localidades que presenten temperaturas medias mensuales por debajo de los $20^{\circ} \mathrm{C}$, las ventanas deben $(V)$ tener la posibilidad de cerrarse, y en todas las zonas bioambientales, excepto la 1, el proyecto debe (VI) posibilitar la ventilación cruzada. El acceso a la iluminación natural en los ambientes debe ser garantizado con una o más aperturas al exterior, las cuales sumen mínimamente el $12,5 \%$ de la superficie útil del ambiente (Eletrobras 2013).

\subsubsection{Processo AQUA - Alta Qualidade Ambiental}

El AQUA es una certificación de desempeño ambiental con adopción voluntaria, destinada a nuevos edificios y emprendimientos que busquen optimizar su rendimiento. Consiste en una herramienta que se enfoca en la operación del edificio, involucrando sus etapas de diseño, construcción y uso. 
Su proceso de evaluación analiza el desempeño ambiental en dos etapas, una a partir del Sistema de Gestión de Emprendimiento - SGE y la segunda sobre la Calidad Ambiental de Edificio - QAE. La primera considera que la correcta gestión de la edificación garantiza niveles satisfactorios de calidad ambiental. Para atender a esta etapa se debe presentar un informe con la descripción del nivel de calidad ambiental deseado y el compromiso en garantizar la ejecución de las medidas propuestas en la etapa QAE. La segunda consiste en demostrar cuales son las estrategias y criterios establecidos por el AQUA que se encuentran empleados en edificio.

Los criterios se distribuyen entre las categorías de aspectos de salud, confort, gestión y sobre sitio y construcción, las cuales se ramifican en 14 sub categorías, cada cual con sus respectivos requerimientos.

Las medidas de diseño que propone para alcanzar la eficiencia energética contemplan (I) la mejora de la calidad de la envolvente a través de los valores de transmitancia térmica, capacidad térmica, o del atendimiento de los niveles A, B y C de los requisitos de envolvente aplicados para el RTQ-R del PBE Edifica; (II) garantizar acceso de iluminación natural a los dormitorios y estar mediante una o más aperturas hacia el exterior; (III) optimizar el partido arquitectónico para reducir su consumo energético total en función de la aplicación de algunas medidas ejemplificadas por el AQUA para limitar las necesidades de resfriamiento e iluminación artificial; (IV) adoptar medidas para la protección optima en relación al sol y al calor y potenciar las medidas bioclimáticas; (V) promover buenas condiciones de confort higrotérmico anual; (VI) cumplir con los valores máximos de factor de ganancia solar de elementos opacos (FSo) para cerramientos exteriores y atender a los valores máximos de transmitancia y capacidad térmica para cerramientos exteriores; (VII) garantizar que el valor mínimo diario de la temperatura del aire interno sea mayor o igual al valor mínimo diario de la temperatura del aire exterior $+3^{\circ} \mathrm{C}$ (Tabla 7).

La verificación del cumplimiento de los criterios de evaluación se basa en elementos objetivos que permitan la comparación de los valores del proyecto con valores de referencia, tanto para la etapa de proyecto, como para las fases posteriores al emprendimiento. Cuando los datos sean de orden cualitativo, como la descripción de medidas, especificaciones, elementos gráficos, el método puede ser simplificado, cuando los datos sean cuantitativos, se exige la comprobación mediante memorias de cálculo, planillas de medición y programas que indiquen la interacción entre las estrategias y su desempeño de forma integral. 
PARTE I · Delimitación del ámbito de la investigación

\begin{tabular}{|c|c|c|c|}
\hline C & CONCEPTOS & CRITERIOS & PARÁMETRO \\
\hline \multirow{4}{*}{ 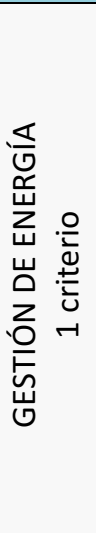 } & \multirow{4}{*}{$\begin{array}{l}\text { Reducción del } \\
\text { consumo } \\
\text { energético a } \\
\text { través de la } \\
\text { concepción } \\
\text { arquitectónica }\end{array}$} & \multirow{2}{*}{$\begin{array}{l}\text { 1. Cumplir con el nivel C de los requisitos de } \\
\text { envolvente aplicados para el RTQ-R. Optimizar la } \\
\text { calidad de la envolvente a través de los valores de } \\
\text { transmitancia térmica, capacidad térmica, o del } \\
\text { atendimiento de los niveles A y B del RTQ-R. }\end{array}$} & $\begin{array}{c}\text { Transmitancia térmica } \\
\text { para cerramientos } \\
\text { opacos }\end{array}$ \\
\hline & & & $\begin{array}{l}\text { Capacidad térmica } \\
\text { para cerramientos } \\
\text { opacos }\end{array}$ \\
\hline & & $\begin{array}{l}\text { 2. Garantizar la iluminación natural de los } \\
\text { dormitorios y del estar a través de una apertura } \\
\text { hacia el exterior. }\end{array}$ & $\begin{array}{l}\text { Factor de proporción } \\
\text { superficies vidriadas }\end{array}$ \\
\hline & & $\begin{array}{l}\text { 3. Optimizar el partido arquitectónico para reducir } \\
\text { su consumo energético total. }\end{array}$ & Estratégicas de diseño \\
\hline \multirow{6}{*}{ 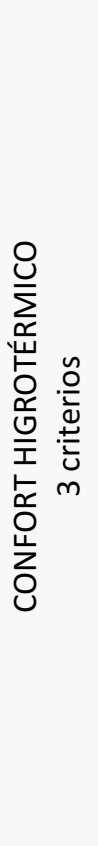 } & \multirow{2}{*}{$\begin{array}{l}\text { Optimización del } \\
\text { confort térmico } \\
2 \text { subcriterios }\end{array}$} & $\begin{array}{l}\text { 4. Adoptar medidas para la protección optima en } \\
\text { relación al sol y al calor. Potenciar las medidas } \\
\text { bioclimáticas. Realizar un estudio aerodinámico para } \\
\text { definir las mejores soluciones. }\end{array}$ & Protección solar \\
\hline & & $\begin{array}{l}\text { 5. Promover buenas condiciones de confort } \\
\text { higrotérmico anual. }\end{array}$ & Confort térmico \\
\hline & \multirow{3}{*}{$\begin{array}{l}\text { Confort } \\
\text { higrotérmico } \\
\text { verano }\end{array}$} & \multirow{3}{*}{$\begin{array}{l}\text { 6. Cumplir con los valores máximos del factor de } \\
\text { ganancia solar (FSo) para cerramientos exteriores. } \\
\text { Garantizar que el valor máximo diario de la } \\
\text { temperatura del aire interno sea } \leq \text { al valor máximo } \\
\text { diario de la temperatura del aire exterior - para } \\
\text { ambientes de primera en día típico de verano. } \\
\text { Respetar el valor de FS } \leq \text { para el Factor Solar de las } \\
\text { superficies vidriadas. }\end{array}$} & $\begin{array}{l}\text { Factor de ganancia } \\
\text { solar para } \\
\text { cerramientos opacos }\end{array}$ \\
\hline & & & $\begin{array}{l}\text { Temperatura del aire } \\
\text { interior }\end{array}$ \\
\hline & & & Factor solar del vidrio \\
\hline & $\begin{array}{l}\text { Confort } \\
\text { higrotérmico } \\
\text { invierno }\end{array}$ & $\begin{array}{l}\text { 7. Garantizar que el valor mínimo diario de la } \\
\text { temperatura del aire interno sea } \geq \text { al valor mínimo } \\
\text { diario de la temperatura del aire exterior }+3^{\circ} \mathrm{C}- \\
\text { para ambientes de primera en día típico de invierno. }\end{array}$ & $\begin{array}{l}\text { Temperatura del aire } \\
\text { interior }\end{array}$ \\
\hline
\end{tabular}

Tabla 7: Criterios de evaluación del Proceso de Alta Calidad Ambiental. Elaboración propia adaptada de (FCAV 2013).

\subsubsection{Selo Casa Azul}

EL Sello Casa Azul es una certificación de sustentabilidad implementada en 2010, con el objetivo de mejorar la calidad de las edificaciones, disminuir su impacto ambiental y promover la concientización de los usuarios. Se destina a todos los edificios residenciales financiados por el banco CAIXA, presenta carácter de cumplimiento voluntario y evalúa los proyectos que adoptan medidas eficientes durante la etapa de construcción, uso y operación.

Clasifica el proyecto de la obra en tres categorías nombradas como bronce, plata y oro, y su método de evaluación es prioritariamente simplificado, el cual permite la presentación de toda documentación técnica, memorial descriptivo, planillas, presupuestos y cronogramas que indiquen atender a los requerimientos de cada criterio conforme especificado en la Guía (CAIXA 2010).

El sistema aborda seis temáticas principales relacionadas a calidad urbana, proyecto y confort, eficiencia energética, conservación de los recursos materiales, gestión del agua y prácticas sociales. 
Para la categoría de proyecto y confort el edificio debe (I) cumplir con los valores de transmitancia térmica, capacidad térmica, absortancia a la radiación solar y factor de ventilación para cerramientos exteriores e interiores, (II) atender al porcentual de superficie vidriada para garantizar condiciones de iluminación y ventilación, y aplicar dispositivos de protección solar en los ambientes, permitiendo el control de la radiación solar en invierno y verano, y (III) adoptar las estrategias de diseño pautadas en la orientación del sol y de los vientos, considerando la condición de invierno y verano.

En el caso de que no se pueda entregar la documentación comprobatoria del cumplimiento de las estrategias de diseño especificadas, o se utilice un sistema constructivo que no se encuentre detallado en la Guía, su atendimiento debe ser validado mediante simulación dinámica (Tabla 8).

\begin{tabular}{|c|c|c|c|c|}
\hline C & & CONCEPTOS & CRITERIOS & PARÁMETRO \\
\hline \multirow{6}{*}{\multicolumn{2}{|c|}{ 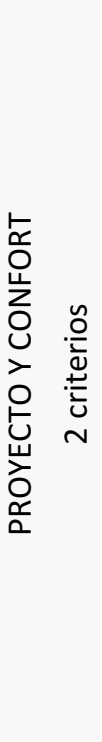 }} & \multirow{5}{*}{$\begin{array}{l}\text { Desempeño } \\
\text { térmico - } \\
\text { cerramientos }\end{array}$} & \multirow{5}{*}{$\begin{array}{l}\text { 1. Cumplir con los valores de transmitancia } \\
\text { térmica, capacidad térmica, absortancia a la } \\
\text { radiación solar y factor de ventilación para } \\
\text { cerramientos opacos exteriores e interiores. } \\
\text { Atender al porcentual de superficie vidriada en } \\
\text { relación a la superficie de muros. Aplicar } \\
\text { dispositivos de protección solar en los ambientes. }\end{array}$} & $\begin{array}{l}\text { Transmitancia térmica } \\
\text { para cerramientos } \\
\text { opacos }\end{array}$ \\
\hline & & & & $\begin{array}{l}\text { Capacidad térmica } \\
\text { para cerramientos } \\
\text { opacos }\end{array}$ \\
\hline & & & & $\begin{array}{l}\text { Absortancia solar ara } \\
\text { cerramientos opacos }\end{array}$ \\
\hline & & & & $\begin{array}{l}\text { Factor de proporción } \\
\text { superficies vidriadas }\end{array}$ \\
\hline & & & & Protección solar \\
\hline & & $\begin{array}{l}\text { Desempeño } \\
\text { térmico }\end{array}$ & $\begin{array}{l}\text { 2. Adoptar las estrategias de diseño para invierno y } \\
\text { verano, pautadas en la orientación del sol y de los } \\
\text { vientos. }\end{array}$ & $\begin{array}{l}\text { Orientación del } \\
\text { edificio }\end{array}$ \\
\hline
\end{tabular}

Tabla 8: Categorías de evaluación del Sello Casa Azul. El * indica los criterios obligatorios. Elaboración propia adaptada de (CAIXA 2010).

\subsubsection{Chile}

\subsubsection{Calificación Energética de viviendas}

La Calificación Energética de Viviendas - CEV consiste en un etiquetado de eficiencia energética publicado en 2013 , con el objetivo de calificar la demanda energética que una vivienda requiere para alcanzar una zona de confort térmico. Establecida con carácter de cumplimiento voluntario, la CEV evalúa el porcentaje de ahorro en energía primaria que posee la vivienda de estudio, en función de un nivel estándar, equivalente a la demanda energética de una unidad habitacional tradicional en el país (Ministerio de Vivienda y Urbanismo 2016) (Tabla 9).

Los criterios analizados para definir el consumo energético de la vivienda varían en función del proceso de calificación, el cual puede ser realizado para obtener la etiqueta de precalificación y/o de calificación.

En la primera etapa el sistema se enfoca en verificar el atendimiento de requerimientos de diseño proyectual, determinando la energía necesaria para calefacción e iluminación en función de las ganancias 
solares, del nivel de aislamiento térmico de la envolvente, y la zona bioambiental que se encuentra ubicada la vivienda.

La segunda etapa se centra, además de los requisitos para diseño proyectual, en los equipos y en el tipo de energía utilizado, determinando la demanda requerida para calefacción, agua caliente sanitaria e iluminación, en función del rendimiento energético de los equipos, del tipo de energía primaria, y del aporte de energías renovables no convencionales para calefacción, agua caliente sanitaria e iluminación.

La evaluación de los requerimientos de diseño proyectual se fundamenta en el análisis de las características térmicas de la envolvente, considerando la superficie y la transmitancia térmica de cada elemento, el sombreamiento y la orientación de las ventanas, el coeficiente de accesibilidad de la ventana - FA, el factor de accesibilidad respecto a elementos de sombra cercanos y remotos - FAV y FAR, el factor solar de los vidrios y el factor del marco de la ventana.

\begin{tabular}{|c|c|c|c|}
\hline C & CONCEPTOS & CRITERIOS & PARÁMETRO \\
\hline 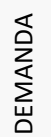 & $\begin{array}{l}\text { Reducción del } \\
\text { consumo } \\
\text { energético }\end{array}$ & $\begin{array}{l}\text { 1. Reducir el consumo energético de la vivienda } \\
\text { en función del estándar actual de la construcción. }\end{array}$ & - \\
\hline
\end{tabular}

\begin{tabular}{|c|c|}
\hline Transmitancia térmica de ventanas & $\begin{array}{c}\text { Transmitancia } \\
\text { térmica para } \\
\text { vidrios }\end{array}$ \\
\hline $\begin{array}{l}\text { Transmitancia térmica de techos, muros, pisos } \\
\text { ventilados y puertas }\end{array}$ & $\begin{array}{c}\text { Transmitancia } \\
\text { térmica para } \\
\text { cerramientos } \\
\text { opacos }\end{array}$ \\
\hline $\begin{array}{l}\text { Transmitancia térmica de piso en contacto con el } \\
\text { terreno }\end{array}$ & $\begin{array}{l}\text { Transmitancia } \\
\text { térmica para pisos }\end{array}$ \\
\hline Sombreamiento y orientación de ventanas & Informativo \\
\hline Coeficiente de accesibilidad de la ventana (FA) & Informativo \\
\hline $\begin{array}{l}\text { Factor de accesibilidad respecto a elementos de } \\
\text { sombra cercanos (FAV) }\end{array}$ & Informativo \\
\hline $\begin{array}{l}\text { Factor de accesibilidad respecto a elementos de } \\
\text { sombra remotos (FAR) }\end{array}$ & Informativo \\
\hline Factor solar del vidrio (FS) & $\begin{array}{l}\text { Factor solar del } \\
\text { vidrio }\end{array}$ \\
\hline Factor del marco de la ventana (FM) & $\begin{array}{l}\text { Coeficiente de } \\
\text { infiltración de aire }\end{array}$ \\
\hline
\end{tabular}

Tabla 9: Criterios de evaluación de la CEV. Elaboración propia adaptada de (Ministerio de Vivienda y Urbanismo 2016).

La clasificación de los niveles de eficiencia posibles de alcanzar varía de la $A$ hasta la $G$, dónde la letra $E$ corresponde al estándar actual de la construcción, representado por un rango de viviendas que consumen $25 \%$ menos a la demanda estándar y $15 \%$ más. Los niveles comprendidos entre A y D indican 
viviendas que presentan más del $25 \%$ de ahorro en su demanda energética, en cuanto los niveles F y G representan viviendas con un consumo de energía superior al 15\% del modelo estándar.

La CEV permite la realización del cálculo de la demanda energética a través del modelo estático y dinámico, especificando que viviendas que presenten una relación de superficie vidriadas y opacas superior a 0,7 , solo se permite el cálculo en base al método dinámico.

\subsubsection{Certificación Edificio Sustentable}

La Certificación Edificio Sustentable - CES consiste en una herramienta implementada en 2014, con el objetivo de estimular la construcción con criterios de sustentabilidad e impulsar su valoración en el mercado. Con aplicación voluntaria, la CES evalúa la calidad ambiental interior y la eficiencia energética de edificios con actividades de uso público, y posibilita la obtención de tres modelos de certificados buscando fomentar la introducción de mejoras en el edificio desde la etapa de diseño, construcción, uso y operación (Instituto de la Construcción 2014).

El pre-certificado Edificio Sustentable analiza las medidas de diseño pasivo y activo utilizadas en el proyecto del edificio, el certificado Edificio Sustentable verifica que el edificio construido, así como sus instalaciones, materiales y características de la envolvente térmica cumplan con las descripciones mencionadas en la etapa de proyecto, y el sello Plus Operación evalúa la gestión del edificio durante su operación mediante la entrega de un informe de auto-diagnostico.

El sistema de clasificación se basa en una estructura organizada en función de que los indicadores no responden únicamente a una división de categorías, sino que considera la relación existente entre ellos. Los criterios evaluados se agrupan en las categorías de calidad del ambiente interior, energía, agua, residuos y gestión, se dividen en requerimientos obligatorios y voluntarios, dónde cada criterio voluntario recibe un puntaje ponderado según su importancia en el conjunto del edificio.

Desde el punto de vista de los requerimientos relacionados a la eficiencia energética y al confort térmico, la certificación establece diferentes medidas que se encuentran agrupadas en las categorías de calidad del ambiente interior y energía (Tabla 10).

Para la temática de calidad del ambiente interior, la CES define que se debe (I) disminuir el periodo de tiempo en el cual los usuarios se encuentren fuera del rango de confort térmico, a través del registro de la temperatura del aire y de humedad relativa, (II) garantizar que la superficie de las ventanas representen el $4 \%$ de la superficie del ambiente, y demostrar un potencial de renovaciones de aire hora en base a ventilación natural que cubra el 100\% del requerimiento de ventilación y caudal de aire mínimo.

Para la temática de energía establece que es necesario (III) mejorar los valores de transmitancia térmica y factor solar de la envolvente mediante información técnica, o disminuir la demanda energética del edificio presentando una evaluación dinámica, (IV) verificar la hermeticidad de la envolvente del edificio a través de la utilización de carpinterías certificadas, sellos apropiados y un ensayo que indique las infiltraciones por la envolvente y la permeabilidad del aire por las ventanas, y (V) reducir mínimamente el 
10\% de demanda de energía necesaria para la calefacción, refrigeración e iluminación de un edificio, en base a atender los valores de transmitancia térmica y factor solar de la envolvente.

La verificación del atendimiento de los requerimientos se fundamenta en que la calidad del ambiente interior de un edificio será mejor representada a partir de un análisis dinámico de las variables del proyecto. Entretanto, se permite la evaluación simplificada para edificios de baja complejidad que presenten datos y medios suficientes para realizar una buena aproximación de su desempeño integral.

\begin{tabular}{|c|c|c|c|c|}
\hline C & C & CONCEPTOS & CRITERIOS & PARÁMETRO \\
\hline \multirow{3}{*}{ 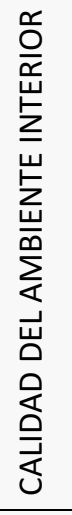 } & \multirow{3}{*}{ 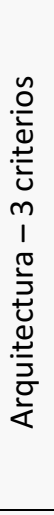 } & $\begin{array}{l}\text { Reducción del } \\
\text { disconfort }\end{array}$ & $\begin{array}{l}\text { 1. Disminuir el tiempo en que la temperatura de } \\
\text { los ambientes de primera se encuentre fuera del } \\
\text { rango de confort de manera pasiva (o para la } \\
\text { humedad relativa y temperatura operativa). }\end{array}$ & Confort térmico \\
\hline & & $\begin{array}{l}\text { Superficie de } \\
\text { ventana / } \\
\text { Renovaciones de } \\
\text { aire hora }\end{array}$ & $\begin{array}{l}\text { 2. Garantizar que la superficie útil de ventanas } \\
\text { represente el } 4 \% \text { de la superficie del ambiente. El } \\
\text { ambiente no debe exceder a una profundidad } \\
\text { mayor a } 8 \text { metros, desde la ventana practicable. }\end{array}$ & $\begin{array}{l}\text { Factor de proporción } \\
\text { superficies vidriadas }\end{array}$ \\
\hline & & $\begin{array}{l}\text { Renovaciones de } \\
\text { aire hora }\end{array}$ & $\begin{array}{l}\text { 2.1. Demostrar un potencial de renovaciones de } \\
\text { aire hora en base a ventilación natural, cubriendo } \\
\text { el } 100 \% \text { del requerimiento de ventilación y caudal } \\
\text { de aire mínimo para el } 75 \% \text { de los recintos. }\end{array}$ & $\begin{array}{l}\text { Factor de ventilación } \\
\text { natural }\end{array}$ \\
\hline \multirow{6}{*}{ 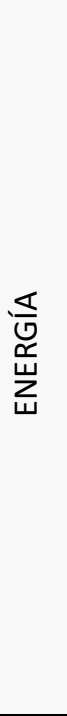 } & \multirow{6}{*}{ 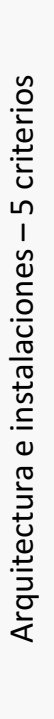 } & \multirow{2}{*}{$\begin{array}{l}\text { Transmitancia } \\
\text { térmica / Factor } \\
\text { solar modificado }\end{array}$} & \multirow{2}{*}{$\begin{array}{l}\text { 3. Cumplir con los valores de transmitancia } \\
\text { térmica y factor solar modificado (FSM) } \\
\text { especificados en la Guía, según el elemento y la } \\
\text { orientación de la envolvente. }\end{array}$} & $\begin{array}{l}\text { Transmitancia para } \\
\text { cerramientos opacos }\end{array}$ \\
\hline & & & & $\begin{array}{l}\text { Factor solar } \\
\text { modificado }\end{array}$ \\
\hline & & $\begin{array}{l}\text { Reducción de la } \\
\text { demanda anual }\end{array}$ & $\begin{array}{l}\text { 3.1. Disminuir al menos el } 10 \% \text { de la demanda de } \\
\text { energía para calefacción, refrigeración e } \\
\text { iluminación de los ambientes, o mejorar los } \\
\text { valores de U y el factor solar modificado. }\end{array}$ & Demanda energética \\
\hline & & $\begin{array}{l}\text { Especificación } \\
\text { apropiada de } \\
\text { sellos }\end{array}$ & $\begin{array}{l}\text { 4. Especificar sellos apropiados para los puntos } \\
\text { donde los sistemas atraviesen la envolvente y para } \\
\text { las carpinterías; según lo especificado en la Guía. }\end{array}$ & $\begin{array}{l}\text { Calidad Térmica } \\
\text { carpinterías }\end{array}$ \\
\hline & & $\begin{array}{l}\text { Permeabilidad al } \\
\text { aire en la } \\
\text { envolvente }\end{array}$ & $\begin{array}{l}\text { 4.1. Verificar la hermeticidad de la envolvente del } \\
\text { edificio a través de un ensayo de infiltraciones }\end{array}$ & Renovaciones de aire \\
\hline & & $\begin{array}{l}\text { Consumo anual } \\
\text { de energía }\end{array}$ & $\begin{array}{l}\text { 5. Reducir al menos } 10 \% \text { del indicador de consumo } \\
\text { de energía para todos los usos finales del edificio. }\end{array}$ & Consumo energético \\
\hline
\end{tabular}

Tabla 10: Criterios de evaluación de la Certificación de Calidad Ambiental y Eficiencia Energética para Edificios. Elaboración propia adaptada de (Instituto de la Construcción 2014).

\subsubsection{México}

\subsubsection{Norma mexicana de edificación sustentable}

La norma mexicana de edificación sustentable - NMX-AA-164-SCFI publicada en 2013, consiste en un instrumento proyectual de aplicación voluntaria, que induce al empleo de soluciones sustentables a todas las edificaciones situadas en el territorio nacional. Para ello, define requerimientos generales y particulares que deben ser atendidos por los edificios, desarrollando una estructura que se asemeja a los sistemas de certificación (Secretaría de Economía, 2013).

Para atender a los requisitos generales, el cliente debe cumplir con las disposiciones legales y con las normativas federales y locales. Proveer información de consumo de agua y energía, y ofrecer orientación 
a los usuarios de la edificación a través de un manual de operación. Los requisitos particulares se encuentran agrupados en las categorías de suelo, energía, agua, materiales y residuos, calidad ambiental y responsabilidad social y pueden ser de carácter obligatorio o voluntario (Secretaría de Economía, 2013).

Las soluciones de diseño que propone para garantizar el confort higrotérmico consisten en (I) mantener una temperatura entre los $18^{\circ} \mathrm{C}$ y $25^{\circ} \mathrm{C}$ en el interior del edificio, y (II) posibilitar la ventilación natural, y/o artificial de manera que sean controladas por el usuario. Las medidas que propone para alcanzar la eficiencia energética consisten en (III) limitar la ganancia de calor a través de la envolvente, (IV) reducir la ganancia de calor en el edificio, $(\mathrm{V})$ cumplir con los niveles de aislamiento térmico establecidos en la norma específica, (VI) cubrir el 10\% de la demanda energética del edificio con energía de fuente renovable, (VII) respetar los valores mínimos aceptables para el rendimiento energético de los edificios, y (VIII) diseñar la edificación con criterios bioclimáticos que favorezcan la iluminación natural (Tabla 11).

\begin{tabular}{|c|c|c|c|}
\hline C & CONCEPTOS & CRITERIOS & PARÁMETRO \\
\hline \multirow{4}{*}{ 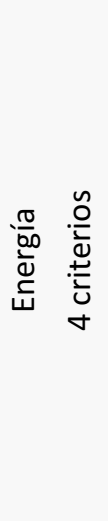 } & \multirow{3}{*}{$\begin{array}{l}\text { Aislación térmica } \\
3 \text { subcriterios }\end{array}$} & $\begin{array}{l}\text { 1. Calcular el presupuesto energético en base a la } \\
\text { NOM-008-ENER-2001 o NOM-020-ENER-2011 para } \\
\text { limitar la ganancia de calor de la envolvente. }\end{array}$ & - \\
\hline & & $\begin{array}{l}\text { 2. Reducir el } 10 \% \text { de la ganancia de calor con } \\
\text { respecto al edificio base establecido en la norma } \\
\text { NOM-008-ENER-2001 o NOM-020- ENER-2011. }\end{array}$ & - \\
\hline & & $\begin{array}{l}\text { 3. Atender a las especificaciones de la NOM-018- } \\
\text { ENER-2011 para la aplicación de aislamientos } \\
\text { térmicos en la edificación. }\end{array}$ & Aislamiento térmico \\
\hline & $\begin{array}{l}\text { Consumo anual } \\
\text { de energía }\end{array}$ & $\begin{array}{l}\text { 4. Atender a los niveles máximos de consumo anual } \\
\text { de energía establecidos en la norma. }\end{array}$ & - \\
\hline \multirow{2}{*}{ 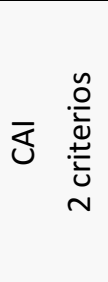 } & Confort térmico & $\begin{array}{l}\text { 5. Mantener los parámetros de confort térmico con } \\
\text { temperaturas entre los } 18 \text { y } 25^{\circ} \mathrm{C} \text {, favoreciendo las } \\
\text { soluciones bioclimáticas sobre las mecánicas. }\end{array}$ & Confort térmico \\
\hline & $\begin{array}{l}\text { Regulación de } \\
\text { ventilación }\end{array}$ & $\begin{array}{l}\text { 6. Permitir la opción de ventilación natural, } \\
\text { mecánica y aire acondicionado en las edificaciones } \\
\text { que requieran climatización. }\end{array}$ & $\begin{array}{l}\text { Factor de ventilación } \\
\text { natural }\end{array}$ \\
\hline \multicolumn{4}{|c|}{8} \\
\hline & & \multicolumn{2}{|c|}{$\begin{array}{l}\text { NOM-020-ENER-2011 - Eficiencia energética en edificaciones. Envolvente de } \\
\text { edificios para uso habitacional. }\end{array}$} \\
\hline & & $\begin{array}{l}\text { Coeficiente global de transferencia de calor elemento } \\
\text { opaco }\end{array}$ & $\begin{array}{l}\text { Transmitancia térmica } \\
\text { para cerramientos } \\
\text { opacos }\end{array}$ \\
\hline & & $\begin{array}{l}\text { Coeficiente global de transferencia de calor elemento } \\
\text { transparente }\end{array}$ & $\begin{array}{l}\text { Transmitancia térmica } \\
\text { para vidrios }\end{array}$ \\
\hline & & $\begin{array}{l}\text { Coeficiente global de transferencia de calor elemento } \\
\text { colindante }\end{array}$ & $\begin{array}{l}\text { Mejoramiento de la } \\
\text { transmitancia para } \\
\text { cerramientos opacos }\end{array}$ \\
\hline & & Barrera de vapor & Informativo \\
\hline & & Coeficiente de sombreado del vidrio & Informativo \\
\hline & & Ganancia de calor solar por orientación & Informativo \\
\hline & & Factor de corrección por sombreado exterior & Informativo \\
\hline
\end{tabular}

Tabla 11: Categorías y criterios de evaluación de la norma mexicana de edificación sustentable. Determinados criterios establecen más de un requisito. Elaboración propia adaptada de (Secretaría de Economía 2013). 


\subsubsection{Programa de Certificación de Edificaciones Sustentables}

El Programa de Certificación de Edificaciones Sustentables - PCES ha sido instituido en 2008, con el objetivo de fomentar el uso eficiente de los recursos naturales, reducir la emisión de gases contaminantes y mejorar la calidad de vida de los habitantes. Presenta carácter de atendimiento voluntario, y se enfoca estimular la aplicación de medidas de sustentabilidad y eficiencia energética en edificios residenciales y de oficinas situados en Distrito Federal, mediante la entrega de un certificado y la concesión de incentivos económicos (Li y Shui 2015).

El PCES evalúa el atendimiento de 46 criterios que se encuentran distribuidos entre las temáticas de energía, agua, residuos sólidos, calidad de vida y responsabilidad social, e impacto ambiental y otros impactos. Cada criterio recibe un puntaje ponderado, según su importancia relativa en el conjunto del edificio, resultando en una sumatoria de 120 puntos. El Programa otorga un certificado de Cumplimiento a los edificios que alcancen mínimamente 21 puntos, una certificación de Eficiencia para una sumatoria entre 51 y 80 puntos, y una calificación de Excelencia para edificios que sumen valores igual o superior a 81 puntos (Secretaría del Medio Ambiente 2012).

Desde el punto de vista de los requerimientos relacionados la energía el PCES define que la edificación debe (I) promover la alta capacidad de conservar y reducir el consumo de energía para calefacción y enfriamiento, mediante el cumplimiento de los requisitos establecidos en las normas NOM-008-ENER2001 y NOM-020-ENER-2011, (II) eliminar o reducir la utilización del aire acondicionado o calefacción, y optimizar el desempeño de la iluminación natural, y (III) posibilitar el uso de ventilación natural o elementos pasivos que permitan reducir el empleo del aire acondicionado (Tabla 12).

\begin{tabular}{|c|c|c|c|}
\hline C & CONCEPTOS & CRITERIOS & PARÁMETRO \\
\hline \multirow{3}{*}{ 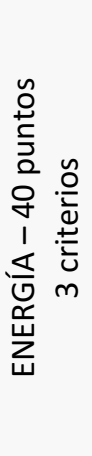 } & $\begin{array}{l}\text { Eficiencia de la } \\
\text { envolvente }\end{array}$ & $\begin{array}{l}\text { 1. Conservar la energía garantizando que la } \\
\text { envolvente (ganancia de calor) cumple con la NOM- } \\
008-E N E R-2001 \text { y la NOM-020-ENER-2011. }\end{array}$ & $\begin{array}{c}\text { Detallada } \\
\text { anteriormente }\end{array}$ \\
\hline & $\begin{array}{c}\text { Diseño } \\
\text { Bioclimático }\end{array}$ & $\begin{array}{l}\text { 2. Implementar estrategias bioclimáticas para } \\
\text { reducir la utilización de aire acondicionado o } \\
\text { calefacción y optimizar el diseño de la iluminación } \\
\text { natural para garantizar el confort higrotérmico. }\end{array}$ & Confort térmico \\
\hline & $\begin{array}{c}\text { Acondicionamiento } \\
\text { ambiental }\end{array}$ & $\begin{array}{l}\text { 3. Promover el uso de la ventilación natural o } \\
\text { elementos pasivos para el acondicionamiento } \\
\text { térmico. }\end{array}$ & $\begin{array}{c}\text { Factor de ventilación } \\
\text { natural }\end{array}$ \\
\hline
\end{tabular}

Tabla 12: Criterios de evaluación del PCES. Elaboración propia adaptada de (Secretaría del Medio Ambiente 2012).

El método de análisis es predominantemente simplificado, y la verificación de cada criterio se fundamenta en la presentación de la documentación técnica, memorial descriptivo, planillas, presupuestos y cronogramas detallados en la guía. Para los criterios de diseño bioclimático y acondicionamiento ambiental, el PCES sugiere que su atendimiento pueda ser comprobado a partir de un análisis dinámico. Una vez comprobado su cumplimiento y en función del nivel alcanzado, pueden recibir hasta 25 y 8 puntos respectivamente. 


\subsubsection{Definición de los sistemas de calificación edilicia}

Con base en la investigación realizada, se encontró que los tres casos expuestos en Argentina poseen indicadores concretos basados en las exigencias del paquete de normas IRAM sobre acondicionamiento térmico. El etiquetado de eficiencia energética de la envolvente de la ciudad de Buenos Aires - IRAM 11.900, el etiquetado nacional de eficiencia energética para viviendas - en construcción, y la normativa sobre aspectos higrotérmicos y demanda energética de las construcciones de la ciudad de Rosario, se fundamentan en las disposiciones establecidas en la Ley $n^{\circ} 13.059 / 03$, motivo por el cual se decide adoptar esta reglamentación como referencia aplicable del país (Figura 16).

En el caso de Brasil, el Sello Casa Azul y el Proceso AQUA sugieren el empleo de criterios de diseño que en su mayor parte, no presentan valores específicos para su atendimiento, pudiendo llevar a que la evaluación se base en inferencias subjetivas. Los demás criterios que disponen de requerimientos cualitativos, establecen valores en función de las definiciones del RTQ-R, el manual empleado por el PBEEdifica, razón por la cual se adopta este sistema para representar el país.

Se verificó que en Chile, ambos sistemas presentan criterios con requerimientos cualitativos, sin embargo se elige la Calificación Energética de Viviendas como modelo del país, ya que la Certificación de Calidad Ambiental en Edificios se destina a edificios pasibles de albergar alguna actividad pública y este trabajo se enfoca en edificaciones residenciales.

En México se adopta la Norma Mexicana de Edificación Sustentable como referencia aplicable del país, ya que el Programa de Certificación de Edificaciones Sustentables sugiere el empleo de criterios de diseño que no presentan valores específicos para su atendimiento.

Como se ha mencionado al principio del capítulo, Colombia, Costa Rica, Ecuador, Paraguay, Perú, y Uruguay han sido excluidos del estudio dada la imposibilidad de simular la aplicación de los modelos edilicios a ciudades de dichos países.

\subsubsection{Caso de referencia Europa}

Para el modelo de referencia se consideró el Código Técnico de la Edificación - CTE dado que desde el año de 2006, España define de forma objetiva los límites de demanda energética que deben ser atendidos con cumplimiento obligatorio por edificios de uso general, lo que permite realizar una lectura precisa de los criterios de confort y eficiencia energética para edificios residenciales establecidos por el CTE (Ministerio de la Vivienda 2006). Además, las ciudades situadas predominantemente en el sur del país poseen requerimientos de grados día similares a localidades situadas en la zona templada de Latinoamérica (ver 5.1 Selección de las localidades de aplicación) y cuentan con una variedad de archivos climáticos disponibles, posibilitando la comparación entre los estándares mínimos de desempeño propuestos en España con los estándares de los sistemas latinoamericanos.

Dado que en un futuro el gobierno tiene la proyección de sustituir la evaluación de la demanda por el consumo energético, se considera que los resultados de esta investigación aporten conocimiento que auxilie en su desarrollo (Escandón, Suárez e Sendra 2017). 


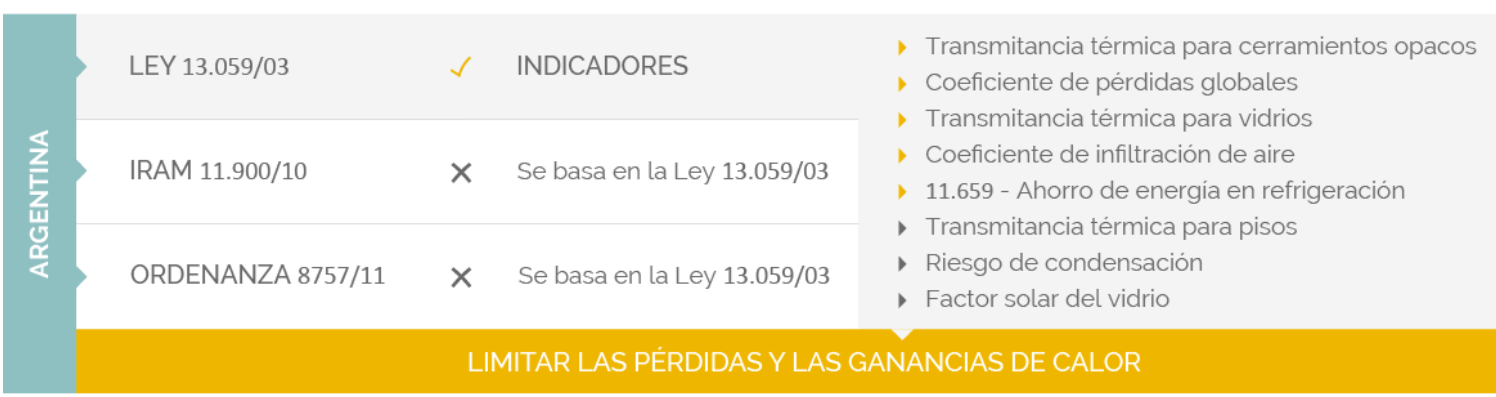

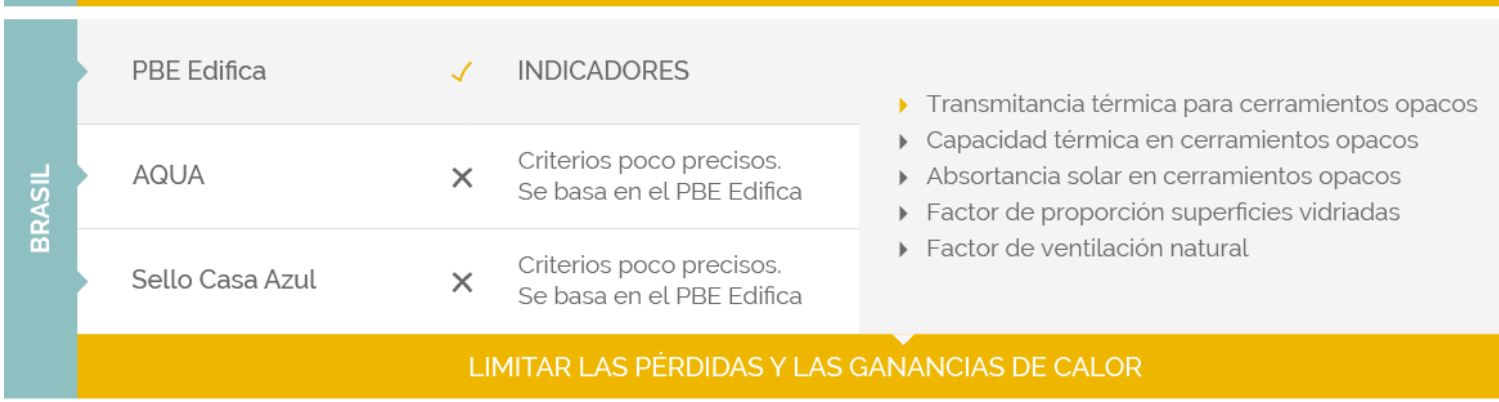

\begin{tabular}{|c|c|c|c|c|}
\hline \multirow{3}{*}{$\frac{\text { 崖 }}{\text { 蒠 }}$} & CEV & $\checkmark$ & INDICADORES & \multirow{2}{*}{$\begin{array}{l}\text { - Transmitancia térmica para vidrios } \\
\text { - Transmitancia térmica para cerramientos opacos } \\
\text { - Coeficiente de infiltración de aire } \\
\text { - Transmitancia térmica para pisos } \\
\text { - Factor solar del vidrio }\end{array}$} \\
\hline & CES & $x$ & $\begin{array}{l}\text { Enfoque en edificios } \\
\text { públicos }\end{array}$ & \\
\hline & & & LIMITAR LAS & DE CALOR \\
\hline
\end{tabular}

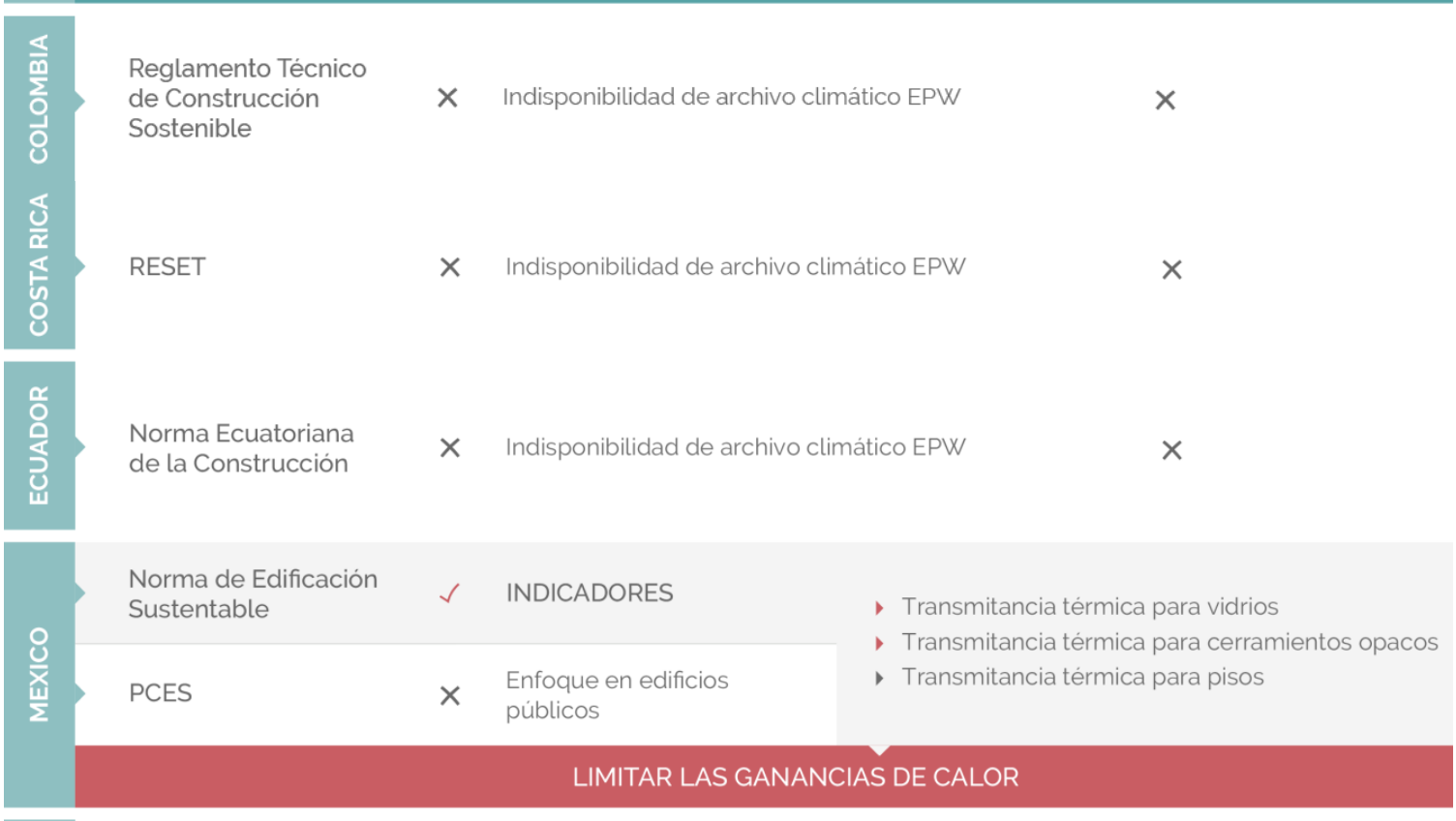
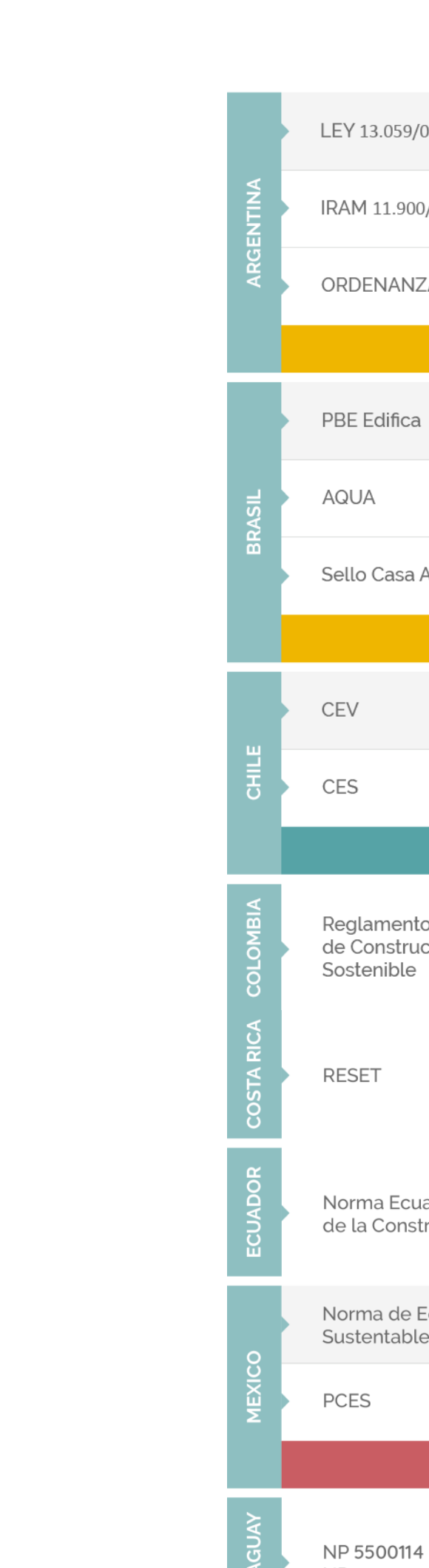

NP 5500215

$\times \quad$ Indisponibilidad de archivo climático EPW

$\times$

Código Técnico

de Construcción

Sostenible

$\times \quad$ Indisponibilidad de archivo climático EPW

$\times$

Resolución

No $5424 / 09$

$\times \quad$ Indisponibilidad de archivo climático EPW

$\times$

Figura 16: Selección de los sistemas de calificación y definición de sus indicadores. Elaboración propia. 


\subsubsection{Definición de los indicadores de estudio}

Para que los modelos energéticos elaborados puedan atender a los requisitos mínimos normativos de desempeño definidos por Argentina, Brasil, Chile, México y España, se buscó identificar los indicadores empleados por los 5 países, permitiendo la comparación entre los estándares propuestos. Para ello, se analizaron los indicadores de confort térmico y eficiencia energética definidos en la Ley $n^{\circ}$ 13.059/03 de Argentina, en el PBE Edifica de Brasil, en la Calificación Energética de Viviendas de Chile y en la Norma Mexicana de Edificación Sustentable de México (Tabla 13).

Para el caso de Argentina, se definió que la Ley $n^{\circ}$ 13.059/03 establece 5 criterios para garantizar condiciones de habitabilidad higrotérmica y su cumplimiento se verifica a partir de atender a los valores definidos para la (I) transmitancia térmica para cerramientos opacos, la (II) transmitancia térmica para superficies vidriadas, el (III) riesgo de condensación, el (IV) coeficiente de pérdidas globales, y el (V) coeficiente de infiltración de aire.

\begin{tabular}{|c|c|c|c|c|c|}
\hline INDICADORES & ARG & BRA & $\mathrm{CHI}$ & MEX & ESP \\
\hline Transmitancia térmica en cerramientos opacos & • & • & • & 0 & • \\
\hline Transmitancia térmica en vidrios & $\bullet$ & & 0 & 0 & 0 \\
\hline Transmitancia térmica para pisos & • & & 0 & & 0 \\
\hline Transmitancia térmica para límites interiores & & & & & • \\
\hline Capacidad térmica en cerramientos opacos & & 0 & & & \\
\hline Absortancia solar en cerramientos opacos & & ○ & & & \\
\hline Absortancia solar en vidrios & & & & & 0 \\
\hline Factor de proporción superficies vidriadas & & 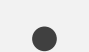 & & & \\
\hline Factor de ventilación natural & & ? & & & \\
\hline Factor solar del vidrio & $\bullet$ & & $\bullet$ & & ○ \\
\hline Coeficiente de infiltración de aire & • & & $\bullet$ & & $\bullet$ \\
\hline Riesgo de condensación & • & & & & $\bullet$ \\
\hline Coeficiente de pérdidas globales & • & & & & \\
\hline Rango de confort & & & & 0 & \\
\hline Mejoramiento de la transmitancia térmica para cerramientos opacos & & & & 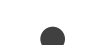 & \\
\hline
\end{tabular}

Tabla 13: Indicadores de la envolvente edilicia considerados por cada sistema analizado. Elaboración propia.

En el caso de Brasil, el PBE - Edifica clasifica la envolvente del edificio a partir de indicadores de consumo relativo para calefacción $\left(C_{A}\right)$, refrigeración $\left(C_{R}\right)$ y grados día resfriamiento $\left(G_{R}\right)$, a través de una ecuación que distribuye el peso de las características físicas y propiedades térmicas analizadas, considerando la sensibilidad de cada indicador en la eficiencia final de la envolvente. Se consideró que los indicadores requeridos por el PBE-Edifica para definir la eficiencia energética de la envolvente edilicia son la (I) transmitancia térmica, (II) capacidad térmica, (III) absortancia solar para cerramientos opacos, (IV) factor de proporción entre superficies opacas y vidriadas, y (V) factor de ventilación natural. 
Para el caso de Chile, la CEV define que la vivienda analizada debe reducir su consumo energético anual en comparación al valor de la demanda del estándar actual del país. Su método de evaluación se centra en el cálculo de la demanda para calefacción e iluminación, a través de un procedimiento que considera criterios de aislamiento térmico y aspectos relacionados con la orientación y la protección solar. Se estableció que los indicadores requeridos por la CEV para definir la demanda de calefacción, dado que algunos parámetros que no presentan un valor específico, son (I) transmitancia térmica para vidrios, (II) transmitancia térmica de cerramientos opacos, (III) transmitancia térmica para pisos, (IV) factor solar del vidrio, y (V) coeficiente de infiltración de aire.

En el caso de México, la norma mexicana de edificación sustentable define que la vivienda analizada debe limitar las ganancias de calor a través de la envolvente, atendiendo a tres normativas sobre aislamiento térmico y consumo energético. La NOM-018-ENER-2011 se centra en la aplicación de aislamientos térmicos a las edificaciones y no establece un valor específico que deba ser atendido. La NOM-008-ENER-2001 se destina a edificios no residenciales, mientras la NOM-020-ENER-2011 a edificaciones residenciales, y ambas definen las condiciones para calcular la ganancia de calor por conducción y radiación a través de la envolvente, estableciendo algunos indicadores específicos y otros informativos. Se consideró que los indicadores objetivos requeridos por la NMX para calcular las ganancias de calor a través de la envolvente, son (I) rango de confort, (II) transmitancia térmica para cerramientos opacos, (III) transmitancia térmica en vidrios, y (IV) mejoramiento de la transmitancia térmica para cerramientos opacos.

Se encontró que las normativas y los etiquetados analizados, evalúan el atendimiento de diversos criterios de forma particular, sin embargo, contrastando los indicadores de cada país, se observa que el único indicador común entre los sistemas analizados es la transmitancia térmica, por lo que se consideró que este será el indicador empleado para construir los diferentes escenarios de cálculo empleados en la etapa de simulación energética. 


\subsection{Selección de los edificios Casos de Estudio}

La selección de los casos de estudio se fundamentó en elegir modelos de edificios de vivienda unifamiliar y multifamiliar representativos del parque edilicio Latinoamericano, de forma que las conclusiones sean posibles de generalizar.

Se han considerado los edificios residenciales dado que corresponden a la tipología más representativa en los países con clima templado, y son los edificios que mayores consumos requieren durante su vida útil (Mercader Moyano, Olivares Santiago e Ramirez de Arellano Agudo 2012).

Para ello, se consideró primeramente que la inversión en vivienda realizada por los países latinoamericanos representa un promedio del $1.5 \%$ del PIB de cada país, destacando la actuación de México y Brasil con un porcentaje de 1.91 y 2.07 respectivamente.

Se observó la relación existente entre los niveles de inversión pública y la necesidad habitacional de cada país, y se verificó que Brasil y Panamá invierten mayores niveles de recursos públicos que Colombia y Perú para atender niveles similares de déficit habitacional en comparación con el tamaño de su población (CAMACOL, 2011).

El principal programa enfocado en la problemática habitacional en Brasil, es el Minha Casa Minha Vida, implementado en 2009 con el objetivo de construir un millón de viviendas para familias con un ingreso mensual igual o menor a 3 salarios mínimos (900 dólares). La Secretaria Nacional de Habitação del Ministério das Cidades de Brasil, informó a los autores que entre los años de 2009 y 2015, el programa MCMV recibió la contratación de 3.988.932 unidades habitacionales en todo el país (Figura 17).

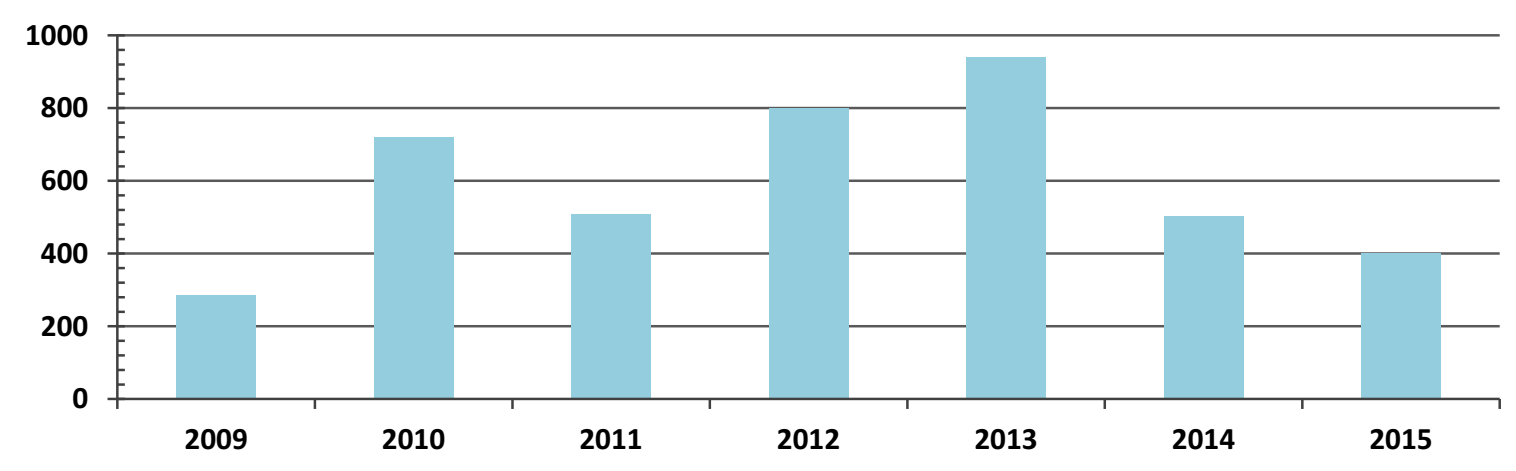

Figura 17: Unidades habitacionales contratadas por el Programa MCMV (en millares). Elaboración propia.

Al considerar un promedio de 2 habitantes para la mitad de las unidades contratadas durante los años de 2009 y 2015, y 4 habitantes para la segunda mitad, llegaríamos a la posibilidad de cubrir el déficit habitacional para aproximadamente 12 millones de personas cuando se concluyan las obras. Esta estimativa corresponde a un 5\% de la población de Brasil, 9\% de la población de México, 27\% de la población de Argentina, y más de la mitad de la población de Chile, indicando la representatividad de las tipologías edilicias construidas por el Programa en el país (Figura 18).

Para definir la tipología considerada en esta investigación, se identificaron los edificios de vivienda estandarizadas por el Programa Minha Casa Minha Vida en la ciudad de Criciúma - SC Brasil, teniendo en 
cuenta la posibilidad de acceder a los edificios para la realización de auditorías energéticas y la aplicación de cuestionarios a los habitantes.

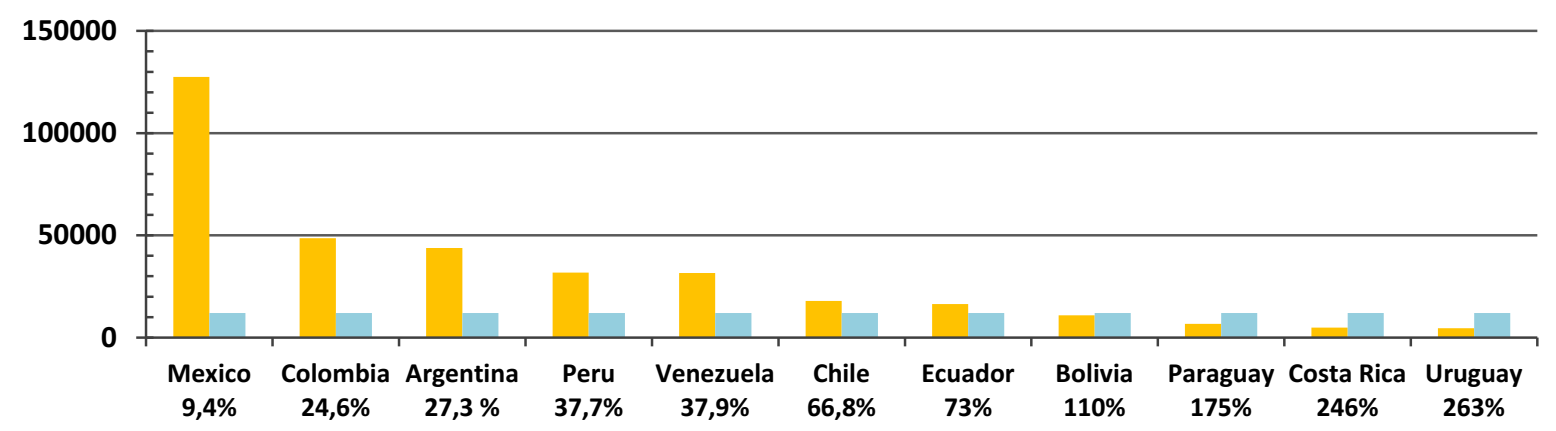

Figura 18: Estimativa de la población asistida por el MCMV en Brasil x la población de cada país Latinoamericano. Elaboración propia.

Inicialmente se consideraron cuatro tipologías de vivienda estándar: un modelo de vivienda de interés social, un modelo de vivienda considerada de clase media, un modelo de edificio multifamiliar de interés social, y un modelo de edificio multifamiliar considerado de clase media (Figura 19).

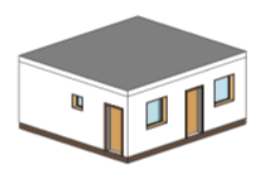

No se ha permitido difundir imágenes.

Modelo vivienda unifamiliar de interés social

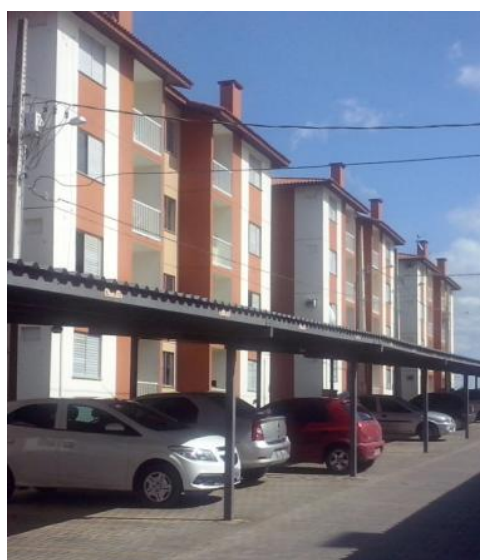

Modelo edificio multifamiliar de interés social

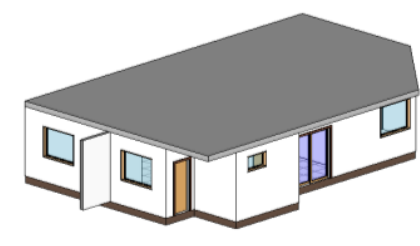

No se ha permitido difundir imágenes.

Modelo vivienda unifamiliar

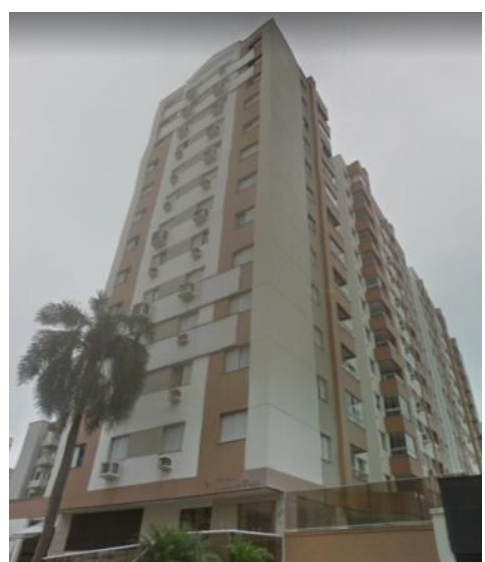

Modelo edificio multifamiliar

Figura 19: Tipologías de edificios residenciales adoptadas inicialmente. Elaboración propia.

Dado que la vivienda unifamiliar de interés social estándar del Programa MCMV es menos convencional en España, se decidió adoptar los modelos de edificios considerados por el Programa como clase media, con el fin de trabajar con las tipologías más representativas. Según el Programa MCMV los edificios considerados de clase media, se destinan a familias con ingreso mensual entre 3 y 6 salarios mínimos (aproximadamente 1.000 y 2.000 dólares) (Arruda 2009).

A la vivienda unifamiliar se la denominará Caso I (Figura 20) y al edificio de vivienda multifamiliar en altura Caso II (Figura 21). 
PARTE I · Delimitación del ámbito de la investigación

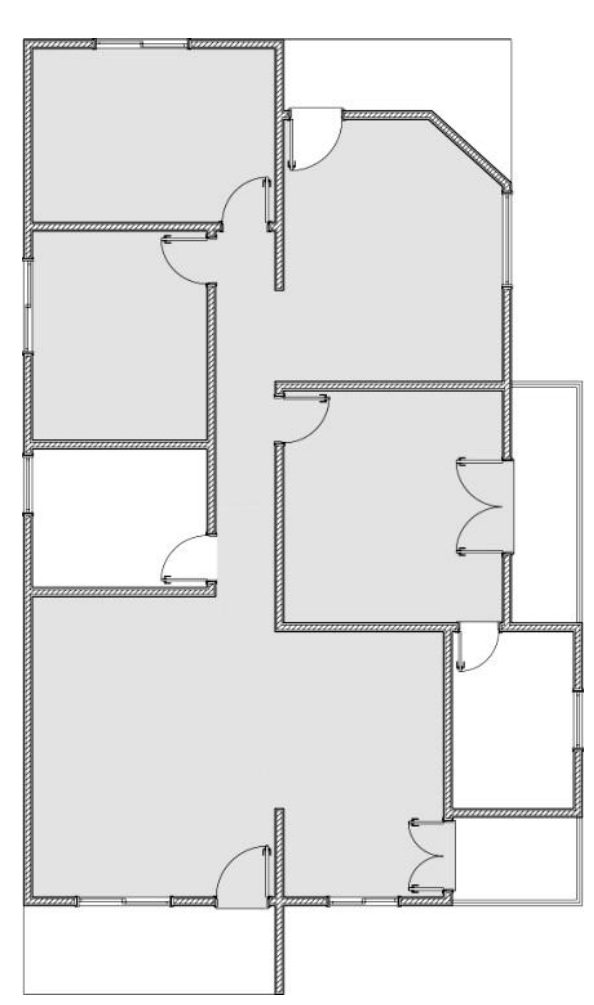

Figura 20: Caso I: vivienda unifamiliar - sin escala. Elaboración propia.

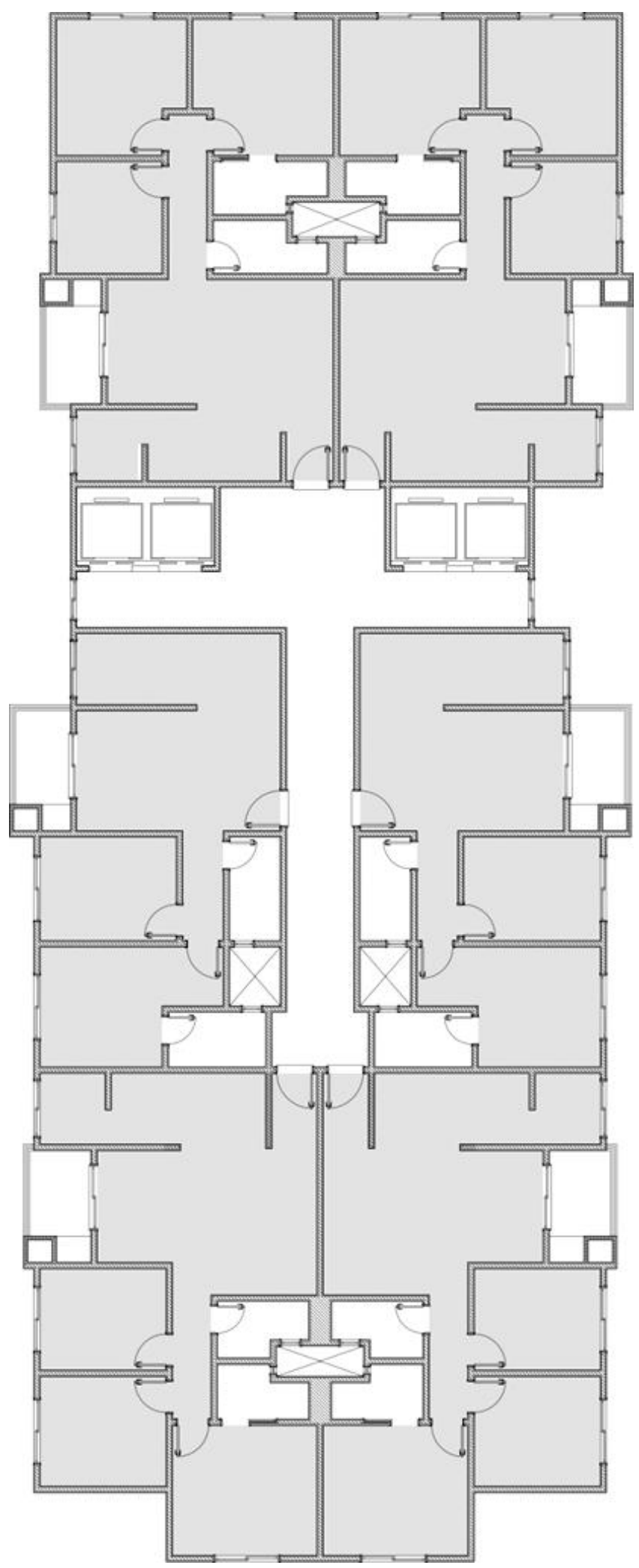

Figura 21: Caso II: vivienda multifamiliar. Planta tipo en los doce niveles - sin escala. Elaboración propia.

Los ambientes marcados con color gris en los planos del Caso I y del Caso II, representan las superficies asignadas en las zonas térmicas para que sean condicionadas. Los ambientes marcados en color blanco, como los baños, balcones, ductos de ventilación vertical, y circulaciones comunes del edificio, representan las superficies no incluidas en las zonas térmicas, ya que se encuentran ventiladas naturalmente (Ver apartado 7.1.1 Modelado de los edificios). 
Se buscó que los Casos de Estudio seleccionados en Criciúma, constituyeran tipologías residenciales representativas no solo del Programa Minha Casa Minha Vida, sino también en distintos programas habitacionales implementados en Argentina, Chile, España y México (Figura 22 a Figura 25).

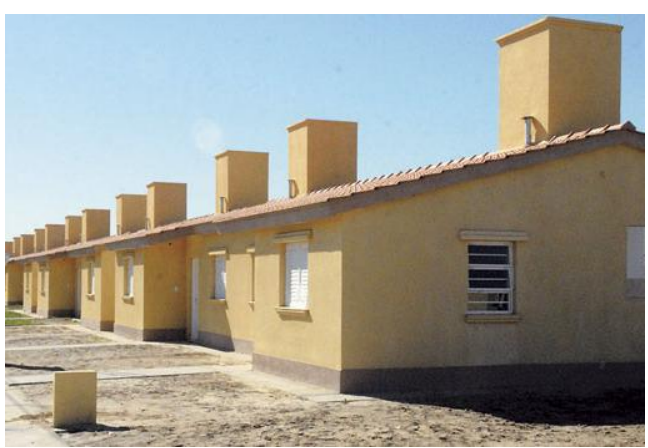

Viviendas en Don Bosco

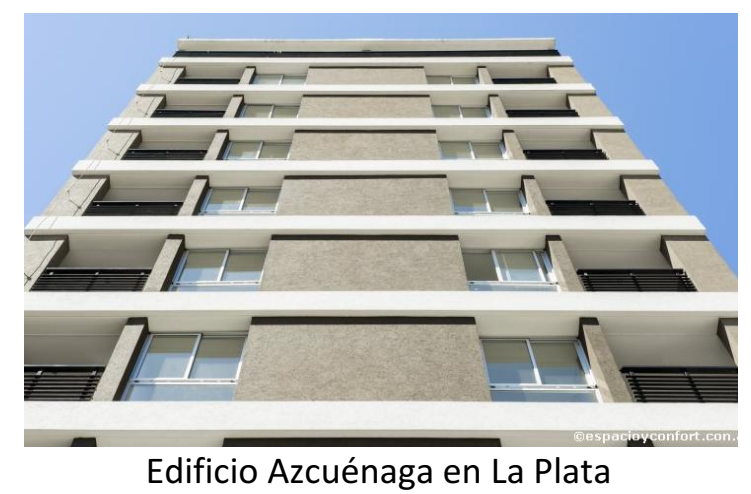

Figura 22: Edificios de vivienda en Argentina. Fuente: Emaco, Credil y Grupo Nisen.

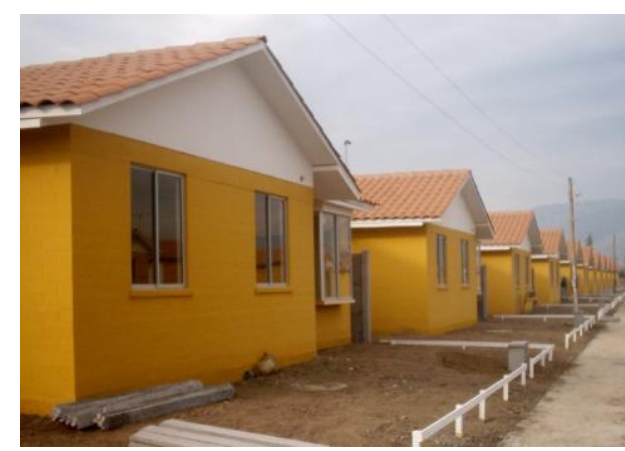

Viviendas de Padre Hurtado en P. Hurtado

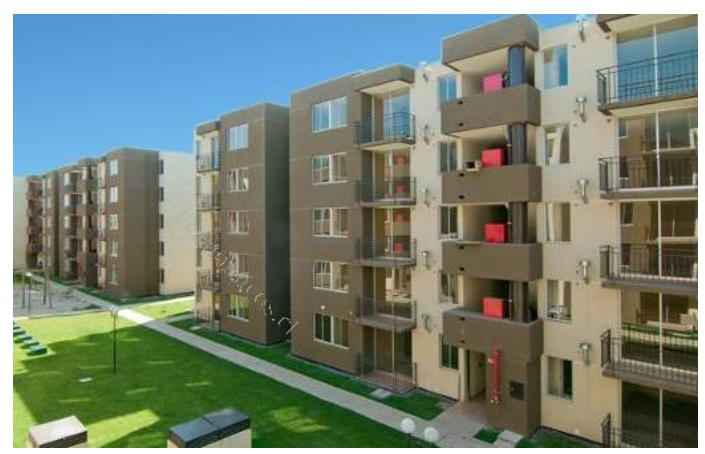

Condominio San Pedro en Puente Alto

Figura 23: Edificios de vivienda en Chile. Fuente: Portal tu vivienda del Ministerio de Vivienda y Urbanismo.

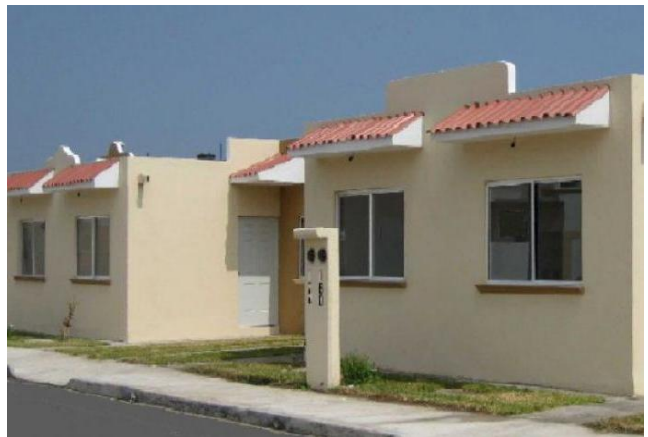

Condomínio Los Heroes en Mérida

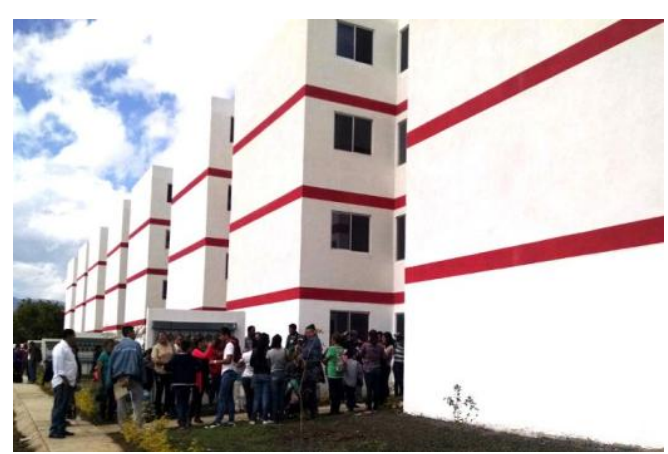

Desarrollo Bosque Real en Gómez Palacio

Figura 24: Edificios de vivienda en México. Fuente: Portal Infonavit.
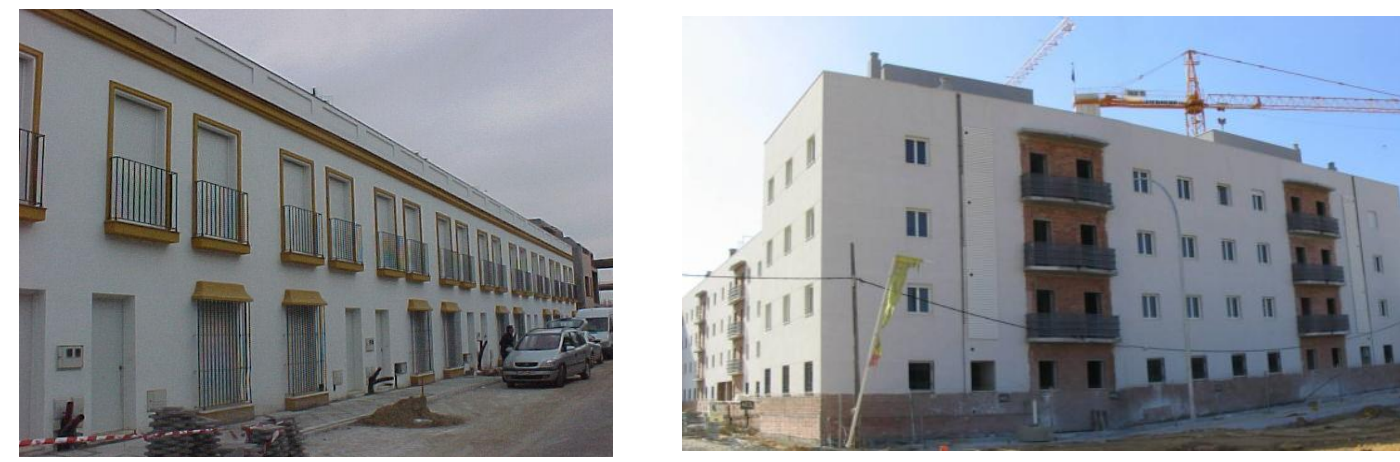

Figura 25: Edificios de vivienda en España. Fuente (Mercader Moyano, Olivares Santiago e Ramirez de Arellano Agudo 2012). 
Los modelos seleccionados situados en Criciúma, poseen características de implantación en el terreno similares a los casos de Argentina, Chile, España y México. Se repiten de forma indiscriminada, sin priorizar la orientación adecuada, siguiendo módulos funcionales predefinidos donde se modifica apenas el sentido de la puerta de acceso principal en relación a la disposición de la línea municipal. Usualmente son edificios exentos en la parcela que cumplen con las tasas mínimas de ocupación e infiltración, presentan un factor de forma compacto, y un porcentaje de superficie vidriado opaco del orden del $20 \%$.

El sistema constructivo tradicional de Argentina, Brasil, Chile y México consiste de una estructura simple de hormigón armado in loco, con muros de ladrillo cerámico hueco revestido con revoque y pintura, carpinterías de aluminio y vidrio simple, sin protección, y una cubierta de losa plana o con teja de aluzinc (Figura 26). El valor de $\mathrm{U}$ para muros exteriores es $2,51 \mathrm{~W} / \mathrm{m}^{2} \mathrm{~K}$, para cubierta es $1,96 \mathrm{~W} / \mathrm{m}^{2} \mathrm{~K}$, y para carpinterías es 5,8 W/m² K (Instituto Argentino de Normalización y Certificación 2002) (Tabla 14).

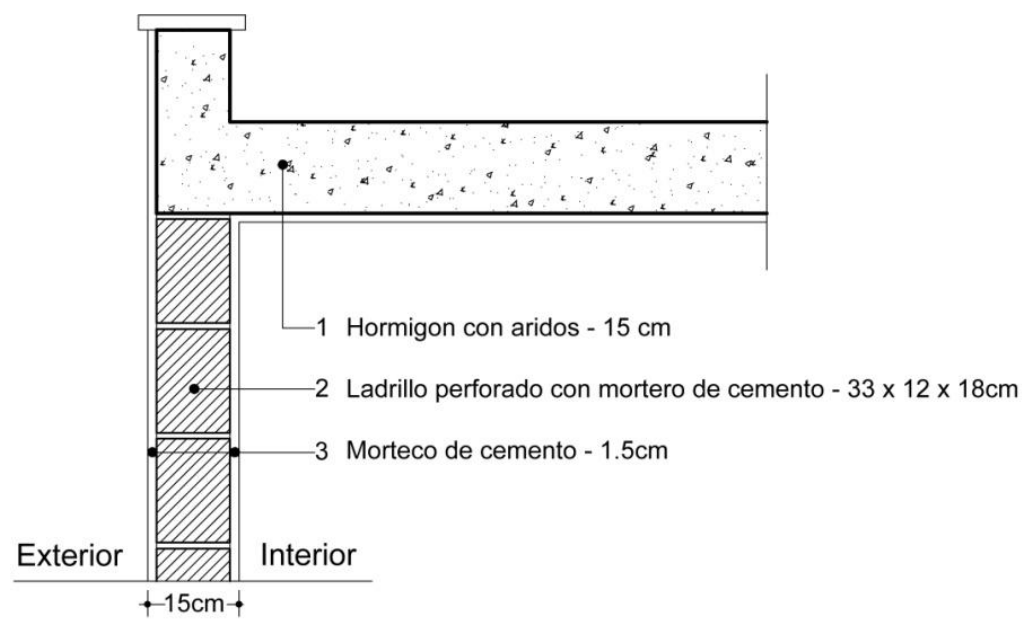

Figura 26: Muro exterior y cubierta tradicional en Latinoamérica. Elaboración propia.

\begin{tabular}{|c|c|c|c|}
\hline Muro exterior & Espesor e (m) & Conductividad $\lambda(\mathrm{W} / \mathrm{mk})$ & Resistencia $\mathrm{R}\left(\mathrm{M}^{2} \mathrm{k} / \mathrm{W}\right)=\mathrm{e} / \lambda$ \\
\hline Resistencia superficial & - & - & 0.120 \\
\hline Mortero de cemento & 0.02 & 1.3 & 0.015 \\
\hline Ladrillo cerámico & 0.15 & 0.75 & 0.200 \\
\hline Mortero de cemento & 0.03 & 1.3 & 0.023 \\
\hline Resistencia superficial & - & - & 0.040 \\
\hline \multicolumn{3}{|l|}{ Resistencia térmica total } & $0.398\left(\mathrm{~m}^{2} \mathrm{~K} / \mathrm{W}\right)$ \\
\hline \multicolumn{3}{|c|}{ Coeficiente de transmitancia térmica $U(1 / R)$} & $2.510\left(\mathrm{~W} / \mathrm{m}^{2} \mathrm{~K}\right)$ \\
\hline
\end{tabular}

\begin{tabular}{lccc}
\hline \multicolumn{1}{c}{ Losa cubierta } & Espesor $\mathbf{~}(\mathrm{m})$ & Conductividad $\boldsymbol{\lambda}(\mathbf{w} / \mathbf{m k})$ & Resistencia $\mathbf{R}\left(\mathbf{m}^{\mathbf{2}} \mathbf{k} / \mathbf{w}\right)=\mathrm{e} / \boldsymbol{\lambda}$ \\
\hline Resistencia superficial & - & - & 0.120 \\
Teja aluzinc & 0.03 & 58 & 0.001 \\
Cámara de aire no ventilada & 0.02 & - & 0.192 \\
Losa hormigón & 0.15 & 1.1 & 0.136 \\
Mortero de cemento & 0.025 & 1.3 & 0.019 \\
Resistencia superficial & - & - & 0.040 \\
Resistencia térmica total & & & $\mathbf{0 . 5 0 8}\left(\mathbf{m}^{\mathbf{2}} \mathbf{K} / \mathbf{W}\right)$ \\
Coeficiente de transmitancia térmica U (1/R) & & $\mathbf{1 . 9 6 7}\left(\mathbf{W} / \mathbf{m}^{\mathbf{2}} \mathbf{K}\right)$ \\
\hline
\end{tabular}

Tabla 14: Composición del muro exterior y de la cubierta tradicional en Latinoamérica. Elaboración propia. 
La solución constructiva tradicional de España, presenta mayor masa y aislamiento térmico que la tipología constructiva de Latinoamérica. Consiste en una estructura simple de hormigón armado, con cerramiento de ladrillo cerámico con adición de poliuretano proyectado + cámara de aire, revestidos con un trasdosado de yeso. Las carpinterías son principalmente de aluminio con vidrio simple, o doble con cámara de aire, y la cubierta es plana, de losa de hormigón con adición de aislante térmico (Figura 27).

El valor de $\mathrm{U}$ para muros exteriores es $0,57 \mathrm{~W} / \mathrm{m}^{2} \mathrm{~K}$, para cubierta es $0,40 \mathrm{~W} / \mathrm{m}^{2} \mathrm{~K}$, para carpinterías con vidrio simple es $5,8 \mathrm{~W} / \mathrm{m}^{2} \mathrm{~K}$, y para carpinterías con vidrio doble + cámara de aire es $3,2 \mathrm{~W} / \mathrm{m}^{2} \mathrm{~K}$, según indica la bibliografía (Instituto Argentino de Normalización y Certificación 2002) (Tabla 15).

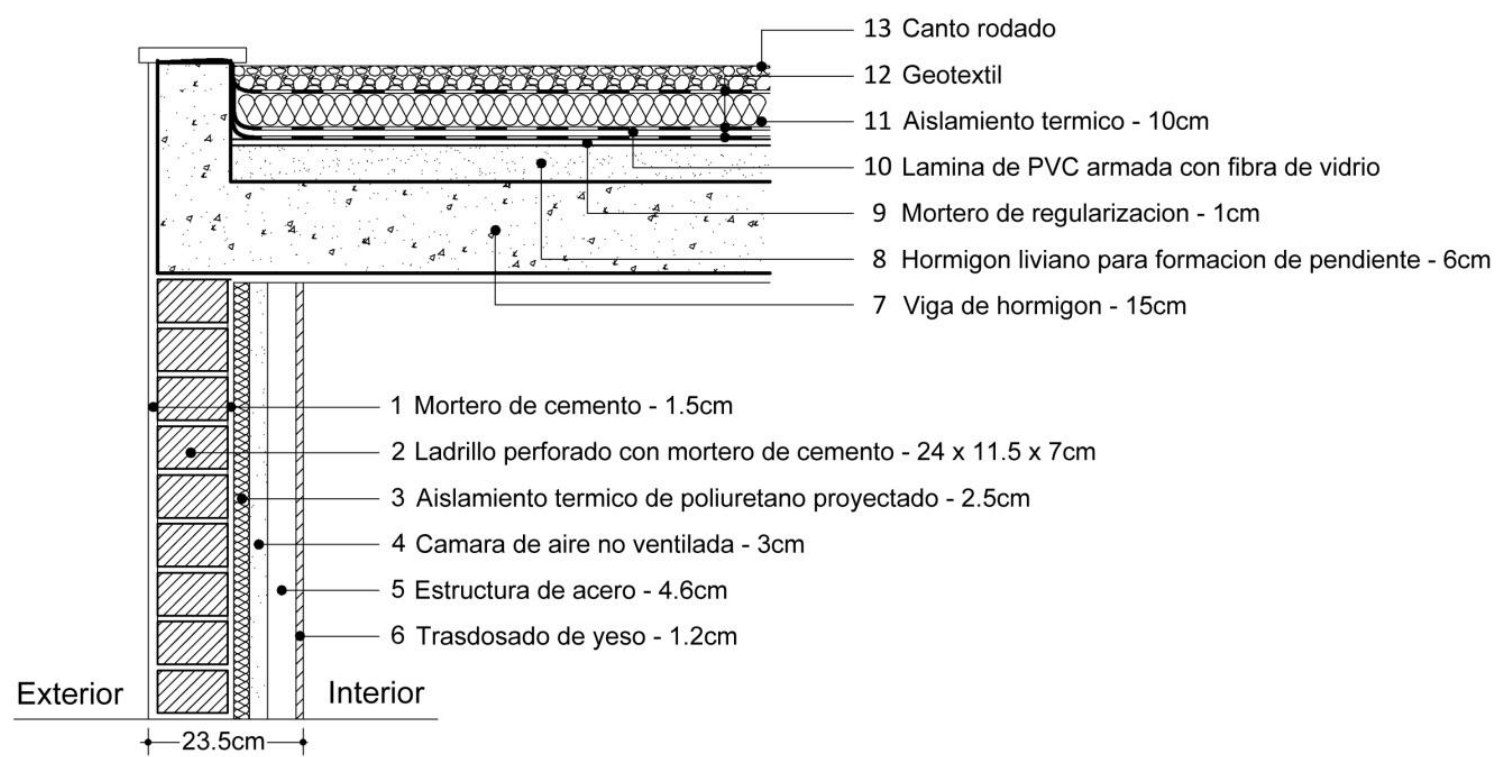

Figura 27: Muro y cubierta tradicional en España. Elaboración propia adaptada de (Marrero Meléndez, et al. 2013).

\begin{tabular}{|c|c|c|c|}
\hline Muro exterior & Espesor e (m) & Conductividad $\lambda$ (W/mk) & Resistencia $R\left(M^{2} k / W\right)=e / \lambda$ \\
\hline Resistencia superficial interna & - & - & 0.12 \\
\hline Mortero de cemento $1800 \mathrm{Kg} / \mathrm{m} 3$ & 0.015 & 1.3 & 0.0115 \\
\hline Ladrillo perforado $780 \mathrm{Kg} / \mathrm{m} 3$ & 0.12 & 0.35 & 0.3429 \\
\hline Mortero de cemento $1800 \mathrm{Kg} / \mathrm{m} 3$ & 0.01 & 1.3 & 0.0077 \\
\hline Poliuretano proyectado $35 \mathrm{Kg} / \mathrm{m} 3$ & 0.025 & 0.028 & 0.8929 \\
\hline Cámara de aire no ventilada & 0.03 & - & 0.1700 \\
\hline Trasdosado de yeso $750 \mathrm{Kg} / \mathrm{m} 3$ & 0.012 & 0.25 & 0.1700 \\
\hline Resistencia superficial externa & - & - & 0.04 \\
\hline Resistencia térmica total & & & $1.755\left(\mathrm{~m}^{2} \mathrm{~K} / \mathrm{W}\right)$ \\
\hline Coeficiente de transmitancia térm & ica U (1/R) & & $0.570\left(\mathrm{~W} / \mathrm{m}^{2} \mathrm{~K}\right)$ \\
\hline Losa cubierta & Espesor e (m) & Conductividad $\lambda$ (W/mk) & Resistencia $R\left(M^{2} k / W\right)=e / \lambda$ \\
\hline Resistencia superficial interna & - & - & 0.12 \\
\hline Mortero de cemento & 0.025 & 1.3 & 0.0192 \\
\hline Fibra de vidrio & 0.1 & 0.05 & 2.0000 \\
\hline Losa hormigón & 0.15 & 0.62 & 0.2419 \\
\hline Canto rodado & 0.05 & 1 & 0.0500 \\
\hline Resistencia superficial externa & - & - & 0.04 \\
\hline \multicolumn{3}{|l|}{ Resistencia térmica total } & $2.471\left(m^{2} K / W\right)$ \\
\hline \multicolumn{3}{|c|}{ Coeficiente de transmitancia térmica $U(1 / R)$} & $0.405\left(\mathrm{~W} / \mathrm{m}^{2} \mathrm{~K}\right)$ \\
\hline
\end{tabular}

Tabla 15: Composición del muro exterior y de la cubierta tradicional en España. Elaboración propia. 


\subsection{Definición de los escenarios de cálculo}

Con el fin de que los modelos edilicios empleados en las simulaciones energéticas cumplan con los estándares de transmitancia térmica - U para cerramientos opacos exteriores definidos por cada país, se identificaron los valores de $U$ para muros y techos establecidos por la regulación y certificación de Argentina, Brasil, Chile, España, y México.

\subsubsection{Argentina}

En Argentina los valores de U admisibles varían en función de la zona bioclimática en que la edificación se encuentra situada. Conforme indica el mapa bioambiental disponible en la norma IRAM 11.603 (Instituto Argentino de Normalización y Certificación 2012), el territorio argentino se encuentra divido en 6 zonas (Figura 28), las cuales se clasifican en función de características climáticas similares (Tabla 16).

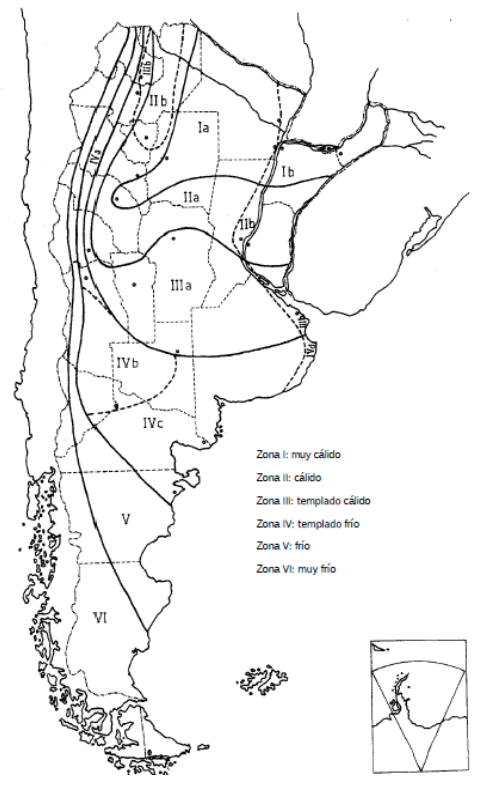

Figura 28: Mapa bioambiental de Argentina. Fuente: (Instituto Argentino de Normalización y Certificación 2012).

\begin{tabular}{|c|c|c|c|c|}
\hline \multicolumn{2}{|c|}{ Clasificación } & Zona & $\begin{array}{c}\text { Temperatura efectiva } \\
\text { corregida (TEC) }\end{array}$ & $\begin{array}{l}\text { Amplitud } \\
\text { Térmica }\end{array}$ \\
\hline I - Muy cálida & $\begin{array}{l}\text { A } \\
B\end{array}$ & Centro este del norte del país & $\begin{array}{l}\text { Verano: Mayores a } 26,3^{\circ} \mathrm{C} \\
\text { Invierno: Mayores a } 12^{\circ} \mathrm{C}\end{array}$ & $\begin{array}{l}\text { > a } 14^{\circ} \mathrm{C} \\
\text { < a } 14^{\circ} \mathrm{C}\end{array}$ \\
\hline II - Cálida & $\begin{array}{l}\text { A } \\
\text { B }\end{array}$ & $\begin{array}{l}\text { Extensión este - oeste del norte del } \\
\text { país }\end{array}$ & $\begin{array}{l}\text { Verano: Mayores a } 24^{\circ} \mathrm{C} \\
\text { Invierno: Entre } 8^{\circ} \mathrm{C} \text { y } 12^{\circ} \mathrm{C}\end{array}$ & $\begin{array}{l}\text { > a } 14^{\circ} \mathrm{C} \\
<\text { a } 14^{\circ} \mathrm{C}\end{array}$ \\
\hline $\begin{array}{l}\text { III - Templada } \\
\text { cálida }\end{array}$ & $\begin{array}{l}\text { A } \\
B\end{array}$ & Predominancia en el centro del país & $\begin{array}{l}\text { Verano: Entre } 20^{\circ} \mathrm{C} \text { y } 26^{\circ} \mathrm{C} \\
\text { Invierno: Entre } 8^{\circ} \mathrm{C} \text { y } 12^{\circ} \mathrm{C}\end{array}$ & $\begin{array}{l}\text { > a } 14^{\circ} \mathrm{C} \\
<\text { a } 14^{\circ} \mathrm{C}\end{array}$ \\
\hline $\begin{array}{l}\text { IV - Templada } \\
\text { fría }\end{array}$ & $\begin{array}{l}A \\
B \\
C \\
D\end{array}$ & $\begin{array}{l}\text { Predominancia en el centro sur del } \\
\text { país }\end{array}$ & $\begin{array}{c}\text { Verano: } 23^{\circ} \mathrm{C} \\
\text { Invierno: Entre } 4^{\circ} \mathrm{C} \text { y } 8^{\circ} \mathrm{C}\end{array}$ & $\begin{array}{l}18^{\circ} \mathrm{C} \\
17^{\circ} \mathrm{C} \\
16^{\circ} \mathrm{C} \\
15^{\circ} \mathrm{C}\end{array}$ \\
\hline V - Fría & & $\begin{array}{l}\text { Extensión norte - sur de la cordillera y } \\
\text { la región central de la Patagonia }\end{array}$ & $\begin{array}{l}\text { Verano: } 16^{\circ} \mathrm{C} \\
\text { Invierno: } 4^{\circ} \mathrm{C}\end{array}$ & - \\
\hline VI - Muy fría & & $\begin{array}{l}\text { Altas cumbres de la Cordillera los } \\
\text { Andes y el ext. Sur de la Patagonia }\end{array}$ & $\begin{array}{l}\text { Verano: Menores a } 12^{\circ} \mathrm{C} \\
\text { Invierno: Máximo } 4^{\circ} \mathrm{C}\end{array}$ & - \\
\hline
\end{tabular}

Tabla 16: Características de las zonas bioclimáticas de Argentina. Elaboración propia adaptada de (Instituto Argentino de Normalización y Certificación 2012). 
Para definir los valores de U, la norma IRAM 11.605 titulada Acondicionamiento térmico de edificios Condiciones de habitabilidad en edificios - Valores máximos de transmitancia térmica en cerramientos opacos (Instituto Argentino de Normalización y Certificación, 2001a), clasifica el desempeño en tres niveles de confort, A - recomendado, B - medio, y C - mínimo, según la condición de verano o invierno.

Dichos niveles establecen los valores de $U$ máximos admisibles que deben ser atendidos por los elementos opacos de la envolvente. La verificación de cumplimiento debe realizarse simultáneamente en condiciones de verano e invierno, excepto para las zonas $\mathrm{V}$ y $\mathrm{VI}$, donde solo se exige que se cumpla con la condición de invierno, y debe atender al nivel $\mathrm{B}$, ya que el nivel $\mathrm{C}$ se destina a viviendas de interés social.

Para la condición de verano, los valores máximos admisibles están definidos según se trate de muros o techos y en función de cada zona bioambiental, conforme se verifica en la Tabla 17. Estos valores están dados para todos elementos cuya superficie exterior presente un coeficiente de absorción de la radiación solar de 0,6 a 0,8 . Para coeficientes menores que 0,6 , se acrecienta al valor de $U$ el $20 \%$ para muros y $30 \%$ para techos, en cuanto para los coeficientes superiores a 0,8 , se disminuye el valor de $U$ en $15 \%$ y $20 \%$, para muros y techos respectivamente.

\begin{tabular}{cccccccc}
\hline \multirow{2}{*}{ Zona bioambiental } & \multicolumn{3}{c}{ Muros } & \multicolumn{3}{c}{ Techos } \\
& Nivel A & Nivel B & Nivel C & Nivel A & Nivel B & Nivel C \\
\hline I y II & 0,45 & 1,10 & 1,80 & 0,18 & 0,45 & 0,72 \\
III y IV & 0,50 & 1,25 & 2,00 & 0,19 & 0,48 & 0,76 \\
\hline
\end{tabular}

Tabla 17: Valores máximos de transmitancia térmica $U$ (W/m2.K) para condiciones de verano. Elaboración propia adaptada de (Instituto Argentino de Normalización y Certificación, 2001a).

Para la situación de invierno, los valores máximos admisibles están definidos en función de la temperatura exterior de diseño - TED del proyecto, la cual se establece en función del nivel de confort que se pretende alcanzar en los ambientes, es decir, en función de la temperatura interior de diseño que se considera como base menos el valor de la temperatura media mínima exterior (Tabla 18 y Tabla 19).

\begin{tabular}{|c|c|c|c|c|c|c|}
\hline \multirow{2}{*}{$\operatorname{TED}\left({ }^{\circ} \mathrm{C}\right)$} & \multicolumn{3}{|c|}{ Muros } & \multicolumn{3}{|c|}{ Techos } \\
\hline & Nivel A & Nivel B & Nivel C & Nivel A & Nivel B & Nivel C \\
\hline-5 & 0,31 & 0,83 & 1,45 & 0,27 & 0,69 & 1,00 \\
\hline-4 & 0,32 & 0,87 & 1,52 & 0,28 & 0,72 & 1,00 \\
\hline-3 & 0,33 & 0,91 & 1,59 & 0,29 & 0,74 & 1,00 \\
\hline-2 & 0,35 & 0,95 & 1,67 & 0,30 & 0,77 & 1,00 \\
\hline-1 & 0,36 & 0,99 & 1,75 & 0,31 & 0,80 & 1,00 \\
\hline$>0$ & 0,38 & 1,00 & 1,85 & 0,32 & 0,83 & 1,00 \\
\hline
\end{tabular}

Tabla 18: Valores máximos de transmitancia térmica U (W/m2.K) para condiciones de invierno. Elaboración propia adaptada de (Instituto Argentino de Normalización y Certificación, 2001a).

\begin{tabular}{lccc}
\multicolumn{1}{c}{ Nivel } & A $\left({ }^{\circ} \mathrm{C}\right)$ & B $\left({ }^{\circ} \mathrm{C}\right)$ & $\mathrm{C}\left({ }^{\circ} \mathrm{C}\right)$ \\
\hline Para verificar la no existencia de condensación superficial & 22 & 20 & 18 \\
$\begin{array}{l}\text { Para el confort a través de la diferencia de temperatura interior } \\
\text { de diseño y superficial de un cerramiento }\end{array}$ & 1 & 2,5 & 4 \\
\hline
\end{tabular}

Tabla 19: Temperatura interior de diseño para niveles de confort A, B y C. Elaboración propia adaptada de (Instituto Argentino de Normalización y Certificación, 2001a). 


\subsubsection{Brasil}

En Brasil los valores de U para los elementos de la envolvente, así como para capacidad térmica y absorción a la radiación, varían en función de la zona bioclimática en que la edificación se encuentra situada (Tabla 20). El mapa bioambiental de Brasil, disponible en la NBR 15.220 (2008), divide el territorio nacional en 8 zonas (Figura 29) según las características bioclimáticas mencionadas en la (Tabla 21).

\begin{tabular}{|c|c|c|c|c|c|c|c|}
\hline \multirow{3}{*}{$\begin{array}{c}\text { Zona } \\
\text { bioambiental }\end{array}$} & \multirow{3}{*}{$\begin{array}{c}\text { Transmitancia } \\
\text { Térmica }\end{array}$} & \multicolumn{2}{|l|}{ Muros } & \multicolumn{4}{|c|}{ Techos } \\
\hline & & Capacidad & Absorción & \multicolumn{3}{|c|}{ Transmitancia Térmica } & \multirow{2}{*}{$\begin{array}{l}\text { Absorción } \\
\text { a radiación }\end{array}$} \\
\hline & & Térmica & a radiación & $\mathrm{M}$ & 1 & $\mathrm{~S}$ & \\
\hline 1 y 2 & $\leq 2,5$ & $\geq 130$ & - & $\leq 2,3$ & $\leq 1,5$ & $\leq 1,0$ & - \\
\hline \multirow{2}{*}{$3,4,5$ y 6} & $\leq 3,7$ & $\geq 130$ & $\alpha^{a} \leq 0,6$ & $\leq 2,3$ & $\leq 1,5$ & $\leq 1,0$ & $\alpha \leq 0,6$ \\
\hline & $\leq 2,5$ & $\geq 130$ & $\alpha^{a}>0,6$ & $\leq 1,5$ & $\leq 1,0$ & $\leq 0,5$ & $\alpha>0,6$ \\
\hline \multirow{2}{*}{7 y $8^{*}$} & $\leq 3,7$ & $\geq 130$ & $\alpha^{a} \leq 0,6$ & $\leq 2,3 \mathrm{FV}$ & $\leq 1,5 \mathrm{FV}$ & $\leq 1,0 \mathrm{FV}$ & $\alpha \leq 0,4$ \\
\hline & $\leq 2,5$ & $\geq 130$ & $\alpha^{a}>0,6$ & $\leq 1,5 \mathrm{FV}$ & $\leq 1,0 \mathrm{FV}$ & $\leq 0,5 \mathrm{FV}$ & $\alpha>0,4$ \\
\hline
\end{tabular}

Tabla 20: Valores de Transmitancia Térmica (W/m3.K), Capacidad térmica (kJ/m2.K) y Absorción a la radiación para muros y techos. Elaboración propia adaptada de (Associação Brasileira de Normas Técnicas 2013).

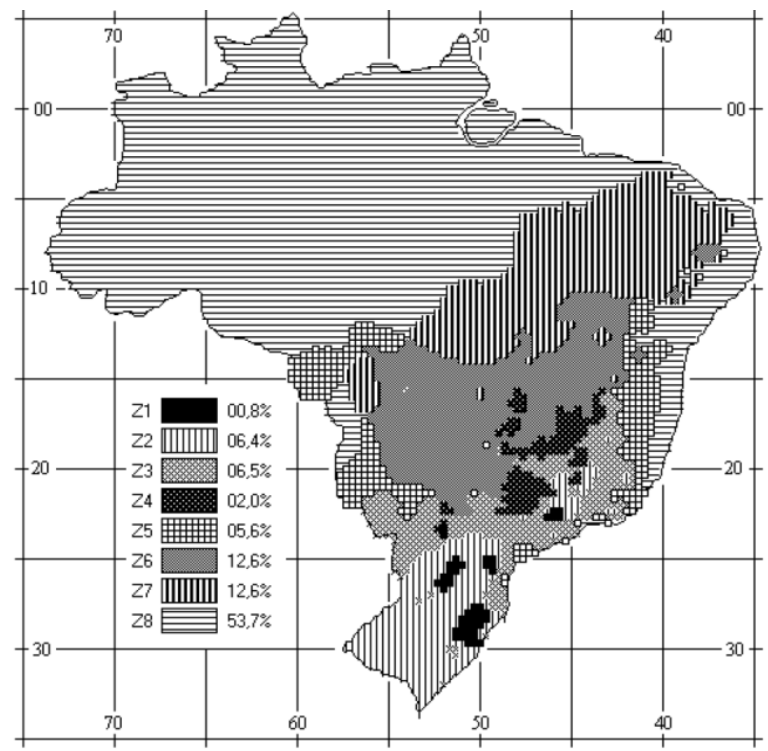

Figura 29: Mapa bioambiental de Brasil. Fuente: (Associação Brasileira de Normas Técnicas 2008).

\begin{tabular}{|c|c|c|c|}
\hline Clasificación & Zona & $\begin{array}{l}\text { Temperatura media } \\
\text { diária * }\end{array}$ & $\begin{array}{l}\text { Amplitud media } \\
\text { anual } * *\end{array}$ \\
\hline I - Más fría & Pequeñas localidades en el sur & Entre $0,7^{\circ} \mathrm{C}$ y $31,4^{\circ} \mathrm{C}$ & $9,0^{\circ} \mathrm{C}$ \\
\hline II & Sur del país & Medias de $18{ }^{\circ} \mathrm{C}^{* *}$ & $11,0^{\circ} \mathrm{C}$ \\
\hline III & Predominancia en el centro sur & Entre $6,0^{\circ} \mathrm{C}$ y $35,9^{\circ} \mathrm{C}$ & $8,0{ }^{\circ} \mathrm{C}$ \\
\hline IV & Pequeñas localidades en el centro oeste & Entre $10,0^{\circ} \mathrm{C}$ y $31,2{ }^{\circ} \mathrm{C}$ & $11,0^{\circ} \mathrm{C}$ \\
\hline $\mathbf{v}$ & $\begin{array}{c}\text { Franjas de extensión norte-sur en el } \\
\text { centro oeste y centro leste }\end{array}$ & Medias de $22^{\circ} \mathrm{C}^{* *}$ & $8,0^{\circ} \mathrm{C}$ \\
\hline VI & Predominancia en el centro & Entre $9,6^{\circ} \mathrm{C}$ y $34,6{ }^{\circ} \mathrm{C}$ & $11,5^{\circ} \mathrm{C}$ \\
\hline VII & Predominancia en el nordeste del país & Entre $11,4^{\circ} \mathrm{C}$ y $37,8^{\circ} \mathrm{C}$ & $11,5^{\circ} \mathrm{C}$ \\
\hline $\begin{array}{l}\text { VIII - Caliente } \\
\text { y húmedo }\end{array}$ & $\begin{array}{l}\text { Predominancia en la zona Amazónica } \\
\text { con una extensión por la costa nordeste }\end{array}$ & Entre $11,9^{\circ} \mathrm{C}$ y $37,9^{\circ} \mathrm{C}$ & $8,5{ }^{\circ} \mathrm{C}$ \\
\hline
\end{tabular}

Tabla 21: Características de las zonas bioclimáticas de Brasil. Elaboración propia adaptada de (Associação Brasileira de Normas Técnicas 2008). 


\subsubsection{Chile}

Los valores admisibles de $U$ para muros exteriores y techos, varían en función de la zona bioclimática en que la edificación se encuentra situada (Tabla 22).

\begin{tabular}{ccc}
\hline Zona & Muros & Techos \\
\hline NL & 2,6 & 0,8 \\
\hline ND & 2,1 & 0,8 \\
\hline NVT & 2,1 & 0,8 \\
\hline CL & 2,0 & 0,9 \\
\hline Cl & 1,9 & 0,9 \\
\hline SL & 1,8 & 1,0 \\
\hline SI & 1,7 & 0,9 \\
SE & 1,6 & 0,7 \\
\hline An & 1,6 & 0,7 \\
\hline
\end{tabular}

Tabla 22: Valores de transmitancia térmica (W/m2.K). Elaboración propia adaptada de (Instituto Nacional de Normalización 1997).

Conforme el mapa bioambiental disponible en la norma NCh1079/2000 (Instituto Nacional de Normalización 1997), el territorio chileno se encuentra divido en 9 zonas bioclimáticas (Figura 30), según las características climáticas mencionadas en la (Tabla 23).

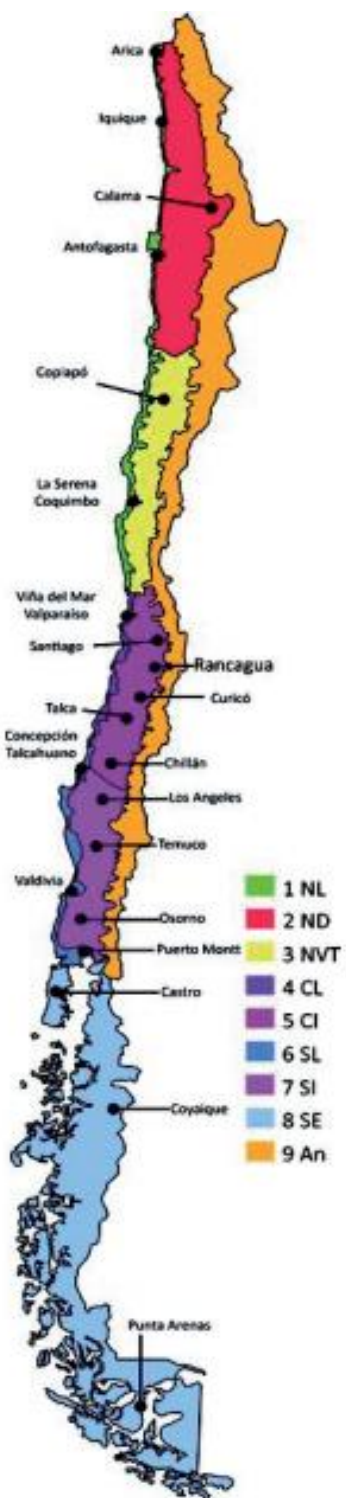

Figura 30: Mapa bioambiental de Chile. Fuente: (Instituto Nacional de Normalización 1997).

\begin{tabular}{|c|c|c|c|}
\hline Clasificación & Zona & Temperatura media * & $\begin{array}{l}\text { Amplitud media } \\
\text { anual }\end{array}$ \\
\hline NL & Norte Litoral & Entre $17,7^{\circ} \mathrm{C}$ y $15^{\circ} \mathrm{C}$ & $7,3^{\circ} \mathrm{C}$ baja \\
\hline ND & Norte Desértica & Entre $15^{\circ} \mathrm{C}$ y $12,3^{\circ} \mathrm{C}$ & $17,6^{\circ} \mathrm{C}$ alta \\
\hline NVT & Norte Valle Transversal & Entre $15^{\circ} \mathrm{C}$ y $15,9^{\circ} \mathrm{C}$ & $16,2^{\circ} \mathrm{C}$ alta \\
\hline $\mathrm{CL}$ & Central Litoral & Entre $12,8^{\circ} \mathrm{C}$ y $14,6^{\circ} \mathrm{C}$ & $9,2^{\circ} \mathrm{C}$ baja \\
\hline $\mathrm{Cl}$ & Central Interior & Entre $13,7^{\circ} \mathrm{C}$ y $14,3^{\circ} \mathrm{C}$ & $17,0^{\circ} \mathrm{C}$ alta \\
\hline SL & Central Interior & Entre $12{ }^{\circ} \mathrm{C}$ y $12,6{ }^{\circ} \mathrm{C}$ & $14,2{ }^{\circ} \mathrm{C}$ media \\
\hline SI & Sur Interior & Entre $10,6^{\circ} \mathrm{C}$ y $12,7^{\circ} \mathrm{C}$ & $16^{\circ} \mathrm{C}$ alta \\
\hline SE & Sur Extremo & Entre $6,7^{\circ} \mathrm{C}$ y $10,8^{\circ} \mathrm{C}$ & $6,5^{\circ} \mathrm{C}$ baja \\
\hline An & Andina & Entre $8,5^{\circ} \mathrm{C}$ y $11,1^{\circ} \mathrm{C}$ & $8,5^{\circ} \mathrm{C}$ baja \\
\hline
\end{tabular}

* Las temperaturas medias fueron tomadas como promedio de las localidades disponibles en la NCh1079/2000.

**Para valores de amplitud se consideró la situación más desfavorable, según datos de la NCh1079/2000.

Tabla 23: Características de las zonas bioclimáticas de Chile. Elaboración propia adaptada de (Instituto Nacional de Normalización 1997). 


\subsubsection{España}

En España los valores admisibles para la transmitancia térmica $(\mathrm{W} / \mathrm{m} 2 \mathrm{~K})$ de los cerramientos opacos y el factor solar modificado para lucernarios varían en función de la zona bioclimática en que la edificación se encuentra situada (Tabla 24). Los valores admisibles de $U$ para superficies vidriadas, bien como su factor solar, están definidos para cada zona bioclimática y en función de la orientación del edificio y del porcentaje de superficie vidriado x opaco (Tabla 25).

\begin{tabular}{cccccc}
\hline Elemento & \multicolumn{5}{c}{ Zona bioclimática } \\
& A & B & C & D & E \\
\hline Muros & 0,94 & 0,82 & 0,73 & 0,66 & 0,57 \\
Pisos & 0,53 & 0,52 & 0,50 & 0,49 & 0,48 \\
Cubiertas & 0,50 & 0,45 & 0,41 & 0,38 & 0,35 \\
Factor Solar Lucernario & 0,29 & 0,32 & 0,37 & 0,36 & 0,36 \\
\hline
\end{tabular}

Tabla 24: Valores admisibles para transmitancia térmica $(\mathrm{W} / \mathrm{m} 2 \mathrm{~K})$ de elementos opacos. Elaboración propia adaptada de (Ministerio de la Vivienda, 2007).

\begin{tabular}{cccccc}
\hline \multirow{2}{*}{ Orientación ventana } & \multicolumn{5}{c}{ Zona bioclimática } \\
& A & B & C & D & E \\
\hline N/NE/NO & 4,7 & 3,8 & 3,4 & 3,0 & 3,1 \\
E/O & 5,7 & 4,9 & 3,9 & 3,5 & 3,1 \\
S & 5,7 & 5,7 & 4,4 & 3,5 & 3,1 \\
SE/SO & 5,7 & 5,7 & 4,4 & 3,5 & 3,1 \\
\hline
\end{tabular}

Tabla 25: Valores admisibles para transmitancia térmica $(\mathrm{W} / \mathrm{m} 2 \mathrm{~K})$ de elementos vidriados considerando un porcentaje de $\mathbf{1 0} \%$ a $\mathbf{2 0 \%}$ en relación la superficie de la envolvente opaca. Elaboración propia adaptada de (Ministerio de la Vivienda, 2007).

La permeabilidad de las carpinterías también se limita en función del clima de la localidad en la que se ubica el edificio. Según la zonificación climática, debe atender los siguientes valores: CLASE 1 (50m3/h $\mathrm{m} 2$ ) para zona A y B, y CLASE 2 (27 m3/h m2) para zona C, D y E.

Conforme el mapa bioambiental disponible en el Documento Básico de Ahorro de Energía del CTE (Ministerio de la Vivienda 2007), el territorio español se encuentra divido en 13 zonas bioclimáticas (Figura 31). La determinación de la zona bioclimática para localidades que disponen de registros climáticos, se realiza mediante el cálculo de las severidades climáticas de invierno y de verano para dichas localidades (Tabla 26 y Tabla 27).

La severidad climática combina los grados-día y la radiación solar de la localidad, de forma que se puede demostrar que cuando dos localidades tienen la misma severidad climática de invierno (SCI) la demanda energética de calefacción de un mismo edificio situado en ambas localidades es sensiblemente igual. Lo mismo es aplicable para la severidad climática de verano (SCV) (Ministerio de la Vivienda, 2007). 


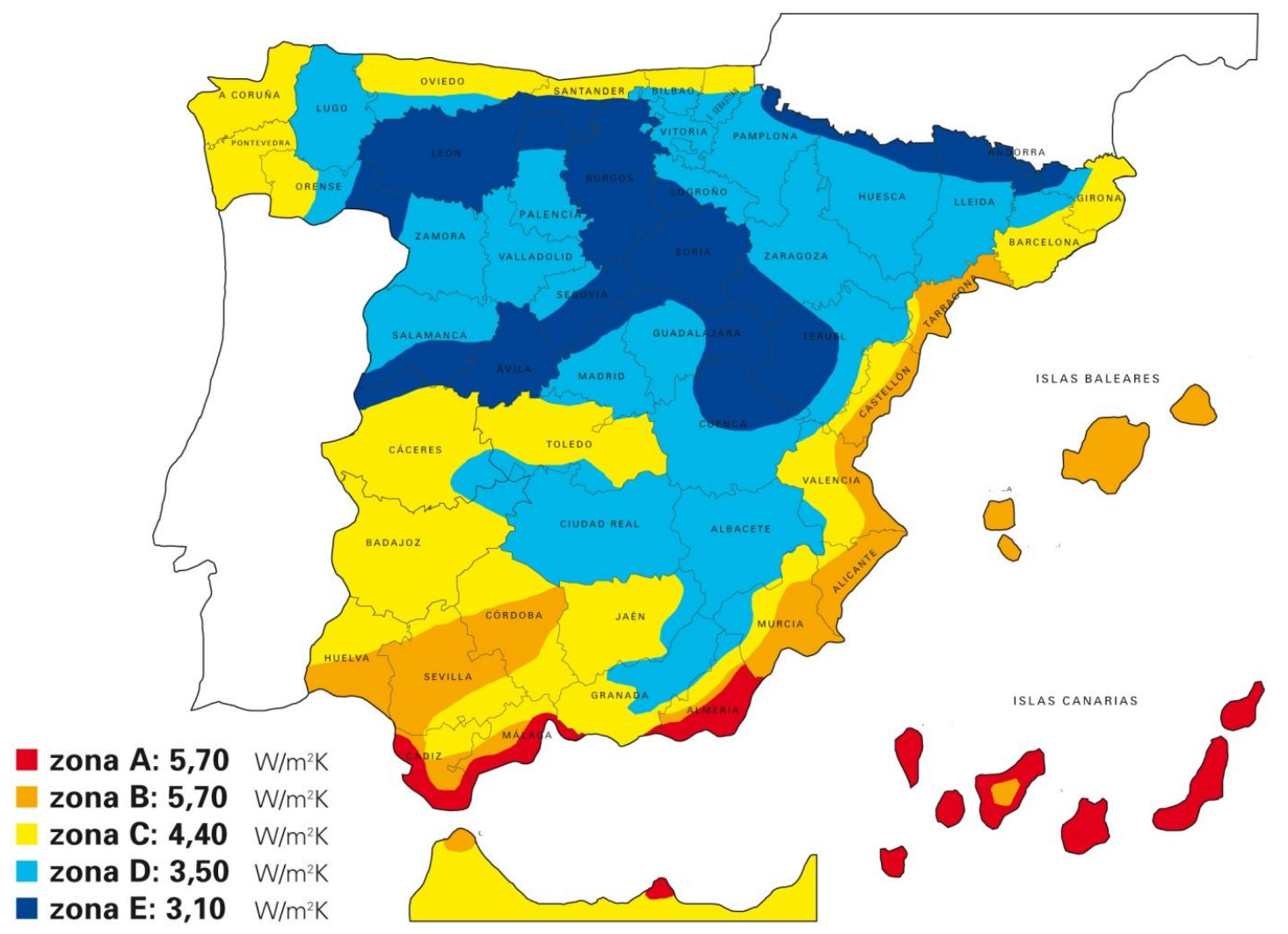

Figura 31: Mapa bioambiental de España. Fuente: (Ministerio de la Vivienda, 2007)

\begin{tabular}{ccccc}
\hline A & B & C & D & E \\
\hline $\mathrm{SCl} \leq 0,3$ & $0,3<\mathrm{SCl} \leq 0,6$ & $0,9<\mathrm{SCl} \leq 0,95$ & $0,95<\mathrm{SCl} \leq 1,3$ & $\mathrm{SCl}>1,3$ \\
\hline
\end{tabular}

Tabla 26: Valores de severidad climática de invierno. Elaboración propia adaptada de (Ministerio de la Vivienda, 2007).

\begin{tabular}{cccc}
\hline $\mathbf{1}$ & $\mathbf{2}$ & $\mathbf{3}$ & $\mathbf{4}$ \\
\hline $\mathrm{SCV} \leq 0,6$ & $0,6<\mathrm{SCV} \leq 0,9$ & $0,9<\mathrm{SCV} \leq 1,25$ & $\mathrm{SCV}>1,25$ \\
\hline
\end{tabular}

Tabla 27: Valores de severidad climática de verano. Elaboración propia adaptada de (Ministerio de la Vivienda, 2007).

Para ciudades que no disponen de la totalidad de los datos necesarios, la zona bioclimática se determina en función de la ubicación del edificio de estudio y la diferencia de altura entre dicha localidad y la altura de referencia de la capital (Tabla 28). 
PARTE I · Delimitación del ámbito de la investigación

\begin{tabular}{|c|c|c|c|c|c|c|c|}
\hline \multirow{2}{*}{ Provincia } & \multirow{2}{*}{ Zona } & \multirow{2}{*}{ Altitud-m } & \multicolumn{5}{|c|}{ Desnivel entre la localidad y la capital de su provincia (m) } \\
\hline & & & $\geq 200<400$ & $\geq 400<600$ & $\geq 600<800$ & $\geq 800<1000$ & $\geq 1000$ \\
\hline Albacete & D3 & 677 & D2 & E1 & E1 & E1 & E1 \\
\hline Alicante & B4 & 7 & C3 & $\mathrm{C} 1$ & D1 & D1 & E1 \\
\hline Almería & A4 & 0 & B3 & B3 & $\mathrm{C} 1$ & $\mathrm{C} 1$ & D1 \\
\hline Ávila & E1 & 1054 & E1 & E1 & E1 & E1 & E1 \\
\hline Badajoz & C4 & 168 & C3 & D1 & D1 & E1 & E1 \\
\hline Barcelona & C2 & 1 & C1 & D1 & D1 & E1 & E1 \\
\hline Bilbao & C1 & 214 & D1 & D1 & E1 & E1 & E1 \\
\hline Burgos & E1 & 861 & E1 & E1 & E1 & E1 & E1 \\
\hline Cáceres & C4 & 385 & D3 & D1 & E1 & E1 & E1 \\
\hline Cádiz & A3 & 0 & B3 & B3 & $\mathrm{C} 1$ & $\mathrm{C} 1$ & D1 \\
\hline Castellón de la Plana & B3 & 18 & $\mathrm{C} 2$ & $\mathrm{C} 1$ & D1 & D1 & E1 \\
\hline Ceuta & B3 & 0 & B3 & $\mathrm{C} 1$ & $\mathrm{C} 1$ & D1 & D1 \\
\hline Ciudad & D3 & 630 & D2 & E1 & E1 & E1 & E1 \\
\hline Córdoba & B4 & 113 & C3 & $\mathrm{C} 2$ & D1 & D1 & E1 \\
\hline Coruña & C1 & 0 & $\mathrm{C} 1$ & D1 & D1 & E1 & E1 \\
\hline Cuenca & D2 & 975 & E1 & E1 & E1 & E1 & E1 \\
\hline San Sebastián & C1 & 5 & D1 & D1 & E1 & E1 & E1 \\
\hline Girona & C2 & 143 & D1 & D1 & E1 & E1 & E1 \\
\hline Granada & C3 & 754 & D2 & D1 & E1 & E1 & E1 \\
\hline Guadalajara & D3 & 708 & D1 & E1 & E1 & E1 & E1 \\
\hline Huelva & B4 & 50 & B3 & $\mathrm{C} 1$ & $\mathrm{C} 1$ & D1 & D1 \\
\hline Huesca & D2 & 432 & E1 & E1 & E1 & E1 & E1 \\
\hline Jaén & C4 & 436 & C3 & D2 & D1 & E1 & E1 \\
\hline León & E1 & 346 & E1 & E1 & E1 & E1 & E1 \\
\hline Lleida & D3 & 131 & D2 & E1 & E1 & E1 & E1 \\
\hline Logroño & D2 & 379 & D1 & E1 & E1 & E1 & E1 \\
\hline Lugo & D1 & 412 & E1 & E1 & E1 & E1 & E1 \\
\hline Madrid & D3 & 589 & D1 & E1 & E1 & E1 & E1 \\
\hline Málaga & A3 & 0 & B3 & $\mathrm{C} 1$ & $\mathrm{C} 1$ & D1 & D1 \\
\hline Melilla & A3 & 130 & B3 & B3 & $\mathrm{C} 1$ & $\mathrm{C} 1$ & D1 \\
\hline Murcia & B3 & 25 & $\mathrm{C} 2$ & $\mathrm{C} 1$ & D1 & D1 & E1 \\
\hline Ourense & C2 & 327 & D1 & E1 & E1 & E1 & E1 \\
\hline Oviedo & C1 & 214 & D1 & D1 & E1 & E1 & E1 \\
\hline Palma de Mallorca & B3 & 1 & B3 & $\mathrm{C} 1$ & $\mathrm{C} 1$ & D1 & D1 \\
\hline Gran canaria & A3 & 114 & A3 & A3 & A3 & B3 & B3 \\
\hline Pamplona & D1 & 456 & E1 & E1 & E1 & E1 & E1 \\
\hline Pontevedra & C1 & 77 & $\mathrm{C} 1$ & D1 & D1 & E1 & E1 \\
\hline Salamanca & D2 & 770 & E1 & E1 & E1 & E1 & E1 \\
\hline Tenerife & A3 & 0 & A3 & A3 & A3 & B3 & B3 \\
\hline Santander & C1 & 1 & $\mathrm{C} 1$ & D1 & D1 & E1 & E1 \\
\hline Segovia & D2 & 1013 & E1 & E1 & E1 & E1 & E1 \\
\hline Sevilla & B4 & 9 & B3 & $\mathrm{C} 2$ & $\mathrm{C} 1$ & D1 & E1 \\
\hline Tarragona & B3 & 1 & $\mathrm{C} 2$ & $\mathrm{C} 1$ & D1 & D1 & E1 \\
\hline Teruel & D2 & 995 & E1 & E1 & E1 & $\mathrm{E} 1$ & E1 \\
\hline Toledo & C4 & 445 & D3 & D2 & E1 & E1 & E1 \\
\hline Valencia & B3 & 8 & C2 & C1 & D1 & D1 & E1 \\
\hline Valladolid & D2 & 704 & E1 & E1 & E1 & E1 & E1 \\
\hline Vitoria-Gasteiz & D1 & 512 & E1 & E1 & E1 & E1 & E1 \\
\hline Zamora & D2 & 617 & E1 & E1 & E1 & E1 & E1 \\
\hline Zaragoza & D3 & 207 & D2 & E1 & E1 & E1 & E1 \\
\hline
\end{tabular}

Tabla 28: Zonas climáticas según diferencia de altitud en relación a la capital de la provincia. Elaboración propia adaptada de (Ministerio de la Vivienda, 2007). 


\subsubsection{México}

En México, a diferencia de Argentina, Brasil, Chile y España los valores de transmitancia térmica están definidos para cada localidad, de manera que el país no posee oficialmente un mapa bioambiental. A continuación se exhiben los valores admisibles para muros exteriores y techos, según la ciudad y el nivel de pisos que posea la edificación (Tabla 29).

\begin{tabular}{|c|c|c|c|}
\hline \multirow{2}{*}{ Ciudad } & \multirow{2}{*}{$\begin{array}{c}\text { Hasta } 3 \\
\text { niveles }\end{array}$} & \multicolumn{2}{|c|}{ + de 3 niveles } \\
\hline & & Techos & Muros \\
\hline Ciudad de México & 0,9 & 0,9 & 0,9 \\
\hline Ecatepec & 0,9 & 0,9 & 0,9 \\
\hline Tijuana & 0,71 & 0,71 & 0,90 \\
\hline Puebla & 0,83 & 0,83 & 0,90 \\
\hline Guadalajara & 0,71 & 0,71 & 0,90 \\
\hline León & 0,71 & 0,71 & 0,90 \\
\hline Juárez & 0,62 & 0,62 & 0,83 \\
\hline Monterrey & 0,55 & 0,55 & 0,71 \\
\hline Nezahualcóyotl & 0,9 & 0,9 & 0,9 \\
\hline Chihuahua & 0,62 & 0,62 & 0,9 \\
\hline Naucalpan de Juárez & 0,9 & 0,9 & 0,9 \\
\hline Mérida & 0,52 & 0,52 & 0,62 \\
\hline San Luis Potosí & 0,83 & 0,83 & 0,90 \\
\hline Aguascalientes & 0,83 & 0,83 & 0,90 \\
\hline Hermosillo & 0,47 & 0,47 & 0,52 \\
\hline Saltillo & 0,83 & 0,83 & 0,90 \\
\hline Mexicali & 0,47 & 0,47 & 0,55 \\
\hline Culiacán Rosales & 0,52 & 0,52 & 0,62 \\
\hline Acapulco de Juárez & 0,52 & 0,52 & 0,62 \\
\hline Tlalnepantla de Baz & 0,9 & 0,9 & 0,9 \\
\hline Cancún & 0,52 & 0,52 & 0,62 \\
\hline Santiago de & 0,83 & 0,83 & 0,90 \\
\hline Chimalhuacán & 0,9 & 0,9 & 0,9 \\
\hline Torreón & 0,52 & 0,52 & 0,62 \\
\hline Morelia & 0,83 & 0,83 & 0,90 \\
\hline Reynosa & 0,52 & 0,52 & 0,62 \\
\hline Tuxtla Gutiérrez & 0,55 & 0,55 & 0,83 \\
\hline Victoria de Durango & 0,83 & 0,83 & 0,90 \\
\hline Toluca de Lerdo & 0,9 & 0,9 & 0,9 \\
\hline Cd López Mateos & 0,9 & 0,9 & 0,9 \\
\hline Cuautitlán Izcalli & 0,9 & 0,9 & 0,9 \\
\hline Heroica Matamoros & 0,55 & 0,55 & 0,83 \\
\hline Veracruz & 0,52 & 0,52 & 0,62 \\
\hline Tlaxcala & 0,90 & 0,90 & 0,90 \\
\hline
\end{tabular}

\begin{tabular}{|c|c|c|c|}
\hline \multirow{2}{*}{ Ciudad } & \multirow{2}{*}{$\begin{array}{c}\text { Hasta } 3 \\
\text { niveles }\end{array}$} & \multicolumn{2}{|c|}{+ de 3 niveles } \\
\hline & & Techos & Muros \\
\hline Jalapa & 0,71 & 0,71 & 0,90 \\
\hline Mazatlán & 0,52 & 0,52 & 0,62 \\
\hline Nuevo Laredo & 0,52 & 0,52 & 0,55 \\
\hline Xico & 0,9 & 0,9 & 0,9 \\
\hline Villahermosa & 0,52 & 0,52 & 0,55 \\
\hline Cuernavaca & 0,71 & 0,71 & 0,90 \\
\hline Tepic & 0,71 & 0,71 & 0,90 \\
\hline Ixtapaluca & 0,9 & 0,9 & 0,9 \\
\hline Victoria & 0,52 & 0,52 & 0,62 \\
\hline Obregón & 0,52 & 0,52 & 0,62 \\
\hline Tampico & 0,52 & 0,52 & 0,62 \\
\hline $\begin{array}{l}\text { Villa Nicolás } \\
\text { Romero }\end{array}$ & 0,9 & 0,9 & 0,9 \\
\hline Ensenada & 0,9 & 0,9 & 0,9 \\
\hline $\begin{array}{l}\text { San Francisco } \\
\text { Coacalco }\end{array}$ & 0,9 & 0,9 & 0,9 \\
\hline Uruapan & 0,83 & 0,83 & 0,90 \\
\hline Los Mochis & 0,52 & 0,52 & 0,62 \\
\hline Pachuca de Soto & 0,90 & 0,90 & 0,90 \\
\hline Oaxaca de Juárez & 0,71 & 0,71 & 0,90 \\
\hline Tehuacán & 0,71 & 0,71 & 0,90 \\
\hline Ojo de Agua & 0,9 & 0,9 & 0,9 \\
\hline Coatzacoalcos & 0,52 & 0,52 & 0,62 \\
\hline $\begin{array}{l}\text { San Francisco de } \\
\text { Campeche }\end{array}$ & 0,52 & 0,52 & 0,62 \\
\hline Monclova & 0,52 & 0,52 & 0,62 \\
\hline La Paz & 0,52 & 0,52 & 0,71 \\
\hline Heroica Nogales & 0,71 & 0,71 & 0,90 \\
\hline Buenavista & 0,9 & 0,9 & 0,9 \\
\hline Puerto Vallarta & 0,52 & 0,52 & 0,62 \\
\hline Tapachula & 0,52 & 0,52 & 0,71 \\
\hline Chilpancingo & 0,71 & 0,71 & 0,90 \\
\hline Guanajuato & 0,71 & 0,71 & 0,90 \\
\hline Chetumal & 0,52 & 0,52 & 0,62 \\
\hline Zacatecas & 0,90 & 0,90 & 0,90 \\
\hline Colima & 0,55 & 0,55 & 0,90 \\
\hline
\end{tabular}

Tabla 29: Valores de transmitancia térmica (W/m2.K). Elaboración propia adaptada de (Secretaría de Energía 2011). 


\subsubsection{Definición de las soluciones constructivas}

Una vez conocidos los valores de $U$ para muros y techos requeridos por cada país, se asignaron los valores correspondientes a cada ciudad de la muestra definida en el apartado 5.1 Selección de las localidades de aplicación (Tabla 30) y se establecieron cinco Escenarios de Cálculo para muros y techos, los cuales serán asignados a los modelos energéticos en la etapa de simulación energética.

\begin{tabular}{|c|c|c|c|c|c|}
\hline País & $\mathbf{N}$ & Ciudad & Zona climática & U para Fachadas & U para Cubiertas \\
\hline \multirow{10}{*}{ 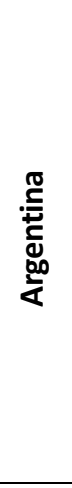 } & 1 & Buenos Aires & IIla & 1.00 & 0.48 \\
\hline & 2 & Catamarca & Ila & 0.90 & 0.45 \\
\hline & 3 & Córdoba & Illa & 0.86 & 0.48 \\
\hline & 4 & Corrientes & $\mathrm{lb}$ & 1.00 & 0.45 \\
\hline & 5 & La Plata & IIIb & 0.95 & 0.48 \\
\hline & 6 & La Rioja & la & 0.93 & 0.45 \\
\hline & 7 & Mar del Plata & IVc & 0.85 & 0.48 \\
\hline & 8 & Paraná & Ilb & 0.99 & 0.45 \\
\hline & 9 & Rosario & Illa & 0.87 & 0.48 \\
\hline & 10 & Santiago del Estero & la & 0.83 & 0.45 \\
\hline \multirow{8}{*}{$\begin{array}{l}\overline{\bar{n}} \\
\overline{0} \\
\bar{\infty}\end{array}$} & 11 & Blumenau & 3 & 3.7 & 2.3 \\
\hline & 12 & Chapecó & 3 & 3.7 & 2.3 \\
\hline & 13 & Criciúma & 3 & 3.7 & 2.3 \\
\hline & 14 & Curitiba & 1 & 2.5 & 2.3 \\
\hline & 15 & Florianópolis & 3 & 3.7 & 2.3 \\
\hline & 16 & Ponta Grossa & 2 & 2.5 & 2.3 \\
\hline & 17 & Porto Alegre & 3 & 3.7 & 2.3 \\
\hline & 18 & Santa Maria & 2 & 2.5 & 2.3 \\
\hline \multirow{6}{*}{$\stackrel{\stackrel{o}{C}}{\mathcal{C}}$} & 19 & Antofagasta & $\mathrm{NL}$ & 2.6 & 0.8 \\
\hline & 20 & Concepción & SL & 1.8 & 1 \\
\hline & 21 & Copiacó & NVT & 2.1 & 0.8 \\
\hline & 22 & Santiago & $\mathrm{Cl}$ & 2 & 0.9 \\
\hline & 23 & Temuco & SI & 1.7 & 0.9 \\
\hline & 24 & Valparaíso & $\mathrm{CL}$ & 2 & 0.9 \\
\hline \multirow{9}{*}{ 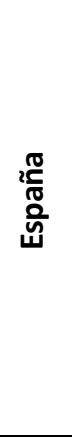 } & 25 & Alicante & B4 & 0.82 & 0.45 \\
\hline & 26 & Barcelona & $\mathrm{C} 2$ & 0.73 & 0.41 \\
\hline & 27 & Córdoba & B4 & 0.82 & 0.45 \\
\hline & 28 & Granada & $\mathrm{C} 3$ & 0.73 & 0.41 \\
\hline & 29 & Málaga & A3 & 0.94 & 0.5 \\
\hline & 30 & Murcia & B3 & 0.82 & 0.45 \\
\hline & 31 & Palma & B3 & 0.82 & 0.45 \\
\hline & 32 & Sevilla & B4 & 0.82 & 0.45 \\
\hline & 33 & Valencia & B3 & 0.82 & 0.45 \\
\hline \multirow{9}{*}{ 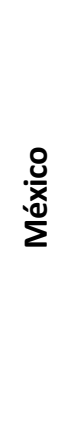 } & 34 & Aguascalientes & - & 0,83 & 0,83 \\
\hline & 35 & Ciudad de Mexico & - & 0,9 & 0,9 \\
\hline & 36 & Guadalajara & - & 0,71 & 0,71 \\
\hline & 37 & Hermosillo & - & 0,47 & 0,47 \\
\hline & 38 & Juárez & - & 0,62 & 0,62 \\
\hline & 39 & León & - & 0,71 & 0,71 \\
\hline & 40 & Monterrey & - & 0,55 & 0,55 \\
\hline & 41 & Puebla & - & 0,83 & 0,83 \\
\hline & 42 & Tijuana & - & 0,71 & 0,71 \\
\hline
\end{tabular}

Tabla 30: Valores de transmitancia de muros y techos en función del código normativo del país. Elaboración propia. 
Se observó que las regulaciones y certificaciones en Argentina, Brasil, Chile y España establecen los valores de $U$ en función de la zona climática del edificio analizado. Para el caso de Argentina existe una diferencia entre los valores de $U$ para invierno y verano, entretanto se consideró el valor más restrictivo para cumplir ambas situaciones.

En México, estos valores se encuentran definidos para determinadas localidades de forma específica, ya que el país no posee oficialmente una clasificación climática. Además, realiza una diferenciación para edificios construidos con más de 3 pisos, por lo tanto, se adoptó el valor más restrictivo para cumplir con todas las situaciones.

Para la construcción de los Escenarios, primeramente se fijó que la tipología constructiva del Caso de Estudio real situado en Criciúma, consistiría el Escenario I ya que ésta tipología también es empleada tradicionalmente en Latinoamérica. Dado que la solución constructiva tradicional en España presenta un nivel de desempeño térmico superior a la solución Latinoamericana, y se acerca a los valores mínimos de U establecidos por cada país, se consideró que esta tipología consistiría el Escenario V.

Para los demás Escenarios se agruparon los valores de $U$ admisibles en grupos con rangos similares, excluyendo los valores que cumplían con el Escenario I y el Escenario V, y se construyeron los nuevos elementos. Al muro del Escenario V se substituyó el poliuretano proyectado por el EIFS, buscando crear una solución más asequible para el contexto de la construcción en Latinoamérica.

La Tabla 31 y la Tabla 32 exhiben los Escenarios creados. El valor de transmitancia térmica establecido para los muros es $1.823 \mathrm{~W} / \mathrm{m}^{2} \mathrm{~K}$ para el Escenario II, $1.101 \mathrm{~W} / \mathrm{m}^{2} \mathrm{~K}$ para el Escenario III, $0.821 \mathrm{~W} / \mathrm{m}^{2} \mathrm{~K}$ para el Escenario IV, y $0.503 \mathrm{~W} / \mathrm{m}^{2} \mathrm{~K}$ para el Escenario V. Para las cubiertas es $0.854 \mathrm{~W} / \mathrm{m}^{2} \mathrm{~K}$ para el Escenario II, $0.680 \mathrm{~W} / \mathrm{m}^{2} \mathrm{~K}$ para el Escenario III, $0.526 / \mathrm{m}^{2} \mathrm{~K}$ para el Escenario IV, y $0.405 \mathrm{~W} / \mathrm{m}^{2} \mathrm{~K}$ para el Escenario $\mathrm{V}$ (Figura 32).

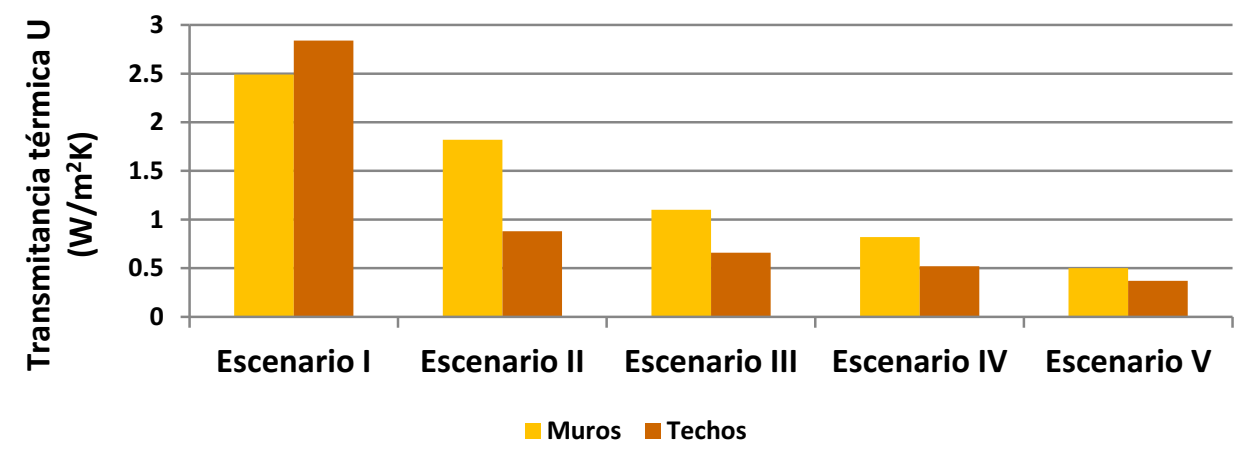

Figura 32: Valores de transmitancia térmica U de muros y techos para cada escenario de cálculo. Elaboración propia.

Buscando controlar el surgimiento de patologías futuras, que llevan al comprometimiento del comportamiento de los aislantes térmicos, caso estos elementos fuesen aplicados en la realidad, se analizaron las posibilidades de riesgo de condensación en los diferentes escenarios. Se verificó que en condiciones normales climatológicas, no se producirán condensaciones superficiales e intersticiales, tanto en los muros exteriores como en las cubiertas (Figura 33). 
PARTE I · Delimitación del ámbito de la investigación

\begin{tabular}{|c|c|c|c|}
\hline Muro II & Espesor e (m) & $\begin{array}{c}\text { Coeficiente de } \\
\text { Conductividad } \lambda \\
(\mathrm{W} / \mathrm{mk})\end{array}$ & $\begin{array}{c}\text { Resistencia } \\
\text { Térmica } R \\
\left(M^{2} k / W\right)=E / \lambda \\
\end{array}$ \\
\hline Resistencia superficial interna & - & - & 0.12 \\
\hline Mortero de cemento & 0.015 & 1.3 & 0.0115 \\
\hline Ladrillo cerámico & 0.1 & - & 0.1750 \\
\hline Revoque & 0.02 & 1.3 & 0.0154 \\
\hline Ladrillo cerámico & 0.1 & - & 0.1750 \\
\hline Mortero de cemento & 0.015 & 1.3 & 0.0115 \\
\hline Resistencia superficial externa & - & - & 0.04 \\
\hline Resistencia térmica total & & & $0.548\left(\mathrm{~m}^{2} \mathrm{~K} / \mathrm{W}\right)$ \\
\hline \multicolumn{2}{|c|}{ Coeficiente de transmitancia térmica $U(1 / R)$} & & $1.823\left(\mathrm{~W} / \mathrm{m}^{2} \mathrm{~K}\right)$ \\
\hline Muro III & Espesor e (m) & $\begin{array}{l}\text { Coeficiente de } \\
\text { Conductividad } \lambda \\
\text { (w/mk) }\end{array}$ & $\begin{array}{c}\text { Resistencia } \\
\text { Térmica } R \\
\left(\mathrm{~m}^{2} \mathrm{k} / \mathrm{w}\right)=\mathrm{e} / \lambda\end{array}$ \\
\hline Resistencia superficial interna & - & - & 0.12 \\
\hline Mortero de cemento & 0.02 & 1.3 & 0.0154 \\
\hline Ladrillo cerámico & 0.12 & - & 0.2400 \\
\hline Revoque & 0.02 & 1.3 & 0.0154 \\
\hline Ladrillo cerámico & 0.12 & - & 0.2400 \\
\hline Poliestireno expandido $20 \mathrm{Kg} / \mathrm{m}^{3}$ & 0.015 & 0.07 & 0.2143 \\
\hline Mortero de cemento & 0.03 & 1.3 & 0.0231 \\
\hline Resistencia superficial externa & - & - & 0.04 \\
\hline Resistencia térmica total & & & $0.908\left(\mathrm{~m}^{2} \mathrm{~K} / \mathrm{W}\right)$ \\
\hline \multicolumn{2}{|c|}{ Coeficiente de transmitancia térmica $U(1 / R)$} & & $1.101\left(\mathrm{~W} / \mathrm{m}^{2} \mathrm{~K}\right)$ \\
\hline Muro IV & Espesor e (m) & $\begin{array}{c}\text { Coeficiente de } \\
\text { Conductividad } \lambda \\
\text { (w/mk) }\end{array}$ & $\begin{array}{c}\text { Resistencia } \\
\text { Térmica } R \\
\left(\mathrm{~m}^{2} \mathrm{k} / \mathrm{w}\right)=\mathrm{e} / \lambda\end{array}$ \\
\hline Resistencia superficial interna & - & - & 0.12 \\
\hline Mortero de cemento & 0.02 & 1.3 & 0.0154 \\
\hline Ladrillo cerámico & 0.15 & - & 0.3200 \\
\hline Fibra de vidrio & 0.035 & 0.05 & 0.7000 \\
\hline Mortero de cemento & 0.03 & 1.3 & 0.0231 \\
\hline Resistencia superficial externa & - & - & 0.04 \\
\hline Resistencia térmica total & & & $1.218\left(\mathrm{~m}^{2} \mathrm{~K} / \mathrm{W}\right)$ \\
\hline \multicolumn{2}{|c|}{ Coeficiente de transmitancia térmica U (1/R) } & & $0.821(\mathrm{~W} / \mathrm{m} 2 \mathrm{~K})$ \\
\hline Muro V & Espesor e (m) & $\begin{array}{c}\text { Coeficiente de } \\
\text { Conductividad } \lambda \\
\text { (w/mk) }\end{array}$ & $\begin{array}{c}\text { Resistencia } \\
\text { Térmica R } \\
\left(\mathrm{m}^{2} \mathrm{k} / \mathrm{w}\right)=\mathrm{e} / \lambda\end{array}$ \\
\hline Resistencia superficial interna & - & - & 0.12 \\
\hline Mortero de cemento & 0.02 & 1.3 & 0.0154 \\
\hline Ladrillo cerámico & 0.15 & - & 0.3200 \\
\hline Poliestireno expandido $30 \mathrm{Kg} / \mathrm{m}^{3}$ & 0.05 & 0.035 & 1.4286 \\
\hline Malla y adhesivo (cemento adhesivo) & 0.008 & 0.2 & 0.0400 \\
\hline Mortero de cemento & 0.03 & 1.3 & 0.0231 \\
\hline Resistencia superficial externa & - & - & 0.04 \\
\hline \multicolumn{2}{|c|}{ Resistencia térmica total } & & $1.987\left(\mathrm{~m}^{2} \mathrm{~K} / \mathrm{W}\right)$ \\
\hline \multicolumn{2}{|c|}{ Coeficiente de transmitancia térmica U (1/R) } & & $0.503\left(\mathrm{~W} / \mathrm{m}^{2} \mathrm{~K}\right)$ \\
\hline
\end{tabular}

Tabla 31: Composición de los cuatro modelos de muros exteriores. Elaboración propia. 
PARTE I · Delimitación del ámbito de la investigación

\begin{tabular}{|c|c|c|c|}
\hline Techo II & Espesor e (m) & $\begin{array}{c}\text { Coeficiente de } \\
\text { Conductividad } \lambda \\
\text { (W/mk) }\end{array}$ & $\begin{array}{c}\text { Resistencia } \\
\text { Térmica } \mathrm{R} \\
\left(\mathrm{M}^{2} \mathrm{k} / \mathrm{W}\right)=\mathrm{E} / \lambda\end{array}$ \\
\hline Resistencia superficial interna & - & - & 0.12 \\
\hline Mortero de cemento & 0.025 & 1.3 & 0.0192 \\
\hline Fibra de vidrio & 0.035 & 0.05 & 0.7000 \\
\hline Losa hormigón & 0.15 & 0.62 & 0.2419 \\
\hline Canto rodado & 0.05 & 1 & 0.0500 \\
\hline Resistencia superficial externa & - & - & 0.04 \\
\hline Resistencia térmica total & & & $1.171\left(\mathrm{~m}^{2} \mathrm{~K} / \mathrm{W}\right)$ \\
\hline \multicolumn{3}{|l|}{ Coeficiente de transmitancia térmica $U$ (1/R) } & $0.854\left(\mathrm{~W} / \mathrm{m}^{2} \mathrm{~K}\right)$ \\
\hline Techo III & Espesor e (m) & $\begin{array}{c}\text { Coeficiente de } \\
\text { Conductividad } \lambda \\
\text { (w/mk) }\end{array}$ & $\begin{array}{c}\text { Resistencia } \\
\text { Térmica } R \\
\left(\mathrm{~m}^{2} \mathrm{k} / \mathrm{w}\right)=\mathrm{e} / \lambda \\
\end{array}$ \\
\hline Resistencia superficial interna & - & - & 0.12 \\
\hline Mortero de cemento & 0.025 & 1.3 & 0.0192 \\
\hline Fibra de vidrio & 0.05 & 0.05 & 1.0000 \\
\hline Losa hormigón & 0.15 & 0.62 & 0.2419 \\
\hline Canto rodado & 0.05 & 1 & 0.0500 \\
\hline Resistencia superficial externa & - & - & 0.04 \\
\hline Resistencia térmica total & & & $1.471\left(\mathrm{~m}^{2} \mathrm{~K} / \mathrm{W}\right)$ \\
\hline Coeficiente de transmitancia térmica $U(1 / \mathrm{F}$ & & & $0.680\left(\mathrm{~W} / \mathrm{m}^{2} \mathrm{~K}\right)$ \\
\hline
\end{tabular}

\begin{tabular}{|c|c|c|c|}
\hline Techo IV & Espesor e (m) & $\begin{array}{c}\text { Coeficiente de } \\
\text { Conductividad } \lambda \\
\text { (w/mk) }\end{array}$ & $\begin{array}{c}\text { Resistencia } \\
\text { Térmica } R \\
\left(\mathrm{~m}^{2} \mathrm{k} / \mathrm{w}\right)=\mathrm{e} / \lambda\end{array}$ \\
\hline Resistencia superficial interna & - & - & 0.12 \\
\hline Mortero de cemento & 0.025 & 1.3 & 0.0192 \\
\hline Poliestireno expandido $30 \mathrm{Kg} / \mathrm{m}^{3}$ & 0.05 & 0.035 & 1.4286 \\
\hline Losa hormigón & 0.15 & 0.62 & 0.2419 \\
\hline Canto rodado & 0.05 & 1 & 0.0500 \\
\hline Resistencia superficial externa & - & - & 0.04 \\
\hline Resistencia térmica total & & & $1.900\left(\mathrm{~m}^{2} \mathrm{~K} / \mathrm{W}\right)$ \\
\hline \multicolumn{3}{|c|}{ Coeficiente de transmitancia térmica U (1/R) } & $0.526(\mathrm{~W} / \mathrm{m} 2 \mathrm{~K})$ \\
\hline Techo IV & Espesor e (m) & $\begin{array}{c}\text { Coeficiente de } \\
\text { Conductividad } \lambda \\
(w / m k)\end{array}$ & $\begin{array}{c}\text { Resistencia } \\
\text { Térmica } R \\
\left(\mathrm{~m}^{2} \mathrm{k} / \mathrm{w}\right)=\mathrm{e} / \lambda \\
\end{array}$ \\
\hline Resistencia superficial interna & - & - & 0.12 \\
\hline Mortero de cemento & 0.025 & 1.3 & 0.0192 \\
\hline Fibra de vidrio & 0.1 & 0.05 & 2.0000 \\
\hline Losa hormigón & 0.15 & 0.62 & 0.2419 \\
\hline Canto rodado & 0.05 & 1 & 0.0500 \\
\hline Resistencia superficial externa & - & - & 0.04 \\
\hline \multicolumn{3}{|c|}{ Resistencia térmica total } & $2.471\left(\mathrm{~m}^{2} \mathrm{~K} / \mathrm{W}\right)$ \\
\hline \multicolumn{3}{|c|}{ Coeficiente de transmitancia térmica $U(1 / R)$} & $0.405(\mathrm{~W} / \mathrm{m} 2 \mathrm{~K})$ \\
\hline
\end{tabular}

Tabla 32: Composición de los cuatro modelos de cubiertas. Elaboración propia. 


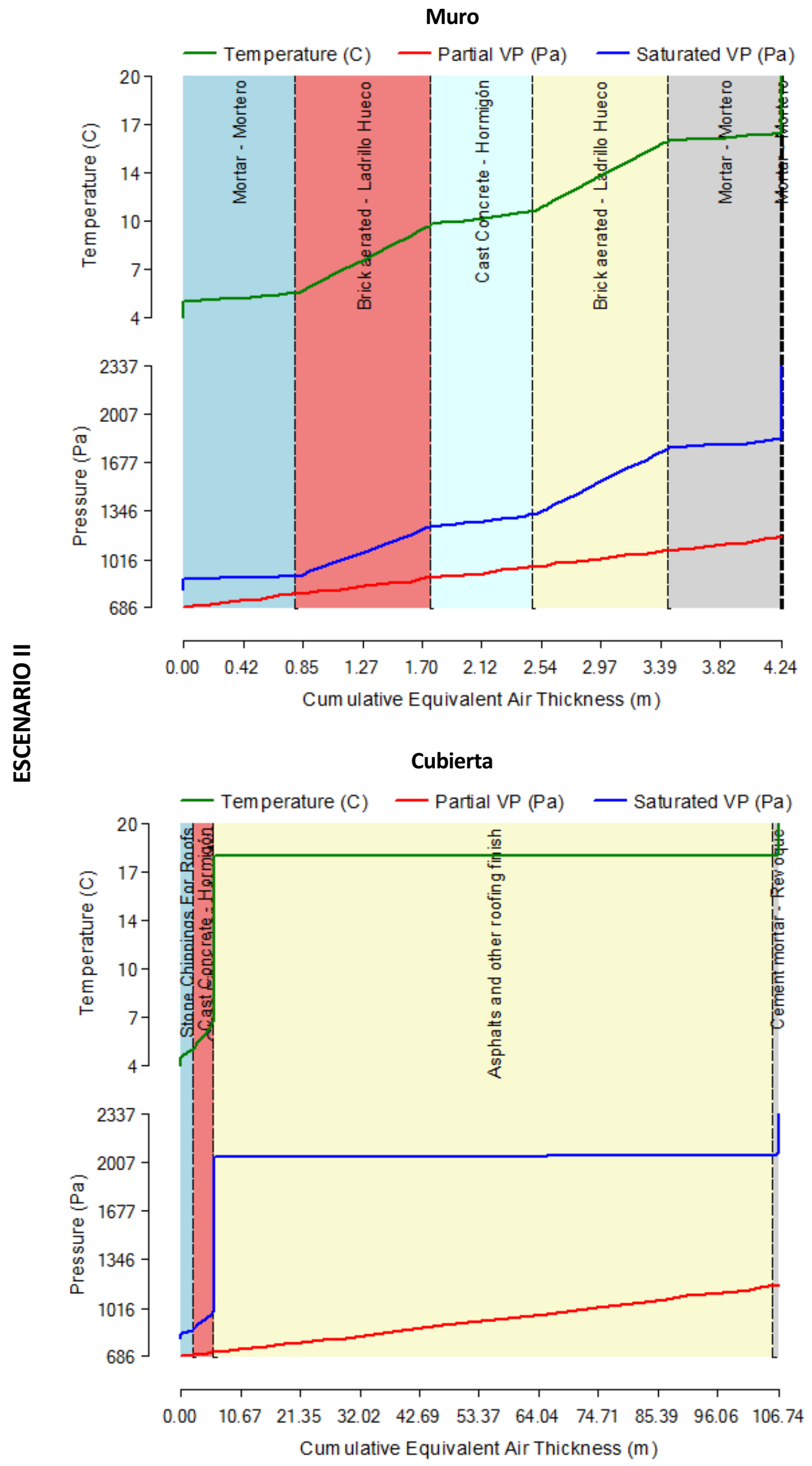


PARTE I · Delimitación del ámbito de la investigación

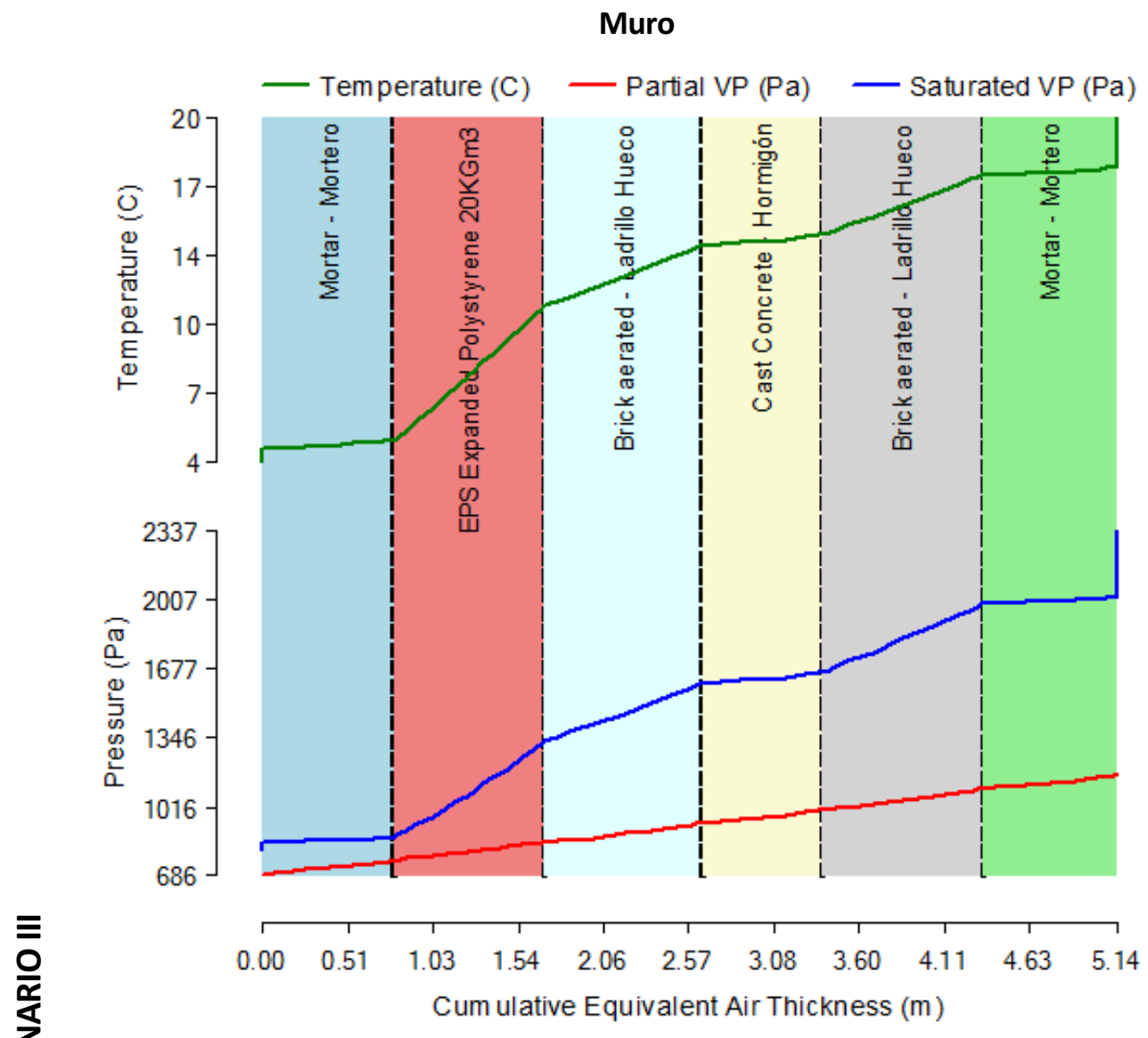

\section{Cubierta}

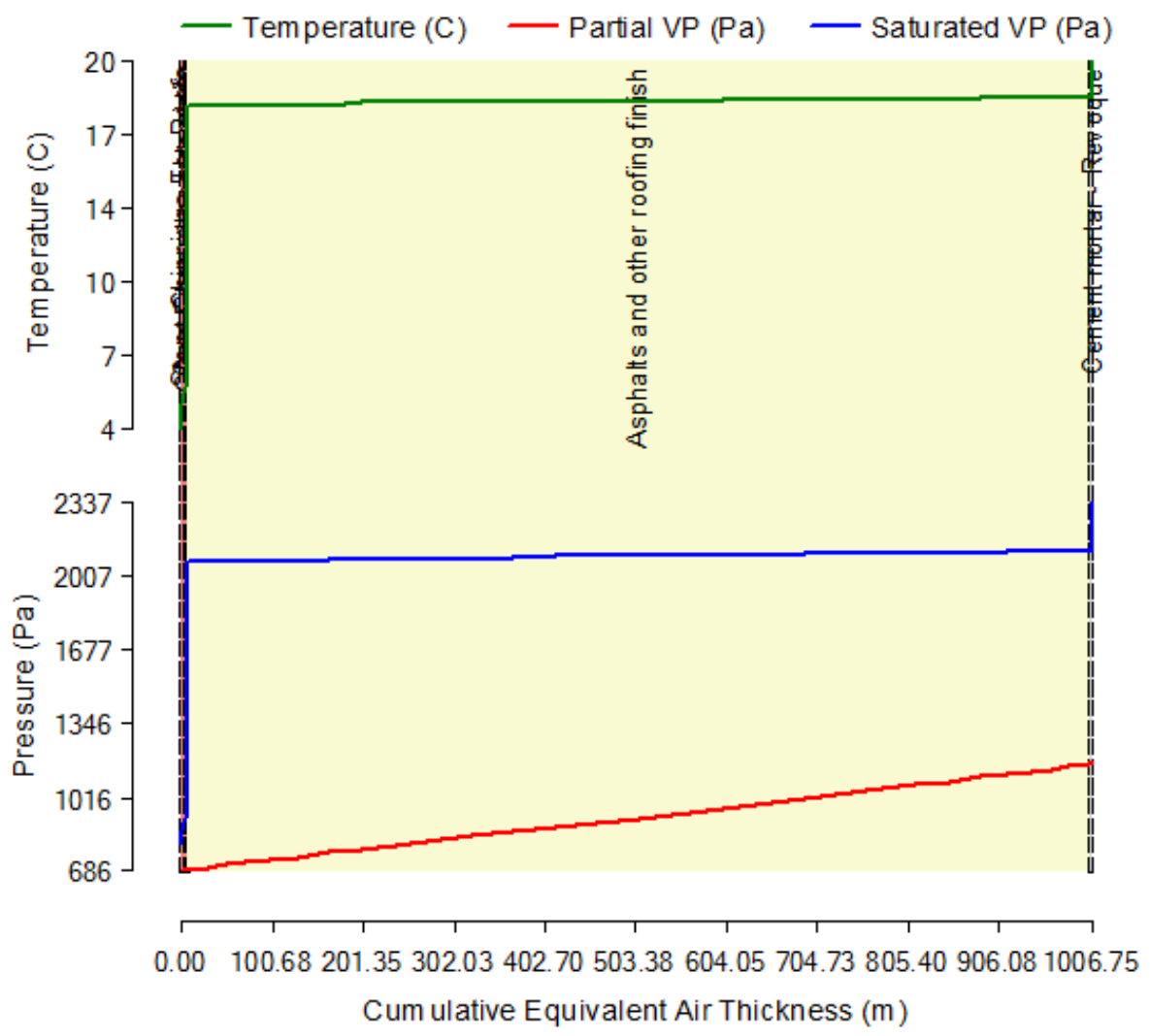




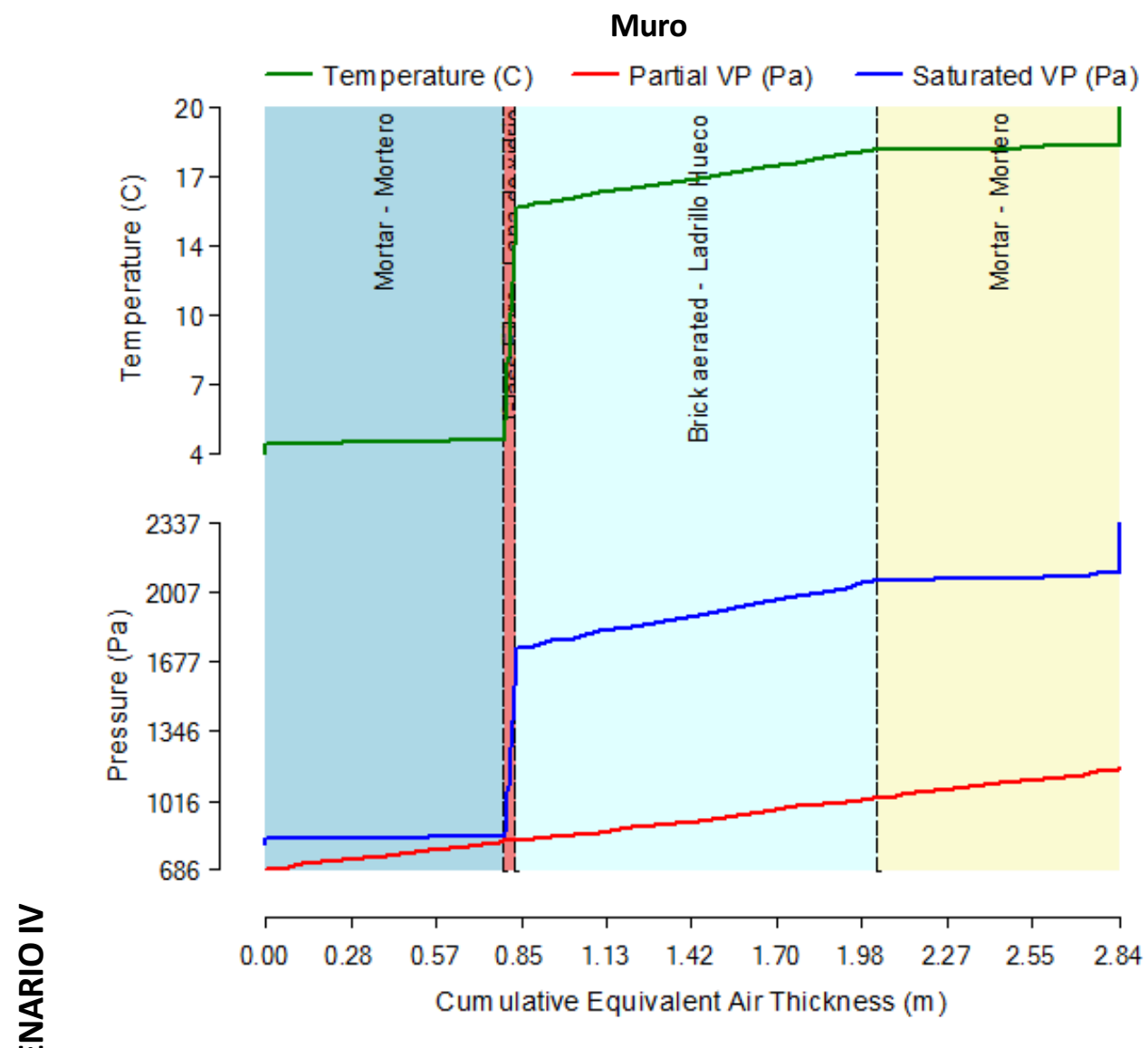

\section{Cubierta}

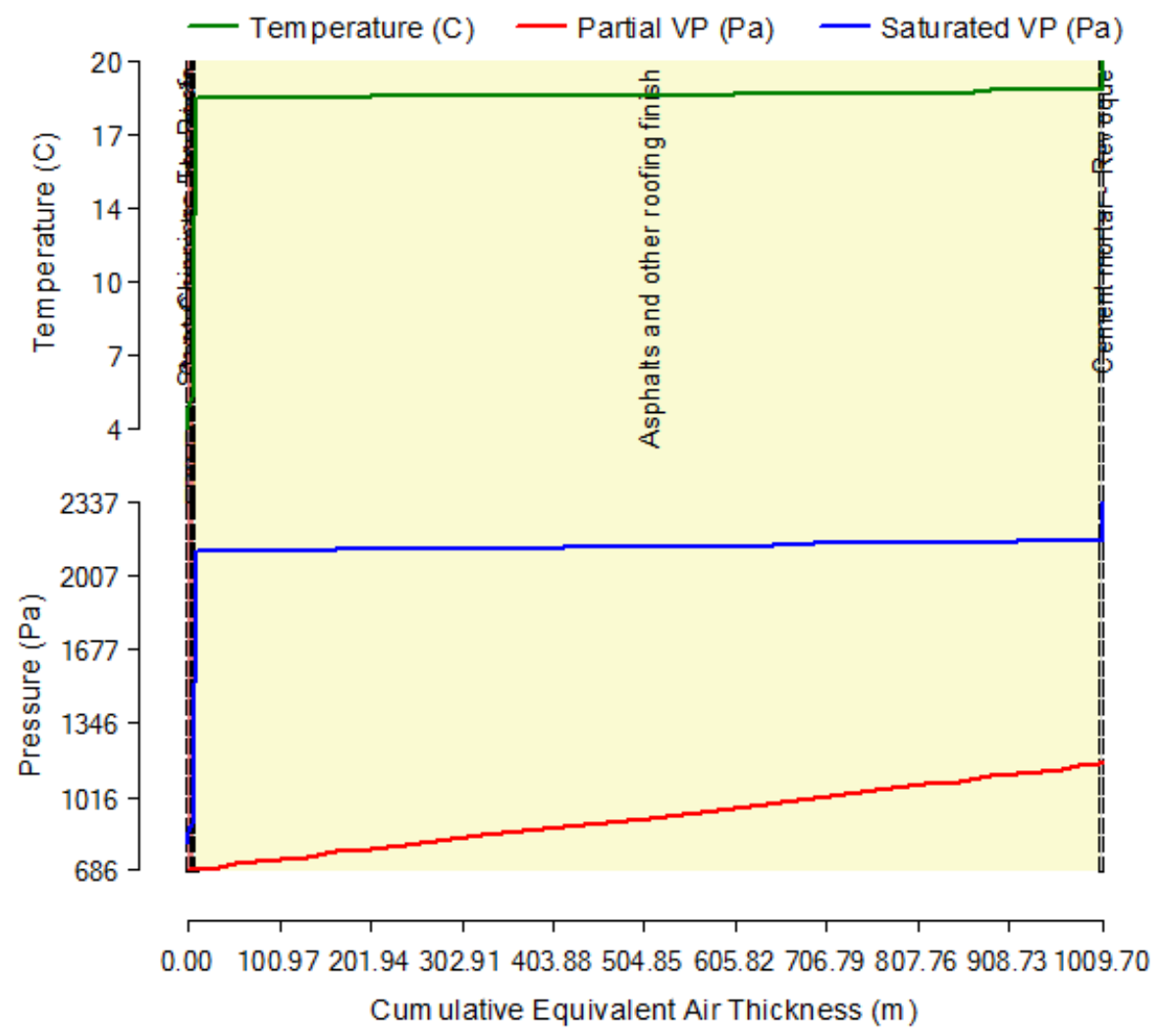


PARTE I · Delimitación del ámbito de la investigación

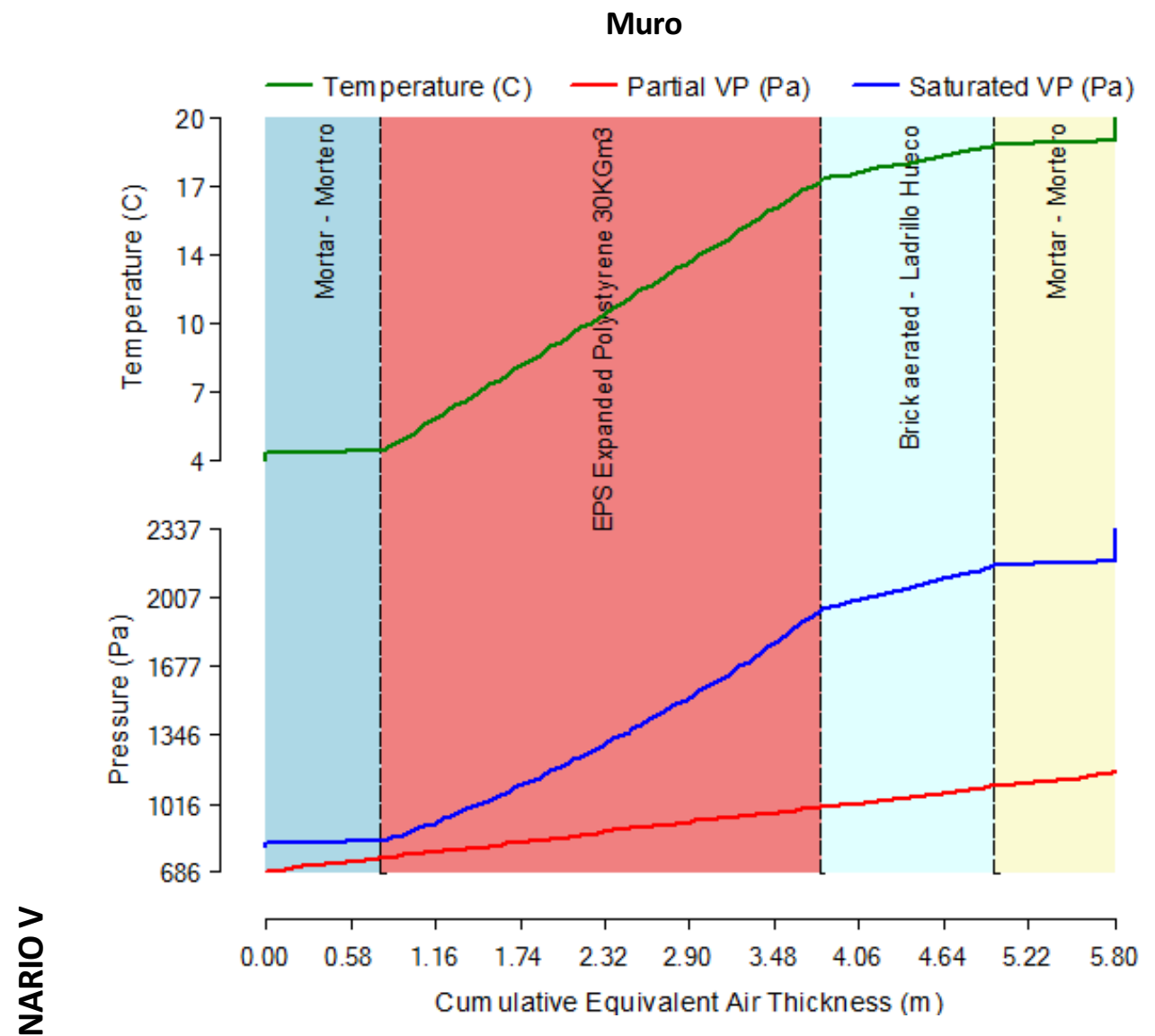

Cubierta

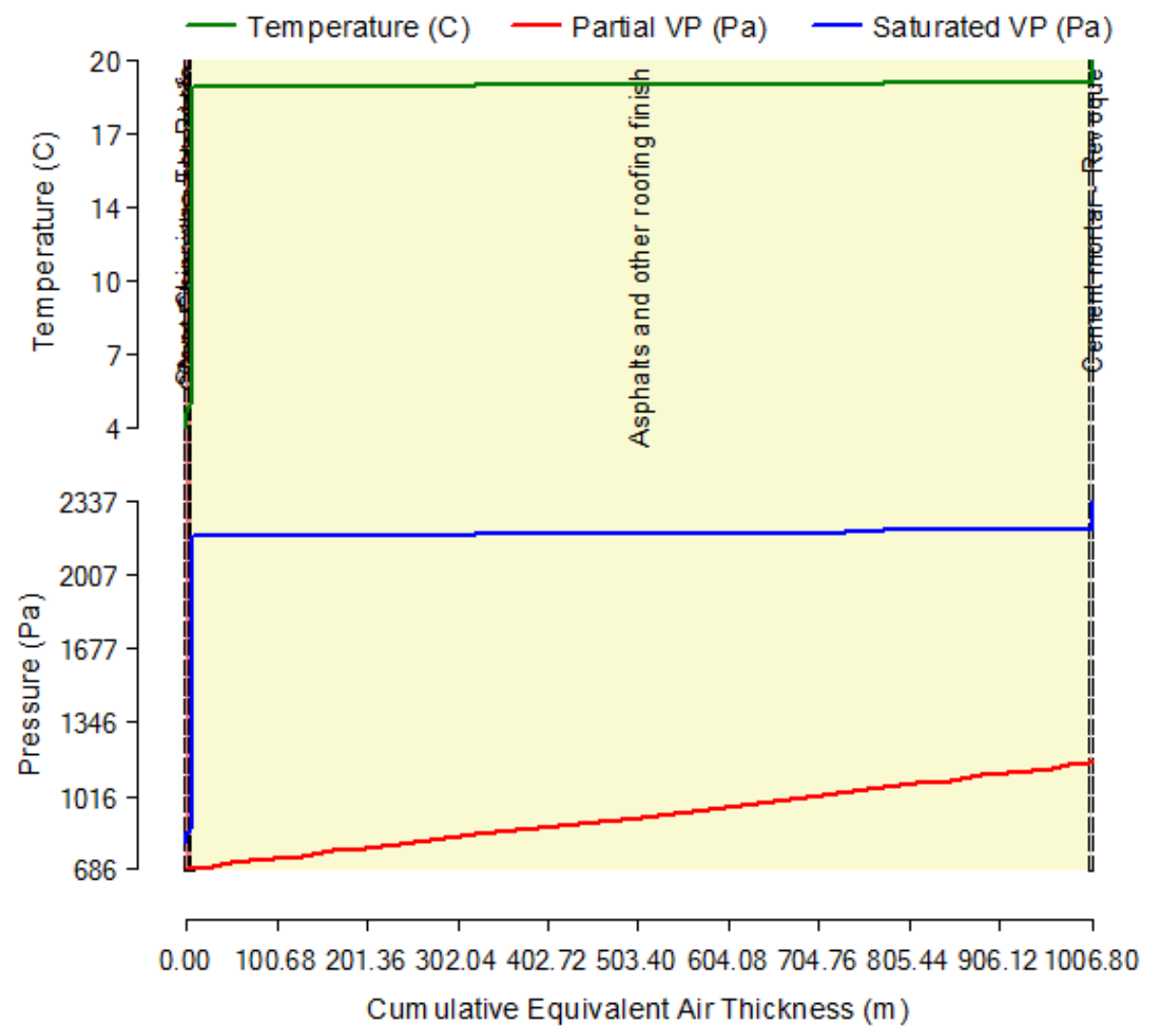

Figura 33: Análisis de riesgo de condensación en los cerramientos opacos de los diferentes escenarios. Fuente: Design Builder 


\section{Conclusiones}

El desarrollo de esta etapa permitió comprender el enfoque que cada iniciativa de calificación edilicia en Latinoamérica establece sobre los criterios de confort térmico y eficiencia energética dentro de cada herramienta. Se logró realizar una comparación entre los parámetros observados en cada caso, posibilitando definir los sistemas y los indicadores aplicados en esta investigación.

En un segundo momento ha sido posible revisar las estrategias y los programas enfocados en la problemática habitacional existente en cada uno de los países seleccionados. Se identificó un programa destinado a la construcción de edificios de vivienda a gran escala, permitiendo definir las tipologías representativas para asignar a los Casos de Estudio de este trabajo.

A continuación se identificaron los valores admisibles para la transmitancia térmica - $U$ de muros y techos exteriores establecidos por cada país, lo que permitió definir los diferentes elementos constructivos posibles de emplear en los Escenarios de Cálculo.

A modo de resumen se rescatan las siguientes consideraciones principales:

I. La definición de los sistemas de calificación aplicables a este estudio se fundamentó en seleccionar iniciativas existentes en Latinoamérica, además de un sistema de referencia con el fin de comprobar si es posible generalizar el rendimiento de edificios situados en localidades con clima templado (Figura 16).

II. Se consideraron las iniciativas de Latinoamérica destinadas a edificios residenciales, con definiciones objetivas sobre los criterios de confort y eficiencia térmica requeridos. Además, se consideraron los países con al menos 5 localidades con clima templado y disponibilidad de archivo climático en extensión EPW.

III. Los sistemas seleccionados han sido las Normas de Acondicionamiento Térmico de Argentina (Departamento de Infraestructura 2010), el etiquetado Programa Brasileiro de Etiquetagem de Edificios de Brasil (Eletrobras 2013), la Etiqueta de Calificación Energética de Viviendas de Chile (Ministerio de Vivienda y Urbanismo 2016) y la Normativa de Edificación Sustentable de México (Secretaría del Medio Ambiente 2012).

IV. El modelo referente internacional elegido ha sido el Código técnico de Edificaciones de España (Ministerio de la Vivienda 2006).

V. Se realizó una reestructuración de los criterios de confort y eficiencia energética definidos por cada uno de los sistemas seleccionados, considerando inicialmente todos los criterios de confort térmico y aquellos criterios de eficiencia energética que incidan en las decisiones de diseño del edificio y en las características constructivas de la envolvente (Tabla 13).

VI. La transmitancia térmica para los cerramientos opacos consiste en el único parámetro común exigido por las iniciativas seleccionadas. 
VII. El Programa Minha Casa Minha Vida - MCMV consiste en la iniciativa de construcción habitacional más representativa encontrada en Latinoamérica.

VIII. Se seleccionaron dos tipologías de edificios residenciales estandarizadas por el Programa MCMV, a las cuales se denominaron Caso I - vivienda unifamiliar y Caso II - edificio de vivienda multifamiliar en altura (Figura 20 y Figura 21).

IX. Se identificaron los valores de transmitancia térmica para muros y techos exteriores para cada una de las 42 localidades seleccionadas en 5.1 Selección de las localidades de aplicación (Tabla 30).

X. Para atender a los estándares de confort definido por Argentina, Brasil, Chile, México y España, se definieron cinco modelos de muros y techos, con diferentes materiales y características térmicas, a los cuales se los denominaron Escenario I, II, III, IV, y V respectivamente (Tabla 31 y Tabla 32).

XI. Se decidió que la tipología con la cual están construidos los Casos de Estudio corresponde al Escenario I, en cuanto la tipología constructiva tradicional de España corresponde al Escenario V (Figura 26 y Figura 27).

XII. Las variables modificadas para los materiales trabajados fueron la conductividad térmica, el calor específico, y la densidad, considerando para las demás propiedades térmicas, valores pre definidos por la biblioteca de Design Builder (ANEXO III - Tomo II). 


\section{Características climáticas}

\section{Objetivo}

En esta etapa se identificarán las ciudades más pobladas de Argentina, Brasil, Chile, España y México, con requerimientos de grados día de calefacción y refrigeración similar y disponibilidad de archivo climático EPW, con el fin de seleccionar las localidades con clima templado en que se aplicarán los Casos de Estudio y determinar las variables climáticas empleadas en la construcción del modelo estadístico. 


\subsection{Selección de las localidades de aplicación}

La selección de las localidades empleadas en este estudio se fundamentó primeramente en encontrar las ciudades de Argentina, Brasil, Chile, España y México que poseen una población superior a 200.000 habitantes, resultando en una muestra inicial con 307 casos ANEXO I.

A continuación, dado que los consumos energéticos se relacionan fuertemente con la rigurosidad del clima, y la rigurosidad climática con los grados día, se consideraron las ciudades con demanda de refrigeración y de calefacción de hasta 1500 grados día por régimen (Blasco Lucas, Hoesé e Luis Facchini 2011). Se definieron 42 localidades de aplicación, priorizando los casos más poblados, distantes entre sí, y con disponibilidad de archivos climáticos (Tabla 33).

Las localidades seleccionadas comprenden el 19,05\% de la población total de Argentina, el 2,52\% de la población de Brasil, el 46,18\% de la población de Chile, el 13,53\% de la población de México y el 8,69\% de la población total de España, demostrando la representatividad de las ciudades consideradas (Figura 34).

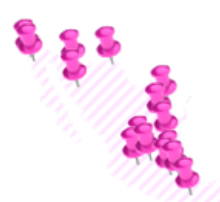

Figura 34: Localidades de Argentina, Brasil, Chile, España y México con clima templado. Elaboración propia. 
PARTE I · Delimitación del ámbito de la investigación

\begin{tabular}{|c|c|c|c|c|c|}
\hline País & $\mathbf{N}$ & Ciudad & Población & GD Refrigeración & GD Calefacción \\
\hline \multirow{10}{*}{ 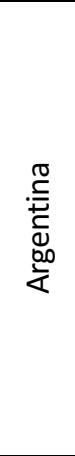 } & 1 & Buenos Aires & 2.890 .150 & 732 & 771 \\
\hline & 2 & Catamarca & 210.000 & 1440 & 531 \\
\hline & 3 & Córdoba & 1.429 .604 & 705 & 714 \\
\hline & 4 & Corrientes & 352.646 & 1308 & 192 \\
\hline & 5 & La Plata & 699.523 & 525 & 1050 \\
\hline & 6 & La Rioja & 215.000 & 1368 & 621 \\
\hline & 7 & Mar del Plata & 664.892 & 141 & 1293 \\
\hline & 8 & Paraná & 247.863 & 738 & 750 \\
\hline & 9 & Rosario & 1.400 .000 & 642 & 957 \\
\hline & 10 & Santiago del Estero & 252.192 & 1311 & 450 \\
\hline \multirow{8}{*}{$\begin{array}{l}\overline{\bar{n}} \\
\frac{\overline{0}}{\bar{\infty}}\end{array}$} & 11 & Blumenau & 343.715 & 975 & 138 \\
\hline & 12 & Chapecó & 209.553 & 648 & 387 \\
\hline & 13 & Criciúma & 209.153 & 792 & 252 \\
\hline & 14 & Curitiba & 1.893 .997 & 243 & 681 \\
\hline & 15 & Florianópolis & 477.798 & 942 & 183 \\
\hline & 16 & Ponta Grossa & 341.130 & 408 & 492 \\
\hline & 17 & Porto Alegre & 1.481.019 & 894 & 372 \\
\hline & 18 & Santa Maria & 277.309 & 759 & 462 \\
\hline \multirow{6}{*}{$\frac{\mathscr{U}}{\frac{\mathrm{C}}{\mathrm{U}}}$} & 19 & Antofagasta & 380.695 & 198 & 657 \\
\hline & 20 & Concepción & 848.023 & 0 & 1490 \\
\hline & 21 & Copiacó & 234.561 & 453 & 435 \\
\hline & 22 & Santiago & 5.631 .839 & 201 & 1375 \\
\hline & 23 & Temuco & 460.824 & 0 & 1334 \\
\hline & 24 & Valparaíso & 824.006 & 0 & 1434 \\
\hline \multirow{9}{*}{ 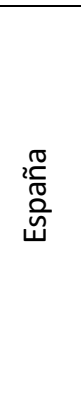 } & 25 & Alicante & 329.988 & 861 & 771 \\
\hline & 26 & Barcelona & 257.349 & 549 & 1276 \\
\hline & 27 & Córdoba & 325.916 & 1080 & 999 \\
\hline & 28 & Granada & 232.770 & 708 & 1360 \\
\hline & 29 & Málaga & 569.002 & 864 & 693 \\
\hline & 30 & Murcia & 443.243 & 1060 & 849 \\
\hline & 31 & Palma & 406.492 & 873 & 792 \\
\hline & 32 & Sevilla & 689.434 & 1173 & 741 \\
\hline & 33 & Valencia & 787.808 & 864 & 756 \\
\hline \multirow{9}{*}{ 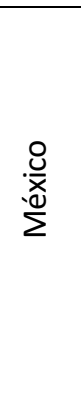 } & 34 & Aguascalientes & 722.250 & 589 & 423 \\
\hline & 35 & Ciudad de Mexico & 8.851 .080 & 195 & 330 \\
\hline & 36 & Guadalajara & 1.494 .134 & 717 & 360 \\
\hline & 37 & Hermosillo & 715.061 & 1404 & 516 \\
\hline & 38 & Juárez & 1.328 .017 & 996 & 1473 \\
\hline & 39 & León & 1.436 .733 & 756 & 189 \\
\hline & 40 & Monterrey & 1.130 .960 & 1388 & 237 \\
\hline & 41 & Puebla & 1.539 .859 & 156 & 429 \\
\hline & 42 & Tijuana & 1.559 .683 & 402 & 657 \\
\hline
\end{tabular}

Tabla 33: Ciudades de aplicación seleccionadas en función de la densidad poblacional, de los valores de grados día para acondicionamiento y la disponibilidad de archivo climático con extensión EPW. Elaboración propia.

\subsubsection{Definición de las variables climáticas}

Para construir la matriz de las variables climáticas, se extrajeron los datos históricos de cada localidad mediante un análisis del archivo climático con el programa Climat Consultant - uso libre.

Dado que las normativas de acondicionamiento de Argentina utilizan los grados día y la temperatura de diseño para clasificar la rigurosidad del día más crítico, Brasil considera los grados hora y la temperatura media mensual máxima y mínima, Chile y España adoptan los grados día, y México considera 
la temperatura media máxima y mínima, se adoptaron los grados día de verano y de invierno, la temperatura de diseño máxima y mínima y la temperatura media máxima y mínima como variables climáticas predominantes. Además, se adoptó la altitud, la latitud, la humedad relativa, la radiación global, la velocidad del viento y el porcentaje de cielo cubierto.

Los valores para temperatura media mensual, humedad relativa, radiación global, velocidad del viento y porcentaje de cielo cubierto, han sido delimitados para dos situaciones con el objeto de determinar qué conjunto de datos guardan mayor correlación con la variación del consumo energético: la primera considerando el promedio anual, la segunda evaluando el promedio de los tres meses más cálidos del año para la situación de refrigeración y el promedio de los tres meses más fríos del año para la situación de calefacción (Tabla 34).

\begin{tabular}{crl}
\hline $\mathbf{N}^{\circ}$ & VARIABLE & DEFINICIóN \\
\hline 1 & Cver1 & Consumo en refrigeración Caso I $\left(\mathrm{kWh} / \mathrm{m}^{2}\right)$ \\
2 & Cver2 & Consumo en refrigeración Caso II $\left(\mathrm{kWh} / \mathrm{m}^{2}\right)$ \\
3 & Cinv1 & Consumo en calefacción Caso I $\left(\mathrm{kWh} / \mathrm{m}^{2}\right)$ \\
4 & Cinv2 & Consumo en calefacción Caso II $\left(\mathrm{kWh} / \mathrm{m}^{2}\right)$ \\
5 & Latitude & $\left({ }^{\circ}\right)$ \\
6 & Altitude & $\left(^{\circ}\right)$ \\
7 & GDver & Grados día en refrigeración \\
8 & GDpverp & Grados día en refrigeración promedio para los 3 meses más cálidos \\
9 & GDpinv & Grados día en calefacción \\
10 & GDinvp & Grados día en calefacción promedio para los 3 meses más fríos \\
11 & TDmax & Temperatura de diseño máxima $\left({ }^{\circ} \mathrm{C}\right)$ \\
12 & TDmin & Temperatura de diseño mínima $\left({ }^{\circ} \mathrm{C}\right)$ \\
13 & TMmax & Temperatura media máxima $\left({ }^{\circ} \mathrm{C}\right)$ \\
14 & TMmin & Temperatura media mínima $\left({ }^{\circ} \mathrm{C}\right)$ \\
15 & RAD & Radiación global (W/ $\left.{ }^{2}\right)$ \\
16 & RADpver & Radiación global promedio para los 3 meses más cálidos $\left(\mathrm{W} / \mathrm{m}^{2}\right)$ \\
17 & RADpinv & Radiación global promedio para los 3 meses más fríos $\left(\mathrm{W} / \mathrm{m}^{2}\right)$ \\
18 & HR & Humedad relativa \% \\
19 & HRpver & Humedad relativa promedio para los 3 meses más cálidos $\%$ \\
20 & HRpinv & Humedad relativa promedio para los 3 meses más fríos $\%$ \\
21 & V V & Velocidad del viento km/h \\
22 & V Vpver & Velocidad del viento promedio para los 3 meses más cálidos $\mathrm{km} / \mathrm{h}$ \\
23 & V Vpinv & Velocidad del viento promedio para los 3 meses más fríos $\mathrm{km} / \mathrm{h}$ \\
24 & CC & Cielo cubierto \% \\
25 & CCpver & Cielo cubierto promedio para los $3 \mathrm{meses} \mathrm{más} \mathrm{cálidos} \%$ \\
26 & CCpinv & Cielo cubierto promedio para los $3 \mathrm{meses} \mathrm{más} \mathrm{fríos} \%$ \\
\hline & &
\end{tabular}

Tabla 34: Descripción de las variables climáticas analizadas. Elaboración propia.

La información sobre densidad poblacional se recolectó a partir de los censos realizados por cada país, y los valores de los grados día correspondientes a cada localidad se calcularon mediante la temperatura media de cada ciudad considerando una base de 18 grados. Para Argentina las normales climatológicas se obtuvieron en la página web del Servicio Meteorológico Nacional (2017), a partir de las series climatológicas comprendidas entre los años 1981 - 2010. Para Brasil las variables se obtuvieron en la 
página web del Instituto Nacional de Meteorología (2009) para valores registrados entre 1961 - 1990, y para Chile se extrajeron del documento Estadística climatología Tomo I, Tomo II, y Tomo III de la Dirección Meteorológica de Chile (2011a) (2011b) (2011c), los cuales compilan los datos históricos correspondientes al período de los años 1970 a 2000 de gran parte de las localidades del país. En España las variables se obtuvieron a partir de la Guía resumida del clima en España, para los períodos de 19812010, 1971-2000 y 1961-1990 (Agencia Estatal de Meteorología 2012), y para México a partir del archivo Normales Climatológicas por Estado para los períodos de 1951-2010, 1971-2000 y 1981-2010 (Servicio Meteorológico Nacional 2018).

Los valores de los grados día correspondientes a cada localidad se calcularon mediante la temperatura media de cada ciudad considerando una base de 18 grados (Instituto Argentino de Normalización y Certificación 2012). La temperatura máxima de diseño se calculó adicionando $3,5^{\circ} \mathrm{C}$ a la temperatura máxima media del mes más cálido, en cuanto para la temperatura mínima de diseño se restó $4,5^{\circ} \mathrm{C}$ a la temperatura mínima media del mes más frío según indica la IRAM 11.603 (Instituto Argentino de Normalización y Certificación 2012). 


\section{Conclusiones}

El desarrollo de esta etapa permitió seleccionar 42 localidades con clima templado de Argentina, Brasil, Chile, España y México, las cuales servirán de base para simular la aplicación de los Casos de Estudio y estimar sus consumos en acondicionamiento térmico (Tabla 33). Estos consumos consistirán en las variables dependientes utilizadas en la etapa de construcción del modelo estadístico.

Así mismo, se definieron 22 variables climáticas asociadas a los datos disponibles en los archivos climáticos de cada localidad. Estos datos serán utilizados como variables secundarias en la etapa de construcción del modelo estadístico (Tabla 34).

Se tomaron los datos de la altitud, la latitud, la temperatura media mensual, la humedad relativa, la radiación global, la velocidad del viento y el porcentaje de cielo cubierto. Además se calcularon los valores de los grados días y de la Temperatura máxima y mínima de diseño.

Los valores para temperatura media mensual, humedad relativa, radiación global, velocidad del viento y porcentaje de cielo cubierto, han sido delimitados para dos situaciones con el objeto de determinar qué conjunto de datos guardan mayor correlación con la variación del consumo energético: la primera considerando el promedio anual, la segunda evaluando el promedio de los tres meses más cálidos del año para la situación de refrigeración y el promedio de los tres meses más fríos del año para la situación de calefacción. 


\section{Características de uso y ocupación}

\section{Objetivo}

En esta etapa se conocerán los hábitos de ocupación y el nivel de confort térmico interior percibido por usuarios de edificios residenciales en altura, con el fin de construir los estándares de ocupación aplicables en las simulaciones energéticas, y obtener información que contribuya a la interpretación de los datos registrados en la auditoría energética.

Así mismo, se registrarán las temperaturas y la humedad interior para conocer el desempeño real del ambiente interno ante la variación del clima, con el propósito de obtener la información necesaria para la construcción de un modelo energético aproximado al modelo real. 


\subsection{Aplicación de las encuestas a los usuarios}

\subsubsection{Delimitación del universo de análisis y planificación del muestreo}

En encuestas realizadas para otros estudios no incluidos en este trabajo, se ha registrado el recibo de correos electrónicos buscando verificar el trasfondo, el alcance de la investigación, así como los antecedentes del personal involucrado en el estudio. Se deduce que el modelo de interacción personal así como la estructura de las preguntas usualmente empleadas en auditorías energéticas, pueden resultar poco confiables para aquél que no se encuentra familiarizado con la dinámica del estudio.

Los datos han sido colectados a través de un cuestionario enviado directamente al responsable de cada unidad habitacional mediante correo electrónico. Aunque la bibliografía indique que las encuestas online presentan un menor porcentaje de respuestas en relación a las entrevistas presenciales y telefónicas (López-Roldán e Fachelli 2015), se optó por un cuestionario que pueda ser autoadministrado, donde se evite cualquier influencia que el entrevistador pueda generar al entrevistado.

También se observó que cuando las preguntas poseían un carácter complejo y los usuarios tenían que ser detallistas en sus descripciones, las preguntas se quedaban vacías en el $87,5 \%$ de los casos, por lo que se concluyó que la aplicación de un cuestionario exhaustivo podría resultar invasivo y laborioso, llevando a un menor número de participantes. Estos resultados condujeron hacia la simplificación de las preguntas y las opciones de respuesta en las encuestas planteadas en este trabajo.

La población seleccionada para la aplicación de las encuestas constituye a los usuarios del edificio del Caso II - edificio de vivienda multifamiliar en altura. El edificio posee dos torres con 12 pisos de altura y 2 departamentos de 2 dormitorios y 4 departamentos de 3 dormitorios por planta tipo. Se consideró la posibilidad de que 2 habitantes ocupen los departamentos de 2 dormitorios y 4 habitantes ocupen los departamentos de 3 dormitorios, resultando en una ocupación estimada de 480 habitantes en dos torres.

Para garantizar la representatividad de la muestra, la selección de la población consideró todos los usuarios, es decir que no se aplicó ninguna restricción de edad, sexo, nivel de ingresos mensuales y otras.

El marco de muestreo consistió en una lista con el correo electrónico del responsable de las familias que ocupan cada una de las viviendas, obtenido en la Administración del edificio. Se estima que la colaboración del personal administrativo con el cual los habitantes del edificio se encuentran familiarizados, auxilia en la construcción de credibilidad de la encuesta, aumentando la posibilidad de que los individuos participen activamente.

\subsubsection{Elección y construcción de las técnicas de observación}

El campo de observación de la encuesta se enfocó en comprender los fenómenos que puedan influenciar los niveles de confort percibido por los usuarios a través de la recolección de información relacionada con los hábitos de ocupación en la vivienda, las preferencias de climatización, la posible modificación de los revestimientos internos, así como las percepciones de confort térmico interior (Figura 35). 
La estructura de la encuesta aplicada se dividió en 2 secciones introductorias y 5 secciones enfocadas en el contenido, detalladas en el ANEXO II.

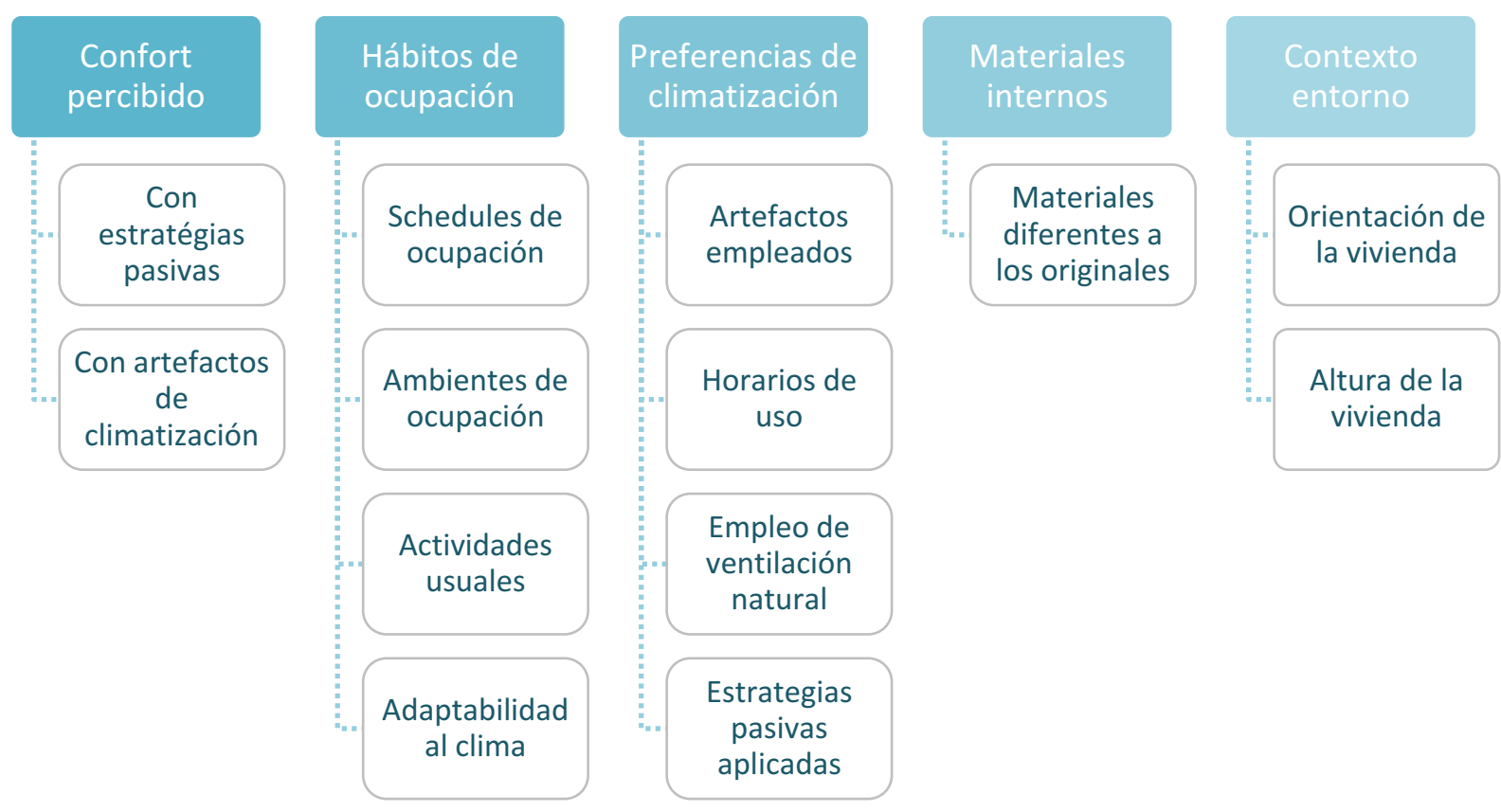

Figura 35: Campos de observación. Elaboración propia.

La sección 1 - Diagnóstico de la vivienda, corresponde al texto visible en el cuerpo del correo electrónico que recibe el usuario junto a la invitación a participar de la encuesta, haciendo mención a la identificación del alcance de la encuesta, el público al que se dirige, y el tiempo estimado para su realización.

La Sección 2 - Propósito de la encuesta, especifica porque la realización de este cuestionario a los usuarios del Caso III es indispensable para el desarrollo de la presente tesis, con el objetivo de generar seguridad en los entrevistados y aumentar su participación.

La sección 3 - Percepción del confort, se centra en identificar la opinión del usuario respecto los niveles de confort térmico que promueve el edificio considerando dos situaciones de uso. La primera cuando el usuario emplea apenas soluciones de acondicionamiento pasivo, y la segunda cuando utiliza artefactos de climatización.

La sección 4 - Características de ocupación, busca conocer aquellos hábitos de uso y ocupación de la vivienda que influencian en la sensación del confort térmico del usuario, así como la preferencia de vestimenta de los habitantes del hogar.

La sección 5 - Equipos de climatización y ventilación, se centra en identificar las preferencias de los usuarios en al momento de climatizar la vivienda, busca conocer el tipo del artefacto utilizado, la frecuencia de uso, si se ventila naturalmente la vivienda, y si se aplican estrategias pasivas para optimizar el confort. 
La sección 6 - Materiales originales o modificados, busca comprender si las condiciones de confort internas pueden verse alteradas por la sustitución o aplicación de algún material diferente a los originales, es decir que influya significativamente en el desempeño térmico de la vivienda.

La sección 7 - Orientación y altura de la vivienda, busca identificar si la vivienda evaluada posee una posición desfavorable o privilegiada en relación a la orientación solar y a los vientos, así como conocer si el departamento posee el piso y el techo protegido, o expuesto al exterior.

\subsubsection{Interpretación de los resultados}

\subsubsection{Percepción del confort}

Se compara la variación entre el nivel de confort térmico percibido por los usuarios cuando la vivienda es climatizada solamente con estrategias pasiva (Figura 36), en contraste a los períodos donde se emplean artefactos de climatización mecánica (Figura 37).

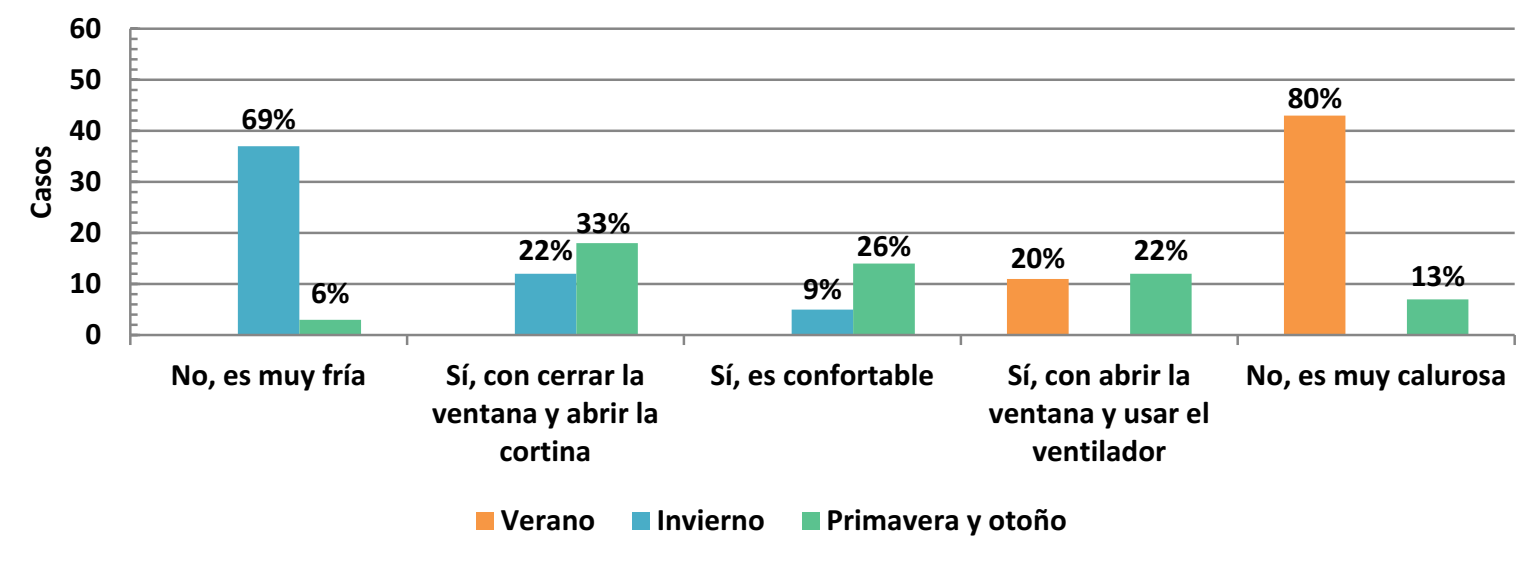

Figura 36: Sección 3 - Percepción del confort con el empleo de estrategias pasivas. Elaboración propia.

Durante los meses de primavera y otoño, $81 \%$ de los casos indican poder alcanzar condiciones de confort apenas con la aplicación de medidas simples, como el abrir y cerrar de ventanas y cortinas, y la utilización del ventilador. En invierno y verano este porcentaje es del orden del 31\% y del $20 \%$ respectivamente, sugiriendo que el clima en verano es más extremo que en invierno o que algunos usuarios ocupan viviendas con mejor orientación solar, permitiendo optimizar las condiciones en invierno y potenciar el disconfort en verano. Analizando las respuestas de la Sección 7 - Orientación y altura de la vivienda, se verificó que 07 encuestas poseían la misma respuesta en relación a la altura del departamento y su ubicación en el plano. Como las respuestas obtenidas se han sobrepuesto, no ha sido posible corroborar si el disconfort producido en invierno se relaciona con la orientación de la vivienda.

Con el empleo de artefactos para la climatización, el $87 \%$ de los casos expresaron ser posible alcanzar condiciones de confort durante todo el año a través del uso del aire acondicionado, el calefactor y la estufa eléctrica (Figura 37). El 14\% de los usuarios indicaron que la vivienda es fría en invierno, en cuanto para el $4 \%$ de los casos la vivienda es calurosa, insinuando la dificultad en adaptarse a las condiciones de 
invierno, o la falta de artefactos que puedan mantener las temperaturas entre los rangos de confort deseado. Cuestionamiento que se resuelve con las respuestas de los artefactos de climatización.

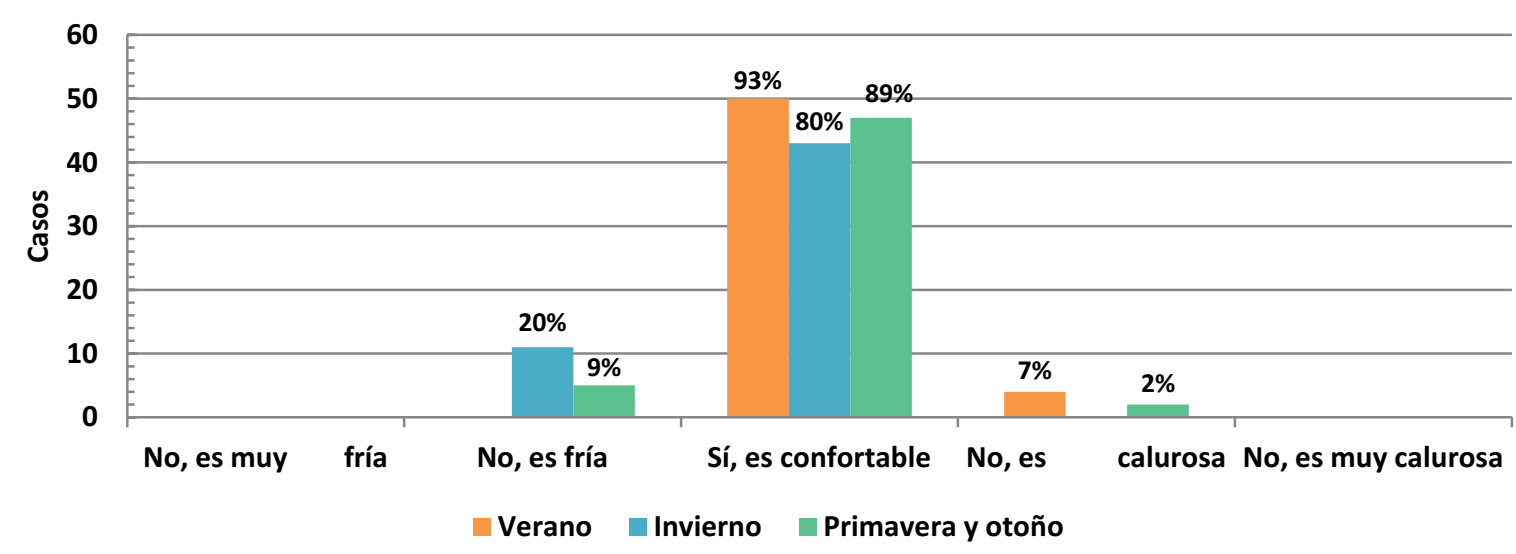

Figura 37: Sección 3 - Percepción del confort con el empleo de artefactos de climatización. Elaboración propia.

\subsubsection{Características de ocupación}

Se contrastan los hábitos de ocupación de las viviendas según la rutina y las preferencias de cada grupo familiar (Figura 38, Figura 39, Figura 40, Figura 41 y Figura 42).

Las respuestas observadas en esta sección sugieren la predominancia de una estructura familiar tradicional, donde el $18 \%$ de los hogares se encuentran ocupados por parejas con más una persona (hijo o adulto), el $14 \%$ por parejas con más 2 personas, y el 38\% por parejas sin hijos (Figura 38). Entre las viviendas ocupadas por un individuo, 7 se encuentran ocupadas por hombres (12\%), 8 por mujeres (14\%), siendo que ninguno de ellos posee hijos. De las unidades ocupadas por parejas, 13 de ellas dividen la vivienda con un empleado domestico (33\%), en cuanto las unidades ocupadas por un individuo no tienen un empleado domestico trabajando en el hogar.

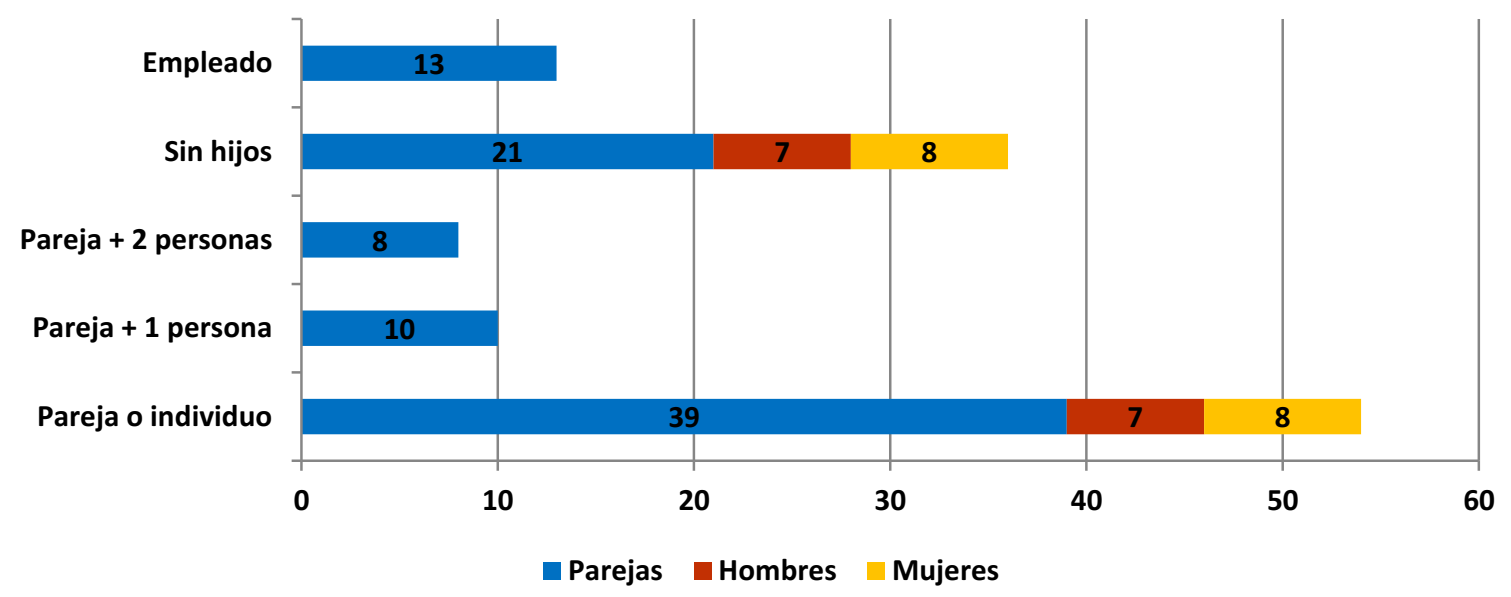

Figura 38: Sección 4 - Estructura familiar por hogar. Elaboración propia.

La mayor ocupación de las viviendas ocurre en el período comprendido entre las 19:00 y las 00hs, alcanzando el $70 \%$ de la capacidad total de habitantes, lo que sugiere que los usuarios trabajan y estudian durante el día y regresan al hogar por la noche, diferente del estándar familiar de España que usualmente 
regresan al hogar a las 14:00hs y por consecuencia tienden a requerir de un mayor consumo energético anual (Figura 39).

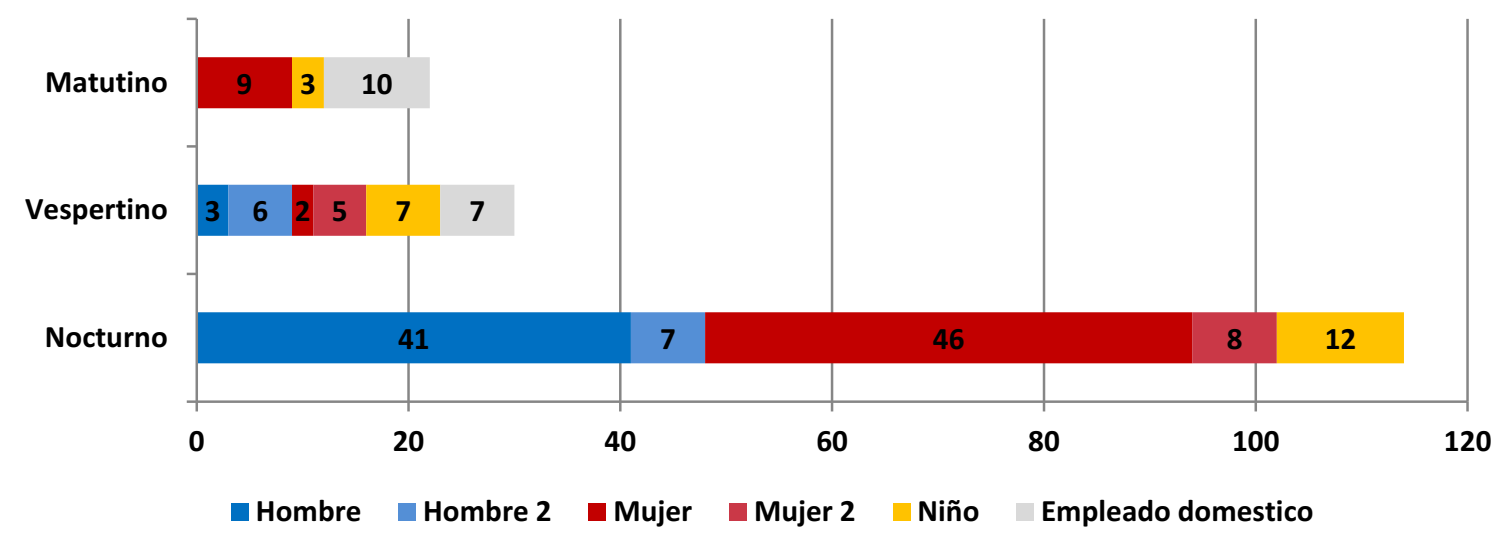

Figura 39: Sección 4 - Ocupación de la vivienda según usuario. Elaboración propia.

Las actividades desempeñadas por el $54 \%$ de los habitantes son generalmente livianas, como leer, mirar televisión, y comer; en cuanto cerca del 39\% de los usuarios también realizan tareas intermedias, como cocinar y limpiar (Figura 40). El primer grupo de actividades se consideran tareas livianas ya que promueven un gasto de energía entre 70 y 120 W/persona, en cuanto el segundo grupo se consideran tareas moderadas, promoviendo un gasto de energía entre 180 y $230 \mathrm{~W} /$ persona. Los empleados domésticos consisten en el $13 \%$ de la población, los cuales desempeñan tareas con un gasto de energía aproximado de $230 \mathrm{~W} /$ persona.

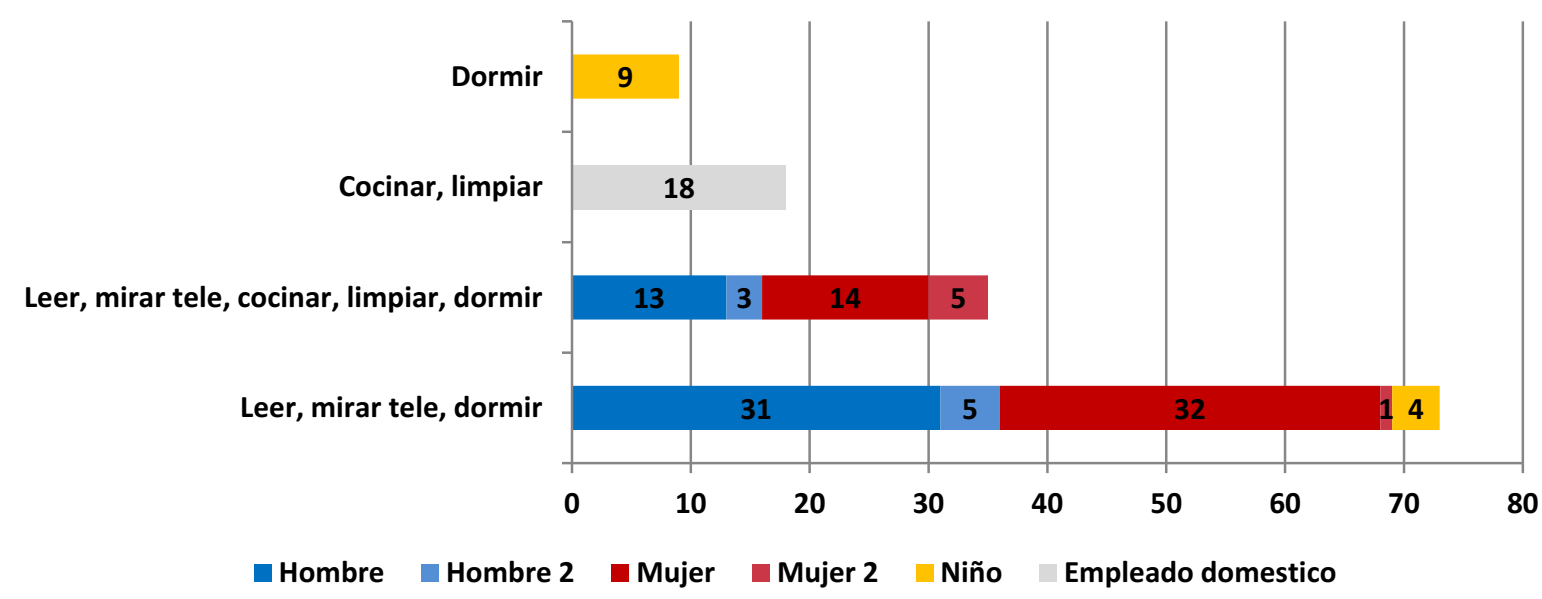

Figura 40: Sección 4 - Actividades desempeñadas según usuario. Elaboración propia.

El 51\% de los ocupantes de las viviendas, incluyendo los empleados domésticos prefieren adaptar la vestimenta según las condiciones del clima (Figura 41). Las mujeres corresponden al 57\%, en cuanto las mujeres al $25 \%$. Entre los usuarios que prefieren usar ropas livianas, el $37 \%$ corresponde a los hombres, el $17 \%$ a las mujeres, en cuanto corresponde a los empleados domésticos. 


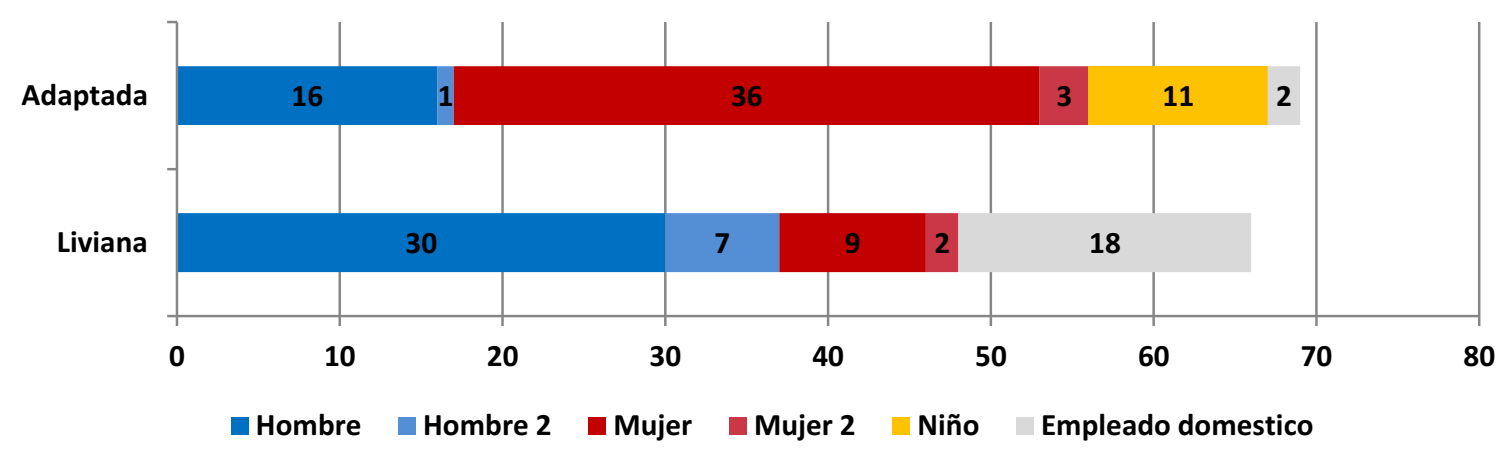

Figura 41: Sección 4 - Preferencia de vestimenta según usuario. Elaboración propia.

El estar comedor se encuentra usualmente ocupado durante 4 horas, en cuanto las habitaciones y la cocina son utilizados durante 2 horas, y los baños y el área de servicio se encuentran ocupados en entre 30 minutos y 2 horas por día (Figura 42).

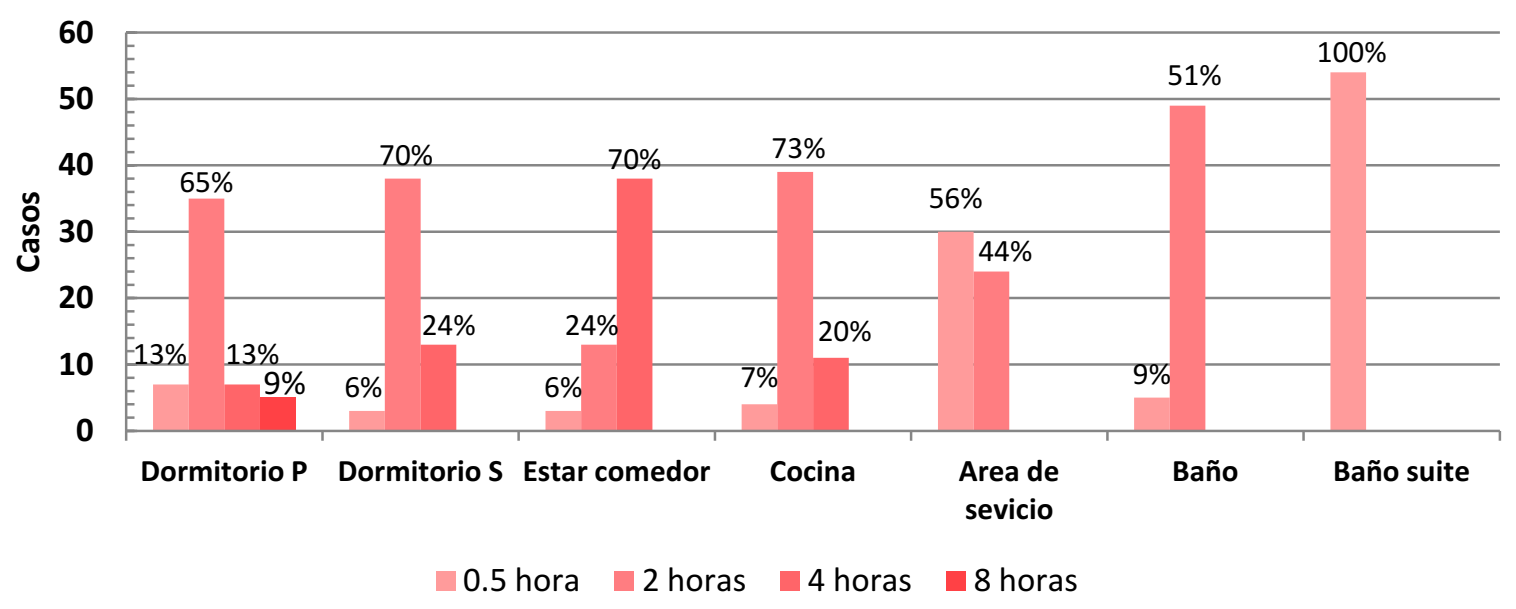

Figura 42: Sección 4 - Ocupación de los ambientes. Elaboración propia.

\subsubsection{Equipos de climatización y ventilación}

Con respecto al uso de artefactos para climatización se verificó que en invierno, todos los usuarios que disponen del aire frío/calor hacen uso del equipo, a la vez que el $20 \%$ de los usuarios no utilizan artefacto de climatización. Este mismo porcentaje de habitantes informa que sin el uso de artefactos en invierno, la vivienda no alcanza condiciones de confort, lo que sugiere que el $20 \%$ de los usuarios no poseen artefactos para aclimatar la vivienda en invierno (Figura 43).

Durante el verano se utilizan más artefactos de climatización, y durante mayor tiempo. Se verifica que el $100 \%$ de las unidades funcionales hacen uso del ventilador en el verano, en cuanto el $69 \%$ utiliza el aire frío/calor y el $41 \%$ el aire frío. La ventilación natural es empleada frecuentemente en las viviendas durante el día en verano, ya que en invierno las ventanas se encuentran mayormente cerradas y se estima que los horarios de apertura varían según la ocupación de la vivienda.

Los horarios de encendido de los equipos, así como la apertura de la ventana para aprovechar la ventilación natural, son muy variados tanto durante el día como para la estación del año. En verano el 
43\% de las viviendas mantienen los artefactos en funcionamiento todo el período en que se encuentran durmiendo. En invierno $54 \%$ de las viviendas encienden los equipos entre las19 y las 00 horas y los demás casos poseen horarios variados de encendido, sugiriendo que el empleo de los artefactos ocurre a medida que ingresan los habitantes al hogar.

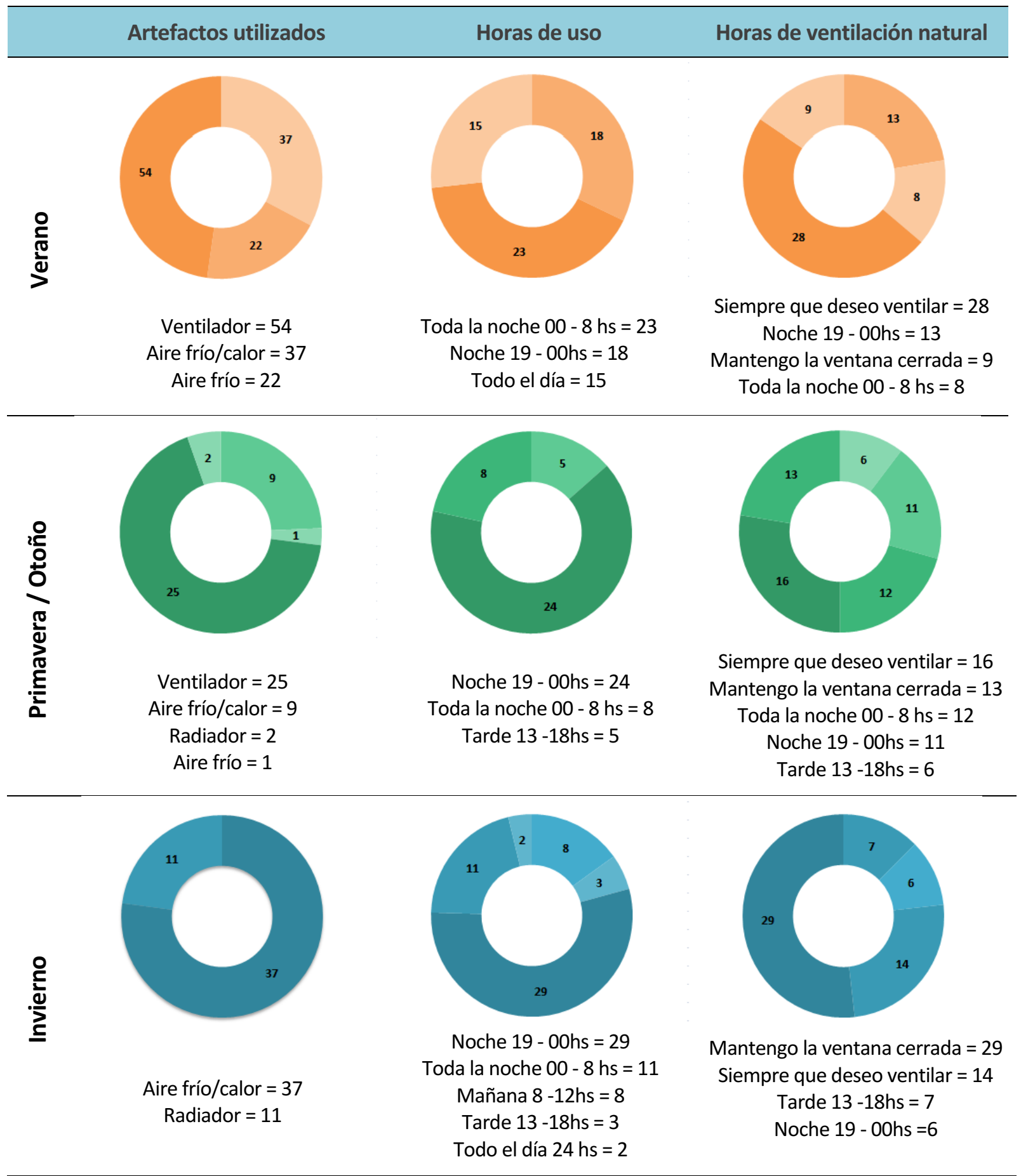

Figura 43: Sección 5 - Equipos de climatización y ventilación. Elaboración propia.

Se deduce que hay un desconocimiento por parte de los usuarios respecto de las posibilidades existentes para aclimatar la vivienda a partir de medidas pasivas principalmente en invierno (Figura 44). Aunque el $70 \%$ de los usuarios indique que la vivienda es fría en invierno solamente el 13\% considera el calor de la producción de los alimentos para acondicionar en invierno, y el 20\% cierra las ventanas y abre 
las cortinas para el acceso de la radiación solar directa. En contrapartida, el 100\% de los usuarios enciende el ventilador, y el $76 \%$ ventila el hogar, siendo que muchas veces no se recomienda abrir las ventanas cuando las temperaturas exteriores son muy elevadas.

Se usa ropas más abrigadas en invierno Se cierra la ventana y abre la cortina para disminuir la sensación de frío en invierno

Se usa el preparo de las comidas para dejar la vivienda más cálida en invierno Se cierran las ventanas y las cortinas para disminuir la sensación de calor en verano Se abren las ventanas para refrescar la vivienda en verano Se usa el ventilador para refrescar la vivienda en verano

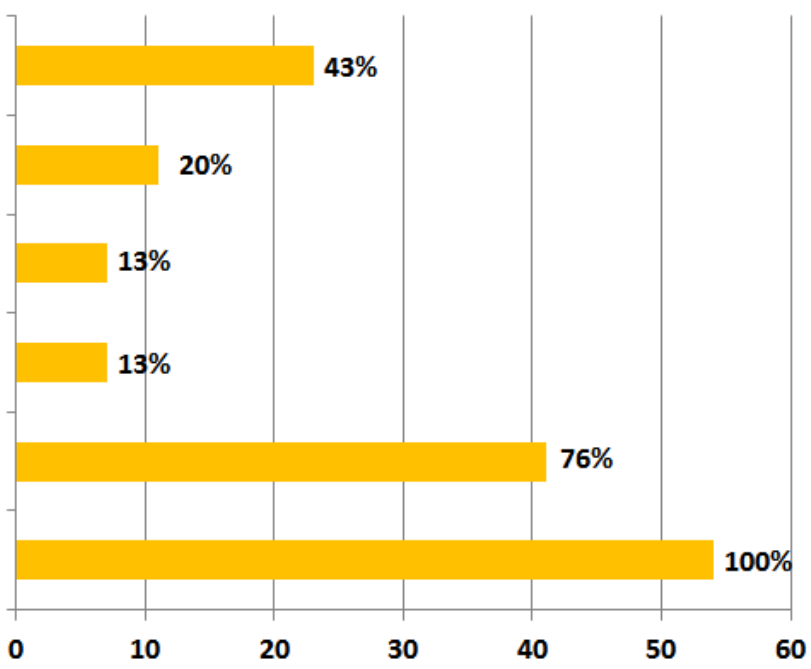

Figura 44: Sección 5 - Empleo de estrategias pasivas por hogar. Elaboración propia.

\subsubsection{Materiales originales o modificados}

Los materiales usualmente sustituidos no representan cambios en la estructura de los elementos constructivos, así como no alteran significativamente las características térmicas de los cerramientos (Figura 45). El $80 \%$ ha realizado alguna refacción en la vivienda aplicando materiales diferentes a los originales. Los materiales aplicados han sido yeso en el cielorraso, porcelanato, cerámicos, y piso flotante en el piso, revestimiento laminado y empapelado en los muros.

En ninguno de los casos se ha aplicado material aislante, o capaz de incrementar significativamente las características de absortancia y retraso en el paso del calor del elemento.

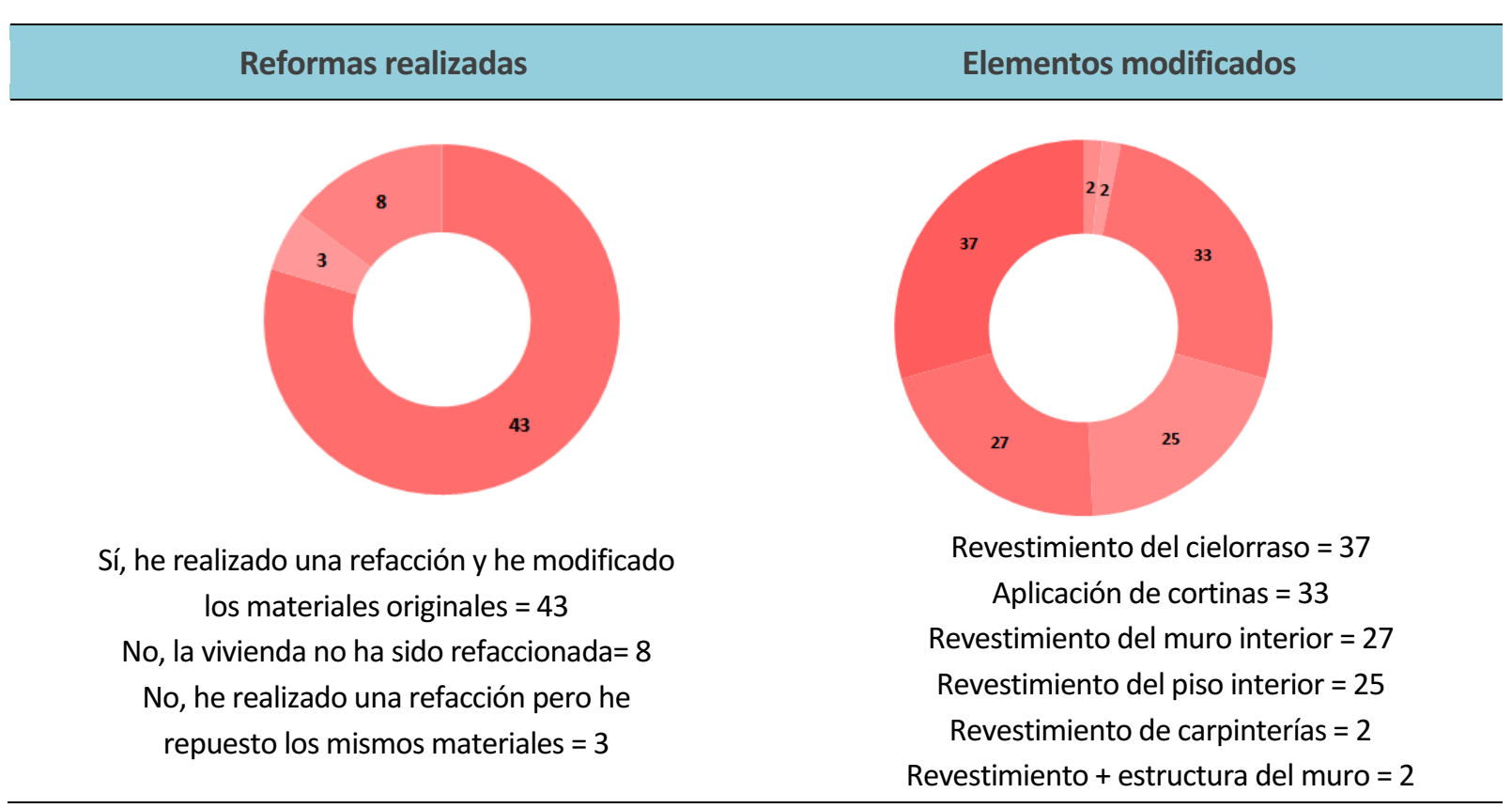

Figura 45: Sección 6 - Modificación de materiales de la envolvente por hogar. Elaboración propia. 


\subsection{Realización del monitoreo energético}

Se realizó un monitoreo energético del Caso I - vivienda unifamiliar además de 7 unidades funcionales ubicadas en una de las torres del Caso II - edificio de vivienda multifamiliar en altura. Analizando las series registradas en el Caso I se dedujo que los usuarios mantuvieron los equipos de climatización encendidos durante 6 días de la medición realizada en verano, razón que llevó a descartar los registros de este edificio y considerar solamente los resultados del Caso II para el ajuste del modelo energético.

El Caso II corresponde a un edificio residencial multifamiliar con planta baja +11 plantas con 6 unidades funcionales cada una. Se sitúa en una parcela ubicada en el centro de Criciúma, Santa Catarina, Brasil, a una latitud $28^{\circ} 41^{\prime}$ sur (Figura 46). El entorno es predominantemente llano con escala residencial, sin la presencia de elementos naturales y/o construidos que pudieran generar afectar significativamente la incidencia solar, o la circulación del aire en el edificio (Figura 47). El terreno se orienta al sudeste, entretanto las dos torres presentan su fachada más larga orientadas hacia el este - oeste.
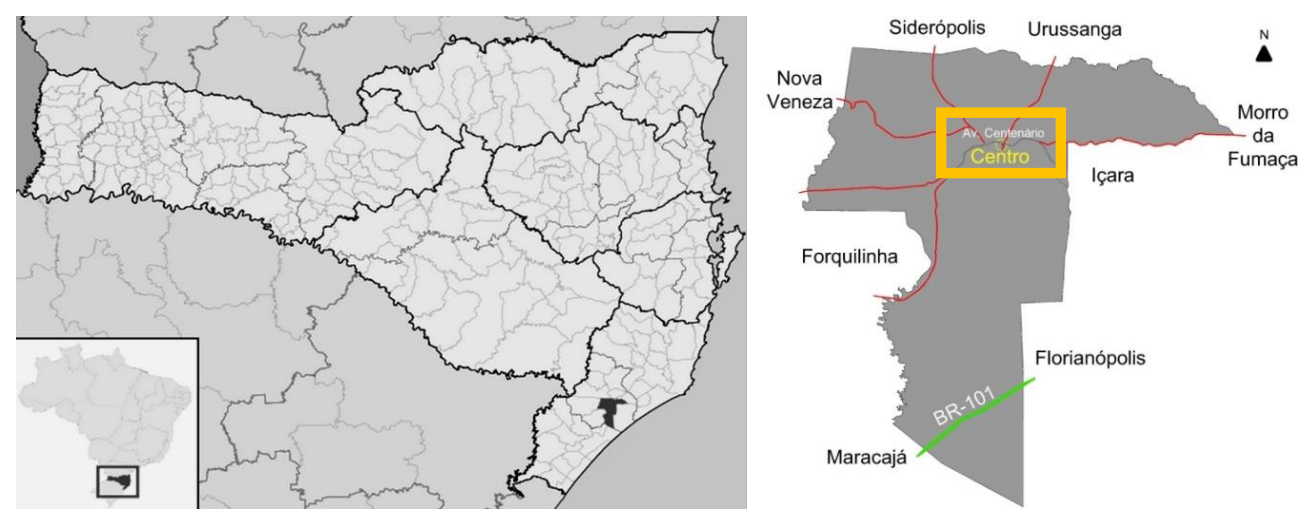

Figura 46: Ubicación de Criciúma en Santa Catarina. Fuente: Mapa de Santa Catarina - Wikipedia. Mapa de Criciúma - elaboración propia.

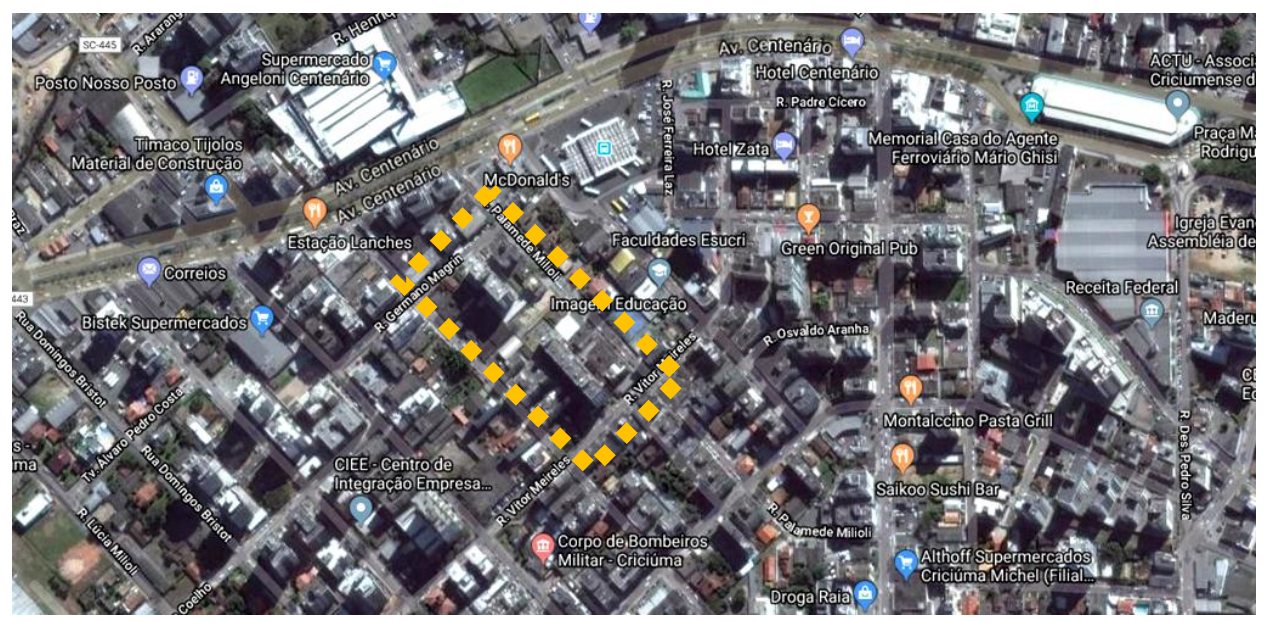

Figura 47: Implantación de la parcela de estudio. Elaboración propia adaptada de Google Maps.

\subsubsection{Características del clima}

El clima, según la clasificación de Koeppen es Cfa - subtropical húmedo con veranos calurosos e inviernos poco rigurosos. La temperatura media anual según datos de Ciram-Epagri3 Centro de

\footnotetext{
${ }^{3}$ Fuente:Sítio web de la Epagri-http://ciram.epagri.sc.gov.br/ - Consultado: 10/12/2016.
} 
Informações de Recursos Ambientais e de Hidrometeorologia de Santa Catarina, es de $19^{\circ} \mathrm{C}$, siendo $15^{\circ} \mathrm{C}$ en invierno y $24^{\circ} \mathrm{C}$ en verano. Las lluvias están bien definidas a lo largo del año, con totales mensuales de $80 \mathrm{~mm}$ en junio y $200 \mathrm{~mm}$ en febrero, sin estación de sequias definidas. Según la NBR 15220: desempenho térmico de Edificações, Criciúma se sitúa en la zona bioambiental III la cual es mayormente presente en el sur de Brasil y presenta temperaturas medias de $18^{\circ} \mathrm{C}$ y amplitud media anual de $11^{\circ} \mathrm{C}$ (Figura 48).

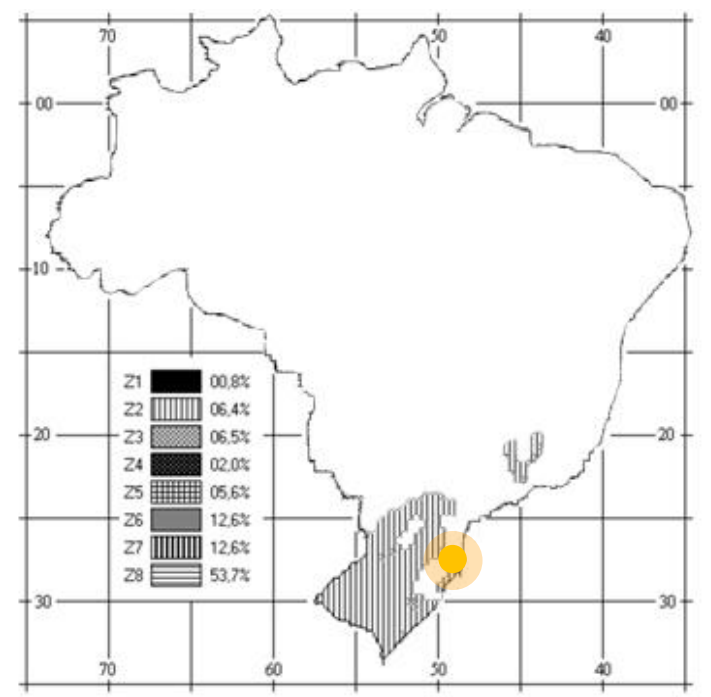

Figura 48: Ubicación de Criciúma en la zona II del mapa bioambiental de Brasil. Elaboración propia adaptada de (Associação Brasileira de Normas Técnicas 2008).

Según los análisis realizados con el programa Climate Consultant Criciúma presenta veranos con temperaturas medias de $25^{\circ} \mathrm{C}$ e inviernos con $15{ }^{\circ} \mathrm{C}$ (Figura 49). Durante el invierno, se verifican temperaturas mínimas de $3^{\circ} \mathrm{C}$ y máximas de $30^{\circ} \mathrm{C}$; mientras en verano se observan temperaturas de $11^{\circ} \mathrm{C}$ y $38^{\circ} \mathrm{C}$ respectivamente. Se puede predecir ser un clima con pocas amplitudes térmicas en verano, estaciones bien definidas a lo largo del año e inviernos poco rigurosos.

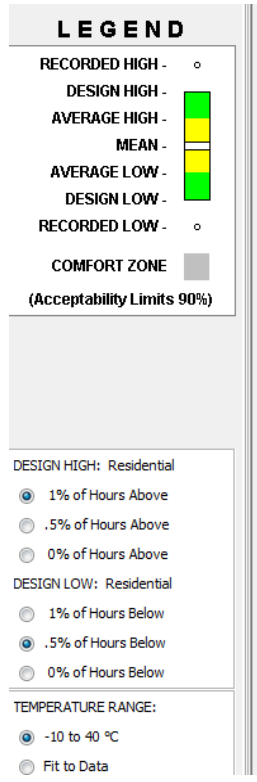

Fit to Data
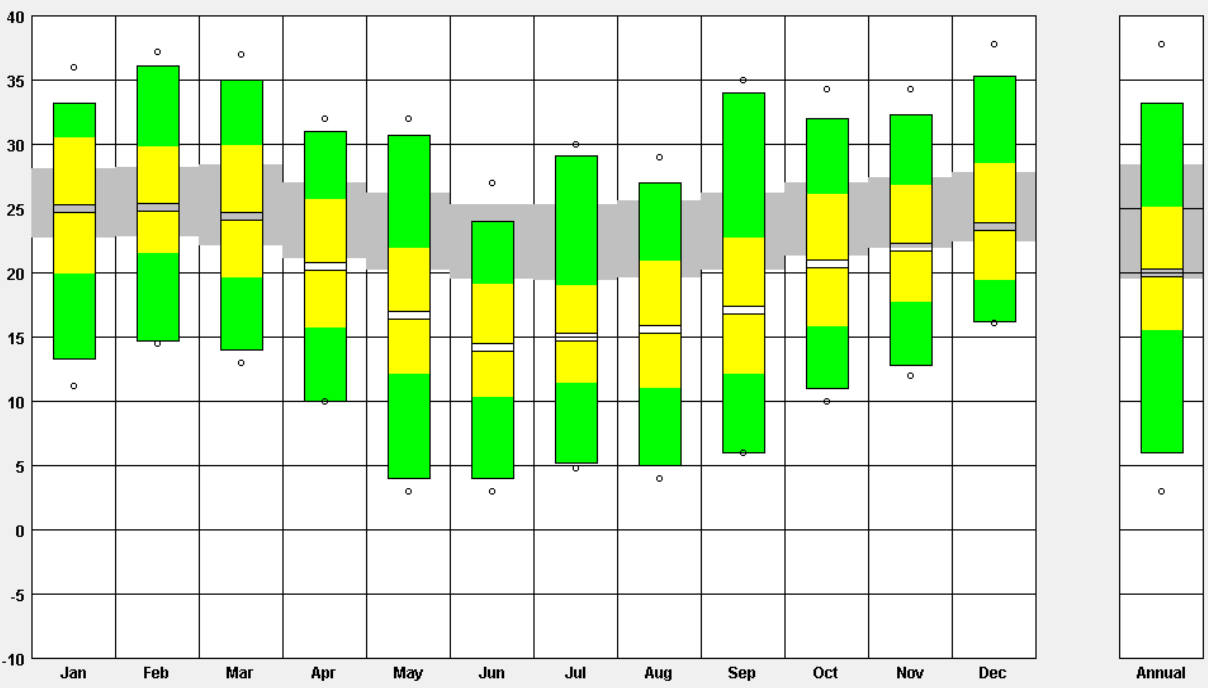

Figura 49: Temperaturas anuales. Fuente: Climat Consultant. 
En los meses de verano, la humedad relativa es del orden del $75 \%$ con variaciones diarias que oscilan entre el $60 \%$ y $90 \%$ durante el día; mientras que en los meses de invierno es del orden del $90 \%$ durante la mañana y la noche, y un 70\% por la tarde (Figura 50).
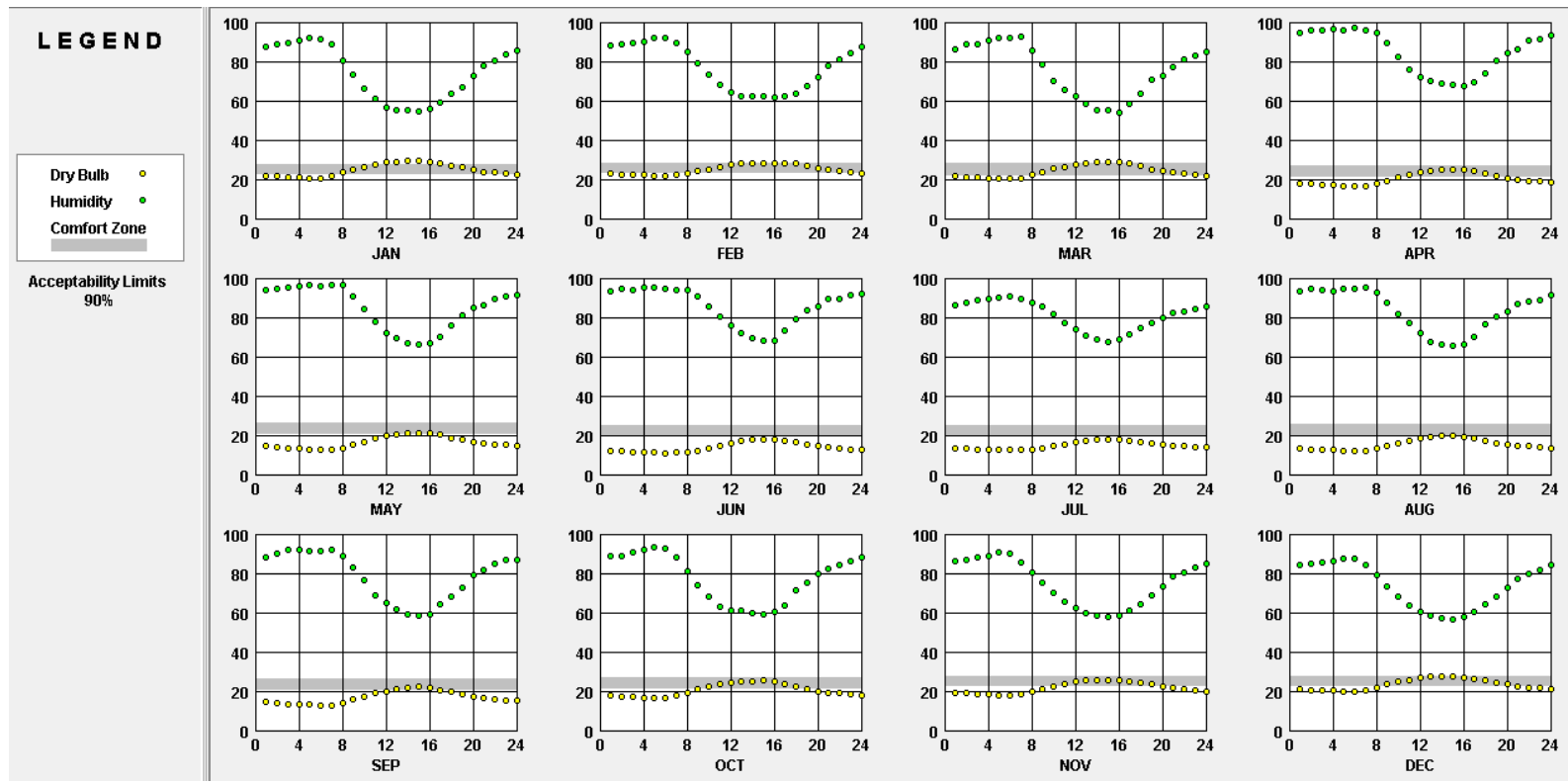

Figura 50: Humedad relativa mensual. Fuente: Climat Consultant.

Los mayores niveles de radiación global se registran en los meses de verano, donde alcanza los 690 Wh/sq.m mientras en invierno presenta un valor de 480 Wh/sq.m (Figura 51). La radiación directa en verano alcanzan los $300 \mathrm{Wh} / \mathrm{sq} . \mathrm{m}$ y en invierno $250 \mathrm{Wh} / \mathrm{sq} . \mathrm{m}$, indicando un clima con predominancia de días con cielo cubierto, como se verifica en la (Figura 52).
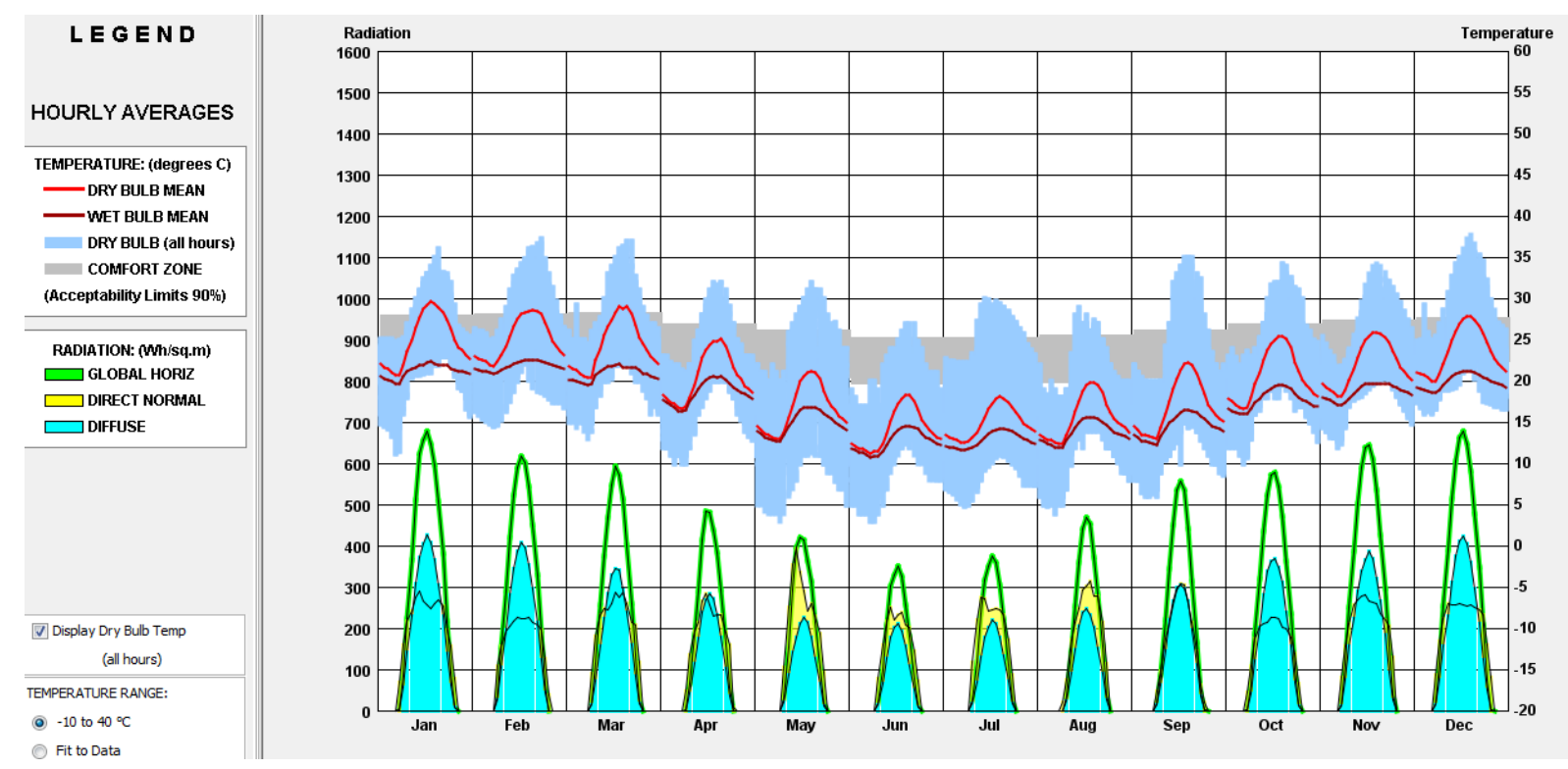

Figura 51: Radiación anual. Fuente: Climat Consultant.

El cielo cubierto en la ciudad de Criciúma presenta un promedio anual de 45\%, alcanzando mínimos de $12 \%$ y máximos de $75 \%$. La nubosidad máxima durante los meses de verano es de un valor cercano al $78 \%$ mientras que la mínima en invierno es del 15\% (Figura 52). 


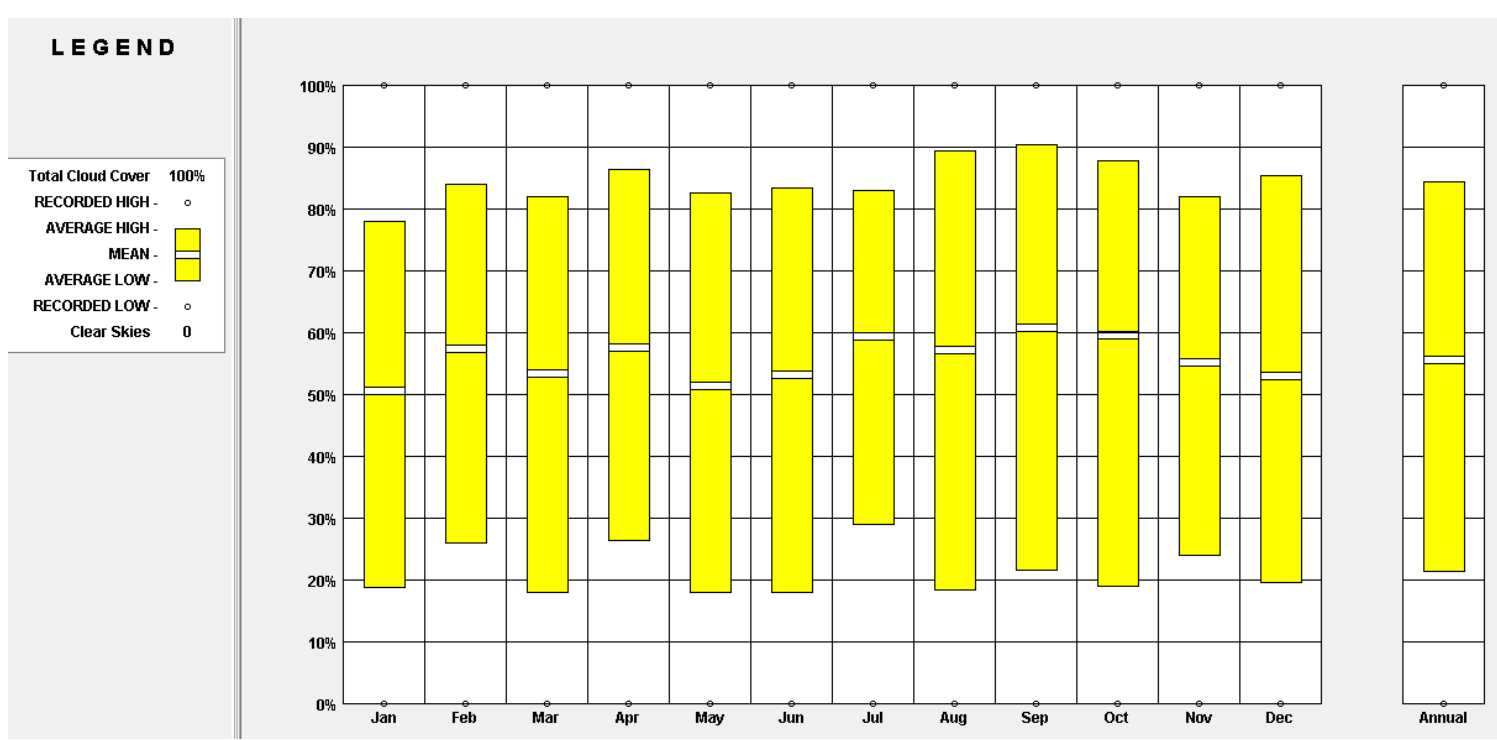

Figura 52: Nubosidad anual. Fuente: Climat Consultant.

La velocidad promedio anual de vientos es del orden de los $3 \mathrm{~m} / \mathrm{s}$, con velocidades máximas medias cercanas a los $8 \mathrm{~m} / \mathrm{s}$ y mínimas medias de $2 \mathrm{~m} / \mathrm{s}$, sin demasiadas variaciones mensuales (Figura 53).
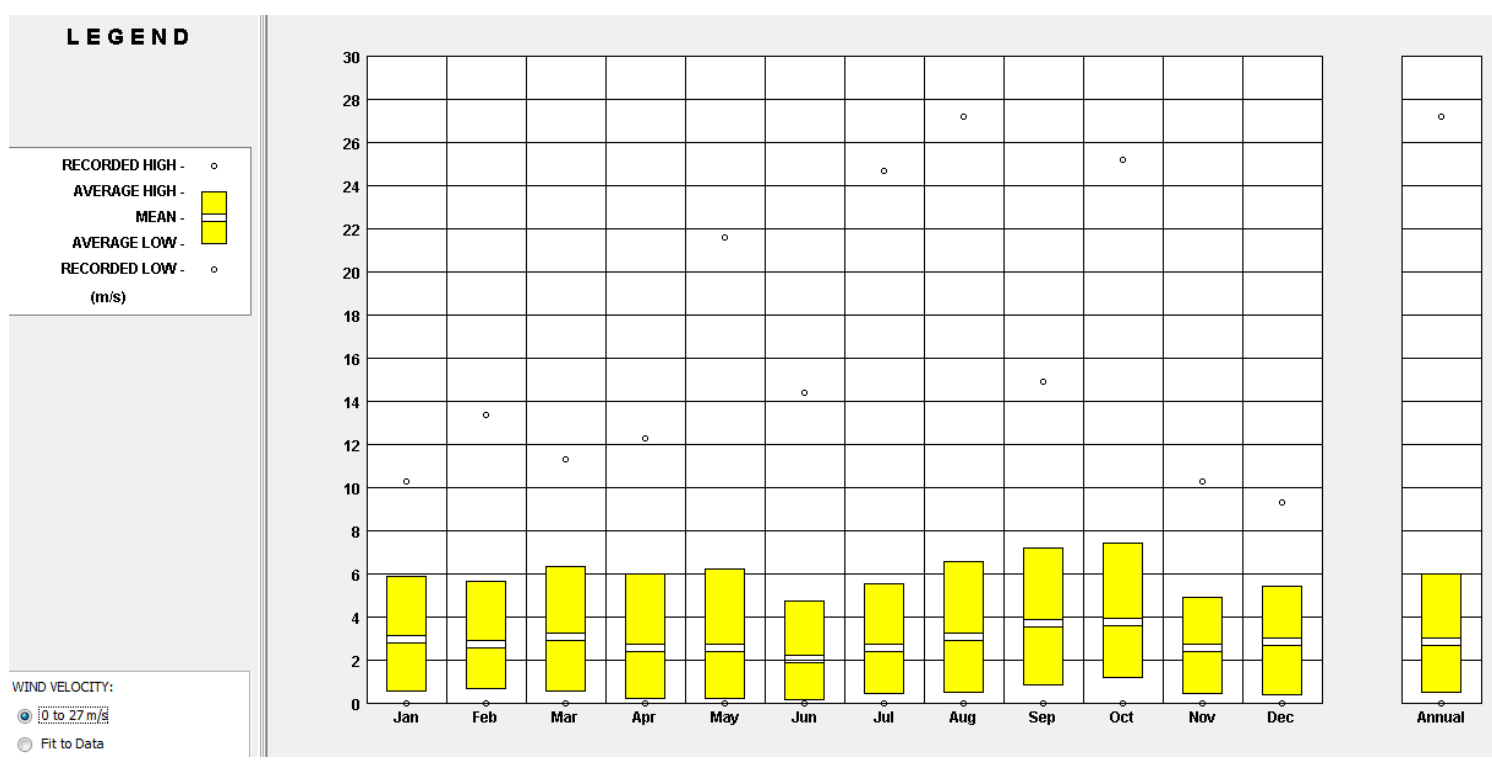

Figura 53: Velocidad del viento anual. Fuente: Climat Consultant.

\subsubsection{Procedimiento de medición}

Para obtener datos reales que permitan calibrar el modelo energético, se registró la temperatura del aire interior y la humedad relativa de 7 unidades funcionales ubicadas en la Torre 1 del Residencial. Tres de ellas orientadas hacia el noreste y cuatro de ellas al sudoeste. En cuanto a la altura, se registraron los datos de 2 viviendas situadas en el primer piso, 3 en el cuerpo de la torre y 2 en el último piso (Figura 54). Se encontró una diferencia de $1,8^{\circ} \mathrm{C}$ entre la temperatura interna promedio de verano registrada en los departamentos situados en el cuerpo del edificio y aquellos ubicados en el último piso, y una variación de $1,3^{\circ} \mathrm{C}$ para la condición de invierno. Con relación a la unidad funcional ubicada en el primero piso y aquellas situadas en el cuerpo del edificio, esa diferencia ha sido de $1,2^{\circ} \mathrm{C}$ y $0,8^{\circ} \mathrm{C}$ para verano e invierno respectivamente. 
Se consideró que la diferencia entre las temperaturas registradas es pequeña, y se verificó que las viviendas orientadas al sudoeste presentan las condiciones higrotérmicas más críticas. A partir de eso, se adoptaron las mediciones de la unidad funcional 303 para dar procedencia a la etapa de ajuste del modelo energético ya que se encuentra en el cuerpo del edificio y consiste la referencia más representativa en comparación con las unidades del primer y del último piso. La etapa relacionada con el ajuste del modelo se detalla en 7.2 Validación del modelo energético.

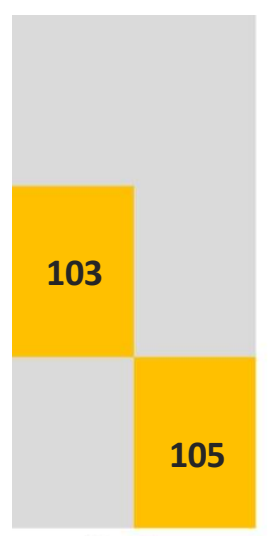

10 piso

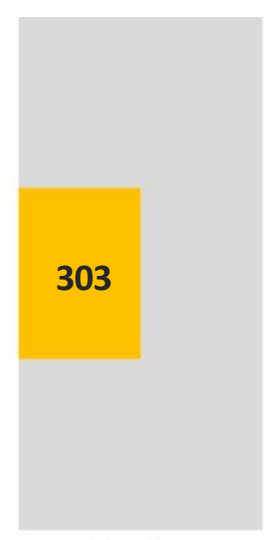

3ำ piso

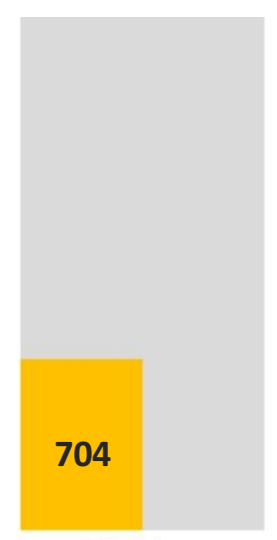

70 piso

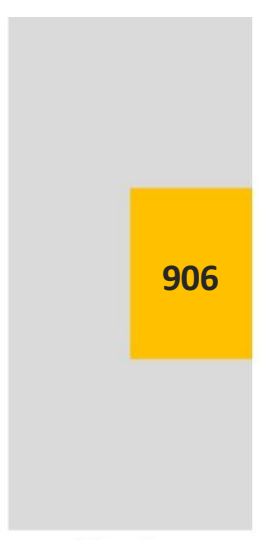

9o piso

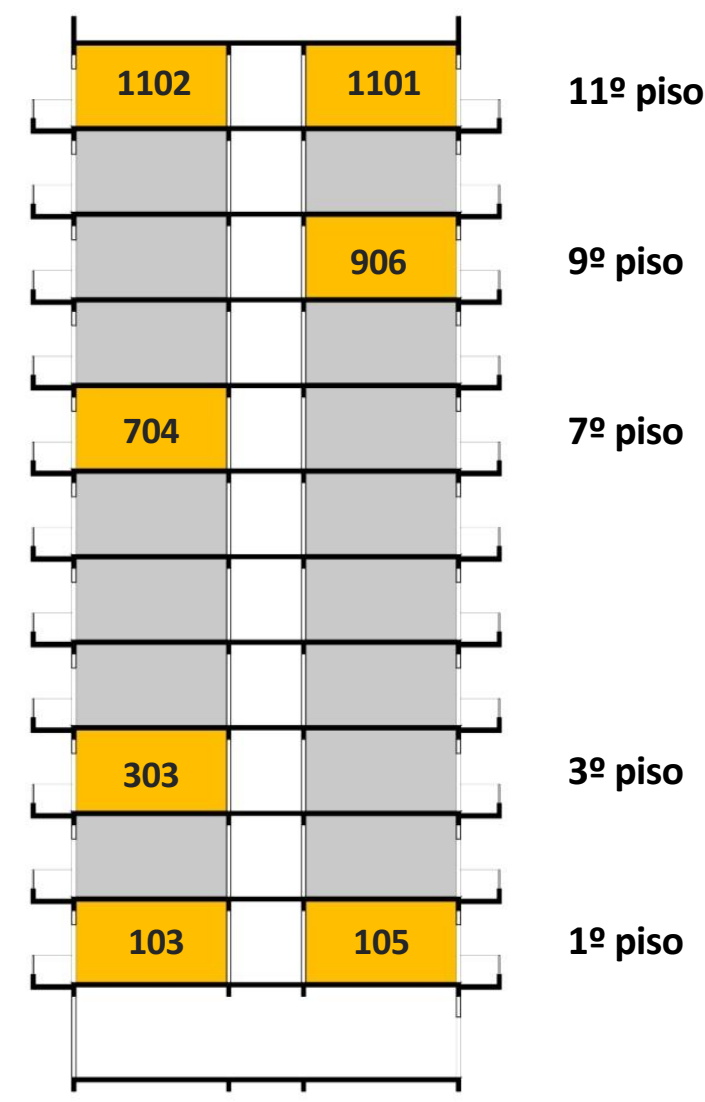

110 piso
11021101

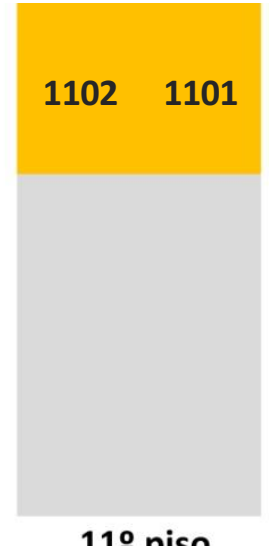


Para la medición de la temperatura y humedad interna se han utilizado 2 micro adquisidores de datos Hobo UX100-003 por vivienda, ubicados a una altura de $150 \mathrm{~cm}$ del piso y protegidos de la posible incidencia de radicación solar directa. El sensor 1 se colocó en el estar comedor integrado a la cocina y al área de servicio, con una puerta ventana orientada el oeste (Figura 55). El sensor 2 se colocó en el dormitorio con una ventana orientada al oeste. Conforme las especificaciones del fabricante, la precisión del sensor para entornos en interiores tales como residencias, oficinas, centros comerciales, escuelas y hospitales es de $3,5 \%, 0 \pm 0.21^{\circ} \mathrm{C}$ y su resolución es de $0.024^{\circ} \mathrm{C}$.

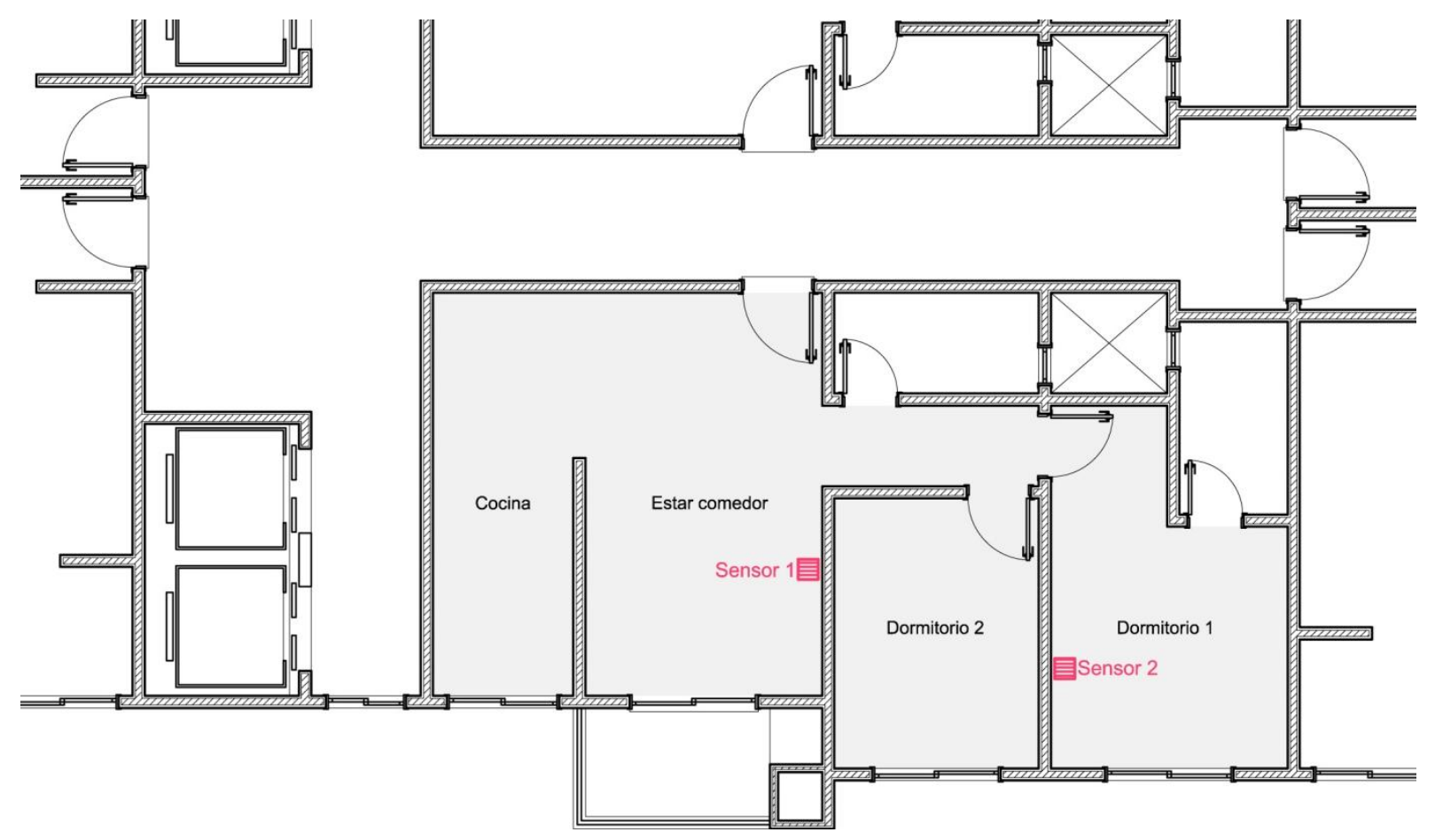

Figura 55: Ubicación de los sensores en planta - unidad funcional 303. Elaboración propia.

Para los datos exteriores se ha empleado un micro adquisidor Hobo UX100-003 el cual registra temperatura, humedad y radiación, con una precisión de $3,5 \%, \mathrm{o} \pm 0.21^{\circ} \mathrm{C}$ y resolución de $0.024^{\circ} \mathrm{C}$. El sensor 3 se ubicó afuera del edificio, en una zona común resguardado de la incidencia solar directa y de la precipitación. No ha sido posible medir los consumos energéticos en el momento de colocación de los sensores, dado que se todos los medidores encuentran en una zona de acceso restricto a los administradores del edificio.

\subsubsection{Condiciones del ambiente interior}

Los valores de temperatura y humedad han sido graficados en la carta bioclimática con el fin de contrastar los datos teóricos con la opinión de los usuarios. Se adoptó la carta de Givoni adaptada para climas cálidos y templados, dado que lleva en consideración la adaptabilidad del usuario a diferentes rangos de temperatura y humedad (Roriz, Ghisi e Lamberts 1999).

El primer rango de confort establecido considera valores de humedad que varían entre $30 \%$ y $50 \%$, en cuanto el según rango de confort considera la adaptación del usuario a valores de humedad de hasta 
$80 \%$. La temperatura para la zona de confort con baja humedad varía entre los $18,5^{\circ}$ y $27,5^{\circ}$, en cuanto la zona de alta humedad considera temperaturas entre $17^{\circ}$ y $26^{\circ}$ (Figura 56).

Según el monitoreo realizado, durante la semana estival el estar comedor registró 3,24\% de las horas medidas en condiciones de confort térmico considerando bajos niveles de humedad, la adopción de una vestimenta liviana, la realización de actividades moderadas, y sin aplicar ninguna estrategia de climatización. Si consideramos el empleo de la ventilación natural con adaptación de los usuarios a valores de humedad de hasta $80 \%$, este porcentaje aumenta para el $28,70 \%$ de las horas medidas. Para el dormitorio, estos valores son de $0,46 \%$ y $10,19 \%$ respectivamente.

En la semana de monitoreo invernal, el estar comedor posee $6,94 \%$ de las horas medidas entre los rangos de confort, considerando bajos niveles de humedad, el uso de vestimenta mediana con realización de actividad moderada, y la ausencia de estrategias pasivas. Al incluir el aporte de la radiación solar al ambiente y la adaptación de los usuarios a valores de humedad de hasta 80\%, este porcentaje aumenta a $49,8 \%$ de las horas registradas en el monitoreo. Para el dormitorio estos valores son de $4,24 \%$ y $38,89 \%$ respectivamente (Figura 56).

Este análisis demuestra que teóricamente el verano es más riguroso que el invierno, y que teniendo en cuenta la aplicación de estrategias pasivas y la adaptabilidad del usuario, es más probable alcanzar condiciones de confort en invierno que en verano. Los ocupantes de la vivienda indican coincidir en que las condiciones del clima en invierno son menos rigurosas que las de verano, entretanto el disconfort térmico se siente principalmente en invierno, ya que en verano es posible aplicar un mayor número de alternativas de climatización pasivas. Durante el invierno los usuarios facilitan el ingreso de la radiación natural en el ambiente para alcanzar mayores condiciones de confort térmico. Durante el verano, hacen uso del ventilador, de cortinas blackout para evitar el ingreso de la radiación directa al ambiente, y emplean la ventilación natural. Tanto en invierno como en verano es importante controlar las variaciones de humedad, ya que potencia la sensación de disconfort térmico percibida por los usuarios.

Estos resultados, así como los datos obtenidos en la etapa 6.1 Aplicación de las encuestas demuestran que los ocupantes adoptan diferentes tipos de vestimenta, intensidad de ventilación y rangos de temperaturas para alcanzar el confort, como sugiere Givoni en su carta adaptada para climas cálidos y templados, el Standard Ashrae 55, demás regulaciones centradas en el confort adaptativo, y diversas investigaciones (Roriz, Ghisi e Lamberts 1999) (American Society of Heating, Refrigerating, and Air Conditioning Engineers 2004) (Filippín, Flores Larsen e Marek 2015) (Ganem, Coch e Esteves 2008) (Ruiz e Correa 2015) (Trebilcock, et al. 2017) (Barbadilla Martín, et al. 2017). 


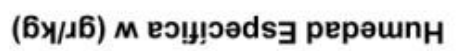

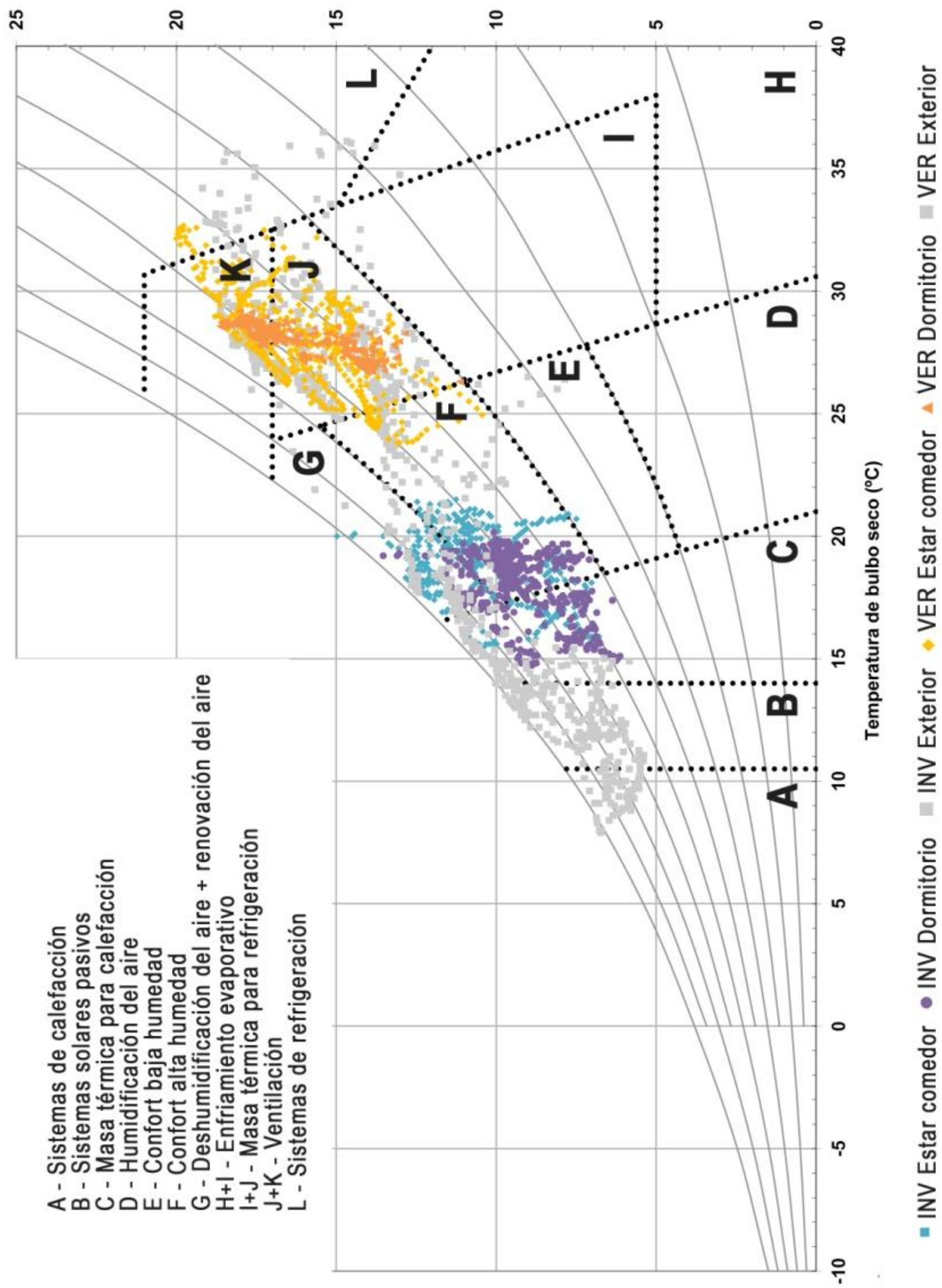

Figura 56: Registro de temperatura y humedad medido en el cuadro bioclimático adaptado. Elaboración propia adaptada de (Roriz, Ghisi e Lamberts 1999). 


\section{Conclusiones}

En esta etapa se aplicó una encuesta online a los habitantes del Caso II, un edificio multifamiliar de mediano porte situado en el centro de Criciúma, una localidad del sur de Brasil con clima templado. Su desarrollo permitió realizar importantes aproximaciones para definir los parámetros de ocupación que se requieren en la etapa de simulación energética (ANEXO II - Tomo II).

También se llevó a cabo el registro de los valores de temperatura y humedad interior de 7 unidades funcionales situadas en el Caso II, permitiendo a los autores acceder a datos reales necesarios para validar el modelo energético en la etapa de simulación energética (Figura 56).

Entre una población estimada de 480 habitantes, se registró una tasa de respuesta de las encuestas aplicadas del $11 \%$.

A modo de resumen, se rescatan los siguientes aspectos considerados para asignar al modelo energético (Tabla 35):

I. El grupo familiar debe poseer una estructura familiar tradicional, con actividades y modos de ocupación usuales de una familia de clase media insertada en nuestra sociedad.

II. De los resultados observados se adopta el número de usuarios por unidad funcional, los períodos de ocupación, las actividades realizadas y las preferencias de vestimenta.

III. La delimitación de los estándares de climatización y ventilación del edificio, tanto para el ajuste del modelo, como para los cálculos de consumo energético se debe fundamentar en el confort adaptativo.

IV. Las simulaciones de consumos energéticos con acondicionamiento térmico deberán contemplar sistemas para refrigeración y para calefacción.

$V$. Se deben mantener los elementos y materiales originales para el ajuste del modelo computacional y modificar solamente los cerramientos opacos para la simulación energética, conforme los estándares definidos en 4.3.5 Definición de los escenarios de cálculo. 



\section{PARTE II}

\section{cuantificación del consumo energético}

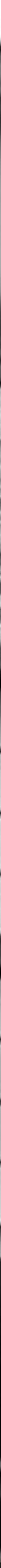




\section{Objetivo del capítulo}

En este capítulo se ejecutarán las actividades necesarias para definir el consumo energético en acondicionamiento de los Casos de Estudio aplicados a las 42 ciudades de Argentina, Brasil, Chile, España y México, con el fin de construir la base de datos de la variable dependiente que será empleada en los cálculos de correlación múltiple (Figura 57).

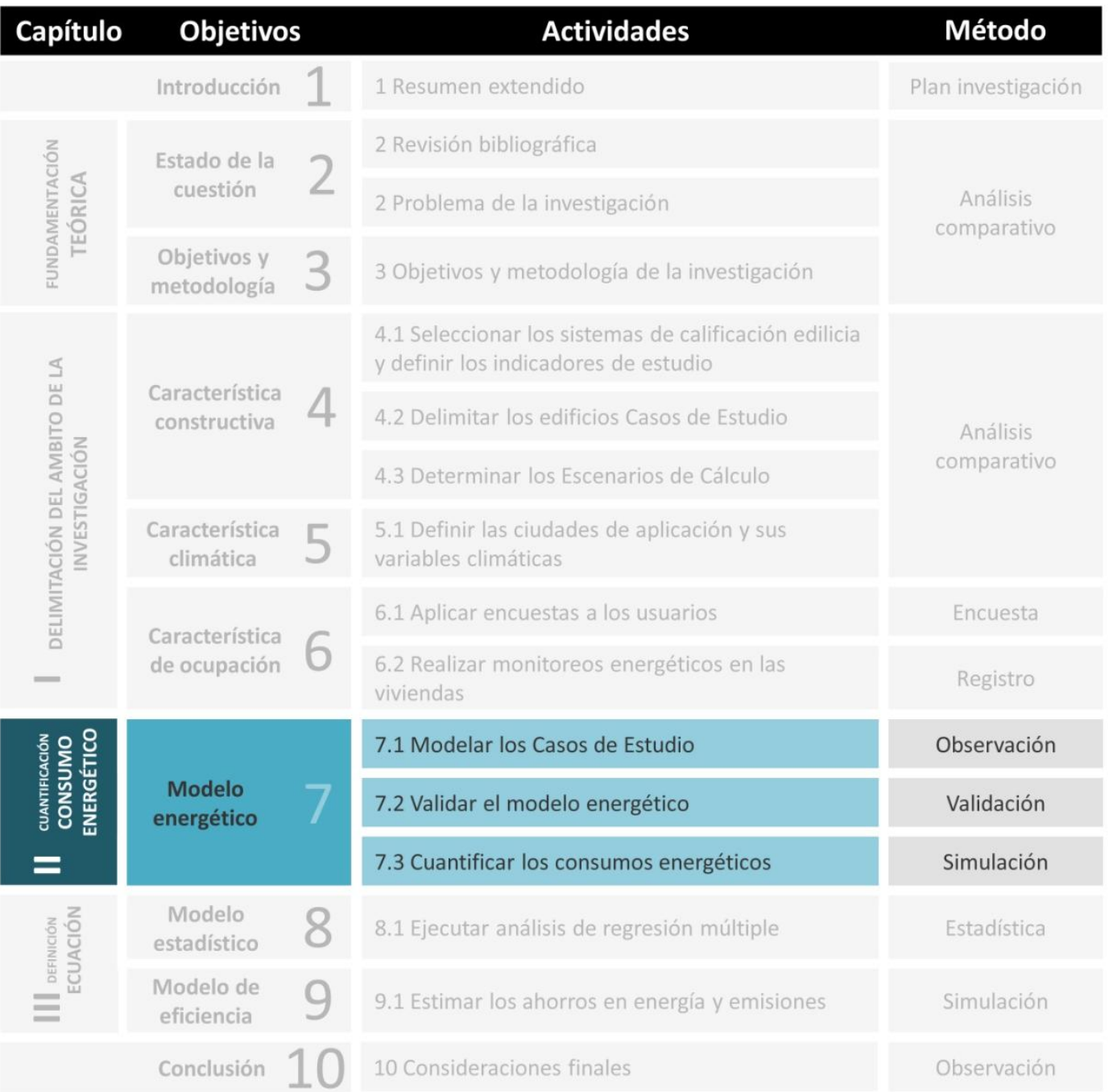

Figura 57: Esquema metodológico Parte II - Cuantificación del consumo energético. Elaboración propia. 


\section{Modelo energético}

\section{Objetivo}

En esta etapa se modelarán los Casos de Estudio seleccionados, asignando las características del edificio, del clima, y de uso y ocupación especificados en la Parte I.

Se realizará la validación del Caso II a partir de la identificación de los parámetros de ajuste del modelo edilicio computacional, con el fin de que las series de temperatura simuladas sean aproximadas a las series registradas en el edificio real.

Y se cuantificarán los consumos en acondicionamiento de ambos Casos de Estudio simulando su aplicación a las 42 localidades de Argentina, Brasil, Chile, España y México definidas en la Parte I. Se considerarán dos situaciones, una adoptando la tipología tradicional - Escenario I, y la segunda adoptando los estándares definidos por cada país, modificando consecuentemente los Escenarios de Cálculo. 


\subsection{Construcción del modelo energético}

Posterior a la definición de las diferentes características necesarias para asignar a los Casos de Estudio, se procedió a la etapa de construcción y ajuste del modelo edilicio, para en seguida realizar las simulaciones energéticas.

La etapa de simulación se fundamenta en estimaciones realizadas para el edificio, considerando los consumos de cada unidad funcional por separado. La etapa de validación del modelo teórico se reduce al análisis apenas del estar comedor del departamento 302, de forma que la aproximación se encuentre lo más controlada posible. Se entiende que una vez que la etapa de calibración se encuentre concluida, el modelo es suficientemente adecuado para proporcionar estimaciones para los consumos energéticos de la totalidad de las unidades funcionales.

\subsubsection{Modelado de los edificios}

Las actividades realizadas para construir el modelo se centraron en (I) dibujar el edificio, (II) definir materiales y elementos de la envolvente, (III, IV) asignar las características de ocupación, calefacción, ventilación y refrigeración, y (V) fijar las condiciones de cálculo para cada localidad (Figura 58 - ANEXO III).

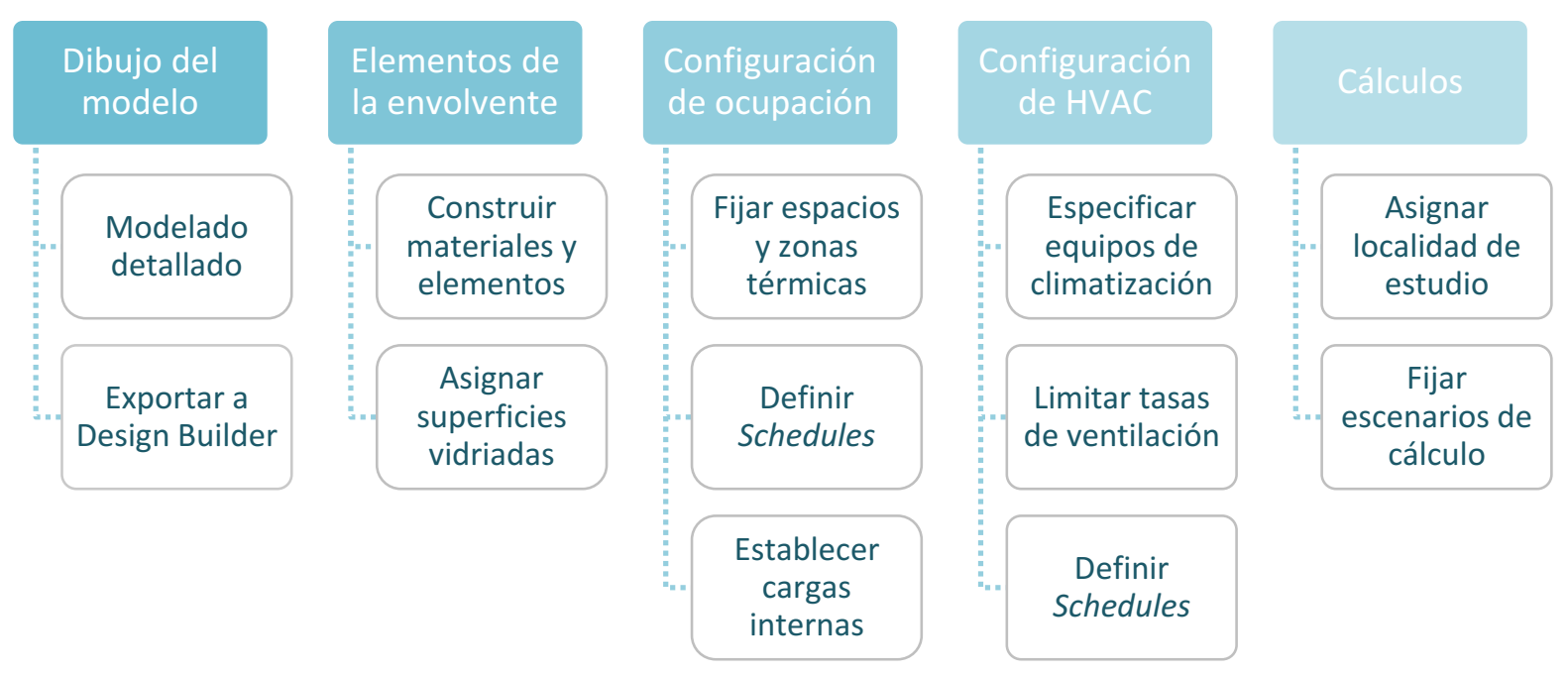

Figura 58: Etapas realizadas en el proceso de construcción del modelo teórico. Elaboración propia.

El modelado de los edificios se realizó en el software Autodesk Revit - Versión 2016 licencia para estudiante, en cuanto las configuraciones del modelo y los cálculos de simulación energética se ejecutaron a través del Design Builder - Versión 5.0.0.137 licencia Universidad de Sevilla. El motor de cálculo utilizado por Design Builder es el DOE-2 y los archivos de datos climáticos horarios poseen extensión EPW para localidades latinoamericanas, y extensión IWEC para localidades españolas.

La etapa de diseño de los edificios se realizó a través de un modelado detallado en Revit, respetando sus divisiones internas, los elementos en contacto con el exterior y aquellos en contacto con superficies acondicionadas. Una vez en la interfaz del Design Builder, se crearon los materiales y elementos opacos de la envolvente, conforme lo definido en 4.3 Definición de los escenarios de cálculo. Para las superficies 
translucidas se adoptó una carpintería de aluminio con vidrio simple de $3 \mathrm{~mm}$, sin protección, conforme las carpinterías existentes en el edificio analizado.

Las características de ocupación se asignaron según el uso de cada espacio definido en 6.Características de uso y ocupación. Las particularidades de los sistemas de acondicionamiento y ventilación se determinaron para cada zona térmica, en función de los datos recogidos en la etapa de medición y de aplicación de las encuestas (Tabla 35).

\begin{tabular}{|c|c|c|c|c|c|c|}
\hline Ocupación y HVAC & Dormitorio P & Dormitorio S & Estar comedor & Cocina & Baño & Área servicio \\
\hline Personas & 2 & 1 & 2 & 1 & 1 & 1 \\
\hline Horas & 8 & 8 & 4 & 2 & 2 & 2 \\
\hline Actividad & Dormir & Dormir & Leer/comer & Cocinar & Duchar & Limpiar \\
\hline Metabolismo (W/pers) & 72 & 72 & 110 & 230 & 180 & 230 \\
\hline Vestimenta (clo) & \multicolumn{6}{|c|}{ Verano $=0,3 \mid$ Invierno $=1,0 \mid$ Primavera otoño $=0,7$} \\
\hline Zona térmica & \multicolumn{3}{|c|}{$1,2,3, \mathrm{n}$} & \multicolumn{3}{|c|}{ Ventilado } \\
\hline Temperatura setpoint & \multicolumn{3}{|c|}{ Mínima $=18 \mid$ Máxima $=25$} & \multicolumn{3}{|c|}{ Ventilado } \\
\hline Renovaciones (n/h) & & & 2 & & & \\
\hline
\end{tabular}

Tabla 35: Configuración de las características de ocupación y sistemas HVAC. Elaboración propia.

Para las características de ocupación se adoptaron las características recogidas en las respuestas de los usuarios. Se consideró dos habitantes para los departamentos de 2 dormitorios y 4 habitantes para los departamentos de 3 dormitorios. Las tareas diarias establecidas se segmentaron entre 8 horas para dormir, 8 horas para trabajar y realizar diligencias, 2 horas para comer y cocinar, 2 horas para higiene y limpieza y 4 horas para desarrollar actividades de ocio. La vestimenta adoptada ha sido tropical para verano (pantalón corto, camisa manga corta y sandalias - clo $=0,3$ ), intermedia para primavera y otoño (clo $=0,5)$ y abrigada liviana para invierno (camisa de manga larga, pantalón grueso, jersey, calcetines gruesos, zapatos - clo $=1,0)$. Para la carga del uso diario de artefactos eléctricos se consideró una heladera enchufada $24 \mathrm{hs}$, dos computadoras y dos televisores utilizados por dos horas, y una ducha por $1 \mathrm{hora}$. Se adoptó la iluminación natural para el periodo comprendido entre las 8:00 hasta las 18:00hs, y una lámpara fluorescente por cada espacio para el rango horario de las 18:00 hasta las 22:00 hs.

Se definió que el edificio dispondrá de la instalación primaria para permitir la implementación de sistemas de refrigeración y de calefacción en las unidades funcionales, y que la producción de calor se realizará con gas natural, en cuanto la extracción del calor con energía eléctrica.

La delimitación de los estándares de climatización se centró en el confort adaptativo, asignando la condición de ventilación natural y de renovaciones de aire para que sea posible ventilar la vivienda de forma híbrida durante todo el año, respetando los datos recogidos en el apartado 6.Características de uso y ocupación. Como no ha sido posible identificar una constante en el horario de apertura de las ventanas, se fijaron 2 renovaciones por hora, según la IRAM 11.604/01 (Instituto Argentino de Normalización y Certificación 2004). Se definió la consigna de que en cuanto haya condición de temperatura y presión 
favorable se hará uso de la ventilación natural, mientras que cuando sea desfavorable se complementará con ventilación mecánica, la cual también de definió la configuración de 24/7.

Para el funcionamiento de los equipos también se ha aplicado la consigna $24 / 7$, siempre que se encuentre por encima de las temperaturas de setpoint asignadas. Para el encendido del equipo de climatización se delimitó que la temperatura operativa (ver 7.2 Validación del modelo energético) debe ser igual o superior a $18^{\circ} \mathrm{C}$ para invierno, e igual o inferior a $27^{\circ} \mathrm{C}$ para verano, respetando los límites establecidos por la carta bioclimática de Givoni adaptada a climas cálidos y templados (Roriz, Ghisi e Lamberts 1999). Los valores de coeficiente de rendimiento - COP adoptados han sido del 2.00 para la refrigeración y 0.92 para calefacción, según las especificaciones del CTE (Ministerio de la Vivienda 2007).

Los baños, áreas de servicio, así como los espacios de circulación común del edificio no han sido acondicionados, mientras que los dormitorios, estar comedor y cocina se agruparon en una única zona térmica, definida según la sectorización de cada unidad funcional.

Una vez concluida la etapa de configuración, se seleccionó la localidad original en donde se encuentra situado el edificio auditado para ajustar el modelo energético. En la etapa de simulación se ha repetido el procedimiento de modificación de la localidad de aplicación para todas las ciudades definidas en 5.1 Selección de las localidades de aplicación, así como se ha realizado la diferenciación de los elementos opacos de la envolvente del edificio, según los estándares definidos en 4.3 Definición de los Escenarios de cálculo. 


\subsection{Validación del modelo energético}

La comparación entre las predicciones del modelo teórico y los registros experimentados permite comprobar si el modelo desarrollado es válido. Una manera sencilla de realizar esta prueba consiste en graficar ambas series temporales y verificar las diferencias y aproximaciones existentes entre ellas. Para ello, se realizó la comparación entre la variación de la temperatura interna registrada en la etapa de medición, con la temperatura estimada para el modelo teórico en variación libre (Figura 59 y Figura 60).

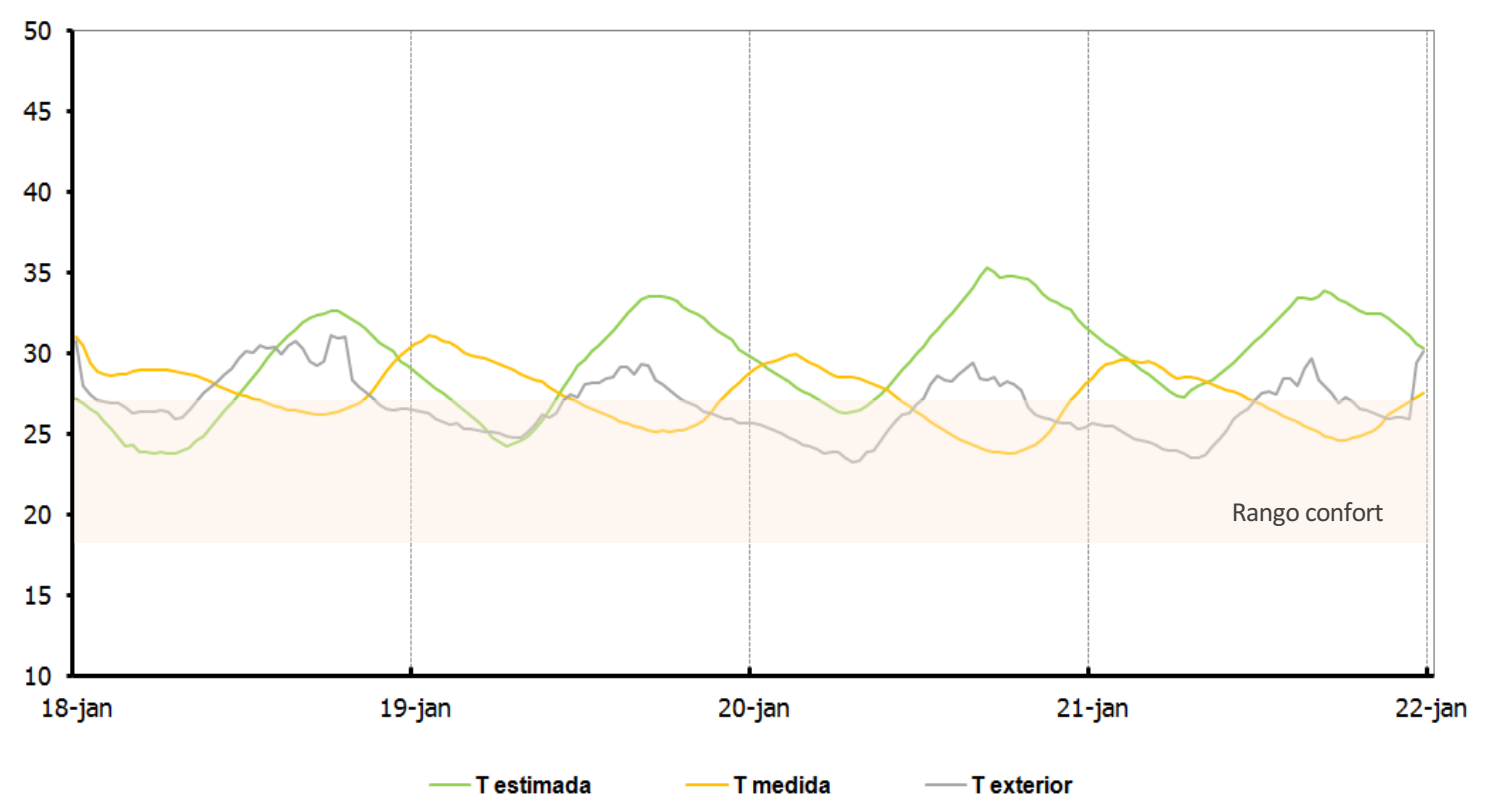

Figura 59: Variación de la temperatura interior medida y estimada para verano. Elaboración propia.

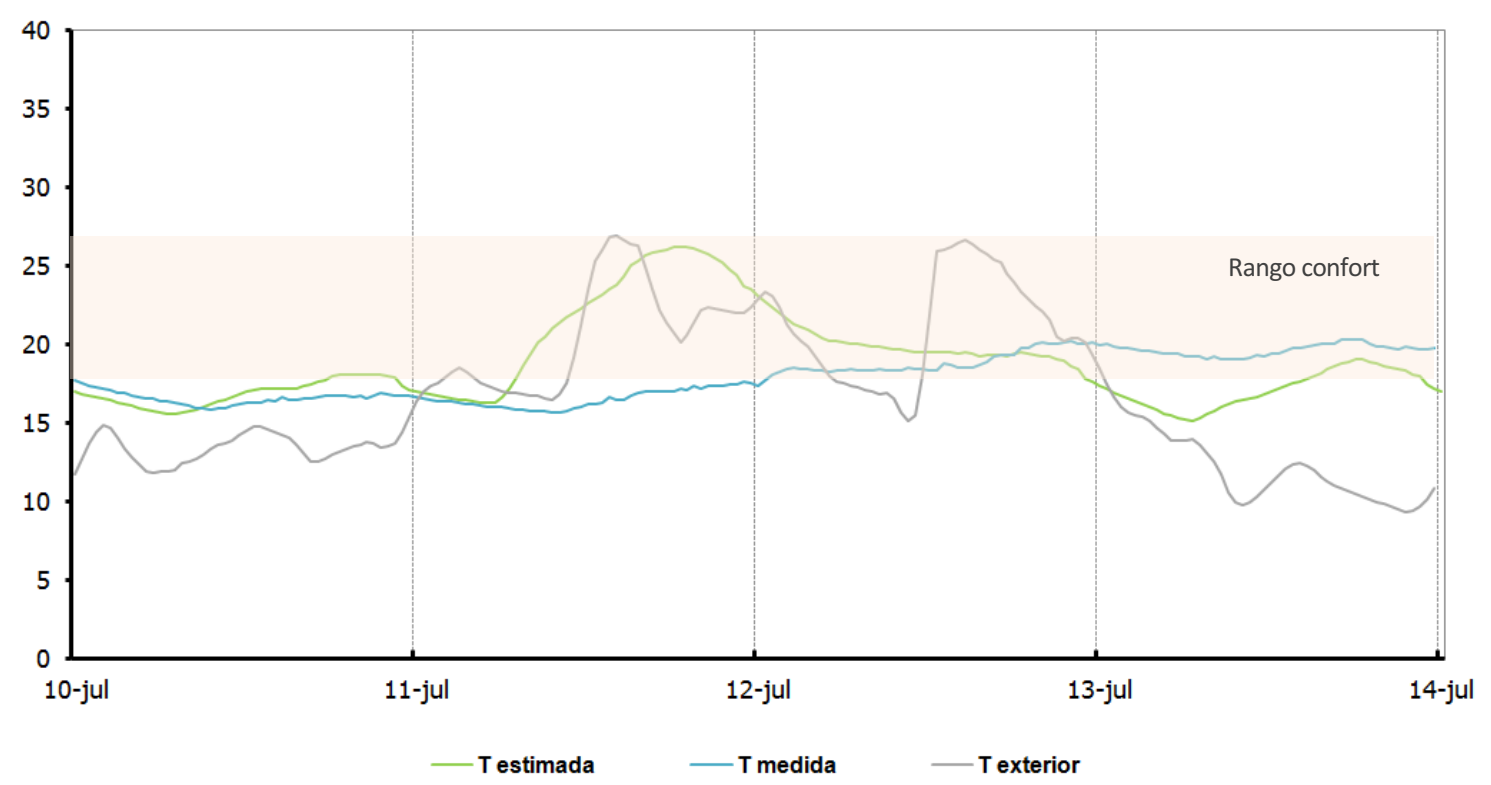

Figura 60: Variación de la temperatura interior medida y estimada para invierno. Elaboración propia.

Se verifica que las series de temperatura interior estimada tienden a acompañar la variación de la temperatura exterior, tanto en verano como en invierno; en cuanto la serie de temperatura interior medida en verano, presenta un retraso térmico de aproximadamente 11 horas respecto la temperatura exterior (Figura 59 y Figura 60). 
Se observa que la serie de la temperatura interior medida en la semana de verano registra valores máximos de $31.1^{\circ} \mathrm{C}$, en cuanto la temperatura interior estimada alcanza picos de $35.3^{\circ} \mathrm{C}$ (Figura 59). En invierno la temperatura interior medida registra valores máximos de $20.3^{\circ} \mathrm{C}$, en cuanto la temperatura interior estimada alcanza picos de $26.2^{\circ} \mathrm{C}$ (Figura 60).

En este caso la diferencia entre los picos de temperatura medida y estimada no ocurre en el mismo momento, sino que con un desfasaje de un día y medio. Cuando analizamos la variación para el 11 de julio a las $18: 30 \mathrm{hs}$ se verifica que el pico de la temperatura medida es de $17.0^{\circ} \mathrm{C}$, en cuanto la temperatura estimada es de $26.2^{\circ} \mathrm{C}$ (Figura 60).

Estos resultados demuestran que el modelo energético predice una temperatura interna de hasta $9^{\circ} \mathrm{C}$ superior a la temperatura registrada en la medición, por lo que se entiende que realiza una estimación por encima de los valores reales experimentados, además de que los cambios de calor en el interior del ambiente simulado ocurren muy concomitantemente con la oscilación de la temperatura exterior.

Este estudio demuestra que la técnica empleada es práctica ya que permite identificar las desviaciones entre la simulación y la medición, sin embargo, la complejidad de un análisis cualitativo a partir de las estimaciones realizadas dificulta el establecimiento de un criterio de validación positivo.

Para poder cuantificar las diferentes fuentes de incertidumbre presente en este estudio, y poder verificar la validez del modelo teórico, se observan las características de la medición experimental realizada, la significancia de los parámetros del modelo y de su estructura, y las posibles alteraciones en la respuesta del modelo.

\subsubsection{Análisis de incertidumbre}

\subsubsection{Incertidumbre de los datos registrados}

La resolución finita de los sensores empleados en las mediciones realizadas en una auditoría energética, otorgan determinado grado de incertidumbre a los datos registrados. De hecho, la mayoría de los fabricantes proporcionan los métodos de cálculo para determinar el porcentaje de la incertidumbre de los sensores en función de sus condiciones de operación.

Dado que la temperatura del aire interior corresponde a la principal variable de análisis en las futuras simulaciones, se analizó la incertidumbre vinculada a su medición, según los procedimientos definidos en la ISO 98 Parte 3: Guía para la expresión de incertidumbre en la medición (International Standarization Organization 2008), debido a la convención internacional en su utilización (Miranda Enríquez 2013).

Se adoptó la evaluación tipo B de la incertidumbre típica ya que se conocen los datos de las mediciones, así como las especificaciones del fabricante. Se considera: la precisión del sensor, la diferencia entre la temperatura del aire en el ambiente medido, la resolución del sistema de adquisición de los datos, y un factor de cobertura K = 2 (Ecuación 2).

$$
u\left(T_{i}\right)=\mathrm{k} \sqrt{\mathrm{u}_{\mathrm{sT}_{\mathrm{i}}}^{2}+\mathrm{u}_{\mathrm{dT}_{\mathrm{i}}}^{2}}
$$

Ecuación 2: Cálculo de la incertidumbre asociada a la medición de la temperatura interna. Fuente: (International Standarization Organization 2008). 
Donde:

$\mathrm{u}_{\mathrm{ST}_{\mathrm{i}}}=$ es la contribución a la incertidumbre debida al sensor para medir la temperatura interna

$\mathrm{u}_{\mathrm{dTi}}=$ es la contribución a la incertidumbre debida a la localización del sensor

Conforme indican las especificaciones del fabricante, la precisión del sensor para entornos en interiores tales como residencias, oficinas, centros comerciales, escuelas y hospitales es de 3,5\%, o \pm $0.21^{\circ} \mathrm{C}$ y su resolución es de $0.024^{\circ} \mathrm{C}$.

Para analizar la heterogeneidad espacial de la temperatura del aire, se realizó la medición de sus valores en tres localizaciones diferentes del ambiente, dado que el registro varía según la posición que se escoja (Figura 61).

Al igual que en 6.2 Realización del monitoreo energético, se ha medido la temperatura durante siete días del período más crítico de invierno, así como siete días de la semana más crítica de verano. Entretanto, en vez de emplear apenas un sensor a la altura de $1,5 \mathrm{~m}$ en el centro del ambiente, se adicionaron dos sensores, uno a $20 \mathrm{~cm}$ del piso próximo de la pared oeste, y el segundo a $20 \mathrm{~cm}$ del cielorraso próximo de la pared este.

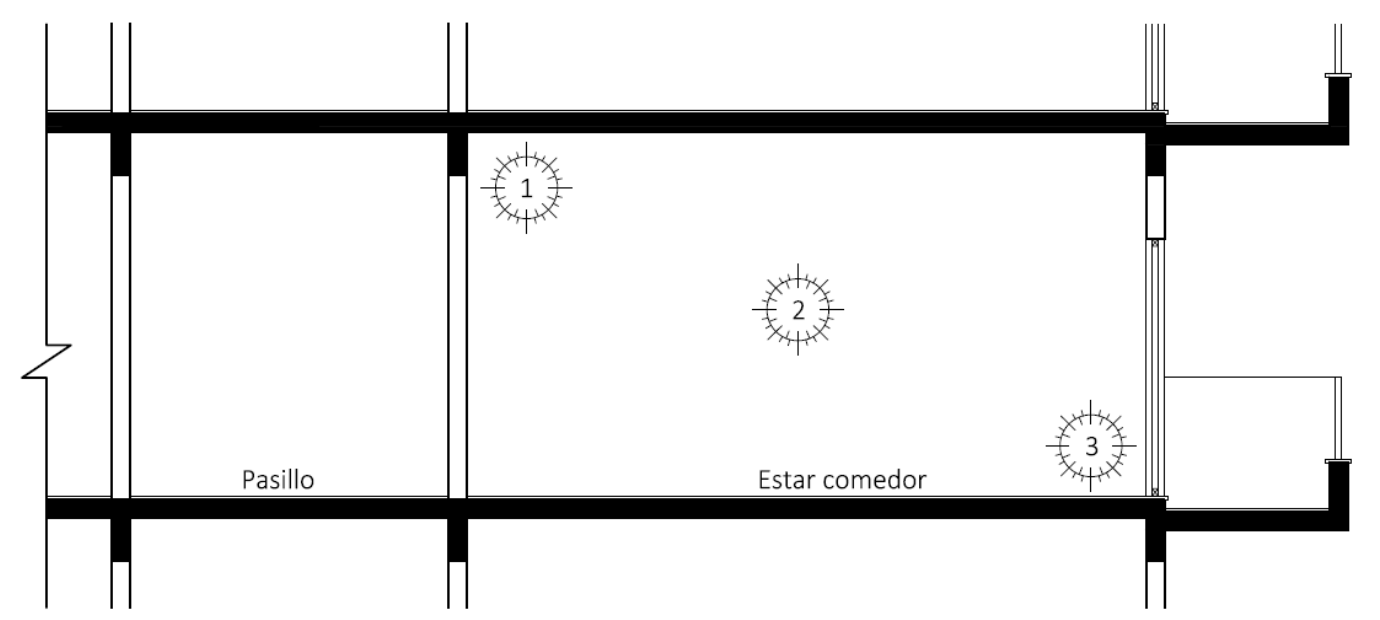

Figura 61: Ubicación de sensores para medir la heterogeneidad espacial de la temperatura del aire. Elaboración propia.

La diferencia de temperatura registrada entre los tres sensores es en torno de $0.59{ }^{\circ} \mathrm{C}$ a lo largo de la serie en verano, $y$ de $0.35^{\circ} \mathrm{C}$ para invierno, por lo que se considera que no existen diferencias significativas entre la temperatura medida en diferentes posiciones del ambiente (Figura 62 y Figura 63).

Para la condición de invierno no se ha verificado diferencias superiores a $0.5 \stackrel{\circ}{ } \mathrm{C}$ entre las diferentes posiciones de medición, por lo que se comprueba de que la estratificación del aire no es significativa. En verano, tanto el sensor ubicado a $25 \mathrm{~cm}$ del piso como el que se encuentra a $250 \mathrm{~cm}$ del piso presentan diferencias de +0.62 ㄷ C y -0.57 ํC respectivamente, en relación al sensor instalado a $150 \mathrm{~cm}$ del piso.

Comparando los datos proveídos por el fabricante de los sensores, y la diferencia de temperatura registrada en los diferentes puntos del ambiente, se observó que la heterogeneidad del aire corresponde a la principal fuente de incertidumbre asociada a la medición de la temperatura interior. La incertidumbre típica total de su medición es de 0.15 드, a un intervalo de confianza del 95\% con un factor de cobertura $\mathrm{k}$ 
$=2$. Por lo tanto, dado que los niveles de incertidumbre relacionados con la medición son bajos y la estratificación del aire en la semana más crítica de verano y de invierno es poco significativa, se mantiene la hipótesis de que todo el aire del ambiente experimental puede ser representado por un mismo valor de temperatura y se concluye que la incertidumbre asociada a la medición es insignificante. Así mismo, se considera válido adoptar una única temperatura de respuesta en los análisis de nivel de confort térmico de cada ambiente del modelo simulado.

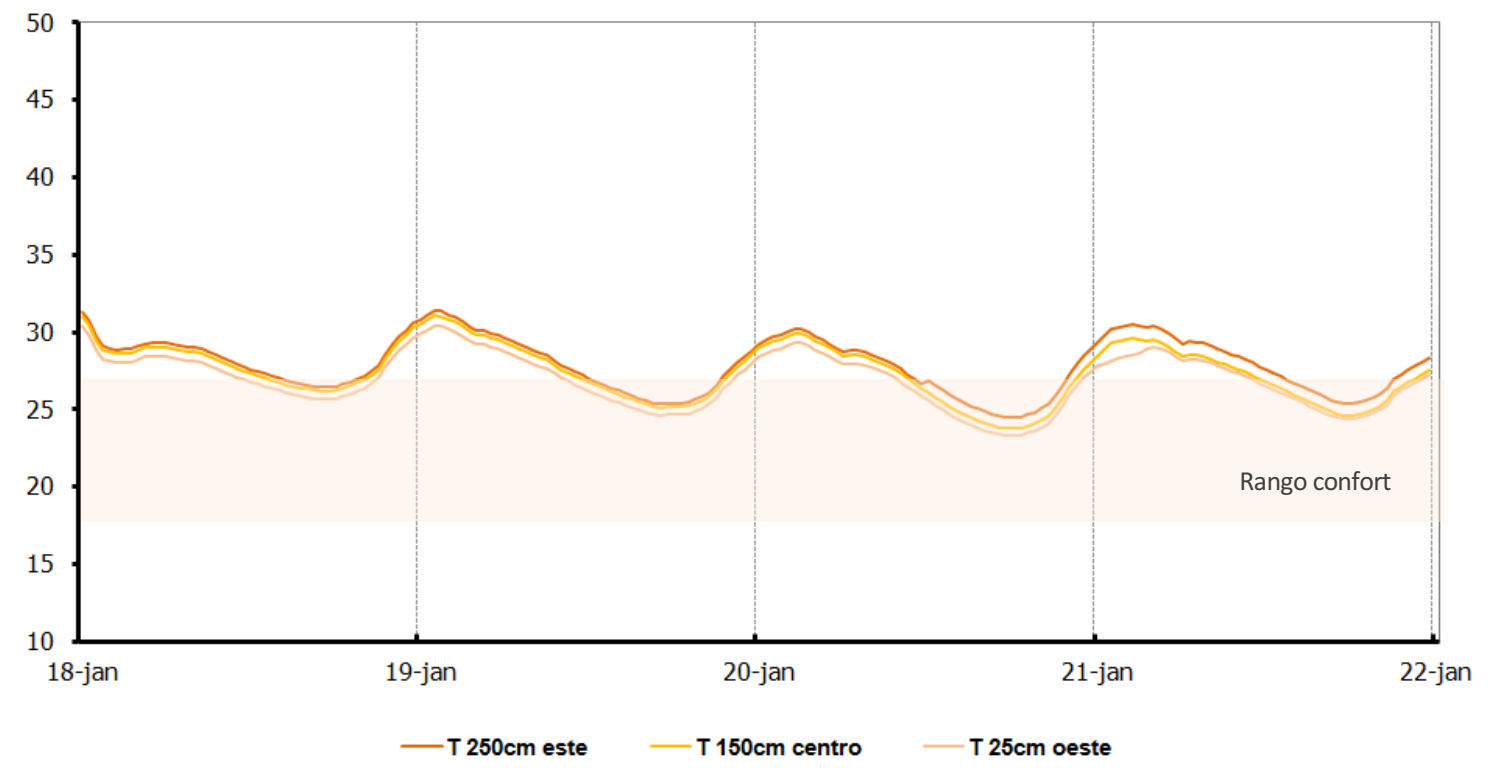

Figura 62: Registro de la temperatura a distintas alturas en el estar comedor - condición de verano. Elaboración propia.

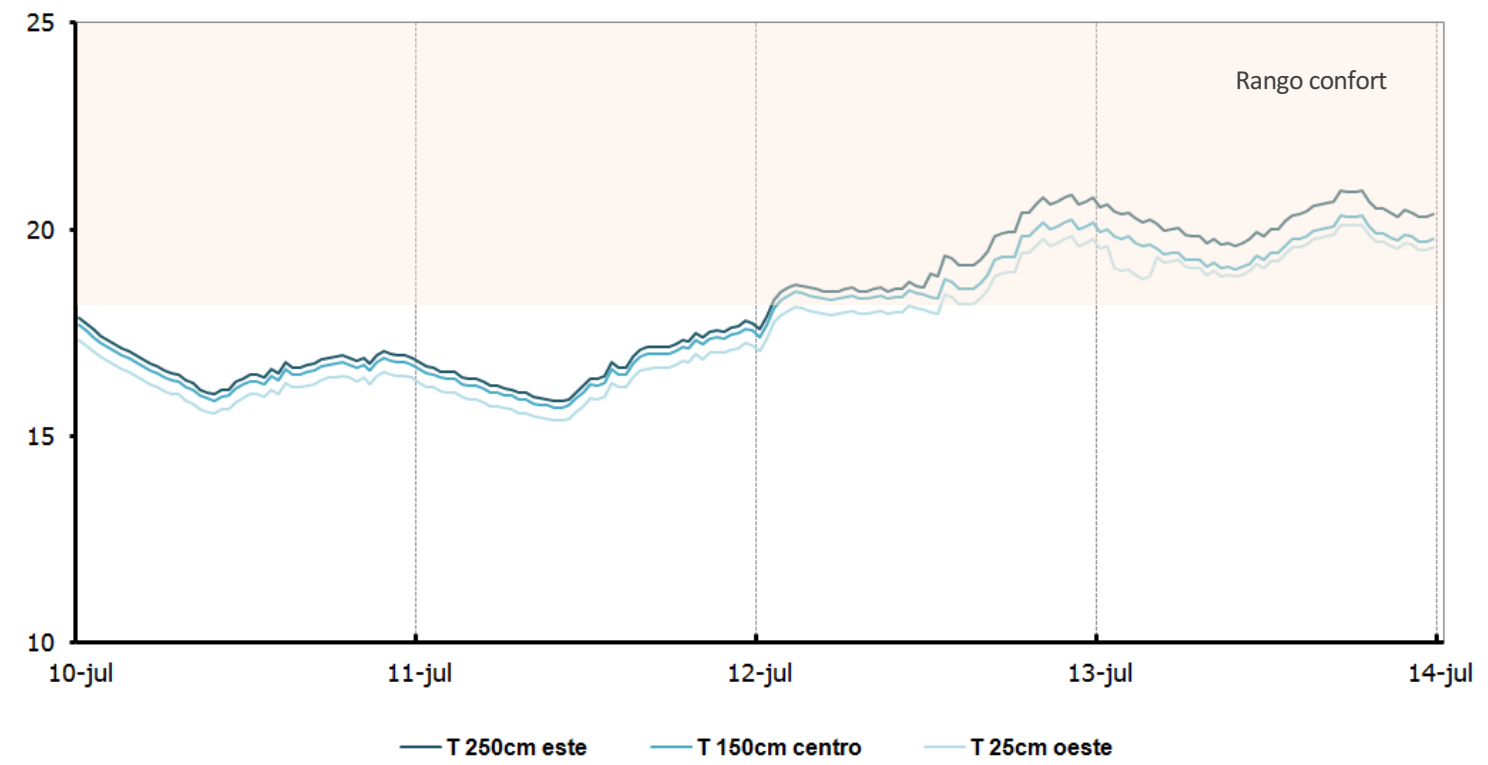

Figura 63: Registro de la temperatura a distintas alturas en el estar comedor - condición de invierno. Elaboración propia.

\subsubsection{Incertidumbre de los parámetros del modelo}

El modelo edilicio teórico posee diversos parámetros inseridos en su diseño, los cuales, a partir de la simulación de un estado, permiten estimar el comportamiento del sistema. Algunos de estos parámetros son considerados activos ya que sus características influencian más fuertemente a una determinada 
variable de respuesta, mientras otros son determinados no activos, ya que no ejercen influencias tan significativas.

Para poder comparar el modelo edilicio teórico con los datos experimentales, es importante conocer cuáles de estos parámetros más afectan la variable de respuesta, ya que van a consistir en los únicos factores posibles de manejar desde la interfaz del programa. Así mismo, también es importante poder identificar la variable de respuesta que más responde a las modificaciones de dichos parámetros para poder hacer una aproximación lo más cercana posible a los datos medidos.

De esta forma el profesional puede proceder con un diseño más asertivo y evitar la modificación de parámetros poco significativos para el ajuste del modelo, los cuales pueden hasta mismo aumentar la diferencia entre la serie real y la estimada en vez de disminuir la incertidumbre del modelo.

Se realizó un análisis de sensibilidad entre tres variables de salida y los parámetros que indican propiedades termofísicas de los materiales, las condiciones generales del edificio y del entorno. Las variables respuestas seleccionadas son la temperatura del aire interior, la temperatura superficial interna y la temperatura operativa del ambiente, en cuanto los parámetros analizados son aquellos correspondientes a los materiales de la envolvente edilicia del ambiente (Tabla 36). Todas las variables utilizadas se extrajeron del Design Builder, considerando el modelo energético objeto de validación.

\begin{tabular}{|c|c|c|c|c|c|c|c|c|c|c|}
\hline Eleme & ento & $n^{\circ}$ & Parámetro & Valor & $\mu$ & $\sigma$ & $\mu_{\mathrm{si}}$ & $\sigma_{\mathrm{si}}$ & $\mu_{0}$ & $\sigma_{\circ}$ \\
\hline \multirow{20}{*}{ 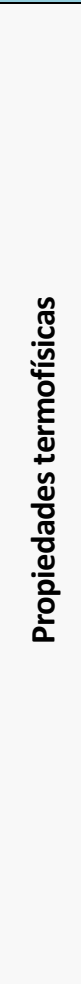 } & \multirow{6}{*}{ 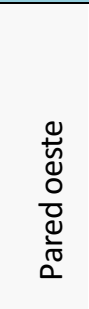 } & 1 & Mortero espesor $(\mathrm{m})$ & 0.02 & 0.00 & 0.01 & 0.00 & 0.01 & -0.01 & 0.08 \\
\hline & & 2 & Mortero conductividad (W/(mK) & 1.30 & -0.02 & 0.03 & 0.07 & 0.00 & 0.01 & 0.02 \\
\hline & & 3 & Mortero calor específico $\left(\mathrm{J} /\left(\mathrm{g}^{\circ} \mathrm{C}\right)\right)$ & 0.83 & 0.00 & 0.00 & 0.03 & 0.03 & 0.00 & 0.03 \\
\hline & & 4 & Mortero densidad $\left(\mathrm{kg} / \mathrm{m}^{3}\right)$ & 1900 & 0.00 & 0.00 & 0.00 & 0.04 & 0.08 & 0.02 \\
\hline & & 5 & Ladrillo hueco espesor (m) & 0.15 & -0.22 & 0.16 & 0.04 & 0.01 & 0.07 & 0.06 \\
\hline & & 6 & Ladrillo hueco conductividad (W/(mK) & 0.75 & 0.11 & 0.00 & -0.04 & 0.00 & 0.21 & 0.13 \\
\hline & \multirow{6}{*}{ 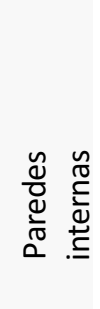 } & 7 & Ladrillo hueco calor específico $\left(\mathrm{J} /\left(\mathrm{g}^{\circ} \mathrm{C}\right)\right)$ & 0.84 & -0.02 & 0.03 & 0.01 & 0.01 & 0.05 & 0.03 \\
\hline & & 8 & Ladrillo hueco densidad $\left(\mathrm{kg} / \mathrm{m}^{3}\right)$ & 2000 & -0.01 & 0.08 & -0.13 & 0.02 & 0.12 & 0.00 \\
\hline & & 9 & Ladrillo hueco espesor (m) & 0.12 & 0.02 & 0.01 & 0.00 & 0.05 & 0.03 & 0.00 \\
\hline & & 10 & Ladrillo hueco conductividad (W/(mK) & 0.86 & -0.14 & 0.03 & -0.21 & 0.01 & -0.19 & 0.11 \\
\hline & & 11 & Ladrillo hueco calor específico $\left(\mathrm{J} /\left(\mathrm{g}^{\circ} \mathrm{C}\right)\right)$ & 0.64 & 0.06 & 0.01 & 0.00 & 0.00 & 0.04 & 0.02 \\
\hline & & 12 & Ladrillo hueco densidad $\left(\mathrm{kg} / \mathrm{m}^{3}\right)$ & 1800 & 0.00 & 0.02 & -0.04 & 0.02 & 0.00 & 0.02 \\
\hline & \multirow{4}{*}{ 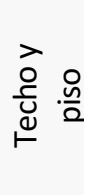 } & 13 & Losa hormigón espesor (m) & 0.15 & 0.01 & 0.04 & 0.03 & 0.04 & 0.01 & 0.04 \\
\hline & & 14 & Losa hormigón conductividad (W/(mK) & 1.10 & 0.08 & 0.00 & 0.02 & 0.00 & 0.11 & 0.10 \\
\hline & & 15 & Losa hormigón calor específico $\left(\mathrm{J} /\left(\mathrm{g}^{\circ} \mathrm{C}\right)\right)$ & 0.83 & 0.06 & 0.00 & 0.00 & 0.01 & 0.04 & 0.02 \\
\hline & & 16 & Losa hormigón densidad $\left(\mathrm{kg} / \mathrm{m}^{3}\right)$ & 2200 & 0.02 & 0.01 & 0.00 & 0.02 & 0.03 & 0.00 \\
\hline & \multirow{4}{*}{$\begin{array}{l}\frac{n}{0} \\
\stackrel{0}{\pi} \\
\stackrel{5}{\pi} \\
\stackrel{0}{\nu}\end{array}$} & 17 & Vidrio espesor $(m)$ & 0.01 & 0.00 & 0.03 & 0.02 & 0.03 & 0.01 & 0.01 \\
\hline & & 18 & Vidrio conductividad (W/(mK) & 0,58 & 0.01 & 0.02 & -0.03 & 0.00 & 0.08 & 0.00 \\
\hline & & 19 & Vidrio calor específico $\left(\mathrm{J} /\left(\mathrm{g}^{\circ} \mathrm{C}\right)\right)$ & 0.83 & 0.00 & 0.01 & 0.06 & 0.00 & 0.00 & 0.03 \\
\hline & & 20 & Vidrio densidad $\left(\mathrm{kg} / \mathrm{m}^{3}\right)$ & 2400 & 0.00 & 0.00 & 0.04 & 0.01 & 0.00 & 0.01 \\
\hline \multirow{5}{*}{\multicolumn{2}{|c|}{ 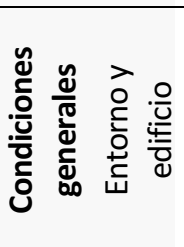 }} & 21 & Resistencia superficial exterior $\left(\mathrm{m}^{2} \mathrm{~K} / \mathrm{W}\right)$ & 0.04 & 0.16 & 0.04 & 0.03 & 0.33 & 0.02 & 0.10 \\
\hline & & 22 & Resistencia superficial interior $\left(\mathrm{m}^{2} \mathrm{~K} / \mathrm{W}\right)$ & 0.12 & 0.00 & 0.02 & 0.01 & 0.14 & 0.12 & 0.04 \\
\hline & & 23 & Convección exterior $\left(\mathrm{W} / \mathrm{m}^{2} \mathrm{~K}\right)$ & 12.4 & 0.05 & 0.04 & 0.12 & 0.02 & -0.45 & 0.12 \\
\hline & & 24 & Convección interior $\left(\mathrm{W} / \mathrm{m}^{2} \mathrm{~K}\right)$ & 8.5 & 0.11 & 0.06 & 0.25 & 0.15 & 0.18 & 0.15 \\
\hline & & 25 & Infiltración (n/hora) & 2 & -0.18 & 0.23 & 0.08 & 0.01 & 0.32 & 0.17 \\
\hline
\end{tabular}

Tabla 36: Definición de parámetros activos y no activos en relación a la temperatura del aire, temperatura superficial interna, y temperatura operativa del ambiente (*Ver leyenda). Elaboración propia. 


\section{Leyenda}

$\mu \quad$ Media de la distribución normal en función de la temperatura del aire

$\sigma$ Varianza en función de la temperatura del aire

$\mu_{\mathrm{si}} \quad$ Media de la distribución normal en función de la temperatura superficial interna

$\mu_{o} \quad$ Media de la distribución normal en función de la temperatura operativa del ambiente

La definición de los parámetros del modelo se fundamenta inicialmente en identificar los parámetros existentes en el modelo, para en un segundo momento clasificarlos entre activos y no activos. Según Palomo y Guyon (2007) un parámetro es activo cuando la media $(\mu)$ de la distribución normal, y/o la varianza $(\sigma)$ es mayor a 0,1.

Mediante la aproximación realizada se observa que algunos de los parámetros son activos en la media y no en la varianza, así como viceversa (Tabla 36). Es posible considerar tanto los parámetros activos en ambas circunstancias, como aquellos considerados activos solamente en la media, o en la varianza.

Considerando los valores superiores a 0,1 , se observa que la temperatura operativa es la variable respuesta que permite la modificación de un mayor número de parámetros, razón por la cual se decide adoptar esta variable para emplear en el procedimiento de validación del modelo, y no la temperatura.

Entretanto no sería adecuado seleccionar dos parámetros activos que se encuentren correlacionados, ya que la variación de cualquiera de ellos produciría el mismo efecto en el modelo, tornando difícil precisar los efectos de diferentes parámetros activos, y definir qué aspecto debe ser modificado.

Por lo que se procede a verificar la correlación entre los parámetros activos que hayan tenido un valor superior a 0.1. Primeramente se seleccionan todos aquellos que presenten un valor de R2 inferior a 0.80 , conforme indica Palomo y Guyon (2004). En seguida se examinan los parámetros que mostraron una correlación alta y se define la consigna de que entre propiedades físicas de un mismo elemento con elevada correlación se adopta apenas un parámetro representativo (Tabla 37). Los parámetros considerados factibles de modificación en el modelo energético serían el número de infiltraciones por hora, la conductividad de las losas y del ladrillo exterior (W/(mK).

\begin{tabular}{llcccccccc}
\hline \multicolumn{1}{c}{ Variable } & $\mathbf{1}$ & $\mathbf{2}$ & $\mathbf{3}$ & $\mathbf{4}$ & $\mathbf{5}$ & $\mathbf{6}$ & $\mathbf{7}$ & $\mathbf{8}$ \\
\hline $\mathbf{1}$ & Ladrillo hueco exterior conductividad $(\mathrm{W} /(\mathrm{mK})$ & 1 & 0.44 & -0.36 & 0.08 & 0.63 & -0.68 & 0.81 & -0.83 \\
$\mathbf{2}$ & Ladrillo hueco exterior densidad $\left(\mathrm{kg} / \mathrm{m}^{3}\right)$ & 0.44 & 1 & -0.87 & -0.75 & -0.13 & 0.17 & 0.72 & -0.11 \\
$\mathbf{3}$ & Ladrillo hueco interior conductividad $(\mathrm{W} /(\mathrm{mK})$ & -0.36 & -0.87 & 1 & 0.32 & 0.07 & -0.52 & -0.27 & -0.86 \\
$\mathbf{4}$ & Losa hormigón conductividad $(\mathrm{W} /(\mathrm{mK})$ & 0.08 & -0.75 & 0.32 & 1 & -0.86 & 0.92 & 0.22 & -0.75 \\
$\mathbf{5}$ & Resistencia superficial interior $(\mathrm{m} 2 \mathrm{~K} / \mathrm{W})$ & -0.63 & -0.13 & 0.07 & -0.86 & 1 & 0.14 & -0.03 & 0.52 \\
$\mathbf{6}$ & Convección exterior $(\mathrm{W} / \mathrm{m} 2 \mathrm{~K})$ & -0.68 & 0.17 & -0.52 & 0.92 & 0.14 & 1 & 0.68 & 0.25 \\
$\mathbf{7}$ & Convección interior $(\mathrm{W} / \mathrm{m} 2 \mathrm{~K})$ & 0.81 & 0.72 & -0.27 & 0.22 & -0.03 & 0.68 & 1 & -0.93 \\
$\mathbf{8}$ & Infiltración (n/hora) & -0.83 & -0.11 & -0.86 & -0.75 & 0.52 & 0.25 & -0.93 & 1 \\
\hline
\end{tabular}

Tabla 37: Correlación entre los parámetros activos para la temperatura operativa. Elaboración propia.

\subsubsection{Incertidumbre propagada a la respuesta del modelo}

Para la incertidumbre propagada a la respuesta del modelo se definió que no se posee un dominio detallado de la totalidad de los procedimientos que realiza el programa de simulación computacional y que analizar la posible incertidumbre propagada a través del software excede los objetivos de este 
trabajo. Cómo el motor de cálculo del programa se encuentra ampliamente validado en el medio académico, se supone que la incertidumbre es poco significante.

\subsubsection{Incertidumbre estructural del modelo}

La incertidumbre estructural del modelo puede proceder de diferentes aspectos vinculados al diseño, a las características del modelo energético, y a los inúmeros procedimientos de cálculo. Puede haber un conocimiento imperfecto sobre la geometría o composición del objeto de estudio, existir la falta de mediciones de algún parámetro, además de la incertidumbre asociada al uso detallado del sistema (Miranda Enríquez 2013).

Se considera que la geometría del modelo es igual al modelo experimental, ya que se tomaron todas las medidas in loco. Las propiedades térmicas y físicas de todos los materiales han sido especificadas manualmente según la construcción real. Debido a que el archivo de datos climáticos consiste en una representación estadística, se considera que las series analizadas representan la diferencia entre los datos contenidos en el archivo climático y los monitorizados. Los únicos aspectos posibles de controlar y modificar en el modelo corresponden a las características de ocupación, debido a que fueron establecidas en función de la respuesta de los usuarios, la cual lleva implícita cierta la subjetividad de cada usuario.

Como las temperaturas estimadas se encontraban por encima de la temperatura registrada, se analizó el balance energético del ambiente y se encontró que las cargas internas y las ganancias solares a través de la superficie vidriada aportaban un porcentaje significativo de calor al ambiente (Figura 64).

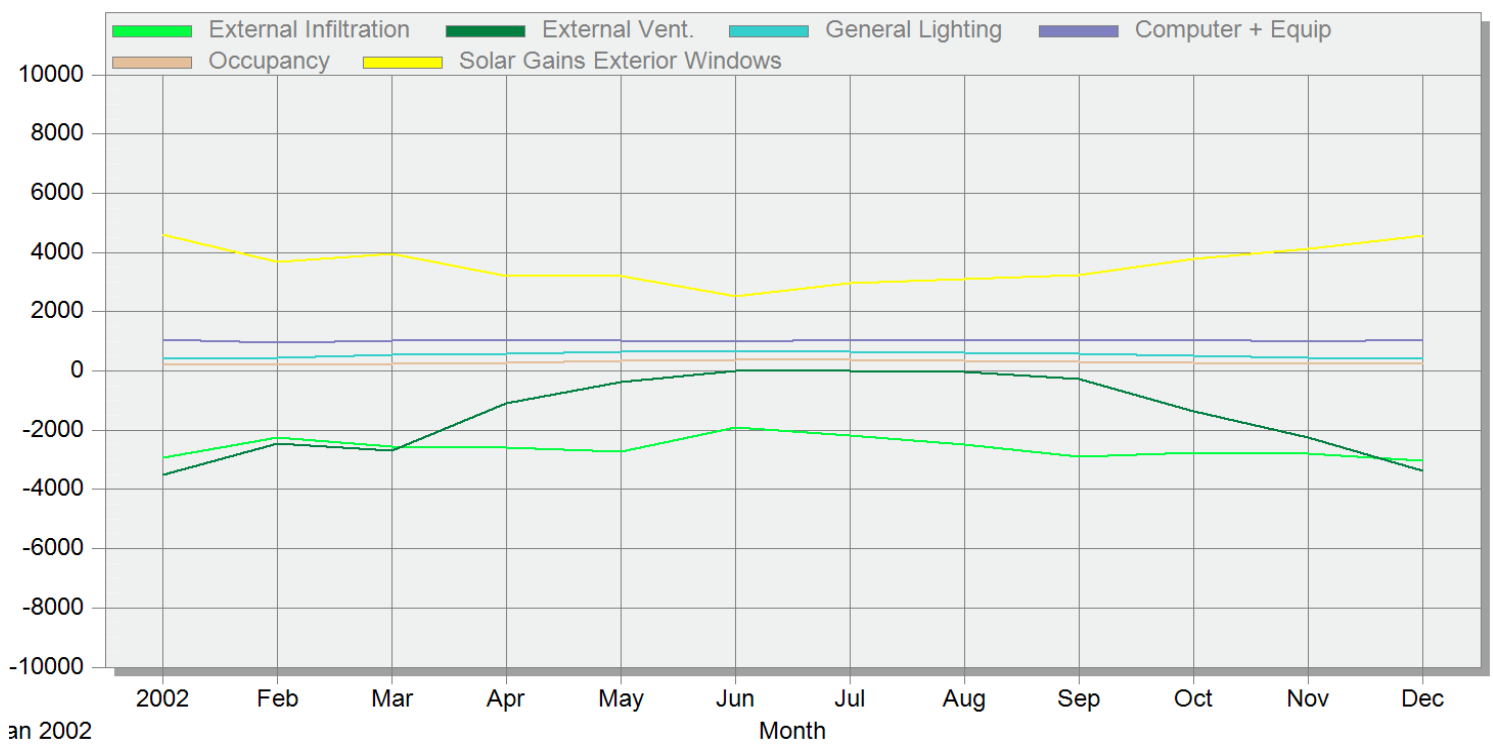

Figura 64: Balance térmico para la unidad funcional analizada. Fuente Design Builder.

Se retiraron las cargas de cocción, de los equipos e iluminación, y según el resultado obtenido en el análisis de la incertidumbre de los parámetros del modelo, se modificó el número de renovaciones de aire de 2 para $0.5 \mathrm{r} / \mathrm{h}$ cómo indica el CTE. Las características de los elementos opacos se mantuvieron para no comprometer la representatividad de los diferentes escenarios de cálculo cuando se modifiquen los cerramientos del modelo. 
Con el fin de asegurar la fiabilidad de los datos reales ingresados al modelo teórico, se decide no realizar mayores modificaciones en el modelo. Al comparar nuevamente las series obtenidas, se observa que la temperatura interior estimada mejorada registra valores máximos de $33.14{ }^{\circ} \mathrm{C}$ para la semana de verano, y de $25.75^{\circ} \mathrm{C}$ para la semana de invierno (Figura 65 y Figura 66). El pico mínimo para la temperatura estima mejorada de invierno es de $14,42^{\circ} \mathrm{C}$, en cuanto la temperatura mínima medida ha sido de $15.7^{\circ} \mathrm{C}$.

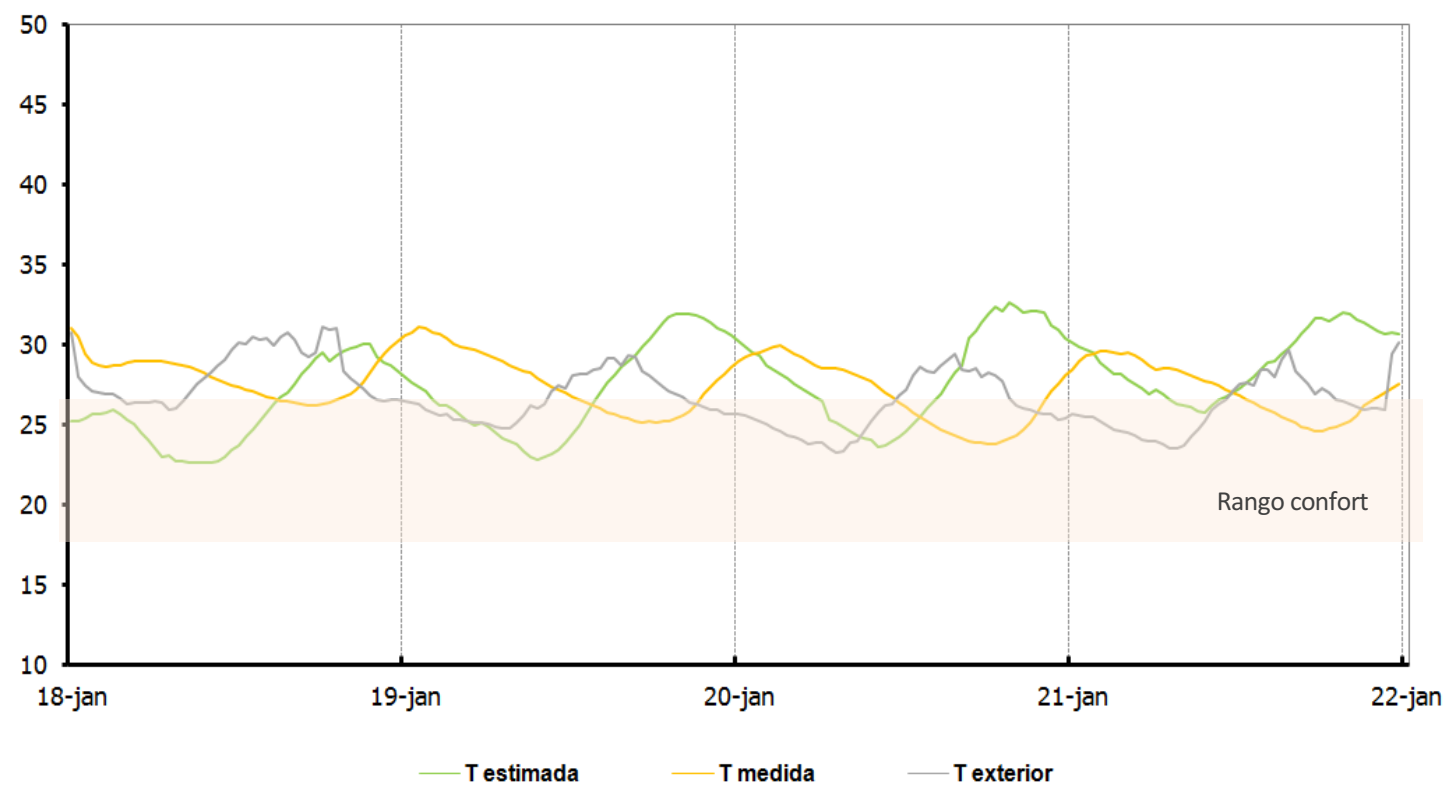

Figura 65: Variación de la temperatura interior medida y estimada mejorada para la condición de verano. Elaboración propia.

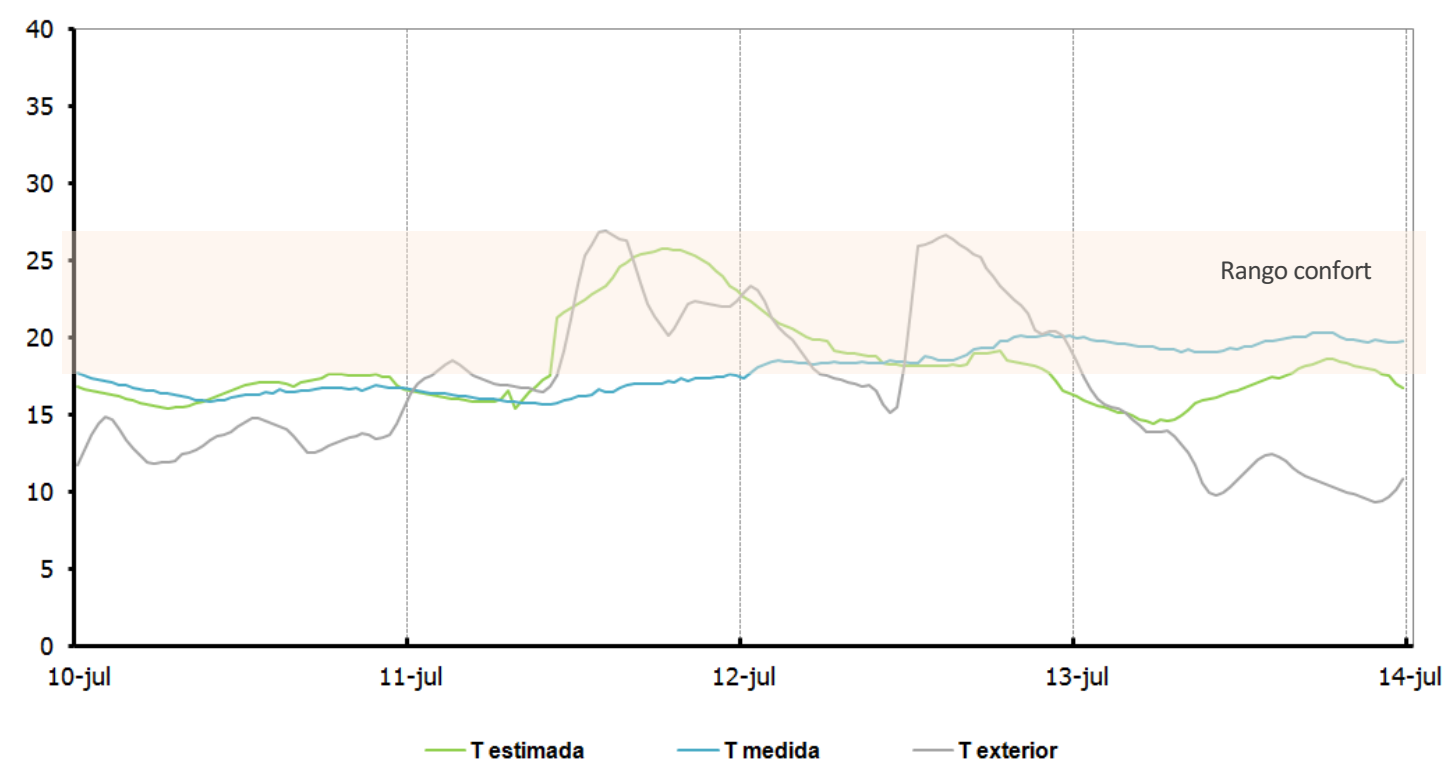

Figura 66: Variación de la temperatura interior medida y estimada mejorada para la condición de invierno. Elaboración propia.

Posterior a la mejora del modelo energético se observó una diferencia de $1,3{ }^{\circ} \mathrm{C}$ entre los picos mínimos de temperatura interna medida x estimada para invierno, y de $2,1^{\circ} \mathrm{C}$ entre los picos máximos de temperatura interna medida $\mathrm{x}$ estimada para verano. El retraso térmico de verano entre la temperatura estimada y la temperatura medida se redujo para 6 horas. 


\subsection{Cuantificación del consumo energético}

En la Tabla 38 y Tabla 39 se visualizan los consumos en acondicionamiento térmico para el Caso I y el Caso II, en verano e invierno para el escenario tradicional (T) y según el estándar U para cada país (N).

\begin{tabular}{|c|c|c|c|c|c|c|}
\hline País & $\mathbf{N}$ & Ciudad & Invierno T & Invierno N & Verano $\mathbf{T}$ & Verano $\mathbf{N}$ \\
\hline \multirow{10}{*}{ 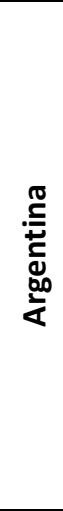 } & 1 & Buenos Aires & 152.9 & 32.8 & 45.6 & 32 \\
\hline & 2 & Catamarca & 34.1 & 2.1 & 111.6 & 73.2 \\
\hline & 3 & Córdoba & 101.8 & 16.3 & 36.7 & 27.8 \\
\hline & 4 & Corrientes & 15.77 & 0.1 & 104.69 & 69.53 \\
\hline & 5 & La Plata & 153.1 & 35 & 36.3 & 30.1 \\
\hline & 6 & La Rioja & 44.8 & 4.1 & 136.6 & 82.2 \\
\hline & 7 & Mar del Plata & 236.52 & 55.37 & 6.25 & 7.04 \\
\hline & 8 & Paraná & 74.5 & 9.2 & 62.5 & 43.9 \\
\hline & 9 & Rosario & 90.7 & 14.5 & 58.7 & 39.7 \\
\hline & 10 & Santiago del Estero & 27.2 & 2 & 106.6 & 66.9 \\
\hline \multirow{8}{*}{ 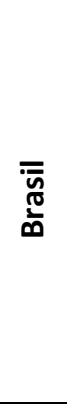 } & 11 & Blumenau & 19.5 & 8.5 & 43.6 & 34.2 \\
\hline & 12 & Chapecó & 65 & 35.6 & 20.9 & 15.7 \\
\hline & 13 & Criciúma & 47.7 & 23.3 & 49.8 & 39.7 \\
\hline & 14 & Curitiba & 41.1 & 21.2 & 28.6 & 21 \\
\hline & 15 & Florianópolis & 7.09 & 3.14 & 72.15 & 59.45 \\
\hline & 16 & Ponta Grossa & 45.6 & 24 & 37.1 & 28.3 \\
\hline & 17 & Porto Alegre & 26.1 & 12 & 74.8 & 60.5 \\
\hline & 18 & Santa Maria & 67.2 & 34.4 & 49.2 & 37.4 \\
\hline \multirow{6}{*}{ 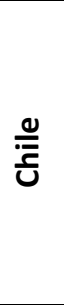 } & 19 & Antofagasta & 3.6 & 1.2 & 17 & 12.7 \\
\hline & 20 & Concepción & 222.4 & 78.4 & 1.9 & 2.4 \\
\hline & 21 & Copiacó & 62.5 & 16 & 13 & 11 \\
\hline & 22 & Santiago & 195 & 95.59 & 29.4 & 19.87 \\
\hline & 23 & Temuco & 269.48 & 103.52 & 4.37 & 4 \\
\hline & 24 & Valparaíso & 97.8 & 37 & 7.7 & 5.4 \\
\hline \multirow{9}{*}{ 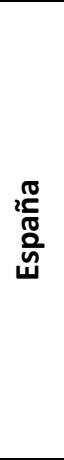 } & 25 & Alicante & 94 & 6.1 & 49.7 & 37.7 \\
\hline & 26 & Barcelona & 220.8 & 24.5 & 41 & 28.6 \\
\hline & 27 & Córdoba & 167.7 & 20.2 & 62.2 & 40.7 \\
\hline & 28 & Granada & 245.7 & 33.5 & 34.6 & 26.5 \\
\hline & 29 & Málaga & 87.2 & 4.5 & 48.2 & 36.5 \\
\hline & 30 & Murcia & 139.9 & 17.4 & 35.5 & 28.7 \\
\hline & 31 & Palma & 141 & 16.5 & 60.7 & 38.4 \\
\hline & 32 & Sevilla & 96.1 & 6.7 & 95.6 & 52.7 \\
\hline & 33 & Valencia & 136.8 & 15.9 & 64.7 & 40.2 \\
\hline \multirow{9}{*}{ 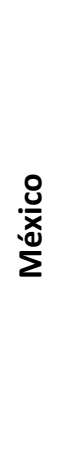 } & 34 & Aguascalientes & 4.9 & 0 & 60.2 & 45.6 \\
\hline & 35 & Ciudad de México & 11.3 & 0.1 & 9.2 & 9.7 \\
\hline & 36 & Guadalajara & 7.9 & 0.1 & 48.2 & 37.1 \\
\hline & 37 & Hermosillo & 2 & 0 & 233.3 & 122.4 \\
\hline & 38 & Juárez & 165.3 & 29.3 & 120.6 & 69.5 \\
\hline & 39 & León & 1.1 & 0 & 49 & 42.2 \\
\hline & 40 & Monterrey & 31 & 1.7 & 134.7 & 82.9 \\
\hline & 41 & Puebla & 7.7 & 0 & 12.6 & 13.9 \\
\hline & 42 & Tijuana & 22.4 & 0.8 & 29 & 23.1 \\
\hline
\end{tabular}

Tabla 38: Consumo en acondicionamiento térmico para el Caso I - condición tradicional x según norma (kWh/m2). 
PARTE II · Cuantificación del consumo energético

\begin{tabular}{|c|c|c|c|c|c|c|}
\hline País & $\mathbf{N}$ & Ciudad & Invierno T & Invierno N & Verano T & Verano $\mathbf{N}$ \\
\hline \multirow{10}{*}{ 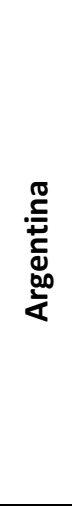 } & 1 & Buenos Aires & 339.9 & 242.5 & 43.6 & 32.9 \\
\hline & 2 & Catamarca & 120.7 & 86.3 & 132.9 & 102.5 \\
\hline & 3 & Córdoba & 258.3 & 183.6 & 37.8 & 27.9 \\
\hline & 4 & Corrientes & 74 & 48.6 & 148.6 & 113.5 \\
\hline & 5 & La Plata & 364.8 & 263.6 & 30.9 & 22.6 \\
\hline & 6 & La Rioja & 150.3 & 114.5 & 152.5 & 113.6 \\
\hline & 7 & Mar del Plata & 511.1 & 371.8 & 4.1 & 2.5 \\
\hline & 8 & Paraná & 209 & 150.6 & 70.3 & 51.3 \\
\hline & 9 & Rosario & 248.4 & 181.3 & 64.6 & 47.2 \\
\hline & 10 & Santiago del Estero & 111.2 & 82.9 & 126.8 & 94.7 \\
\hline \multirow{8}{*}{$\begin{array}{l}\overline{\bar{n}} \\
\overline{\bar{n}} \\
\bar{\infty}\end{array}$} & 11 & Blumenau & 59.2 & 53.4 & 53.9 & 49.5 \\
\hline & 12 & Chapecó & 149.3 & 136.7 & 14 & 11.8 \\
\hline & 13 & Criciúma & 115 & 104.9 & 67.6 & 61.7 \\
\hline & 14 & Curitiba & 148.4 & 139.1 & 17.3 & 14.3 \\
\hline & 15 & Florianópolis & 33 & 30.4 & 92.9 & 85.6 \\
\hline & 16 & Ponta Grossa & 112.5 & 103.3 & 32.5 & 28.1 \\
\hline & 17 & Porto Alegre & 101 & 93.7 & 96.7 & 89.5 \\
\hline & 18 & Santa Maria & 162.7 & 149.7 & 62.2 & 56.6 \\
\hline \multirow{6}{*}{$\frac{\mathscr{U}}{\frac{\mathfrak{C}}{U}}$} & 19 & Antofagasta & 65.6 & 63.4 & 2.6 & 1.7 \\
\hline & 20 & Concepción & 507.5 & 392.4 & 0 & 0 \\
\hline & 21 & Copiacó & 238.9 & 200.3 & 1.2 & 0.6 \\
\hline & 22 & Santiago & 432.6 & 372.4 & 14.8 & 10.7 \\
\hline & 23 & Temuco & 632.4 & 506.8 & 0.9 & 0.3 \\
\hline & 24 & Valparaíso & 301.9 & 259.3 & 0.2 & 0 \\
\hline \multirow{9}{*}{$\begin{array}{l}\text { 宽 } \\
\frac{0}{0} \\
\frac{0}{4}\end{array}$} & 25 & Alicante & 231 & 153.3 & 56.2 & 45.6 \\
\hline & 26 & Barcelona & 437.1 & 287 & 40.4 & 28.5 \\
\hline & 27 & Córdoba & 344.4 & 233.1 & 60.3 & 46.3 \\
\hline & 28 & Granada & 541.9 & 342 & 30 & 24 \\
\hline & 29 & Málaga & 213.3 & 139.6 & 49.9 & 40.1 \\
\hline & 30 & Murcia & 303.9 & 204.4 & 42.9 & 35.1 \\
\hline & 31 & Palma & 334.8 & 245.1 & 71.8 & 52.8 \\
\hline & 32 & Sevilla & 243.7 & 174.1 & 89.4 & 63.7 \\
\hline & 33 & Valencia & 297.2 & 206.8 & 72 & 53.1 \\
\hline \multirow{9}{*}{ 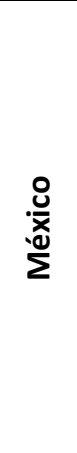 } & 34 & Aguascalientes & 36.6 & 25 & 42.2 & 31.5 \\
\hline & 35 & Ciudad de México & 68 & 44.1 & 1.8 & 1 \\
\hline & 36 & Guadalajara & 63.3 & 48.6 & 26.9 & 17.3 \\
\hline & 37 & Hermosillo & 19.6 & 12.4 & 306.7 & 225.7 \\
\hline & 38 & Juárez & 359.3 & 248.3 & 101.7 & 72.8 \\
\hline & 39 & León & 14.7 & 7.9 & 36.5 & 27.7 \\
\hline & 40 & Monterrey & 92.2 & 56.7 & 194.3 & 147.5 \\
\hline & 41 & Puebla & 71.7 & 50.2 & 2.9 & 1.4 \\
\hline & 42 & Tijuana & 146.4 & 115.2 & 6.4 & 3.2 \\
\hline
\end{tabular}

Tabla 39: Consumo en acondicionamiento térmico para el Caso II - condición tradicional x según norma $\left(\mathrm{kWh} / \mathrm{m}^{2}\right)$. Elaboración propia. 


\section{Conclusiones}

Esta etapa realizó la construcción del modelo edilicio teórico, su ajuste al modelo experimental, y los cálculos de consumos energéticos con sistemas de climatización, permitiendo construir la matriz de datos necesaria para la etapa de análisis de correlación empleada en la Parte III.

A modo de resumen, se rescatan los siguientes aspectos:

I. Se construyó el modelo teórico con las características morfológicas observadas en la auditoría energética, y los materiales y elementos constructivos del edificio conforme la especificación del memorial del proyecto arquitectónico (ANEXO III - Tomo II).

II. Se asignaron las características de ocupación respetando la información recolectada en la aplicación de las encuestas, y las características del sistema HVAC según las especificaciones del CTE (Tabla 35).

III. Ajustar el modelo teórico al modelo experimental resultó una tarea compleja, involucrando gran cantidad de variables difíciles de controlar.

IV. La incertidumbre de los datos registrados y aquellas propagadas a la respuesta del modelo no son consideradas significativas para comprometer la validación del modelo teórico.

V. Es posible adoptar un único valor de temperatura de salida teórica para predecir la temperatura en todo el ambiente objeto de la simulación, ya que la estratificación del aire en el ambiente experimental es en torno de $0.59{ }^{\circ} \mathrm{C}$ a lo largo de la serie en verano, y de $0.35^{\circ} \mathrm{C}$ para invierno

\section{(Figura 61).}

VI. La temperatura operativa del ambiente es la variable de respuesta que mayor se relaciona con los parámetros posibles de modificar por el profesional (Tabla 36). 



\section{PARTE III}

\section{definición de la ecuación}
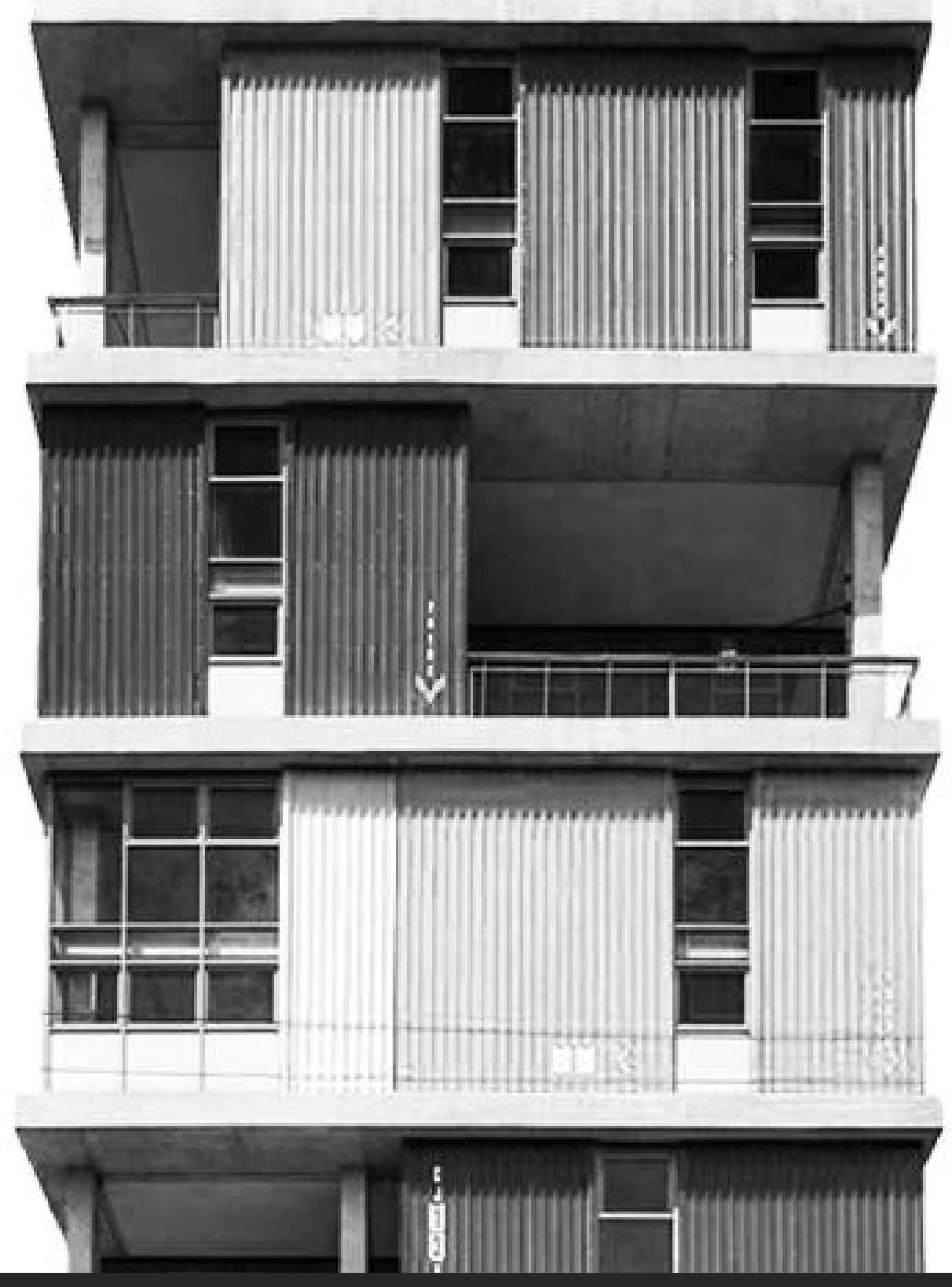

Box 298 | Andrade Morettin Arquitetos | 2009 


\section{Objetivo del capítulo}

En este capítulo se ejecutarán las actividades necesarias para construir el modelo estadístico de consumo energético y realizar su aplicación regional, definiendo las bases para la creación de un estándar de eficiencia energética para Latinoamérica (Figura 67).

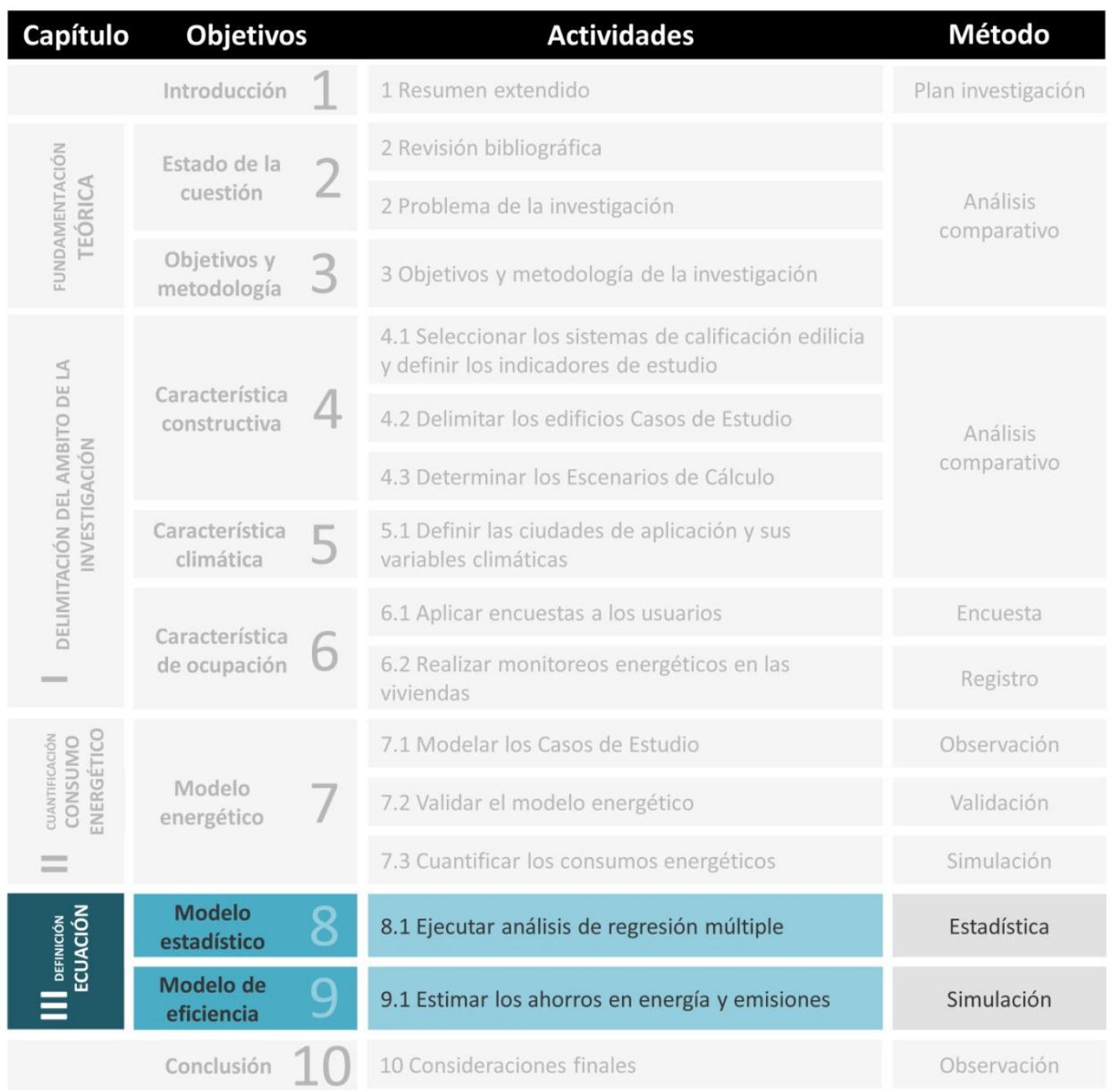

Figura 67: Esquema metodológico Parte III - Definición de la ecuación. Elaboración propia. 


\section{Modelo estadístico}

\section{Objetivo}

En esta etapa se analizará relación existente entre el consumo energético en acondicionamiento térmico de ambos Casos de Estudio con las variables climáticas de las 42 ciudades dónde se simularon su aplicación, con el fin de construir una ecuación capaz de predecir el consumo de edificios residenciales situados en clima templado. 


\subsection{Análisis de regresión lineal múltiple}

Para construir los modelos estadísticos se aplicó un estudio de regresión lineal múltiple para identificar las variables climáticas que están más relacionadas con la variación en el consumo energético en calefacción y refrigeración.

Para la ejecución de los cálculos se ha utilizado el programa SPSS versión 15.0. La interpretación de los resultados se fundamentó en considerar que valores del coeficiente de determinación $R^{2}$ presentan correlación nula entre sus variables $\left(R^{2}=0\right)$, valores entre 0,01 a 0,19 correlación muy baja, entre 0,2 a 0,39 correlación baja, entre 0,4 a 0,69, correlación moderada, entre 0,70 a 0,89 correlación alta, entre 0,9 a 0,99 correlación muy alta, y valor de $R^{2}=1$ correlación grande y perfecta (Pearson 1920). Los valores negativos del $\mathrm{R}^{2}$ indican que a medida que una variable aumenta, la otra disminuye; en cuanto los valores positivos demuestran que a medida que una variable aumenta, la otra también se incrementa.

La interpretación de la linealidad entre las variables analizadas en la regresión múltiple se realizó con base en la misma magnitud de los valores mencionados anteriormente. Para determinar la confiabilidad del modelo matemático, se utilizó los valores del $R^{2}$ ajustado, el cual considera el valor de la muestra y el número de variables analizadas.

La relevancia del modelo estadístico y la significancia de las variables han sido comprobadas en cada caso mediante la prueba de la hipótesis nula del P-value en el análisis de la varianza, y de los valores de probabilidad. Para contrastar la hipótesis de que la variable analizada es significativa para explicar el modelo estadístico se ha adoptado el valor $\leq 0.05$

El método empleado para el análisis de regresión múltiple ha sido el de adicionar las variables hacia adelante. En este método el programa identifica cuál es la variable que tiene mayor relación con la variable dependiente (consumo energético), convirtiéndose en la variable principal. Luego se añaden variables progresivamente para incrementar el coeficiente de determinación $R^{2}$, siempre que influya en la variable dependiente y mejore el modelo actual, siendo estas nuevas variables las variables secundarias. De esta forma, el último modelo corresponde al resultado que alcanza el mayor nivel de $\mathrm{R}^{2}$ entre la variable dependiente y las variables determinadas - principal y secundarias, por lo que corresponde al modelo óptimo. Las variables que no aparecen en los modelos no son significativas para explicar la variación de la variable dependiente.

\subsubsection{Muestra de estudio}

En la Tabla 40, 41, 42, y 43 es posible observar las variables consideradas en la muestra utilizada en el análisis de regresión múltiple. En las columnas 3, 4, 5 y 6 de la Tabla 40 se detallan los datos de la variable dependiente, la cual consiste en el consumo en calefacción y refrigeración estimado para los modelos energéticos en el apartado 7.3 Cuantificación del consumo energético. En las columnas 7 y 8 de la Tabla 40, y en las columnas 3, 4, 5, 6, 7 y 8 de la Tabla 41, 42, y 43 se detallan los valores de las variables secundarias, las cuales consisten en las variables climáticas correspondientes a cada localidad definidas en el apartado 5.1 Selección de las localidades de aplicación. 
PARTE III · Definición de la ecuación

\begin{tabular}{|c|c|c|c|c|c|c|c|}
\hline & Ciudad & Cver1 & Cver2 & Cinv1 & Cinv2 & Latitud & Altitud \\
\hline 1 & Buenos Aires & 45.6 & 43.6 & 152.9 & 339.9 & -34.4 & 25 \\
\hline 2 & Catamarca & 111.6 & 132.9 & 34.1 & 120.7 & -28.3 & 519 \\
\hline 3 & Córdoba & 36.7 & 37.8 & 101.8 & 258.3 & -31.3 & 576 \\
\hline 4 & Corrientes & 104.69 & 148.6 & 15.77 & 74 & -27.3 & 52 \\
\hline 5 & La Plata & 36.3 & 30.9 & 153.1 & 364.8 & -34.6 & 26 \\
\hline 6 & La Rioja & 136.6 & 152.5 & 44.8 & 150.3 & -29.2 & 515 \\
\hline 7 & Mar del Plata & 6.25 & 4.1 & 236.52 & 511.1 & -38 & 38 \\
\hline 8 & Paraná & 62.5 & 70.3 & 74.5 & 209 & -31.4 & 77 \\
\hline 9 & Rosario & 58.7 & 64.6 & 90.7 & 248.4 & -32.6 & 25 \\
\hline 10 & Santiago del Estero & 106.6 & 126.8 & 27.2 & 111.2 & -27.5 & 182 \\
\hline 11 & Blumenau & 43.6 & 53.9 & 19.5 & 59.2 & -26.5 & 519 \\
\hline 12 & Chapecó & 20.9 & 14 & 65 & 149.3 & -27.1 & 670 \\
\hline 13 & Criciúma & 49.8 & 67.6 & 47.7 & 115 & -28.4 & 46 \\
\hline 14 & Curitiba & 28.6 & 17.3 & 41.1 & 148.4 & -25.3 & 934 \\
\hline 15 & Florianópolis & 72.15 & 92.9 & 7.09 & 33 & -27.4 & 0 \\
\hline 16 & Ponta Grossa & 37.1 & 32.5 & 45.6 & 112.5 & -25.1 & 975 \\
\hline 17 & Porto Alegre & 74.8 & 96.7 & 26.1 & 101 & -30 & 10 \\
\hline 18 & Santa Maria & 49.2 & 62.2 & 67.2 & 162.7 & -29.4 & 113 \\
\hline 19 & Antofagasta & 17 & 2.6 & 3.6 & 65.6 & -23.4 & 40 \\
\hline 20 & Concepción & 1.9 & 0 & 222.4 & 507.5 & -36.5 & 12 \\
\hline 21 & Copiacó & 13 & 1.2 & 62.5 & 238.9 & -27.2 & 383 \\
\hline 22 & Santiago & 29.4 & 14.8 & 195 & 432.6 & -33.3 & 520 \\
\hline 23 & Temuco & 4.37 & 0.9 & 269.48 & 632.4 & -38.5 & 122 \\
\hline 24 & Valparaíso & 7.7 & 0.2 & 97.8 & 301.9 & -30 & 10 \\
\hline 25 & Alicante & 49.7 & 56.2 & 94 & 231 & 38.2 & 5 \\
\hline 26 & Barcelona & 41 & 40.4 & 220.8 & 437.1 & 41.21 & 8 \\
\hline 27 & Córdoba & 62.2 & 60.3 & 167.7 & 344.4 & 37.53 & 106 \\
\hline 28 & Granada & 34.6 & 30 & 245.7 & 541.9 & 37.1 & 684 \\
\hline 29 & Málaga & 48.2 & 49.9 & 87.2 & 213.3 & 36.43 & 8 \\
\hline 30 & Murcia & 35.5 & 42.9 & 139.9 & 303.9 & 37.59 & 42 \\
\hline 31 & Palma & 60.7 & 71.8 & 141 & 334.8 & 39.34 & 24 \\
\hline 32 & Sevilla & 95.6 & 89.4 & 96.1 & 243.7 & 37.23 & 11 \\
\hline 33 & Valencia & 64.7 & 72 & 136.8 & 297.2 & 39.28 & 16 \\
\hline 34 & Aguascalientes & 60.2 & 42.2 & 4.9 & 36.6 & 21.9 & 1888 \\
\hline 35 & Ciudad de México & 9.2 & 1.8 & 11.3 & 68 & 19.3 & 2250 \\
\hline 36 & Guadalajara & 48.2 & 26.9 & 7.9 & 63.3 & 20.4 & 1566 \\
\hline 37 & Hermosillo & 233.3 & 306.7 & 2 & 19.6 & 29.1 & 210 \\
\hline 38 & Juárez & 120.6 & 101.7 & 165.3 & 359.3 & 31.4 & 1137 \\
\hline 39 & León & 49 & 36.5 & 1.1 & 14.7 & 21.1 & 1815 \\
\hline 40 & Monterrey & 134.7 & 194.3 & 31 & 92.2 & 25.4 & 530 \\
\hline 41 & Puebla & 12.6 & 2.9 & 7.7 & 71.7 & 19 & 1704 \\
\hline 42 & Tijuana & 29 & 6.4 & 22.4 & 146.4 & 32.3 & 31 \\
\hline
\end{tabular}

Tabla 40: Muestra empleada en el análisis de regresión múltiple - Parte I. Elaboración propia. 
PARTE III · Definición de la ecuación

\begin{tabular}{|c|c|c|c|c|c|c|c|}
\hline & Ciudad & GDver & GDpver & GDpinv & GDinvp & TDmax & TDmin \\
\hline 1 & Buenos Aires & 732 & 178 & 771 & 185 & 33.6 & 2.9 \\
\hline 2 & Catamarca & 1440 & 265 & 531 & 157 & 41.1 & -3.2 \\
\hline 3 & Córdoba & 705 & 164 & 714 & 182 & 36.6 & -4.3 \\
\hline 4 & Corrientes & 1308 & 246 & 192 & 64 & 39.4 & 0.2 \\
\hline 5 & La Plata & 525 & 155 & 1050 & 236 & 35.5 & -2.5 \\
\hline 6 & La Rioja & 1368 & 265 & 621 & 180 & 42.4 & -2.5 \\
\hline 7 & Mar del Plata & 141 & 47 & 1593 & 285 & 35.6 & -4.4 \\
\hline 8 & Paraná & 738 & 183 & 750 & 183 & 37 & -1 \\
\hline 9 & Rosario & 642 & 163 & 957 & 219 & 37.3 & -4 \\
\hline 10 & Santiago del Estero & 1311 & 249 & 450 & 137 & 41.9 & -5.1 \\
\hline 11 & Blumenau & 975 & 196 & 138 & 46 & 33.1 & 6.6 \\
\hline 12 & Chapecó & 648 & 145 & 387 & 93 & 32.3 & 6.2 \\
\hline 13 & Criciúma & 792 & 175 & 252 & 71 & 32 & 4.7 \\
\hline 14 & Curitiba & 243 & 75 & 681 & 139 & 30.1 & 3.6 \\
\hline 15 & Florianópolis & 942 & 192 & 183 & 39 & 31.9 & 8.8 \\
\hline 16 & Ponta Grossa & 408 & 105 & 492 & 118 & 31.6 & 3.9 \\
\hline 17 & Porto Alegre & 894 & 198 & 372 & 101 & 33.7 & 6.2 \\
\hline 18 & Santa Maria & 759 & 181 & 462 & 118 & 33.9 & 5 \\
\hline 19 & Antofagasta & 198 & 54 & 657 & 113 & 29.6 & 7.3 \\
\hline 20 & Concepción & 0 & 0 & 2010 & 264 & 26.3 & 1.3 \\
\hline 21 & Copiacó & 453 & 112 & 435 & 106 & 31 & 2.8 \\
\hline 22 & Santiago & 201 & 67 & 1575 & 279 & 40.9 & -2.7 \\
\hline 23 & Temuco & 0 & 0 & 2334 & 305 & 27.3 & -0.5 \\
\hline 24 & Valparaíso & 0 & 0 & 1434 & 189 & 24.9 & 4.7 \\
\hline 25 & Alicante & 861 & 204 & 771 & 174 & 34.3 & 1.8 \\
\hline 26 & Barcelona & 549 & 152 & 1276 & 252 & 32 & -0.1 \\
\hline 27 & Córdoba & 1080 & 267 & 999 & 232 & 40.4 & -0.9 \\
\hline 28 & Granada & 708 & 205 & 1560 & 192 & 37.7 & -3.4 \\
\hline 29 & Málaga & 864 & 205 & 693 & 158 & 34.3 & 2.9 \\
\hline 30 & Murcia & 1060 & 250 & 849 & 197 & 37.7 & 0.2 \\
\hline 31 & Palma & 873 & 206 & 792 & 171 & 32.9 & 3.8 \\
\hline 32 & Sevilla & 1173 & 272 & 741 & 187 & 39.5 & 1.2 \\
\hline 33 & Valencia & 864 & 206 & 756 & 171 & 33.7 & 2.6 \\
\hline 34 & Aguascalientes & 589 & 118 & 423 & 116 & 32.8 & 0 \\
\hline 35 & Ciudad de México & 195 & 46 & 330 & 85 & 30.9 & 1.9 \\
\hline 36 & Guadalajara & 717 & 130 & 360 & 102 & 34.5 & 0 \\
\hline 37 & Hermosillo & 2604 & 382 & 51 & 25 & 43.3 & 5.7 \\
\hline 38 & Juárez & 996 & 202 & 1473 & 339 & 38.5 & -6.8 \\
\hline 39 & León & 756 & 133 & 189 & 59 & 30.7 & 2.8 \\
\hline 40 & Monterrey & 1788 & 287 & 237 & 79 & 38 & 3.7 \\
\hline 41 & Puebla & 156 & 36 & 429 & 105 & 31.4 & 0.4 \\
\hline 42 & Tijuana & 402 & 66 & 657 & 121 & 29.1 & 3.3 \\
\hline
\end{tabular}

Tabla 41: Muestra empleada en el análisis de regresión múltiple - Parte II. Elaboración propia. 
PARTE III · Definición de la ecuación

\begin{tabular}{|c|c|c|c|c|c|c|c|c|}
\hline & Ciudad & TMmax & TMmin & RADg & RADpver & RADpinv & HR & HRpver \\
\hline 1 & Buenos Aires & 30.1 & 7.4 & 0.32 & 0.42 & 0.22 & 72.47 & 70.31 \\
\hline 2 & Catamarca & 34 & 8 & 0.39 & 0.44 & 0.33 & 55.93 & 54.91 \\
\hline 3 & Córdoba & 31.1 & 5.5 & 0.34 & 0.39 & 0.27 & 66.63 & 68.27 \\
\hline 4 & Corrientes & 33 & 10.7 & 0.37 & 0.43 & 0.3 & 73.41 & 71.24 \\
\hline 5 & La Plata & 28.8 & 5.5 & 0.37 & 0.49 & 0.25 & 78.38 & 74.53 \\
\hline 6 & La Rioja & 35 & 4.4 & 0.37 & 0.41 & 0.3 & 58.87 & 58.66 \\
\hline 7 & Mar del Plata & 26.3 & 3.8 & 0.28 & 0.37 & 0.19 & 78.76 & 76.9 \\
\hline 8 & Paraná & 31.3 & 6.8 & 0.36 & 0.44 & 0.27 & 70.92 & 68.41 \\
\hline 9 & Rosario & 30.8 & 5.3 & 0.35 & 0.43 & 0.26 & 72.83 & 69.41 \\
\hline 10 & Santiago del Estero & 33.9 & 5.6 & 0.36 & 0.41 & 0.31 & 64.26 & 65.07 \\
\hline 11 & Blumenau & 29.6 & 11.1 & 0.3 & 0.38 & 0.25 & 83.67 & 82.95 \\
\hline 12 & Chapecó & 28.8 & 10.7 & 0.36 & 0.44 & 0.28 & 73.65 & 72.68 \\
\hline 13 & Criciúma & 28.5 & 9.2 & 0.31 & 0.36 & 0.27 & 81.86 & 81.37 \\
\hline 14 & Curitiba & 26.6 & 8.1 & 0.29 & 0.32 & 0.27 & 83.27 & 82.27 \\
\hline 15 & Florianópolis & 28.4 & 13.3 & 0.31 & 0.36 & 0.26 & 80.96 & 80.73 \\
\hline 16 & Ponta Grossa & 28.1 & 8.4 & 0.36 & 0.4 & 0.3 & 77.98 & 78.72 \\
\hline 17 & Porto Alegre & 30.2 & 10.7 & 0.38 & 0.47 & 0.3 & 82.01 & 78.84 \\
\hline 18 & Santa Maria & 30.4 & 9.5 & 0.35 & 0.44 & 0.24 & 75.72 & 73.1 \\
\hline 19 & Antofagasta & 26.1 & 11.8 & 0.48 & 0.58 & 0.36 & 76.3 & 76.48 \\
\hline 20 & Concepción & 22.8 & 5.8 & 0.35 & 0.52 & 0.19 & 81.95 & 78.55 \\
\hline 21 & Copiacó & 27.5 & 7.3 & 0.43 & 0.54 & 0.33 & 75.74 & 73.46 \\
\hline 22 & Santiago & 37.4 & 1.8 & 0.38 & 0.55 & 0.22 & 66.8 & 59.31 \\
\hline 23 & Temuco & 23.8 & 4 & 0.3 & 0.44 & 0.17 & 79.25 & 75.78 \\
\hline 24 & Valparaíso & 21.4 & 9.2 & 0.31 & 0.42 & 0.19 & 79.09 & 77.52 \\
\hline 25 & Alicante & 30.8 & 6.3 & 0.38 & 0.48 & 0.28 & 66.12 & 65.14 \\
\hline 26 & Barcelona & 28.5 & 4.4 & 0.32 & 0.42 & 0.22 & 74.03 & 73.6 \\
\hline 27 & Córdoba & 36.9 & 3.6 & 0.38 & 0.51 & 0.26 & 63.79 & 51.04 \\
\hline 28 & Granada & 34.2 & 1.1 & 0.39 & 0.52 & 0.27 & 59.72 & 47.03 \\
\hline 29 & Málaga & 30.8 & 7.4 & 0.39 & 0.5 & 0.27 & 66.05 & 60.38 \\
\hline 30 & Murcia & 34.2 & 4.7 & 0.35 & 0.44 & 0.26 & 71.19 & 71.58 \\
\hline 31 & Palma & 29.4 & 8.3 & 0.36 & 0.48 & 0.24 & 79.01 & 76.72 \\
\hline 32 & Sevilla & 36 & 5.7 & 0.39 & 0.51 & 0.27 & 62.63 & 53.24 \\
\hline 33 & Valencia & 30.2 & 7.1 & 0.35 & 0.47 & 0.25 & 68.4 & 69.49 \\
\hline 34 & Aguascalientes & 29.3 & 4.5 & 0.45 & 0.45 & 0.41 & 46.96 & 49.5 \\
\hline 35 & Ciudad de México & 27.4 & 6.4 & 0.38 & 0.37 & 0.38 & 64.74 & 67.59 \\
\hline 36 & Guadalajara & 31 & 4.5 & 0.44 & 0.44 & 0.4 & 56.53 & 61.86 \\
\hline 37 & Hermosillo & 39.8 & 10.2 & 0.44 & 0.48 & 0.39 & 42.83 & 40.75 \\
\hline 38 & Juárez & 35 & -2.3 & 0.49 & 0.56 & 0.39 & 39.81 & 34.65 \\
\hline 39 & León & 27.2 & 7.3 & 0.45 & 0.46 & 0.4 & 52.63 & 59.5 \\
\hline 40 & Monterrey & 34.5 & 8.2 & 0.39 & 0.47 & 0.31 & 67.62 & 66.19 \\
\hline 41 & Puebla & 27.9 & 4.9 & 0.45 & 0.45 & 0.43 & 57.79 & 61.21 \\
\hline 42 & Tijuana & 25.6 & 7.8 & 0.43 & 0.53 & 0.33 & 71.87 & 77.06 \\
\hline
\end{tabular}

Tabla 42: Muestra empleada en el análisis de regresión múltiple - Parte III. Elaboración propia. 
PARTE III · Definición de la ecuación

\begin{tabular}{|c|c|c|c|c|c|c|c|c|}
\hline & Ciudad & HRpinv & V v & V Vpver & V Vpinv & CC & CCpver & CCpinv \\
\hline 1 & Buenos Aires & 75.04 & 15.89 & 17.11 & 13.85 & 48.09 & 41.73 & 53.4 \\
\hline 2 & Catamarca & 57.79 & 18.72 & 23.24 & 14.02 & 39.56 & 39.37 & 38.34 \\
\hline 3 & Córdoba & 65.38 & 13.6 & 13.89 & 13 & 46.02 & 43.28 & 48.11 \\
\hline 4 & Corrientes & 74.61 & 12.36 & 11.88 & 12.3 & 44.02 & 41.46 & 45.16 \\
\hline 5 & La Plata & 84.08 & 16.71 & 18.37 & 15.12 & 56.59 & 49.59 & 62.14 \\
\hline 6 & La Rioja & 61.76 & 6.75 & 8.65 & 5.16 & 41.49 & 46.95 & 39.23 \\
\hline 7 & Mar del Plata & 81.64 & 15.56 & 17.69 & 14.08 & 52.5 & 46.3 & 57.13 \\
\hline 8 & Paraná & 75.16 & 12.03 & 11.51 & 11.86 & 41.66 & 39.27 & 42.86 \\
\hline 9 & Rosario & 77.6 & 12.55 & 12.38 & 11.76 & 45.95 & 43 & 49.21 \\
\hline 10 & Santiago del Estero & 63.51 & 9.92 & 10.12 & 9.28 & 45.56 & 46.32 & 43.87 \\
\hline 11 & Blumenau & 84.71 & 3.9 & 3.92 & 3.8 & 50 & 50 & 50 \\
\hline 12 & Chapecó & 73.51 & 14.06 & 12.59 & 15.91 & 50 & 50 & 50 \\
\hline 13 & Criciúma & 82.08 & 2.72 & 2.9 & 2.46 & 50 & 50 & 50 \\
\hline 14 & Curitiba & 84 & 11.18 & 11.46 & 10.31 & 69.58 & 78.3 & 57.36 \\
\hline 15 & Florianópolis & 79.47 & 10.93 & 11.36 & 10.61 & 65.6 & 68.2 & 59.56 \\
\hline 16 & Ponta Grossa & 76.42 & 6.4 & 6.45 & 6.26 & 50 & 50 & 50 \\
\hline 17 & Porto Alegre & 86.14 & 10.63 & 11.24 & 9.5 & 51.48 & 44.6 & 53.39 \\
\hline 18 & Santa Maria & 79.17 & 7.41 & 7.13 & 7.42 & 50 & 50 & 50 \\
\hline 19 & Antofagasta & 74.78 & 14.32 & 15.62 & 12.35 & 52.46 & 42.51 & 64.34 \\
\hline 20 & Concepción & 86.53 & 13.83 & 15.89 & 13.08 & 47.87 & 30.28 & 65.76 \\
\hline 21 & Copiacó & 78.3 & 16.77 & 17.99 & 15.11 & 43.03 & 33.69 & 48.65 \\
\hline 22 & Santiago & 78.23 & 8.86 & 12.05 & 5.98 & 53.57 & 36.61 & 70.34 \\
\hline 23 & Temuco & 85.21 & 8.04 & 8.58 & 8.13 & 70.36 & 61.81 & 78.58 \\
\hline 24 & Valparaíso & 81.16 & 12.26 & 13.76 & 10.33 & 73.35 & 65.63 & 80.49 \\
\hline 25 & Alicante & 66.35 & 24.12 & 24.12 & 24.12 & 50 & 50 & 50 \\
\hline 26 & Barcelona & 71.84 & 12.13 & 11.71 & 13.23 & 43.22 & 40.58 & 41.72 \\
\hline 27 & Córdoba & 77.72 & 24.12 & 24.12 & 24.12 & 50 & 50 & 50 \\
\hline 28 & Granada & 73.88 & 24.12 & 24.12 & 24.12 & 50 & 50 & 50 \\
\hline 29 & Málaga & 71 & 24.12 & 24.12 & 24.12 & 50 & 50 & 50 \\
\hline 30 & Murcia & 71.7 & 24.12 & 24.12 & 24.12 & 50 & 50 & 50 \\
\hline 31 & Palma & 80.9 & 10.59 & 11.03 & 10.73 & 42.15 & 32.25 & 49.86 \\
\hline 32 & Sevilla & 75.48 & 9.64 & 10.57 & 9.33 & 30.73 & 19.27 & 39.75 \\
\hline 33 & Valencia & 68.25 & 12.84 & 10.75 & 16.17 & 39.68 & 36.44 & 41.74 \\
\hline 34 & Aguascalientes & 45.22 & 7.05 & 6.66 & 7.2 & 56.13 & 60.63 & 51.55 \\
\hline 35 & Ciudad de México & 63.64 & 9.35 & 9.72 & 8.52 & 66.62 & 70.27 & 62.08 \\
\hline 36 & Guadalajara & 53.59 & 6.33 & 7.21 & 5.12 & 50 & 50 & 50 \\
\hline 37 & Hermosillo & 45.39 & 6.47 & 8.19 & 4.66 & 47.13 & 43.75 & 45.78 \\
\hline 38 & Juárez & 46.76 & 13.34 & 13.5 & 12.22 & 25.04 & 21.38 & 29.54 \\
\hline 39 & León & 46.54 & 13.94 & 14.58 & 12.96 & 55.14 & 57.64 & 54.96 \\
\hline 40 & Monterrey & 69.78 & 18.92 & 19.07 & 18.53 & 62.15 & 52.94 & 67.56 \\
\hline 41 & Puebla & 54.38 & 9.8 & 8.62 & 10.53 & 55.83 & 60.44 & 47.41 \\
\hline 42 & Tijuana & 65.13 & 9.34 & 9.32 & 9.28 & 43.29 & 44.63 & 39.88 \\
\hline
\end{tabular}

Tabla 43: Muestra empleada en el análisis de regresión múltiple - Parte IV. Elaboración propia. 


\subsubsection{Variable principal}

Según los resultados de los modelos estadísticos calculado a partir de una única variable secundaria principal, se construyeron la Tabla 44 y Tabla 45. En la primera columna de ambas tablas se verifica a cual Caso de Estudio y a qué situación del año corresponden los resultados expresados en las columnas 2, 3, 4, 5, 6, y 7. La columna 2 de la Tabla 44 indica la variable secundaria principal que mayormente se relaciona con los consumos en refrigeración o calefacción para cada Caso de estudio, y la columna 4 indica el coeficiente de determinación entre la variable dependiente y la secundaria principal.

Según los resultados se observa que los grados día consisten en la variable secundaria principal, tanto para el Caso I como para el Caso II. Para la vivienda unifamiliar se encontraron coeficientes de determinación $R^{2}=0.78$ para invierno y un $R^{2}=0.86$ para verano, en cuanto para el edificio multifamiliar, se verificó un $R^{2}=0.86$ para invierno y un $R^{2}=0.87$ para verano, lo que indica que los consumos en refrigeración y calefacción varían fuertemente en función de los grados día.

\begin{tabular}{llllll}
\hline Caso de estudio & Variable & $\mathbf{R}$ & $\mathbf{R}^{2}$ & $\mathbf{R}^{2}$ corregido & Error típico \\
\hline Caso I - Verano & GDver & .930 & .865 & .862 & 16.70023 \\
Caso I - Invierno & GDinv & .889 & .789 & .784 & 37.40689 \\
Caso II - Verano & GDver & .936 & .877 & .874 & 16.39443 \\
Caso II - Invierno & GDinv & .929 & .863 & .860 & 59.35259 \\
\hline
\end{tabular}

Tabla 44: Resumen de los modelos estadísticos con una variable principal - Caso I y Caso II, verano e invierno. Elaboración propia adaptada del SPSS.

\begin{tabular}{ccccccc}
\hline $\begin{array}{c}\text { Caso de } \\
\text { estudio }\end{array}$ & Variable & \multicolumn{2}{c}{$\begin{array}{c}\text { Coef. no estandarizados } \\
\text { B }\end{array}$} & $\begin{array}{c}\text { Coef. estandarizados } \\
\text { Brror típico }\end{array}$ & t & Sig. \\
\hline Caso I & (Constante) & -5.925 & 4.637 & - & -1.278 & .209 \\
Verano & GDver & .082 & .005 & .930 & 16.014 & .000 \\
\hline Caso I & (Constante) & -14.245 & 10.211 & - & -1.395 & .171 \\
Invierno & GDinv & .137 & .011 & .889 & 12.247 & .000 \\
\hline Caso II & (Constante) & -17.832 & 4.553 & - & -3.917 & .000 \\
Verano & GDver & .085 & .005 & .936 & 16.890 & .000 \\
\hline Caso II & (Constante) & 8.300 & 16.202 & - & .512 & .611 \\
Invierno & GDinv & .282 & .018 & .929 & 15.887 & .000 \\
\hline
\end{tabular}

Tabla 45: Coeficientes para los modelos estadísticos con una variable principal - Caso I y Caso II, verano e invierno. Elaboración propia adaptada del SPSS.

En la columna 3 de la Tabla 45, se observan los coeficientes aplicables a cada variable para la construcción de los modelos estadísticos correspondientes. Los modelos construidos se describen en el siguiente apartado debido a que el objetivo es incrementar los niveles de correlación obtenidos con la inclusión de más variables secundarias. En la columna 7 se expresan los valores considerados para comprobar la significancia de cada variable, según la prueba de la hipótesis nula del $P$-value.

Considerando las regulaciones y certificaciones de los países analizados en este trabajo, se construyó la Tabla 46, donde se detallan cuales son las variables climáticas requeridas para describir el clima en los diferentes procedimientos de cálculo definidos por cada país. En la columna 3 se detalla cual es el objetivo 
de las iniciativas de cada país, y en las columnas 5 y 6 se detalla cuales son las variables climáticas empleadas en los métodos de cálculo para caracterizar la rigurosidad del clima.

\begin{tabular}{|c|c|c|c|c|c|c|}
\hline País & Iniciativa & Evalúa & Condición & $\begin{array}{c}\text { Variable climática } \\
\text { principal }\end{array}$ & $\begin{array}{c}\text { Variable climática } \\
\text { secundaria }\end{array}$ & Dónde se aplica \\
\hline ARG & $\begin{array}{l}\text { IRAM } 11659 \\
\text { IRAM } 11604 \\
\end{array}$ & $\begin{array}{l}\text { Carga } \\
\text { térmica }\end{array}$ & $\begin{array}{l}\text { Verano } \\
\text { Invierno }\end{array}$ & $\begin{array}{c}\text { Temperatura } \\
\text { Diseño Máxima } \\
\text { Grados día }\end{array}$ & $\begin{array}{c}\text { Radiación } \\
- \\
\end{array}$ & $\begin{array}{l}\text { Dato ingresado en la } \\
\text { planilla de cálculo }\end{array}$ \\
\hline BRA & PBE Edifica & Consumo & $\begin{array}{l}\text { Verano } \\
\text { Invierno }\end{array}$ & $\begin{array}{l}\text { Grados Hora } \\
\text { Grados Hora }\end{array}$ & $\begin{array}{l}- \\
-\end{array}$ & $\begin{array}{l}\text { Dato incluido en la } \\
\text { planilla de cálculo }\end{array}$ \\
\hline $\mathrm{CHI}$ & $\begin{array}{c}- \\
\text { CEV }\end{array}$ & $\begin{array}{c}- \\
\text { Consumo }\end{array}$ & $\begin{array}{l}\text { Verano } \\
\text { Invierno }\end{array}$ & - & $\begin{array}{c}- \\
\text { Altitud }\end{array}$ & $\begin{array}{l}\text { Dato incluido en la } \\
\text { planilla de cálculo }\end{array}$ \\
\hline ESP & CEE & Demanda & $\begin{array}{l}\text { Verano } \\
\text { Invierno }\end{array}$ & $\begin{array}{l}\text { Grados día } \\
\text { Grados día }\end{array}$ & $\begin{array}{l}\text { Radiación } \\
\text { Radiación }\end{array}$ & $\begin{array}{l}\text { Dato incluido en la } \\
\text { planilla de cálculo }\end{array}$ \\
\hline MEX & $\begin{array}{c}\text { NOM-020 } \\
-\end{array}$ & $\begin{array}{c}\text { Carga } \\
\text { térmica } \\
-\end{array}$ & $\begin{array}{l}\text { Verano } \\
\text { Invierno }\end{array}$ & $\begin{array}{c}\text { Temperatura } \\
\text { Media Máxima } \\
-\end{array}$ & $\begin{array}{c}\text { Radiación } \\
-\end{array}$ & $\begin{array}{l}\text { Dato ingresado en la } \\
\text { planilla de cálculo }\end{array}$ \\
\hline
\end{tabular}

Tabla 46: Relación de las variables climáticas empleadas en los sistemas de calificación estudiados. Elaboración propia.

Según la tabla construida, se observa que en Argentina los grados día de invierno son considerados para determinar la rigurosidad del clima en los cálculos de la carga térmica para calefacción, en cuanto para la carga térmica en refrigeración emplea la temperatura de diseño máxima. En Brasil se utilizan los grados hora para calcular el consumo en refrigeración y calefacción y calificar la eficiencia energética de la envolvente edilicia. En Chile se adoptan los grados día para predecir las características del clima apenas en los cálculos de consumo en calefacción, ya que la etiqueta no evalúa el consumo en refrigeración. En España los grados día son empleados para identificar la rigurosidad del clima y estimar la demanda en calefacción y refrigeración. En México, de forma similar a Argentina, la temperatura media máxima es empleada en los cálculos de carga térmica para refrigeración. A diferencia de Argentina, la norma mexicana no califica la carga térmica para calefacción.

Si bien los grados día de calefacción y refrigeración son los que tienen una mayor influencia en los respectivos consumos energéticos, al analizar cuáles son las variables climáticas utilizadas en los cinco países de estudio para determinar la rigurosidad del clima (Tabla 46) se observa que, en general sí se utilizan los grados días, pero que existen casos puntuales como Argentina y México que utilizan variables diferentes. En el caso de Argentina y México se utiliza la Temperatura de Diseño Máxima y la Temperatura Máxima Media, respectivamente, para caracterizar la rigurosidad climática de verano.

En México, además, no existe normativa para las condiciones de invierno, así como en Chile no se regulan las condiciones de verano. Al analizar los consumos en refrigeración para las localidades de Chile (Tabla 38 y Tabla 39) se observa que el clima de estas ciudades demuestra ser poco riguroso en verano, por lo que no sería necesario incorporar regulación. Sin embargo, los consumos de calefacción en México resultan significativos por lo que sería conveniente incluir el análisis de la carga térmica de calefacción en su normativa. 


\subsubsection{Variables secundarias}

Analizando la inclusión de las demás variables climáticas, se observó que la magnitud de la correlación del consumo con los grados día se potenció en ambos Casos de estudio, tanto en la condición de invierno como para verano (Tabla 47, Tabla 49, Tabla 51 y Tabla 53).

\begin{tabular}{clcccc}
\hline \multirow{2}{*}{ Modelo } & \multicolumn{1}{c}{ Variables } & $\mathbf{R}$ & R cuadrado & $\begin{array}{c}\text { R cuadrado } \\
\text { corregida }\end{array}$ & $\begin{array}{c}\text { Error típ. de } \\
\text { la estimación }\end{array}$ \\
\hline 1 & GDver & .930 & .865 & .862 & 16.70023 \\
2 & GDver, VV & .946 & .894 & .889 & 14.95914 \\
3 & GDver, VV, HRpver & .960 & .922 & .916 & 13.01692 \\
4 & GDver, VV, HRpver, Altitud & .965 & .931 & .923 & 12.44655 \\
$\mathbf{5}$ & GDver, VV, HRpver, Altitud, GDpver & .970 & .940 & .932 & $\mathbf{1 1 . 7 3 9 9 4}$ \\
\hline
\end{tabular}

Tabla 47: Resumen de los modelos estadísticos para el Caso I - verano. Elaboración propia adaptada del SPSS.

\begin{tabular}{|c|c|c|c|c|c|c|}
\hline \multirow{2}{*}{ Modelo } & \multirow{2}{*}{ Variables } & \multicolumn{2}{|c|}{ Coef. no estandarizados } & \multirow{2}{*}{$\begin{array}{c}\text { Coef. estandarizados } \\
\text { Beta }\end{array}$} & \multirow{2}{*}{$\mathbf{t}$} & \multirow{2}{*}{ Sig. } \\
\hline & & B & Error típ. & & & \\
\hline \multirow{2}{*}{1} & (Constante) & -5.925 & 4.637 & - & -1.278 & .209 \\
\hline & GDver & .082 & .005 & .930 & 16.014 & .000 \\
\hline \multirow{3}{*}{2} & (Constante) & 10.957 & 6.597 & - & 1.661 & .105 \\
\hline & GDver & .083 & .005 & .941 & 18.055 & .000 \\
\hline & VV & -1.382 & .419 & -.172 & -3.294 & .002 \\
\hline \multirow{4}{*}{3} & (Constante) & 71.356 & 17.408 & - & 4.099 & .000 \\
\hline & GDver & .075 & .005 & .852 & 16.531 & .000 \\
\hline & VV & -1.666 & .373 & -.207 & -4.466 & .000 \\
\hline & HRpver & -.753 & .205 & -.193 & -3.675 & .001 \\
\hline \multirow{5}{*}{4} & (Constante) & 101.462 & 21.811 & - & 4.652 & .000 \\
\hline & GDver & .071 & .005 & .802 & 14.711 & .000 \\
\hline & VV & -1.982 & .386 & -.246 & -5.133 & .000 \\
\hline & HRpver & -1.034 & .236 & -.266 & -4.381 & .000 \\
\hline & Altitud & -.009 & .004 & -.116 & -2.136 & .039 \\
\hline \multirow{6}{*}{5} & (Constante) & 109.010 & 20.819 & - & 5.236 & .000 \\
\hline & GDver & .098 & .012 & 1.114 & 7.859 & .000 \\
\hline & VV & -1.670 & .388 & -.208 & -4.307 & .000 \\
\hline & HRpver & -1.076 & .223 & -.276 & -4.817 & .000 \\
\hline & Altitud & -.011 & .004 & -.148 & -2.796 & .008 \\
\hline & GDpver & -.176 & .074 & -.343 & -2.364 & .024 \\
\hline
\end{tabular}

Tabla 48: Coeficientes para los modelos estadísticos para el Caso I - verano. Elaboración propia adaptada del SPSS.

Según los resultados, se observa que las correlaciones para el Caso I registraron un coeficiente $R^{2}=$ 0.94 para verano y un $R^{2}=89$ para invierno, en cuanto para el Caso 2 se registró un $R^{2}=0.92$ para verano $y$ un valor $R^{2}=0.93$ para invierno. Estos resultados indican que el consumo energético se relaciona muy fuertemente con las variables empleadas en los modelos estadísticos finales. Es decir que los consumos en refrigeración para las viviendas unifamiliares se explican el 92\% por la variación de los grados día de verano, la velocidad del viento, la humedad relativa promedio para los 3 meses más cálidos y la altitud del lugar en donde se sitúa el edificio. Y los consumos en calefacción para los edificios multifamiliares se explican el 93\% por la variación de los grados día de invierno, la radiación global promedio para los 3 
meses más fríos, la temperatura media mínima y la velocidad del viento promedio para los tres meses más fríos. Los $8 \%$ y los $7 \%$ restantes respectivamente, corresponden a variables que no han sido incluidas en el estudio, por lo que se considera que la aproximación del modelo es muy alta.

\begin{tabular}{clcccc}
\hline Modelo & \multicolumn{1}{c}{ Variables } & R & R cuadrado & $\begin{array}{c}\text { R cuadrado } \\
\text { corregida }\end{array}$ & $\begin{array}{c}\text { Error típ. de } \\
\text { la estimación }\end{array}$ \\
\hline 1 & GDinv & $.889(\mathrm{a})$ & .789 & .784 & 37.40689 \\
2 & GDinv, VVpinv & $.911(\mathrm{~b})$ & .829 & .820 & 34.12701 \\
3 & GDinv, VVpinv, RADpinv & $.926(\mathrm{c})$ & .857 & .846 & 31.64931 \\
4 & GDinv, VVpinv, RADpinv, TMmin & $.948(\mathrm{~d})$ & .898 & .887 & $\mathbf{2 7 . 0 5 1 6 3}$ \\
\hline
\end{tabular}

Tabla 49: Resumen de los modelos estadísticos para el Caso I - invierno. Elaboración propia adaptada del SPSS.

\begin{tabular}{|c|c|c|c|c|c|c|}
\hline \multirow{2}{*}{ Modelo } & \multirow{2}{*}{ Variables } & \multicolumn{2}{|c|}{ Coef. no estandarizados } & \multirow{2}{*}{$\begin{array}{c}\text { Coef. estandarizados } \\
\text { Beta }\end{array}$} & \multirow{2}{*}{$t$} & \multirow{2}{*}{ Sig. } \\
\hline & & B & Error típ. & & & \\
\hline \multirow{2}{*}{1} & (Constante) & -14.245 & 10.211 & - & -1.395 & .171 \\
\hline & GDinv & .137 & .011 & .889 & 12.247 & .000 \\
\hline \multirow{3}{*}{2} & (Constante) & -44.119 & 13.613 & - & -3.241 & .002 \\
\hline & GDinv & .130 & .010 & .843 & 12.430 & .000 \\
\hline & VVpinv & 2.886 & .959 & .204 & 3.010 & .005 \\
\hline \multirow{4}{*}{3} & (Constante) & 45.419 & 35.367 & - & 1.284 & .207 \\
\hline & GDinv & .111 & .012 & .723 & 9.369 & .000 \\
\hline & VVpinv & 2.760 & .891 & .195 & 3.099 & .004 \\
\hline & RADpinv & -256.951 & 94.808 & -.207 & -2.710 & .010 \\
\hline \multirow{5}{*}{4} & (Constante) & 213.793 & 52.933 & - & 4.039 & .000 \\
\hline & GDinv & .064 & .016 & .418 & 4.076 & .000 \\
\hline & VVpinv & 2.245 & .773 & .159 & 2.905 & .006 \\
\hline & RADpinv & -495.888 & 101.829 & -.399 & -4.870 & .000 \\
\hline & TMmin & -8.573 & 2.213 & -.325 & -3.875 & .000 \\
\hline
\end{tabular}

Tabla 50: Coeficientes para los modelos estadísticos para el Caso I - invierno. Elaboración propia adaptada del SPSS.

\begin{tabular}{clcccc}
\hline Modelo & \multicolumn{1}{c}{ Variables } & R & R cuadrado & $\begin{array}{c}\text { R cuadrado } \\
\text { corregida }\end{array}$ & $\begin{array}{c}\text { Error típ. de } \\
\text { la estimación }\end{array}$ \\
\hline 1 & GDver & $.936(\mathrm{a})$ & .877 & .874 & 16.39443 \\
2 & GDver, Latitud & $.951(\mathrm{~b})$ & .904 & .899 & 14.67044 \\
3 & GDver, Latitud, GDpver & $.959(\mathrm{c})$ & .920 & .913 & $\mathbf{1 3 . 5 8 5 0 2}$ \\
\hline
\end{tabular}

Tabla 51: Resumen de los modelos estadísticos para el Caso II - verano. Elaboración propia adaptada del SPSS.

\begin{tabular}{|c|c|c|c|c|c|c|}
\hline \multirow{2}{*}{ Modelo } & \multirow{2}{*}{ Variables } & \multicolumn{2}{|c|}{ Coef. no estandarizados } & \multirow{2}{*}{$\begin{array}{l}\text { Coef. estandarizados } \\
\text { Beta }\end{array}$} & \multirow{2}{*}{$t$} & \multirow{2}{*}{ Sig. } \\
\hline & & B & Error típ. & & & \\
\hline \multirow{2}{*}{1} & (Constante) & -17.832 & 4.553 & - & -3.917 & .000 \\
\hline & GDver & .085 & .005 & .936 & 16.890 & .000 \\
\hline \multirow{3}{*}{2} & (Constante) & -22.240 & 4.286 & - & -5.189 & .000 \\
\hline & GDver & .089 & .005 & .987 & 19.013 & .000 \\
\hline & Latitud & -.253 & .076 & -.172 & -3.310 & .002 \\
\hline \multirow{4}{*}{3} & (Constante) & -13.616 & 5.069 & - & -2.686 & .011 \\
\hline & GDver & .123 & .013 & 1.353 & 9.513 & .000 \\
\hline & Latitud & -.221 & .072 & -.150 & -3.078 & .004 \\
\hline & GDpver & -.207 & .076 & -.394 & -2.735 & .009 \\
\hline
\end{tabular}

Tabla 52: Coeficientes para los modelos estadísticos para el Caso II - verano. Elaboración propia adaptada del SPSS. 
PARTE III · Definición de la ecuación

\begin{tabular}{clcccc}
\hline Modelo & \multicolumn{1}{c}{ Variables } & R & R cuadrado & $\begin{array}{c}\text { R cuadrado } \\
\text { corregida }\end{array}$ & $\begin{array}{c}\text { Error típ. de } \\
\text { la estimación }\end{array}$ \\
\hline 1 & GDinv & $.929(\mathrm{a})$ & .863 & .860 & 59.35259 \\
2 & GDinv, RADpinv & $.946(\mathrm{~b})$ & .895 & .889 & 52.78454 \\
3 & GDinv, RADpinv, TMmin & $.962(\mathrm{c})$ & .925 & .920 & 44.95103 \\
4 & GDinv, RADpinv, TMmin, VVpinv & $.968(d)$ & .938 & .931 & $\mathbf{4 1 . 5 8 2 0 7}$ \\
\hline
\end{tabular}

Tabla 53: Resumen de los modelos estadísticos para el Caso II - invierno. Elaboración propia adaptada del SPSS.

\begin{tabular}{|c|c|c|c|c|c|c|}
\hline \multirow{2}{*}{ Modelo } & \multirow{2}{*}{ Variables } & \multicolumn{2}{|c|}{ Coef. no estandarizados } & \multirow{2}{*}{$\begin{array}{c}\text { Coef. estandarizados } \\
\text { Beta }\end{array}$} & \multirow{2}{*}{$\mathbf{t}$} & \multirow{2}{*}{ Sig. } \\
\hline & & B & Error típ. & & & \\
\hline \multirow{2}{*}{1} & (Constante) & 8.300 & 16.202 & - & .512 & 611 \\
\hline & GDinv & .282 & .018 & .929 & 15.887 & .000 \\
\hline \multirow{3}{*}{2} & (Constante) & 192.751 & 56.100 & - & 3.436 & .001 \\
\hline & GDinv & .242 & .020 & .799 & 12.359 & .000 \\
\hline & RADpinv & -537.190 & 157.903 & -.220 & -3.402 & .002 \\
\hline \multirow{4}{*}{3} & (Constante) & 464.670 & 83.480 & - & 5.566 & .000 \\
\hline & GDinv & .162 & .026 & .533 & 6.163 & .000 \\
\hline & RADpinv & -933.288 & 167.410 & -.382 & -5.575 & .000 \\
\hline & TMmin & -14.385 & 3.622 & -.277 & -3.972 & .000 \\
\hline \multirow{5}{*}{4} & (Constante) & 394.912 & 81.366 & - & 4.854 & .000 \\
\hline & GDinv & .164 & .024 & .541 & 6.759 & .000 \\
\hline & RADpinv & -871.390 & 156.525 & -.357 & -5.567 & .000 \\
\hline & TMmin & -12.793 & 3.401 & -.246 & -3.762 & .001 \\
\hline & VVpinv & 3.233 & 1.188 & .116 & 2.722 & .010 \\
\hline
\end{tabular}

Tabla 54: Coeficientes para los modelos estadísticos para el Caso II - invierno. Elaboración propia adaptada del SPSS.

En este caso, analizando la inclusión de más variables climáticas consideradas por los sistemas de evaluación energética de la edificación estudiados para describir el clima, se verifica que Argentina no incluye otras variables en el cálculo de la demanda de calefacción, pero así como México, considera la radiación solar para estimar la demanda en refrigeración. En Brasil se emplean apenas los grados horas, en Chile se aplica una corrección a los valores de grados día de calefacción a partir de la altitud de cada ciudad. En España, la zonificación climática introducida en el CTE y posteriormente utilizada en los cálculos de demanda del Certificado de Eficiencia Energética - CEE, se fundamenta en el índice de severidad climática el cual adopta los grados día de verano e invierno en conjunto con la radiación, realizando una corrección a partir de la altitud de la localidad (Tabla 46).

A diferencia de lo analizado entre los sistemas estudiados, los resultados de los modelos estadísticos demuestran que además de los grados día, la radiación y la altitud, es necesario incluir la velocidad del viento, la humedad, y la temperatura media para describir con mayor precisión las características del clima de las localidades con clima templado.

Este resultado aumenta la relación de las variables climáticas con el consumo en acondicionamiento, y sugiere que las variables consideradas por Argentina, Brasil y México pueden incluir más variables para aumentar la precisión en la descripción del clima. El modelo estadístico elaborado presenta mayor relación con las variables climáticas empleadas en Chile y España. 
Con el fin de verificar las afirmaciones que surgen a partir de este análisis, se elaboraron las ecuaciones para predecir el consumo energético en acondicionamiento y se procedió a realizar una comparación con los procedimientos de cálculo empleados por los sistemas estudiados.

\subsubsection{Definición de las ecuaciones}

A partir de los resultados obtenidos con la inclusión de más variables climáticas para incrementar el nivel de correlación del modelo, se delimitaron las ecuaciones para calcular el consumo en calefacción y refrigeración de edificios residenciales en altura en clima templado (Ecuación 3, Ecuación 4, Ecuación 5 y Ecuación 6). Se adoptaron los últimos modelos obtenidos para el Caso I y para el Caso II tanto para verano como para invierno, se corroboró mediante la prueba de la hipótesis nula del $P$-value que cada variable fuera significativa para el modelo, y según los coeficientes asignados a cada variable climática (Columna B de la Tabla 48, Tabla 50, Tabla 52 y Tabla 54) se construyeron las ecuaciones.

$$
109.010+\left(0.098 * G D_{\text {ver }}\right)-(1.670 * \mathrm{VV})-\left(1.076 * \mathrm{HR}_{\mathrm{pver}}\right)-(0.011 * \mathrm{~A})-\left(0.176 * \mathrm{GD}_{\mathrm{pver}}\right)
$$

Ecuación 3: Consumo estival para el Caso I - vivienda unifamiliar. Elaboración propia.

$\mathrm{GD}_{\text {ver }}=$ Grados día de verano (base $\left.18^{\circ} \mathrm{C}\right)$

$\mathrm{VV}=$ Velocidad del viento promedio anual $(\mathrm{km} / \mathrm{h})$

$\mathrm{HR}_{\text {pver }}=$ Humedad relativa promedio para los tres meses más cálidos (\%)

$A=\operatorname{Altitud}(m)$

$\mathrm{GD}_{\text {pver }}=$ Grados día promedio para los tres meses más cálidos (base $18^{\circ} \mathrm{C}$ )

$$
213.793+\left(0.064 * G D_{\text {inv }}\right)+\left(2.245 * \mathrm{VV}_{\text {pinv }}\right)-\left(495.888 * \mathrm{RAD}_{\text {pinv }}\right)-\left(8.573 * \mathrm{TM}_{\text {min }}\right)
$$

Ecuación 4: Consumo invernal para el Caso I - vivienda unifamiliar. Elaboración propia.

$\mathrm{GD}_{\text {inv }}=$ Grados día de invierno (base $18^{\circ} \mathrm{C}$ )

$\mathrm{VV}_{\text {pinv }}=$ Velocidad del viento promedio para los tres meses más fríos $(\mathrm{km} / \mathrm{h})$

$\mathrm{RAD}_{\text {pinv }}=$ Radiación global promedio para los tres meses más fríos $(\mathrm{W} / \mathrm{m} 2)$

$\mathrm{TM}_{\text {min }}=$ Temperatura media mínima $\left({ }^{\circ} \mathrm{C}\right)$

Se verifica que para el Caso I en la condición de verano, cuanto mayor sea la velocidad del viento, la humedad relativa pver, la altitud, y los grados día pver menor será el consumo con refrigeración. En cuanto para la condición de invierno, solo la radiación pinv y la temperatura media mínima disminuyen los consumos en calefacción. Para el Caso Il en la condición de verano se observa que cuanto mayor sea la latitud y el valor de los grados día pver, menor será el consumo en refrigeración. En cuanto para invierno, cuanto mayor sea la radiación pinv, la temperatura media mínima, y la velocidad del viento pinv, menor será el consumo en calefacción.

Diferente a lo esperado, la variable de los grados día pver se encuentra en la misma ecuación con los grados día anuales de verano, para ambos edificios. Esto indica que cuanto mayor sea la suma de los grados día correspondiente a los tres meses más cálidos, menor será el consumo anual con refrigeración. 


$$
\left(0.123 * G D_{\text {ver }}\right)-(0.221 * \mathrm{~L})-\left(0.207 * \mathrm{GD}_{\text {pver }}\right)-13.616
$$

Ecuación 5: Consumo estival para el Caso II - edificio multifamiliar. Elaboración propia.

$\mathrm{GD}_{\text {ver }}=$ Grados día de verano (base $18^{\circ} \mathrm{C}$ )

$\mathrm{L}=$ Latitud (m)

$\mathrm{GD}_{\text {pver }}=$ Grados día promedio para los tres meses más cálidos (base $18^{\circ} \mathrm{C}$ )

$$
394.912+\left(0.164 * G D_{\text {inv }}\right)-\left(871.390 * \mathrm{RAD}_{\text {pinv }}\right)-\left(12.793 * \mathrm{TM}_{\text {min }}\right)+\left(3.233 * \mathrm{VV}_{\text {pinv }}\right)
$$

Ecuación 6: Consumo invernal para el Caso II - edificio multifamiliar. Elaboración propia.

$\mathrm{GD}_{\text {inv }}=$ Grados día de invierno $\left(\right.$ base $\left.18^{\circ} \mathrm{C}\right)$

$\mathrm{RAD}_{\text {pinv }}=$ Radiación global promedio para los tres meses más fríos $(\mathrm{W} / \mathrm{m} 2)$

$\mathrm{TM}_{\text {min }}=$ Temperatura media mínima $\left({ }^{\circ} \mathrm{C}\right)$

$\mathrm{VV}_{\text {pinv }}=$ Velocidad del viento promedio para los tres meses más fríos $(\mathrm{km} / \mathrm{h})$

La Figura 68 muestra la correlación existente entre los consumos de calefacción y refrigeración obtenidos mediante simulación energética y los valores estimados mediante las ecuaciones creadas.
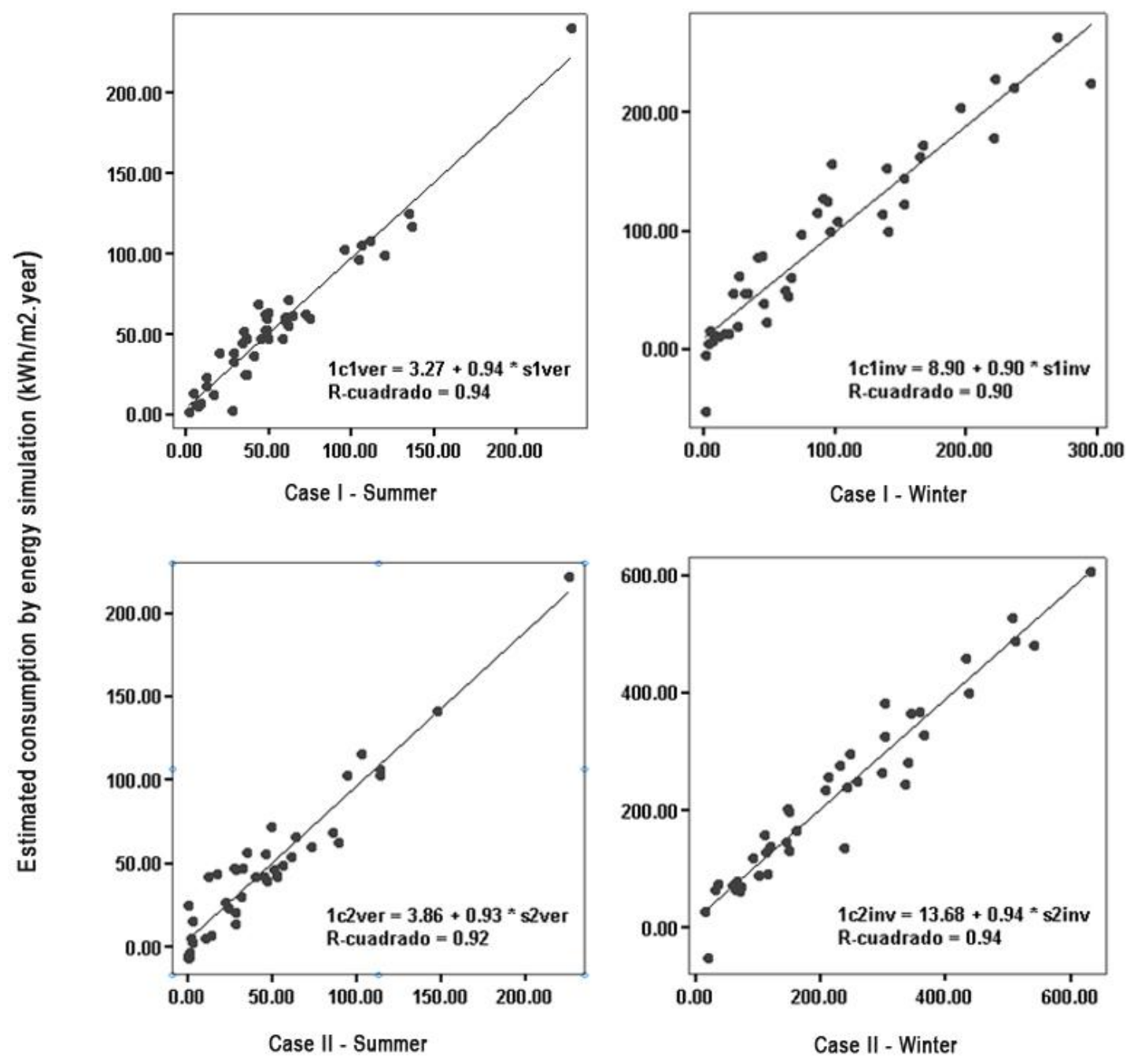

Estimated consumption by statistical model ( $\mathrm{kWh} / \mathrm{m} 2$.year)

Figura 68: Consumo estimado por simulación energética x modelo estadístico ( $\mathrm{kWh} / \mathrm{m2}$.año). Elaboración propia. 
Se observa que el valor del $\mathrm{R}^{2}$ obtenido es de 0.94 para verano y de 0.90 para invierno para edificios del Caso I, y de 0.92 para verano y 0.94 para invierno en edificios del Caso II. Estos resultados indican que la confiabilidad en la predicción de los modelos estadísticos elaborados es muy alta, haciendo con que la definición de ecuaciones simplificadas para predecir el consumo en acondicionamiento sea viable.

\subsubsection{Comparación con los métodos de cálculo de Brasil, Chile, y España}

Se realizó una comparación entre el método creado en la presente investigación y los procedimientos de cálculo empleados en los sistemas de calificación edilicia de Brasil, Chile y España, con el fin de identificar las principales diferencias y similitudes que permitan validar y optimizar el método propuesto.

Se compararon los consumos del Caso I obtenidos con las ecuaciones creadas, con los valores obtenidos con las planillas de cálculo simplificado suministradas por el PBE Edifica de Brasil, y por la CEV de Chile. En el caso de España, existen diversas herramientas, ya sean simplificadas o generales. Para este análisis se utilizó la herramienta CE3X, la cual posee un método de cálculo simplificado (Tabla 55).

\begin{tabular}{|c|c|c|c|c|c|c|c|}
\hline \multirow{3}{*}{ País } & \multirow{3}{*}{ Ciudad } & \multicolumn{3}{|c|}{ Invierno } & \multicolumn{3}{|c|}{ Verano } \\
\hline & & \multirow{2}{*}{$\begin{array}{l}\text { Modelo } \\
\text { Consumo }\end{array}$} & \multicolumn{2}{|c|}{ PBE } & \multirow{2}{*}{$\begin{array}{l}\text { Modelo } \\
\text { Consumo }\end{array}$} & \multicolumn{2}{|c|}{ PBE } \\
\hline & & & Consumo & Calificación & & Consumo & Calificación \\
\hline \multirow{8}{*}{$\begin{array}{l}\overline{\bar{n}} \\
\frac{\bar{D}}{\infty}\end{array}$} & Blumenau & 12.0 & 9.1 & B & 68.6 & 8.3 & B \\
\hline & Chapecó & 43.6 & 9.1 & B & 37.9 & 8.3 & B \\
\hline & Criciúma & 22.7 & 9.1 & B & 63.2 & 8.3 & B \\
\hline & Curitiba & 77.1 & 21.5 & B & 2.2 & 2.6 & D \\
\hline & Florianópolis & 6.3 & 9.1 & B & 62.4 & 8.3 & B \\
\hline & Ponta Grossa & 38.5 & 10.5 & $A$ & 24.4 & 4.3 & $A$ \\
\hline & Porto Alegre & 18.39 & 9.1 & B & 59.08 & 8.3 & B \\
\hline & Santa Maria & 59.53 & 10.5 & $A$ & 59.26 & 4.3 & $A$ \\
\hline \multirow{10}{*}{$\frac{0}{\frac{D}{U}}$} & & Modelo & \multicolumn{2}{|c|}{ CEV } & Modelo & \multicolumn{2}{|c|}{ CEV } \\
\hline & & Consumo & Consumo & Calificación & Consumo & Consumo & Calificación \\
\hline & Antofagasta & 3.8 & 53.8 & $E$ & - & - & - \\
\hline & Concepción & 227.8 & 201.6 & G & - & - & - \\
\hline & Copiapó & 49.3 & 56.0 & $E$ & - & - & - \\
\hline & Santiago & 203.5 & 167.2 & G & - & - & - \\
\hline & Temuco & 262.8 & 231.2 & G & - & - & - \\
\hline & \multirow[t]{3}{*}{ Valparaíso } & 155.6 & 147.5 & $\mathrm{~F}$ & - & - & - \\
\hline & & Modelo & \multicolumn{2}{|c|}{ CEE } & Modelo & \multicolumn{2}{|c|}{ CEE } \\
\hline & & Consumo & Demanda & Calificación & Consumo & Demanda & Calificación \\
\hline \multirow{9}{*}{ 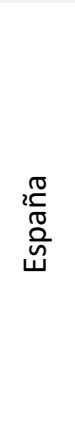 } & Alicante & 124.3 & 167.5 & G & 47.1 & 55.1 & $E$ \\
\hline & Barcelona & 178.3 & 258.75 & G & 36.5 & 16.5 & $\mathrm{E}$ \\
\hline & Córdoba & 172.0 & 167.5 & G & 71.5 & 46.2 & $\mathrm{E}$ \\
\hline & Granada & 211.5 & 255 & G & 43.9 & 66 & $E$ \\
\hline & Málaga & 114.8 & 123.75 & G & 52.3 & 66 & $\mathrm{E}$ \\
\hline & Murcia & 152.9 & 167.5 & G & 51.1 & 66 & $E$ \\
\hline & Palma & 98.3 & 152 & $\mathrm{D}$ & 57.8 & 23.1 & $\mathrm{D}$ \\
\hline & Sevilla & 99.4 & 167.5 & G & 102.6 & 46.2 & $E$ \\
\hline & Valencia & 113.6 & 168.75 & G & 61.0 & 67.1 & $E$ \\
\hline
\end{tabular}

Tabla 55: Comparación entre los consumos estimados con el método propuesto y los consumos estimados con las herramientas de cálculo del PBE de Brasil, la CEV de Chile y del CEE de España. Elaboración propia. 
En el caso de España y Chile las planillas permiten obtener la demanda, por lo que se aplicaron los resultados obtenidos a la Ecuación $\mathbf{7}$ con el fin de obtener los consumos. Los valores adoptados para el rendimiento medio estacional de verano han sido de 1.02 y de invierno 1.45, conforme indica el Instituto para la diversificación y ahorro de la energía y el Ministerio de la Vivienda (IDAE) de España (2009).

$$
\mathrm{C}=\frac{\mathrm{D}}{\eta}
$$

Ecuación 7: Consumo invernal para el Caso II - edificio multifamiliar. Fuente: (Instituto para la Diversificación y Ahorro de la Energía 2009).

$\mathrm{C}=$ Consumo en energía final $(\mathrm{kWh} / \mathrm{m} 2$ año)

$\mathrm{D}=$ Demanda energética $(\mathrm{kWh} / \mathrm{m} 2$ año)

$\eta=$ Rendimiento medio estacional (\%)

Se observó que el consumo en calefacción estimado por el modelo propuesto se encuentra 11,2\% distante del valor calculado con la CEV, 21\% distante del resultado del CE3X, y $210 \%$ alejado del valor estimado por el PBE Edifica. Para el consumo en refrigeración el valor estimado por el modelo propuesto se encuentra $43 \%$ y $596 \%$ por encima de lo que estima CE3X y PBE Edifica, respectivamente.

Estos resultados indican que el modelo se aproxima a los consumos en calefacción establecidos por las herramientas de Chile y España y se encuentra distante de los consumos en refrigeración calculados por España y Brasil.

Con respecto a las características del edificio requeridas por los sistemas analizados, se observó que en el PBE Edifica el usuario debe ingresar a la planilla de datos la superficie útil y la altura del ambiente analizado, la transmitancia térmica, capacidad térmica y absortividad de muros exteriores y techos, la superficie y orientación de los muros y superficies vidriadas de la envolvente, el factor de sombra y de abertura de las ventanas, y la superficie de muros interiores.

En la CEV se debe seleccionar el tipo de vivienda que se busca calificar, la superficie útil y la altura de la planta, la superficie y la transmitancia térmica de todos los elementos de la envolvente edilicia, el perímetro del ambiente y su transmitancia térmica, el factor de sombra de las ventanas, su orientación, y la absortividad del marco.

En la CEE se debe introducir el tipo de edificio, la superficie útil y la altura de la planta, el número de pisos que posee la edificación, el número de renovaciones por hora, la superficie, la transmitancia térmica y la masa de todos los elementos de la envolvente edilicia, la orientación y el factor de sombra de los muros y superficies vidriadas de la envolvente, la permeabilidad del hueco y la absortividad del marco.

En el modelo creado todas estas variables han sido asignadas al modelo energético, por lo que se verifica una estrecha relación entre los indicadores utilizados en la metodología propuesta y las herramientas analizadas. La principal diferencia encontrada corresponde a que en el modelo propuesto estas variables han sido utilizadas para la elaboración de los modelos estadísticos, en cuanto en las herramientas analizadas se solicita la información ejecutar la calificación. Como en el modelo propuesto 
se trabaja con un edificio estándar, no es posible modificar la tipología edilicia dado que esta información se encuentra implícita en la ecuación de cálculo.

Con respecto a las características del clima consideradas por las herramientas estudiadas, se observa que en Brasil y Chile el usuario debe seleccionar la zona climática en que se sitúa el edificio analizado para que el programa asigne las variables del clima. En España el usuario debe seleccionar la ciudad para que el programa asigne la zona climática y las variables climáticas. A diferencia de los procedimientos analizados, el método creado se enfoca en la variación del clima como condicionante prioritario a ser modificado por el usuario. En Brasil, Chile y España es posible modificar la tipología constructiva dejando las características climáticas implícitas en el cálculo de la herramienta, en cuanto en el modelo se modifican las variables climáticas, dejando implícito las características del edificio.

Analizando los consumos calculados por la CEE, se puede verificar que las localidades de Alicante, Córdoba, Murcia, Sevilla y Valencia de España poseen un consumo similar tanto para invierno como para verano, aunque tengan entre sí variaciones de $650 \mathrm{~km}$ de distancia con una oscilación de más de 600 metros de altitud. De forma parecida ocurre con las ciudades de Blumenau, Chapecó, Criciúma, Florianópolis y Porto Alegre de Brasil, que se encuentran a una distancia de hasta 590 km entre sí, y según la planilla del PBE Edifica poseen el mismo consumo en calefacción y refrigeración.

En el caso de España el procedimiento de sectorización empleado en la construcción de la zonificación climática del país, lleva en consideración las variables de grados día, radiación solar, además de realizar una corrección a partir de la altitud en que se encuentra la localidad. Entretanto, al momento de utilizar las características del clima para estimar la demanda energética y definir la calificación del edificio se hace uso del Índice de Severidad Climática, un indicador resultante del cociente entre la demanda energética de un edificio en una localidad y la demande del mismo edificio situado en Madrid (Ministerio de Fomento 2017).

En Brasil también se observa que los consumos no varían para ciudades que presentan diferentes condiciones climáticas, aunque los criterios de sectorización empleados sean diferentes al de España. Cuando observamos el procedimiento de agrupamiento de las localidades en la zonificación de Brasil, se verifica que las zonas climáticas han sido definidas en función de las estrategias de diseño aplicables a las localidades (Roriz, Ghisi e Lamberts 1999).

La zonificación dividió el territorio en 8 zonas, lo que ha sido objeto de discusión durante muchos años debido a que se estimaba que la cantidad de zonas no representaba adecuadamente la extensa superficie y diversidad climática del país. Desde el año de 2012, la zonificación vigente se encuentra en proceso de revisión y se pretende establecer 24 zonas climáticas (Laboratório de Eficiência Energética em Edificações 2014). Entretanto, la herramienta del PBE Edifica y la regulación del país aún definen los estándares de desempeño en función de la clasificación climática vigente.

En la Tabla 55 es posible observar que los consumos estimados por el modelo propuesto varían según las ciudades de Alicante, Córdoba, Murcia, Sevilla, Valencia, Blumenau, Chapecó, Criciúma, Florianópolis y 
Porto Alegre. Así mismo, al comparar los consumos estimados por las ecuaciones propuestas (Tabla 40) con los requerimientos de grados días para las 42 localidades (Tabla 33), existe una muy alta relación de los consumos con los grados días. No obstante, para Brasil y España, los consumos estimados por sus sistemas presentan baja y muy baja relación con los grados días, respectivamente, indicando que el método propuesto se ajusta más a la variación de la rigurosidad del clima local (Figura 69).
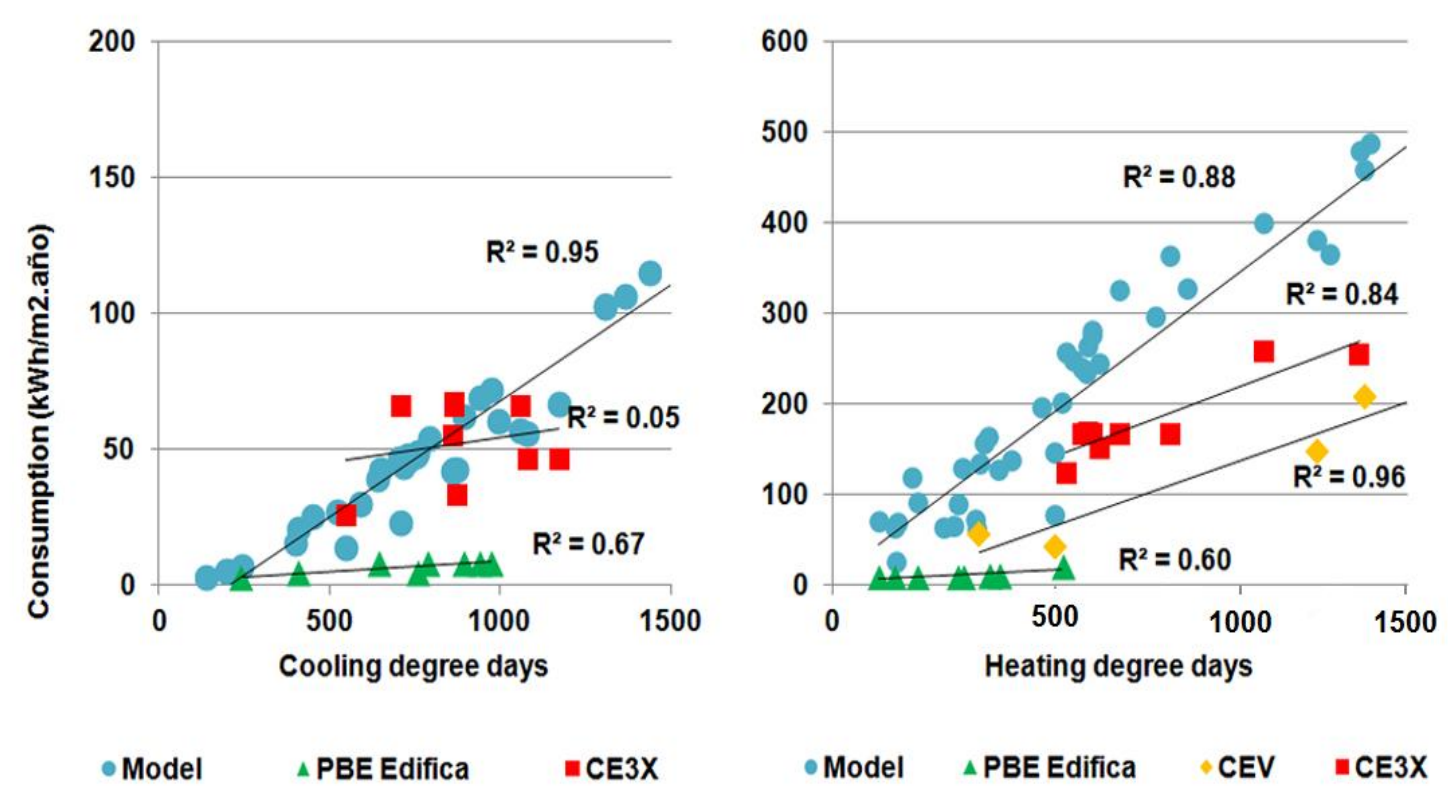

Figura 69: Consumo estimado por el modelo creado y por los sistemas de Brasil, Chile y España en relación con los grados días de las 42 localidades analizadas - Caso 1.

A raíz de los resultados se observa que mientras en los sistemas de Brasil y España las condiciones climáticas se introducen mediante la selección de una zona climática (composición estadística) arrojando el mismo consumo energético para las diferentes localidades de la misma zona (por ejemplo Blumenau, Chapecó, Criciúma, Florianópolis y Porto Alegre en Brasil), en el sistema propuesto se introducen datos climáticos específicos de cada localidad, lo cual sugiere que el método propuesto logra una mayor aproximación a las condiciones reales. En este sentido, la escasa diferencia respecto a los consumos calculados por el sistema de Chile demuestra una alta correlación entre el consumo energético y los grados días de cada ciudad.

Se considera que las características climáticas deben ser empleadas en las herramientas de cálculo de forma más específica, buscando la mayor representatividad de la rigurosidad del clima. No es posible analizar en igualdad de condiciones la asignación de las características climáticas para el caso de Brasil porque el país se basa en las estrategias de diseño correspondiente a cada localidad. Entretanto para el caso de España se verifica que las variables empleadas son muy similares a las variables que el modelo propuesto indica estar fuertemente relacionadas con los consumos energéticos.

Para el caso de España, la relación entre las características climáticas de la localidad donde se inserta el edificio de estudio en comparación con el clima de Madrid, lleva a cuestionar si la demanda del edificio analizado debería vincularse a la demanda de un edificio de base situado en otra ciudad, o si debería estar 
relacionada con la demanda de un edificio de referencia construido en la misma ciudad que el edificio de estudio con características constructivas de base.

Se considera importante revisar las propuestas de zonificación de Brasil y España, con el fin de verificar la posibilidad de generar un mayor número de zonas climáticas, las cuales puedan representar con mayor precisión el clima de las diferentes localidades. Aunque las variables climáticas empleadas en España coinciden con los resultados obtenidos en esta investigación, puede ser que la cantidad de zonas establecidas sea insuficiente para describir el clima de todas las localidades y sea la respuesta a la similitud en los consumos visualizados. Así mismo se recomienda revisar el peso de las variables climáticas en la determinación de la eficiencia energética de las edificaciones en ambos instrumentos.

Con respecto a las características de uso y ocupación, se observa que tanto las herramientas como el modelo elaborado llevan implícito el aporte de las cargas internas en sus procedimientos de cálculo.

En el caso del PBE Edifica no se encontró información oficial que indique que la planilla de cálculo considera las cargas internas correspondiente al uso y ocupación del edificio. Para el método de cálculo simulado del PBE Edifica se establece que las cargas internas deben ser asignadas por el profesional considerando 2 usuarios por habitación. Se consideran también los horarios de ocupación de la vivienda, las actividades realizadas, la iluminación, los equipos eléctricos, y demás artefactos. Los Schedules de ocupación deben ser asignados para dormitorios y estar, siendo que los dormitorios se encuentran ocupados de las 21:00 hasta las 7:00, en cuanto el estar se ocupa de las 18:00 hasta las 21:00. Lo que lleva a creer, que si la planilla de cálculo considera la carga interna correspondiente a la ocupación de la vivienda para la determinación de la eficiencia de la envolvente, se utilizan las características detalladas.

En la CEV se considera una carga interna asociada al uso de la iluminación, de los equipos eléctricos, y los artefactos de cocina según la ocupación de cada usuario en la vivienda. Para ello, el usuario debe asignar el número de dormitorios que posee la vivienda, para que se establezca automáticamente el perfil de las cargas internas correspondiente al Schedule de ocupación pre establecido por la CEV. Se verifica que la herramienta establece una carga mínima para la vivienda durante todo el día, la cual aumenta a partir de las 17:00 y va incrementándose hasta las 21:00, donde atinge su pico máximo y se mantiene hasta las 8:00 del otro día, donde retoma a los valores iniciales de carga mínima.

En el caso de la CEE las cargas internas están pre definidas según los parámetros establecidos en el CTE, por lo que no se requiere la carga de ninguna información a la herramienta. Así como en la CEV, el CTE establece una densidad para la carga interna total que posee la vivienda en función de la ocupación de los habitantes del hogar. Para ello lleva en consideración los horarios de ocupación de la vivienda, la iluminación, los equipos eléctricos, y demás artefactos.

Se observa que las cargas internas asignadas en la construcción del modelo elaborado son similares a los datos incorporados por las herramientas analizadas. En Chile, España y en el modelo creado esta información se encuentra implícita en los cálculos, aplicando un perfil del usuario estándar relacionado con el uso tradicional de cada lugar. 
La principal diferencia encontrada, corresponde a que mientras este modelo se construyó a partir de un perfil de uso resultante de un perfil real, en la herramienta española el perfil de uso viene prefijado para uso residencial con una carga de ocupación muy superior a la empleada usualmente en Latinoamérica. Esta diferencia entre los perfiles sin duda produce diferencias en los consumos energéticos obtenidos entre las herramientas de los países estudiados y el método propuesto.

Con respecto a las características de las instalaciones se verifica que en el caso del PBE Edifica dichas variables se encuentran pre establecidas en la planilla, de forma que el consumo estimado se calcula automáticamente posterior al ingreso de las características del edificio. En la solapa relacionada con la eficiencia de los sistemas presentes en el edificio, es posible ingresar algunas características correspondientes a los artefactos de calefacción y refrigeración, como la eficiencia del equipo, la potencia de los sistemas instalados, y el coeficiente de performance de las bombas de calor. Entretanto, estos aspectos no modifican el consumo del edificio, sino que influencian los niveles de eficiencia obtenidos para la envolvente.

En la CEV y en la CEE se permite introducir más información sobre la instalación de los sistemas, ya que son herramientas para evaluar la eficiencia del edificio, y no de la envolvente como es el caso del PBE Edifica. Se debe ingresar el tipo de generador y la fuente energética utilizada, la potencia nominal del sistema, el rendimiento general del equipo, y la corrección por distribución y por control en el caso de Chile y la carga media real en el caso de España.

Durante los análisis realizados se observó que cuando se modifican las características de los equipos, el consumo final calculada por la CEV presenta mayores variaciones que el consumo obtenido con la CEE. Es decir que los sistemas instalados en el edificio parecen tener mayor influencia para la etiqueta de Chile que en el certificado de España. Según lo verificado en diferentes foros y grupos de auxilio al empleo de la herramienta CE3X, los resultados no se ven afectados de forma significativa cuando se modifican las características de los equipos de climatización, así como el número de renovaciones de aire por hora.

Cómo las características de los sistemas instalados en el edificio influyen de mayor forma en los consumos finales de Chile que en España, se estima que esta diferencia en el procedimiento de cálculo de los dos países sea el justificante por la mayor aproximación del modelo propuesto a los valores de Chile, que en España.

Con respecto a la calificación de eficiencia energética asignada por cada sistema en función del consumo en acondicionamiento de las diferentes ciudades, se verifica cierta relación entre los niveles establecidos en Chile y España. Entre estos dos países, un gran porcentaje de las calificaciones poseen nivel E y G, en cuanto en Brasil los resultados predominantes son de nivel A y $B$.

Cuando se comparan los consumos en calefacción para Curitiba, Copiapó, y Sevilla, se verifica que los consumos estimados por el modelo propuesto son similares para las dos primeras localidades y un poco superior para Sevilla. Estos resultados guardan relación con los resultados de la CEV y de la CEE y sugieren que las tres ciudades deberían poseer el mismo nivel de eficiencia, o similar. Entretanto, las etiquetas 
asignadas por Chile y España expresan que la eficiencia de los edificios para Copiapó y Sevilla es E y G respectivamente, en cuanto la eficiencia del etiquetado de Brasil para Curitiba alcanza el nivel B.

De forma similar ocurre con la condición de verano, donde Santa Maria en Brasil presenta un nivel de eficiencia $A$, en cuanto Valencia en España presenta un nivel de eficiencia $E$ para consumos similares estimados con el modelo propuesto. Incluso en el caso de la Barcelona, donde los valores de consumo calculados por la CEE son más bajos, la calificación obtenida es nivel E, en cuanto en Brasil valores similares poseen nivel B.

Es importante rescatar que el PBE Edifica califica la eficiencia de la envolvente edilicia, en cuanto la CEV y el CEE la eficiencia del edificio. Si regresamos a la Tabla 30, corroboramos que los valores de transmitancia térmica establecidos por Brasil para muros y techos son más permisivos que los demás países, aspecto que indica los elevados niveles de eficiencia obtenidos en comparación a los demás sistemas, ya que en definitivita, la envolvente cumple con los requisitos de la normativa.

Como ya mencionado anteriormente, la zonificación de Brasil incluye una gran cantidad de ciudades en una única zona climática, a la cual define los valores de $\mathrm{U}$ admisibles. Si comparamos los estándares de U definidos por cada país para localidades con características climáticas similares, verificamos que los valores de $U$ establecidos por la regulación de Brasil son más permisivos que los valores definidos por los demás países, tanto para muros como para techos (Figura 70).
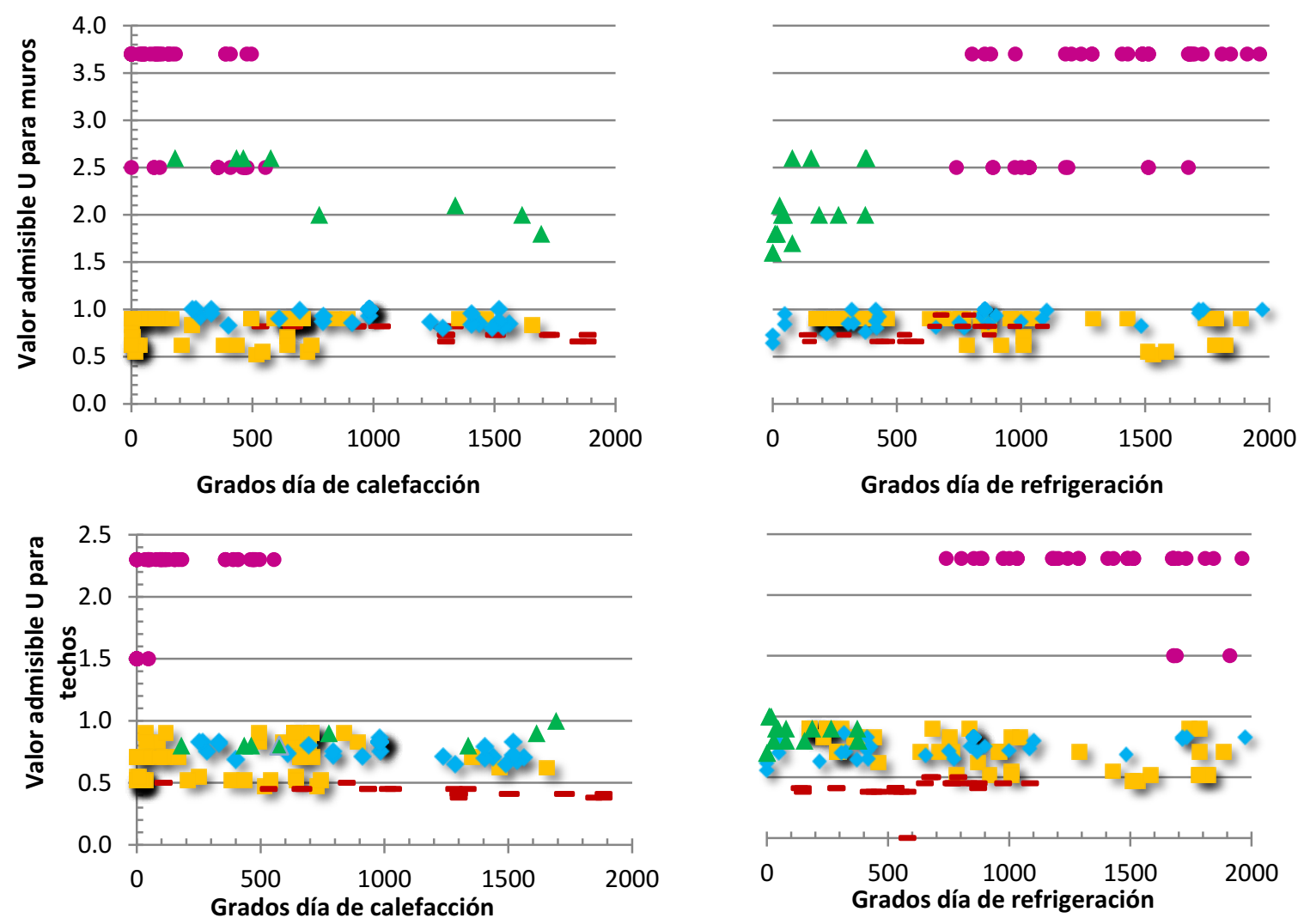

Figura 70: Relación entre los valores de U para muros y techos con los grados día de refrigeración y calefacción para localidades de Argentina, Brasil, Chile, España y México. Elaboración propia. 
Se considera importante revisar los valores admisibles de transmitancia térmica asignados a los elementos de la envolvente para cada localidad en la regulación de Brasil, así como los niveles de eficiencia establecidos por el PBE Edifica.

Se observa que los valores de U propuestos por la regulación de España, se asemejan a los valores establecidos por las normativas de Argentina y México. Sin embargo, aunque estos valores sean similares y cada regulación proponga otros valores de $U$ asociados a demás niveles de desempeño térmico posibles, las regulaciones en Latinoamérica no se aplican efectivamente en cuanto en España sí. Este contexto legal remete a la forma de construir real verificada en el apartado 4.2 Selección de los edificios Casos de Estudio, donde se demostró que las características constructivas tradicionales de la envolvente edilicia en España poseen un desempeño superior a la solución constructiva tradicionalmente empleada en Latinoamérica.

Este escenario impulsa la optimización de la calidad de la envolvente en Latinoamérica, ya que indica que la envolvente tradicional es poco eficiente y la inclusión de pocos materiales, tanto en el muro exterior como en el techo, posibilitaría obtener una mejora substancial en los niveles de confort, consumo energético y del impacto ambiental.

De modo general, estas colocaciones llevan a concluir que el modelo propuesto se encuentra mayormente relacionado con los procedimientos de Chile y España. Se observó que el modelo responde mejor en la condición de invierno que en verano. Así mismo, se verifica que el clima de las localidades demuestra ser más riguroso en invierno que en verano, de forma que los consumos en refrigeración estimados por el PBE Edifica y por la CEE son reducidos.

Esto lleva a que la diferencia entre los consumos del modelo propuesto con los consumos estimados por la CEE sea más significativa que si existiera la misma diferencia entre consumos energéticos mayores. Es interesante aplicar la ecuación a localidades con veranos más duraderos, que presenten rangos de grados día más elevados a los considerados en la muestra del presente trabajo, para verificar si la respuesta del modelo se incrementa o se mantiene.

La metodología desarrollada en la presente investigación se asemeja mayormente a los métodos empleados por Petersdorff, Boermans y Harnisch (Petersdorff, Boermans y Harnisch 2006) y Nath y Lamberts (Nath Lopes y Lamberts 2018). En ambos casos se simula la aplicación de un modelo energético a diferentes situaciones climáticas, para obtener los consumos aplicables en el análisis estadístico. Sin embargo, el modelo propuesto trabaja con 42 localidades, en cuanto los trabajos revisados trabajan con 3 y 18 localidades respectivamente.

Además, las características de la envolvente edilicia en el modelo propuesto se centra en la modificación de los niveles de aislamiento, sin embargo Petersdorff, Boermans y Harnisch (Petersdorff, Boermans y Harnisch 2006) también varían las tipologías de los edificios, y Nath y Lamberts (Nath Lopes y Lamberts 2018) trabajan con 15 variables del edificio y de la envolvente, sin modificar los niveles de 
aislamiento. Las características de los sistemas HVAC tienen mayor importancia en el modelo de Nath y Lamberts (Nath Lopes y Lamberts 2018) ya que se destinan a edificios de oficina. 


\section{Conclusiones}

Esta etapa permitió determinar cuáles son las variables climáticas que más influencian en el consumo energético de edificios residenciales situados en localidades con clima templado, construir una ecuación simplificada para la condición de verano e invierno aplicado a una vivienda unifamiliar y a un edilicio multifamiliar, y comparar los resultados obtenidos con sistemas vigentes en Brasil, Chile y España.

A modo de resumen se rescatan los siguientes aspectos:

I. Los grados día consisten en un parámetro sencillo para predecir la riguridad del clima templado y estimar el consumo energético de los sistemas de acondicionamiento (Tabla 44).

II. El análisis de un mayor número de variables climáticas permite una mejor aproximación a la condición del clima en donde la edificación se inserta, así como una mayor linealidad en la predicción del rendimiento energético del edificio (Tabla 47, Tabla 49, Tabla 51 y Tabla 53).

III. Las variables climáticas que mejor justifican los consumos en acondicionamiento para los modelos edilicios analizados corresponden a los grados día, la velocidad del viento, humedad relativa promedio para los 3 meses más cálidos, altitud, radiación global promedio para los 3 meses más fríos, temperatura media mínima y velocidad del viento promedio para los tres meses más fríos.

IV. Se encontró una aproximación muy significativa entre los consumos estimados a través del modelo energético construido con datos reales, auditados y validados, y los modelos estadísticos elaborados, lo que indica la confiabilidad de las ecuaciones para predecir el consumo (Figura 68).

V. El nivel de confiabilidad de la ecuación para estimar el consumo anual en refrigeración alcanza el 93\% para el Caso I, y del 91\% para el Caso II. Para el consumo anual en calefacción el nivel de confiabilidad es del $88 \%$ para el Caso I y del $93 \%$ para el Caso II.

VI. Se han obtenido resultados satisfactorios, posibles de aplicar de forma simplificada por cualquier persona que disponga de algunas características del clima de la localidad.

VII. El modelo de cálculo propuesto se encuentra mayormente relacionado con los procedimientos de cálculo implementados en las herramientas de calificación edilicia de Chile y España (Tabla 55).

VIII. Las características del edificio, de uso y ocupación, y de las instalaciones empleadas para construir el modelo propuesto, son similares a los datos de entrada considerados por las herramientas analizadas para estimar el gasto energético.

IX. Las características climáticas son diferentes, ya que el modelo propuesto asigna las variables para la ciudad analizada, en cuanto las demás herramientas trabajan con una aproximación en función de las zonas climáticas en que se encuentra el edificio.

$X$. La principal fortaleza del método desarrollado consiste en que logra determinar con mayor precisión las particularidades del clima de cada ciudad. En cuanto la mayor debilidad se centra en que no se puede aplicar a diferentes tipologías edilicias.

XI. Se recomienda que la zonificación de Brasil y España incorporen un mayor número de zonas climáticas, con el fin de representar de forma más precisa la variación del clima entra las ciudades. 
XII. Se recomienda que la regulación de Brasil revise los valores mínimos admisibles para la transmitancia térmica de muros y techos, así como los niveles de eficiencia energética de la envolvente del edificio en el PBE Edifica.

XIII. Para los sistemas de calificación edilicia que evalúan la carga térmica - Argentina y México, así como aquellos países con clima templado que no disponen de una regulación de eficiencia energética edilicia, se considera adecuado que incorporen la evaluación del consumo energético, pudiendo emplear como método de cálculo las ecuaciones elaboradas. 


\section{Modelo de eficiencia energética}

\section{Objetivo}

En esta etapa se estimarán los ahorros potenciales energéticos y en emisiones de $\mathrm{CO} 2$ resultantes de la aplicación de los estándares de transmitancia térmica definidos por cada país, con el fin de establecer los porcentajes de ahorro requeridos por el modelo energético ambiental propuesto. 
En un trabajo realizado anteriormente por los autores se ha desarrollado una zonificación climática a partir de los grados día requeridos por diversas localidades de Latinoamérica (Reus Netto 2017).

La base para la construcción de la zonificación se centró en los grados día para calefacción y refrigeración de 455 localidades de diferentes países latinoamericanos, resultando en 16 zonas climáticas sectorizadas cada 500 grados día (Figura 71).

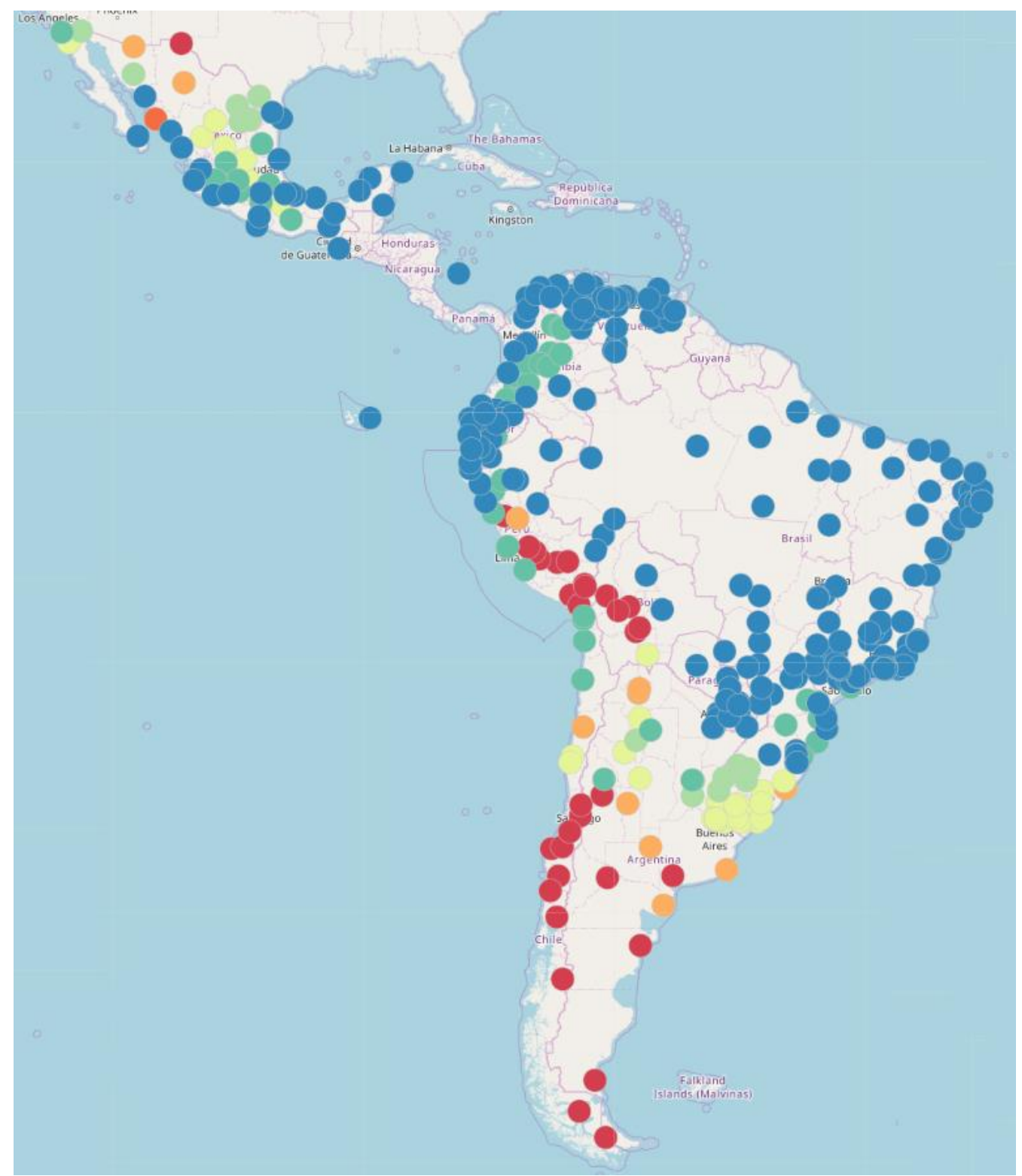

Figura 71: Esquema de la zonificación climática propuesta en (Reus Netto 2017). Elaboración propia.

Leyenda

\begin{tabular}{|c|c|c|c|c|c|}
\hline & \multirow{2}{*}{ Grados Día } & \multicolumn{4}{|c|}{ Refrigeración } \\
\hline & & $0-500$ & $501-1000$ & $1001-1500$ & $<1501$ \\
\hline \multirow{4}{*}{ 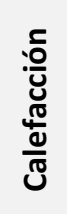 } & $<1501$ & 1 & 2 & 3 & 4 \\
\hline & $1001-1500$ & 5 & 6 & 7 & 8 \\
\hline & $501-1000$ & 9 & 10 & 11 & 12 \\
\hline & $0-500$ & 13 & 14 & 15 & 16 \\
\hline
\end{tabular}


En la presente tesis se propone adoptar la zonificación climática en conjunto con el método de cálculo desarrollado, para construir las bases de un modelo energético ambiental para edificios residenciales aplicable a Latinoamérica. La propuesta consiste en utilizar el método propuesto para estimar los ahorros posibles de alcanzar en una determinada situación constructiva tradicional, cumpliendo con los estándares de transmitancia térmica definidos por la Ley $n^{\circ}$ 13.059/03 de Argentina, el PBE Edifica de Brasil, la Calificación Energética de Viviendas de Chile, la Norma Mexicana de Edificación Sustentable de México, y el Código Técnico de la Edificación de España. La zonificación serviría como parámetro para delimitar los rangos de ahorro energético y en emisiones de $\mathrm{CO} 2$ que deben ser atendidos por los edificios de cada zona climática (Figura 72).

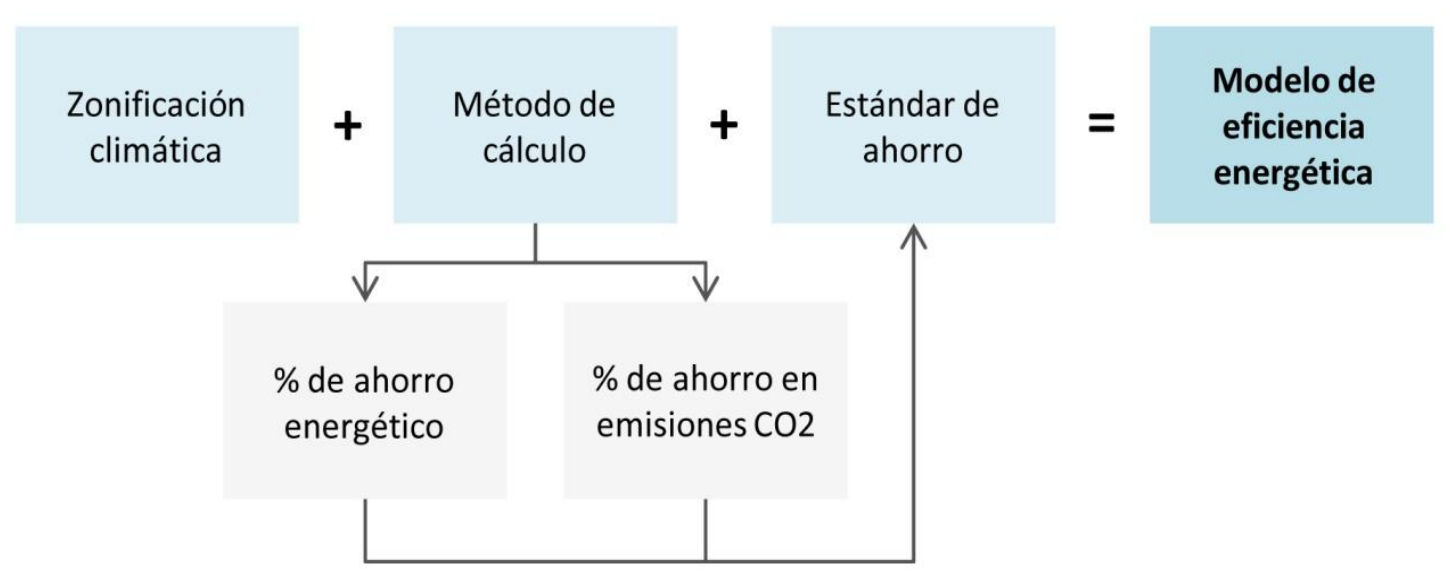

Figura 72: Etapas para la construcción del modelo de eficiencia energética. Elaboración propia.

Para la definición de los porcentajes de ahorro se considera la reducción promedio en el consumo obtenido con la aplicación de los estándares de transmitancia térmica en muros y techos establecidos por Argentina, Brasil, Chile, y México, respecto los consumos de edificios construidos con tipología tradicional - Escenario I. Así mismo se consideran los ahorros posibles de alcanzar en las emisiones de $\mathrm{CO} 2$ de cada país, en función de la disminución del consumo energético asociado a la matriz energética de cada país.

\subsection{Ahorros energéticos}

Para estimar el ahorro energético potencial resultante de la aplicación de las normativas de cada país se valora la influencia de la modificación de los estándares de transmitancia térmica en fachadas y cubiertas sobre el consumo del modelo edilicio tradicional.

En la Figura 73 se puede observar el consumo de los casos de estudio aplicados a las 42 localidades de Argentina, Brasil, Chile, México y España en dos condiciones. Una considerando la construcción del edificio con una tipología tradicional - Escenario I, y la segunda según los estándares mínimos de transmitancia térmica para muros y cubiertas establecidos por la reglamentación de cada país.

Se verificó que los mayores ahorros en calefacción se dan con la aplicación del CTE de España, el cual indica disminuir el 32\% del consumo de gas natural. Para refrigeración ocurren con la aplicación de la NOM de México, reduciendo el $27 \%$ del consumo eléctrico con aire acondicionado. Tanto para invierno 
como para verano, los estándares propuestos por la normativa de Brasil propician los menores ahorros, disminuyendo el $7 \%$ del consumo de calefacción y el 12\% de la energía eléctrica para refrigeración.

Como se ha demostrado en el apartado anterior, este análisis indica que los estándares de transmitancia térmica definidos en la normativa de Brasil son significativamente más permisivos que los valores admisibles de Argentina, España y México para localidades con clima similar. En Chile esta diferencia es menos representativa.

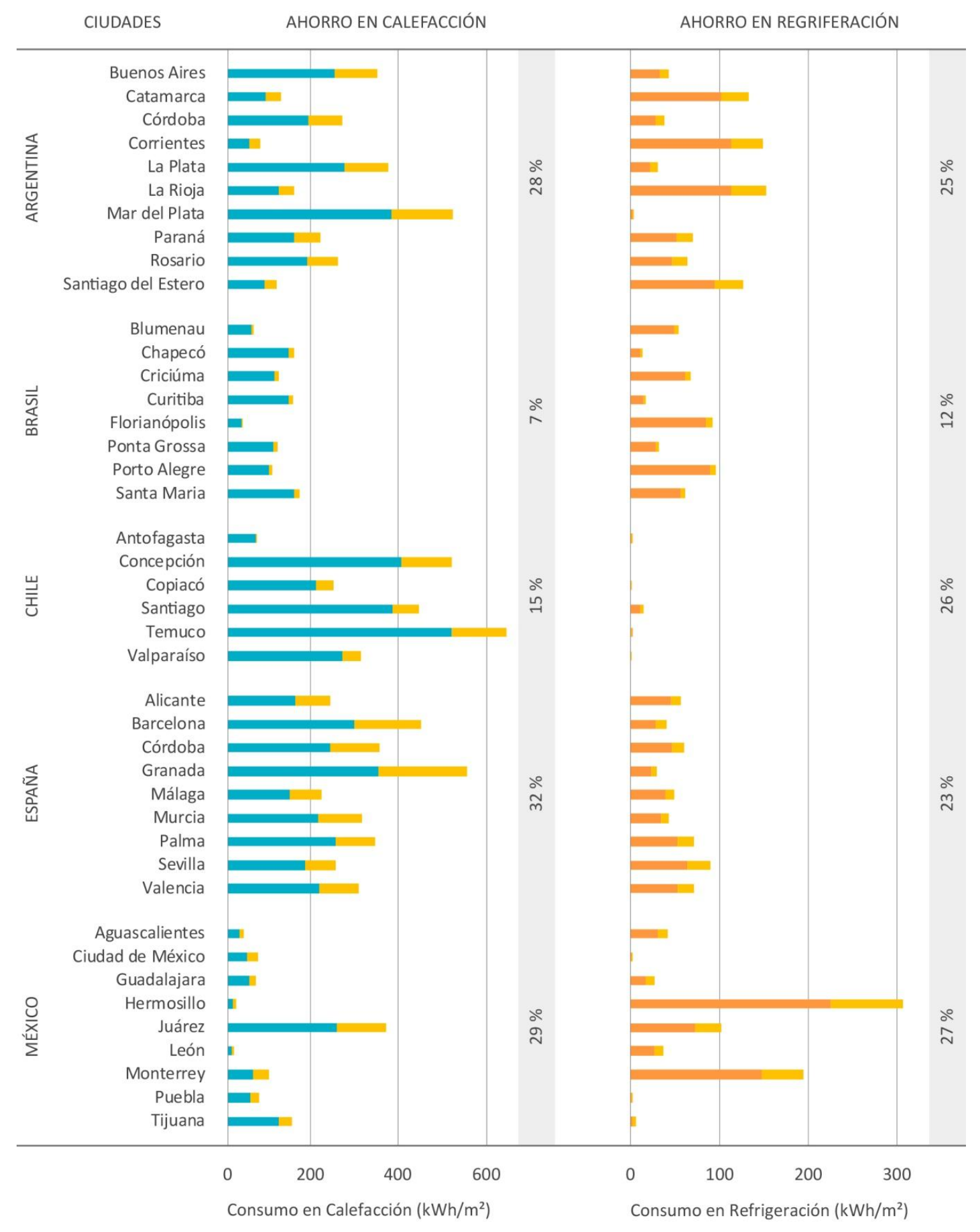

Escenario Tradicional

Ahorro según nivel mínimo de U de cada país

Escenario Tradicional

Figura 73: Ahorro potencial en calefacción y refrigeración de una vivienda tradicional en relación a una vivienda que atienda el estándar óptimo de Argentina, Brasil, Chile, España y México. Elaboración propia. 
Se resalta que además de los valores de transmitancia térmica, el PBE Edifica de Brasil también establece el cumplimiento de requisitos vinculados a la capacidad térmica y absortancia solar de cerramientos opacos, y la protección solar de vidriados. Es decir que los valores indicados en los resultados representan la variación de apenas un indicador en el desempeño del edificio, y que para conocer el ahorro potencial alcanzado con la aplicación de la totalidad de los requerimientos establecidos, sería necesario incorporar en el análisis los demás parámetros mencionados.

Con el fin de verificar la posibilidad de optimizar los valores admisibles para transmitancia térmica establecido por Chile y Brasil, y poder definir un porcentaje de ahorro homogéneo a todos los países, se asignó el Escenario de cálculo correspondiente a los estándares definidos en la IRAM para Buenos Aires al edifico Caso I, y se simuló su aplicación a las localidades de Criciúma en Brasil y Santiago en Chile.

Em ambos casos se observó la reducción de aproximadamente $35 \%$ del consumo, tanto para calefacción como para refrigeración, y un aumento de las horas que se encuentran por encima del rango de confort del orden de $6 \%$ en Santiago y $9 \%$ en Criciúma. Los resultados demuestran que los beneficios obtenidos con la mejora en la calidad de la envolvente son más significativos que los perjuicios posibles de obtener con las horas de sobrecalentamiento, ya que se considera que estas pueden ser mitigadas con el uso de ventiladores y el empleo de elementos que promuevan la protección del edificio contra la ganancia de la radiación solar.

Esto sugiere que es posible mejorar los valores admisibles para las localidades de Brasil y Chile, y que modificando apenas los valores de transmitancia térmica en muros y techos para edificios residenciales compactos situados en clima templado, se pueden alcanzar ahorros en consumo para acondicionamiento del orden del 20\%, 25\%, y 30\%, como proponen las demás regulaciones estudiadas (Figura 73).

\subsection{Ahorros en emisiones de $\mathrm{CO} 2$}

Para estimar el ahorro en las emisiones de $\mathrm{CO} 2$ consecuentes de la aplicación de las normativas de cada país a las localidades de estudio, se valoró la reducción del consumo con acondicionamiento térmico obtenido, considerando la cantidad de $\mathrm{CO} 2$ emitida para producir una unidad de energía según la matriz energética de cada país.

Para calcular las emisiones de $\mathrm{CO} 2$ relacionadas con el consumo del gas natural en el edificio, se debe analizar la cantidad de $\mathrm{CO} 2$ emitida en la combustión de cada unidad de gas natural o gas licuado de petróleo, ya que la generación de este tipo de energía implica en el uso directo del propio recurso (González 2010). Según el Panel Intergubernamental para el Cambio Climático - PICC se adopta un valor de $56 \mathrm{~kg}$ de $\mathrm{CO} 2$ para cada GJ de energía proveniente del gas natural, y $63 \mathrm{~kg}$ de $\mathrm{CO} 2$ para el GJ si proviene de GLP (Intergovernmental Panel on Climate Change 2006).

Para estimar las emisiones de $\mathrm{CO} 2$ vinculadas al uso de la energía eléctrica se debe considerar todas las fuentes empleadas en la generación de la electricidad del país (González 2010). En este caso es necesario acceder a la matriz eléctrica nacional y a los porcentajes que cada fuente ocupa en la 
producción de la energía eléctrica, para identificar las emisiones correspondientes a cada recurso y las emisiones finales relacionadas con el consumo de una unidad de electricidad.

A partir de los datos extraídos del sitio web de la U.S. Energy Information Administration, se procedió a registrar la matriz eléctrica de Argentina, Brasil, Chile, México y España (U.S. Energy Information Administration 2015).

En la Tabla 56 se puede observar los porcentajes de cada recurso en la generación de la energía eléctrica de cada país para el año de 2015. Según el PICC se adopta un valor de 95 kg CO2 por cada GJ de energía eléctrica producida a través de la quema del carbón, el $75 \mathrm{~kg} \mathrm{CO2/GJ}$ proveniente del petróleo, y el $56 \mathrm{~kg} \mathrm{CO} 2$ por GJ de electricidad procedente del gas natural (Intergovernmental Panel on Climate Change 2006). Se consideran sin emisiones operativas las generaciones de energía eólica, solar, hidroeléctrica, y nuclear.

\begin{tabular}{lcccccccccc}
\hline Origen & Argentina & \% & Brasil & \% & Chile & \% & México & \% & España & \% \\
\hline Gas natural & 64.755 & 48.4 & 44.252 & 7.8 & 7.450 & 10.3 & 156.355 & 53.0 & 44.408 & 16.8 \\
Petróleo & 21.889 & 16.4 & 7.922 & 1.4 & 4.741 & 6.6 & 36.082 & 12.2 & 17.489 & 6.6 \\
Carbón & 4.560 & 3.4 & 75.944 & 13.4 & 27.771 & 38.4 & 44.100 & 15.0 & 51.881 & 19.6 \\
Renovables & 36.094 & 27.0 & 426.638 & 75.0 & 32.368 & 44.7 & 47.095 & 16.0 & 95.660 & 36.2 \\
Nuclear & 6.519 & 4.9 & 13.892 & 2.4 & 0 & 0.0 & 11.185 & 3.8 & 54.759 & 20.7 \\
Total & $\mathbf{1 3 3 . 8 1 7}$ & $\mathbf{1 0 0}$ & $\mathbf{5 6 8 . 6 5 0}$ & $\mathbf{1 0 0}$ & $\mathbf{7 2 . 3 3 2}$ & $\mathbf{1 0 0}$ & $\mathbf{2 9 4 . 8 1 7}$ & $\mathbf{1 0 0}$ & $\mathbf{2 6 4 . 1 9 7}$ & $\mathbf{1 0 0}$ \\
\hline
\end{tabular}

Tabla 56: Matriz eléctrica de Argentina, Brasil, Chile, México y España para 2015, según fuente de energía. (Billones kWh) (U.S. Energy Information Administration 2015). Elaboración propia.

Entretanto, cómo la generación de energía eléctrica producida por combustión presenta un factor de conversión energética, es necesario aplicar una corrección a las emisiones de $\mathrm{CO} 2$ producidas por la quema de cada fuente de energía. Para ello, se consideró que gran parte de las centrales térmicas en Argentina operan sin el aprovechamiento del calor, por lo cual se aplicó la misma condición a los demás países (González 2010). Se adoptaron los valores establecidos para centrales convencionales: 2,5 para gas, 3,1 para carbón, y 1 para generaciones a partir de fuente renovable y nuclear (Fushimi, et al. 2008).

Se calculó la cantidad de emisiones de $\mathrm{CO} 2$ relacionada con la producción de una unidad de electricidad (Tabla 57 - Columna 8), mediante el producto del factor de eficiencia de conversión por las emisiones asociadas a cada recurso establecido por el PICC. En seguida, en función del porcentaje de incidencia de cada recurso en la matriz eléctrica de cada país, se calcularon las emisiones correspondientes al consumo de una unidad de energía eléctrica para cada país (Tabla 57 - Columna 2 - 6).

\begin{tabular}{lccccccc}
\hline Origen & Argentina & Brasil & Chile & México & España & $\begin{array}{c}\text { Factor de } \\
\text { conversión }\end{array}$ & $\begin{array}{c}\text { Emisiones } \\
\text { CO2 }\end{array}$ \\
\hline Gas natural & 68.244 & 10.998 & 14.523 & 74.73 & 23.688 & 2,5 & 141 \\
Petróleo & 31.488 & 2.688 & 12.672 & 23.424 & 12.672 & 2,5 & 192 \\
Carbón & 9.996 & 39.396 & 112.896 & 44.1 & 57.624 & 3,1 & 294 \\
Total & $\mathbf{1 0 9 . 7 3}$ & $\mathbf{5 3 . 0 8}$ & $\mathbf{1 4 0 . 0 9}$ & $\mathbf{1 4 2 . 2 5}$ & $\mathbf{9 3 . 9 8}$ & - & - \\
\hline
\end{tabular}

Tabla 57: Emisiones de CO2 en la generación eléctrica según el combustible y el factor de conversión (kg CO2/GJ electricidad). Elaboración propia. 
En función de los ahorros energéticos obtenidos con la aplicación de los estándares de transmitancia térmica para muros y techos en relación a la construcción del edificio tradicional, se aplicó el valor de las emisiones de $\mathrm{CO} 2$ correspondiente a la generación del combustible en cada país y se identificaron los ahorros posibles de obtener, según cada matriz energética (Figura 74).

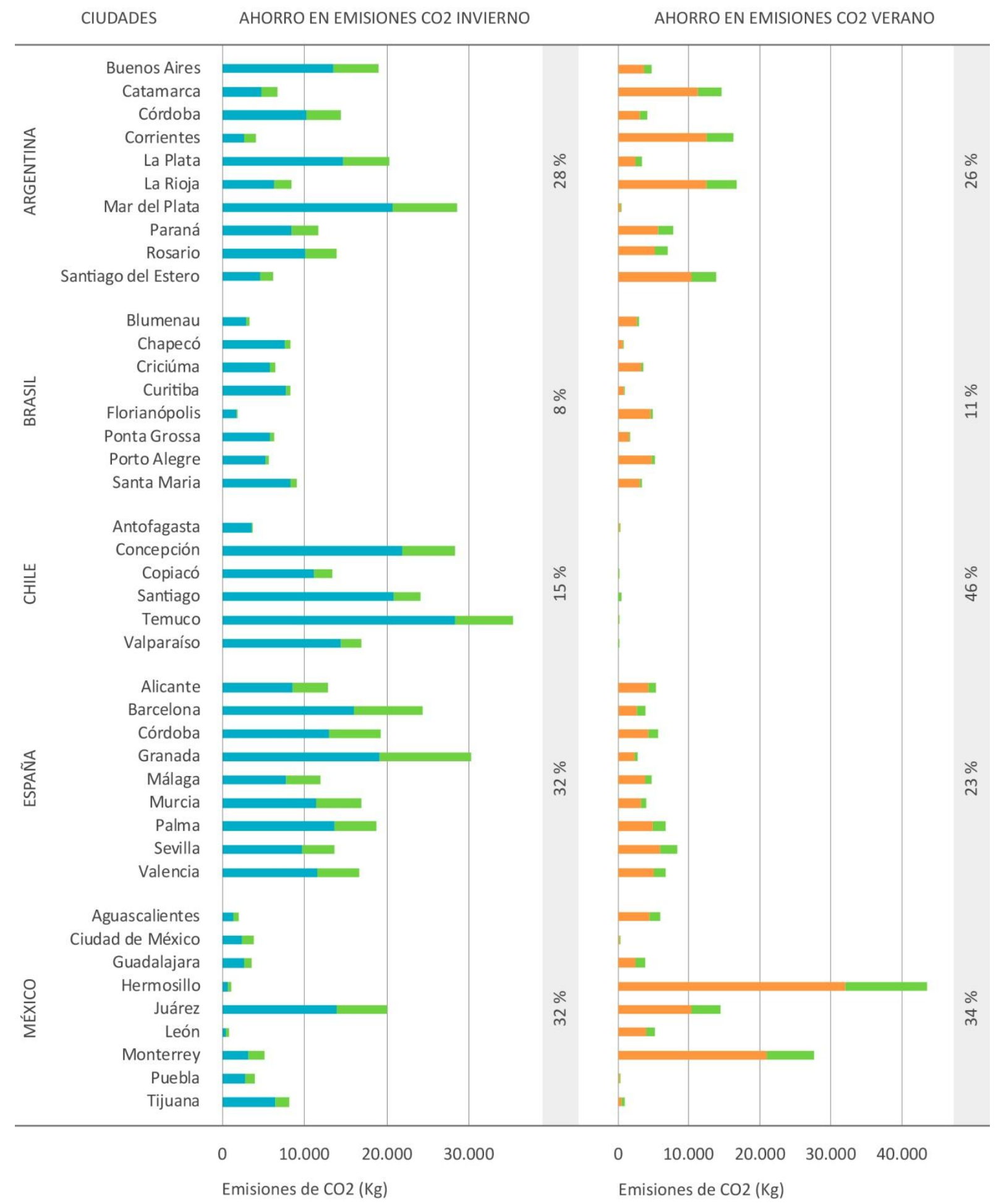


Se verificó que los mayores ahorros en la emisión de dióxido de carbono se dan con la aplicación de la NOM de México, alcanzando el $32 \%$ en invierno y el $34 \%$ en verano. Estos resultados se muestran muy similares a los ahorros alcanzados en España que consigue el 32\% de ahorro en invierno y el $23 \%$ de ahorro en verano. Entretanto, debido al elevado porcentaje de gas natural presente en la matriz eléctrica de México, el país posee el mayor factor de emisión de $\mathrm{CO} 2$ por unidad de energía eléctrica entre los países analizados, lo que hace con que al ahorrar una unidad de energía, deja de emitir menos cantidad de dióxido de carbono que los demás países.

A modo de ejemplificación, EE.UU. presenta un factor de emisión de CO2 aproximado de 170 kg CO2 por GJ de energía eléctrica, dado el gran porcentaje de carbón y gas natural en su matriz eléctrica nacional (González 2010). Entre los países estudiados, Brasil y España presentan las emisiones más bajas, debido a que más del $50 \%$ de la matriz eléctrica de estos países están constituidas con energía limpia. Este factor explica porque los ahorros en emisión de España son superiores para el consumo en calefacción, ya que aunque la energía eléctrica sea responsable por emitir una mayor cantidad de $\mathrm{CO} 2$ que el consumo de gas natural, gran parte del consumo eléctrico correspondiente al uso del aire acondicionado para refrigeración en España se suple con energía limpia.

En Argentina se obtienen ahorros de $28 \%$ para invierno y de $26 \%$ para verano, en cuanto en Chile estos valores son menos significativos. En el caso de verano para Chile se alcanzan elevados porcentajes debido a que el consumo en refrigeración de las ciudades en el país es bajo, llevando a que la diferencia entre los porcentajes tenga una mayor significancia que si los valores de consumo fueran superiores.

En Brasil los porcentajes de ahorro en el consumo son bajos y la matriz eléctrica del país es la que emite menos dióxido de carbono por producción de energía, lo que lleva a que el país tenga niveles de ahorro en emisión de $\mathrm{CO} 2$ inferiores a los demás países analizados.

\subsection{Definición de los estándares de ahorro}

La adopción de los valores de transmitancia térmica admisibles para edificios residenciales compactos situados en clima templado, permite alcanzar importantes ahorros tanto en consumo energético como en emisiones de dióxido de carbono.

Se verifica que los estándares definidos por Argentina, España y México proponen una reducción del consumo energético significativa, y que Brasil y Chile pueden establecer valores más estrictos para la transmitancia térmica de muros exteriores y techos con el fin de alcanzar ahorros similares. Según lo analizado en el apartado anterior, las regulaciones de Argentina, España y México proponen ahorros cercanos al $30 \%$ para el consumo en calefacción y aproximados del $25 \%$ para consumo en refrigeración.

De acuerdo con las simulaciones realizadas, se observó una disminución del orden de $35 \%$ en el consumo anual de los edificios situados en Curitiba y Santiago, lo que sugiere que Brasil y Chile podrían igualarse a los niveles de ahorro propuestos por Argentina, España y México. Suponiendo que no todas las localidades de Brasil y Chile respondan de la misma manera, y considerando que aunque los valores de 
Argentina y México sean cercanos al 30\%, la aplicabilidad de estos niveles al día de hoy es muy reducida, se define que el modelo energético propuesto debe centrarse en reducir el $20 \%$ de ahorro energético.

En cuanto a los ahorros en las emisiones de dióxido de carbono se considera que los porcentajes pueden centrarse en una reducción del 30\%, con la aplicación de una bonificación para los casos en que tengan una fuente de energía renovable incorporada en las instalaciones del edificio, o se sitúen en países con una matriz predominantemente limpia. Las especificaciones de la bonificación propuesta serán definidas en un futuro, posterior a la realización de una investigación más profunda en el campo de las energías renovables.

Al principio se consideraría que el método desarrollado, así como los ahorros establecidos deben ser aplicados a las zonas climáticas 5, 6, 7, 9, 10, 11, 13, 14, y 15 de la Figura 71, ya que estas zonas incluyen localidades con hasta 1500 grados día para calefacción y refrigeración. Para las demás zonas, es necesario que se aplique la metodología creada a una muestra de ciudades con grados día superiores a 1500, realizando la división entre ciudades cálidas y frías. 


\section{Conclusiones}

En esta etapa ha sido posible estimar los ahorros en consumo energético para acondicionamiento del Caso II resultante de la aplicación de los estándares de transmitancia térmica definidos por cada país a cada una de las 42 localidades utilizadas en este estudio (Figura 73). En función de los ahorros en consumo arrojados, se calculó su correspondencia en la reducción de las emisiones de dióxido de carbono a la atmosfera posibilitando realizar las estimaciones necesarias (Figura 74).

A modo de resumen se rescatan los siguientes aspectos:

I. Se definió un estándar inicial de $20 \%$ para el consumo energético y del $30 \%$ para las emisiones de $\mathrm{CO} 2$, con la aplicación de una bonificación para edificios con instalaciones de fuente de energía limpia o situados en localidades con matriz energética con significativos aportes de energía renovable.

II. Los porcentajes definidos serán aplicables a las zonas 5, 6, 7, 9, 10, 11, 13, 14, y 15 de la zonificación establecida (Figura 71).

III. Para las demás zonas se pretende replicar el método desarrollado en la presente investigación a dos muestras con localidades diferentes, considerando en una las ciudades que tengan necesidades de grados día por encima de los 1500 grados día de refrigeración, y en otra aquellas ciudades con requerimiento de grados día por encima de los 1500 grados día de calefacción. 



\section{Consideraciones finales}

Este trabajo permitió definir un método de cálculo simplificado para evaluar el consumo energético en calefacción y refrigeración de edificios de vivienda unifamiliar y multifamiliar situados en clima templado, cumpliendo con el objetivo establecido.

La metodología empleada ha sido predominantemente manual, permitiendo construir una herramienta más asequible que los programas de simulación computacional. Los datos empleados fueron medidos, observados y producidos por el autor, posibilitando una fácil reproducción por otros investigadores, replicable a diferentes tipologías edilicias y ámbitos geográficos.

La construcción del método de cálculo propuesto se fundamentó en datos reales de ocupación, de las características del edificio y de sus instalaciones, además de emplear datos climáticos históricos ampliamente validados en el medio académico, elaborando un modelo de predicción integral destinado a enriquecer la investigación en el área del consumo energético de la edificación.

Los consumos energéticos estimados a partir de los modelos simplificados creados (procedimiento estadístico) poseen un coeficiente de dependencia muy alto con los consumos estimados mediante simulación computacional (procedimiento resultante del monitoreo energético de un modelo real + ajuste del modelo + simulación), demostrando la viabilidad de emplear el modelo creado como una herramienta para cuantificar el consumo energético edilicio.

Se identificaron las variables climáticas primarias y secundarias que mayor influencia ejercen en los consumos de calefacción y refrigeración, permitiendo determinar las variables climáticas que mejor representan la rigurosidad del clima templado en función de la tipología de la edificación analizada. Se concluye que:

- Los grados día consisten en un parámetro sencillo para predecir la riguridad del clima templado y estimar el consumo energético de calefacción y refrigeración para ambas tipologías edilicias. 
- La inclusión de la velocidad del viento, humedad relativa promedio para los 3 meses más cálidos, altitud, radiación global promedio para los 3 meses más fríos, temperatura media mínima y velocidad del viento promedio para los tres meses más fríos, permiten una mejor aproximación de la rigurosidad del clima, así como una mayor linealidad en la predicción del rendimiento energético del edificio.

Se identificaron las variables de entrada requeridas en los procedimientos de cálculo empleados en las certificaciones de Brasil, Chile y España, así como los valores de consumo resultante de cada método de cálculo, posibilitando identificar las principales diferencias y similitudes existentes con el método propuesto. Se concluye que:

- Las características del edificio, de uso y ocupación, y de las instalaciones empleadas para construir el modelo propuesto, son similares a los datos de entrada considerados por las herramientas de Brasil, Chile, y España. En el modelo propuesto, las características constructivas del edificio están implícitas en la ecuación, mientras que en los países analizados, estos datos son posibles de modificar por el usuario.

- La principal debilidad del método propuesto en comparación con los procedimientos de los países analizados, consiste en que no puede ser aplicado a diferentes tipologías edilicias.

- Las características climáticas son diferentes a los datos de entrada considerados por las herramientas de Brasil, Chile, y España. En el modelo propuesto, el usuario debe ingresar las variables climáticas correspondientes a la ciudad analizada, mientras que en los países analizados se trabaja con una aproximación de las variables en función de las zonas climáticas en que se sitúa el edificio.

- La principal fortaleza del método desarrollado en comparación con los procedimientos de los países analizados, consiste en poder determinar con mayor precisión la rigurosidad del clima.

- Se recomienda que la zonificación de Brasil y España incorporen un mayor número de zonas climáticas, con el fin de representar con mayor precisión la rigurosidad del clima de cada localidad.

Se valoró la influencia del estándar mínimo de transmitancia térmica para muros exteriores y techos definido por Argentina, Brasil, Chile, México y España, en los consumos energéticos en calefacción y refrigeración de edificios residenciales aplicados a 42 localidades situadas entre cada país, permitiendo conocer cual normativa propone mejores niveles de confort térmico. Se concluye que:

- Las propuestas superadoras en relación al edificio tradicional - Escenario I son la IRAM de Argentina, el CTE de España, y la NOM de México. Los estándares de transmitancia térmica definidos en la normativa de Brasil son significativamente más permisivos que los valores admisibles de Argentina, España y México para localidades con clima similar. 
- Se recomienda que la regulación de Brasil revise los valores admisibles de U para muros y techos, así como los niveles de eficiencia energética de la envolvente del edificio en el PBE Edifica.

- Para las normativas de Argentina y México, así como aquellos países con clima templado que no disponen de una regulación de eficiencia energética edilicia, se recomienda incorporar la evaluación del consumo energético, pudiendo emplear como procedimiento de cálculo el método elaborado.

De manera inmediata, este trabajo aportó conocimiento para fomentar el desarrollo de instrumentos regulatorios de desempaño edilicio en dos escalas. Una destinada a auxiliar en el progreso de implementación de iniciativas de eficiencia energética edilicia para mitigación del cambio climático ya existentes, y el segundo centrado en contribuir a la creación de regulaciones y certificaciones en aquellos países que actualmente no disponen de estos instrumentos.

Al traspasar el modelo estadístico a una planilla Excel, se obtiene un instrumento de fácil interpretación y manejo, posibilitando su incorporación tanto en el ámbito privado, como en el ámbito público. Puede ser utilizado por profesionales en las etapas de diseño y de reconstrucción de edificios auxiliando en la toma de decisiones, por investigadores en el análisis del desempeño térmico permitiendo evaluar y calificar el edificio de estudio, y por actores gubernamentales para llevar información a la población de forma sencilla, permitiendo capacitar y generar conciencia respecto de la eficiencia energética en la edificación.

Se estima que el trabajo más complejo relacionado a la aplicabilidad del modelo energético ambiental para edificios residenciales en Latinoamérica, se vincule con los procedimientos de incorporación del sistema en el mercado, tanto en la adaptación de los materiales, como capacitación de profesionales, creación de programas de incentivo, y procesos de gestión y control para su aplicación efectiva.

El empleo del método de cálculo simplificado producto de esta investigación, consiste en una herramienta simple para llevar a cabo las evaluaciones de atendimiento de los niveles de ahorro energético, por lo que se estima haber creado un instrumento capaz de agilizar los procesos de gestión y control, contribuyendo a la materialización de esta propuesta.

A futuro se pretende extrapolar el método elaborado a edificios residenciales en general y a localidades con requerimientos de grados día para calefacción y refrigeración superiores a 1500, de forma que se pueda establecer un modelo que contemple las demás tipologías del parque edilicio residencial existente, tanto para clima templado, como para clima cálido y frío.

Una segunda línea de investigación futura posible, es trasladar el modelo estadístico desarrollado a una interfaz computacional, permitiendo la contrastación de los resultados obtenidos a partir del método creado, con los resultados obtenidos a partir de los procedimientos de cálculo desarrollados en programas informáticos existentes. 
Los resultados de este trabajo serán elevados a las reuniones del subcomité de Eficiencia Energética del Instituto Argentino de Normalización y Certificación. 


\section{Bibliografía}

Agence Nationale pour le Développement des Energies Renouvelables et de l'Efficacité Energétique. «Règlement Thermique de Construction au Maroc - Version simplifiée.» 2013. http://www.aust.ma/images/aust/reglementation/Decrets/R\%C3\%A8glement_thermique_de_constructi on_au_Maroc.pdf (accès le 08 26, 2018).

Agencia Estatal de Meteorología. "Guía Resumida del Clima en España.» 2012. http://www.aemet.es/es/conocermas/recursos_en_linea/publicaciones_y_estudios/publicaciones/detall es/guia_resumida_2010 (accès le 02 24, 2018).

Amasyali, K., et N. M. El-Gohary. "A review of data-driven building energy consumption prediction studies.» Renewable and sustainable energy reviews, 2018: 1192-1205.

American Society of Heating, Refrigerating, and Air - Conditioning Engineers. «ANSI/ASHRAE 55:2013 Thermal Environmental Conditions for Human Occupancy.» 2004. https://www.ashrae.org/technicalresources/bookstore/standard-55-thermal-environmental-conditions-for-human-occupancy (accès le 10 $14,2018)$.

—. «ASHRAE's Building EQ Portal.» 2011. https://www.ashrae.org/resources--publications/building-eq (accès le 02 07, 2018).

Arruda, Ignácio. «Programa Minha Casa Minha Vida 1 milhao de casas. Crédito, emprego, benefícios e esperanca para os brasileiros.» 2009. http://www2.senado.leg.br/bdsf/handle/id/385446 (accès le 0404 , 2018).

Associação Brasileira de Normas Técnicas. «NBR n 15220 - desempenho térmico de edificações.» 2008. http://www.abntcatalogo.com.br/norma.aspx?ID=11 (accès le 04 04, 2018).

-. «NBR $\mathrm{n}^{\circ} 15575$ - edificações habitacionais: desempenho.» 2013. http://www.abntcatalogo.com.br/norma.aspx?ID=195568 (accès le 04 04, 2018). 
Australian Building Codes Board. «National Construction Codes Series. Building Codes of Australia.» 2015. http://www.abcb.gov.au/Resources/Publications/Education-Training/NCC-Volumes-One-and-TwoBuilding-Code-of-Australia-Resource-Kit (accès le 09 03, 2018).

Australian Greenhouse Office. «Nationwide House Energy Rating Scheme.» http://www.nathers.gov.au/ (accès le 09 03, 2018).

Baldwin, R., S. J. Leach, J. V. Doggart, et M. P. Attenboroug. BREEAM 1/90 - an Environmental Assessment for New Office Designs. Garston: IHS BRE, 1990.

Barbadilla Martín, E., J. M. Salmerón Lissén, J. Guadix Martín, P. Aparicio Ruiz, et L. Brotas. «Field study on adaptive thermal comfort in mixed mode office buildings in southwestern area of Spain.» Building and Environment, 2017: 163-175.

Blasco Lucas, I., L. Hoesé, et M. Luis Facchini. «Análisis de la relación entre clima y consumo energético residencial en la ciudad de San Juan.» Energías Renovables y Medio Ambiente, 2011: 17-25.

Bordachar, F., F. Furno, et A. P. Lattuca. «Incorporación de exigencias sobre eficiencia energética edilicia. Normativa caso Rosario.» Acta del I Encuentro Nacional sobre Ciudad, Arquitectura y Construcción Sustentable. La Plata, 2016. 545-554.

CAIXA. Guia Caixa. Sustentabilidade Ambiental. Selo Casa Azul. Boas práticas para habitação mais sustentável. Caixa Econômica Federal. São Paulo: Páginas \& Letras, 2010.

CAMACOL. «Informe Económico n 30 - La vivienda social en América Latina: Una revisión de políticas para atender las necesidades habitacionales de la región.» Bogotá, 2011.

Carlucci, S., L. Bai, R. de Dear, et L. Yang. «Review of adaptive thermal comfort models in built environmental regulatory documents.» Building and Environment, 2018: 73-89.

Casals, X. G. «Analysis of building energy regulation and certification in Europe: their role, limitations and differences.» Energy and Buildings, 2006: 381-392.

Cole, R. J., D. Rousseau, et I. T. Theaker. «Building Environmental Performance Assessment Criteria: Version 1 - Office Buildings.» Vancouver: The BEPAC Foundation, 1993.

Cole, R. J., et N. Larsson. «Sustainable Building 2000, 22-25 October 2000.» The Netherlands: proceedings. Maastricht, 2000.

Crawley, D. B. «Building performance simulation: A tool for policymaking.» Doctoral thesis. Department of Mechanical Engineering, University of Strathclyde. Glasgow: http://www.esru.strath.ac.uk/Documents/PhD/crawley_thesis.pdf, 2008.

Departamento de Infraestructura. «Decreto no 1.030 - Reglamento de aplicación de la Ley no 13.059.» 2010. http://www.gob.gba.gov.ar/legislacion/legislacion/10-1030.html (accès le 04 04, 2018).

Dirección Meteorológica de Chile. «Estadística climatología - Tomo I.» 2011a. http://164.77.222.61/climatologia/publicaciones/Estadistica_Climatological.pdf (accès le 03 11, 2018).

-. «Estadística climatología - Tomo II.» 2011b. http://164.77.222.61/climatologia/publicaciones/Estadistica_Climatologicall.pdf (accès le 03 11, 2018). 


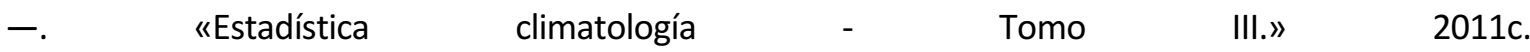

http://164.77.222.61/climatologia/publicaciones/Estadistica_Climatologicalll.pdf (accès le 03 11, 2018).

$\begin{array}{llllll}\text { Eletrobras. } & \text { "Manual para } & & & \end{array}$ http://pbeedifica.com.br/sites/default/files/projetos/etiquetagem/comercial/downloads/manualv02_1.p df (accès le 04 04, 2018).

Escandón, R., R. Suárez, et J. J. Sendra. "On the assessment of the energy performance and environmental behaviour of social housing stock for the adjustment between simulated and measured data: The case of mild winters in the Mediterranean climate of southern Europe.» Energy and Buildings, 2017: 418-433.

Espino Timón, C. «Universitat Oberta de Catalunya.» Análisis predictivo: técnicas y modelos utilizados y aplicaciones del mismo - herramientas Open Source que permiten su uso. 2017. http://openaccess.uoc.edu/webapps/o2/bitstream/10609/59565/6/caresptimTFG0117mem\%C3\%B2ria. pdf (accès le 10 12, 2018).

European Council. «Directive 2002/91/EC of the European Parliament and of the Council of 16 December 2002 on the energy performance of buildings.» Official Journal of the European Communities. 2002. https://www.boe.es/doue/2003/001/L00065-00071.pdf (accès le 08 22, 2018).

Fanger, P. O. Thermal comfort. Analysis and applications in environmental engineering. Copenhagen: Danish Technical Press, 1970.

FCAV, Fundação Vanzolini. "Referencial técnico de certificação AQUA-HQE.» 2013. https://vanzolini.org.br/download/Guia_Pratico_Referencial_Avaliacao_Qualidade_Ambiental_Edif\%C3\% ADcio.pdf (accès le 04 04, 2018).

Feist, W. «The Passive House in Darmstadt - Kranichstein during Spring, Summer, Autumn and Winter.» 2006. https://passiv.de/former_conferences/Kran/Passive_House_Spring_Winter.htm (accès le $0212,2018)$

Filippín, C., S. Flores Larsen, et L. Marek. «Experimental monitoring and post-occupancy evaluation of a non-domestic solar building in the central region of Argentina.» Energy and Buildings, 2015: 267-281.

Foucquier, A., S. Robert, F. Suard, L. Stéphan, et A. Jay. «State of the art in building modelling and energy performances prediction: A review.» Renewable and sustainable energy reviews, 2013: 272-288.

Fumo, N. «A reviewonthebasicsofbuildingenergyestimation.» Renewable and sustainable energy reviews, 2014: 53-60.

Fushimi, A., L. Zárate, M. Moreda, M. Hall, et M. Gómez. «Análisis de sistemas de cogeneración con turbogrupos de gas y calderas de recuperación de una presión.» Avances en Energías Renovables y Medio Ambiente, 2008: 41-48.

Ganem, C., H. Coch, et A. Esteves. «Adaptive comfort and climate-sensitive architecture: How occupants feel in their homes? The 25th Conference on Passive and Low Energy Architecture.» Dublin, 2008. 152-158. 
Global Buildings Performance. «Building Energy Codes Portal.» http://www.gbpn.org/beet-3/countryinfosheets (accès le 02 07, 2018).

González, A. D. «Comparación de energías y gases de efecto invernadero en calentamiento de agua para cocción de alimentos con electricidad y gas natural.» Avances en Energías Renovables y Medio Ambiente, 2010: 25-32.

Institute for Building Environment and Energy Conservation. «Comprehensive Assessment System for Built Environment Efficiency - CASBEE for Building (New Construction).» 2014. http://www.ibec.or.jp/CASBEE/english/ (accès le 11 01, 2017).

Instituto Argentino de Normalización y Certificación. «IRAM 11.601 - Aislamiento térmico de edifícios. Métodos de cálculo. Propiedades térmicas de los componentes y elementos de construcción en régimen estacionario.» Buenos Aires, 2002.

-. «IRAM 11.604 - Aislamiento térmico de edifícios. Ahorro de energía en calefacción. Coeficiente volumétrico G de pérdidas de calor.» Buenos Aires, 2004.

-. «IRAM n 11.603 - Acondicionamiento térmico de edificios: clasificación bioambiental de la Republica Argentina.» 2012. http://web.iram.org.ar/index.php?vernorma\&id=17E5 (accès le 04 04, 2018).

-. «IRAM $n^{\circ} 11605$ - Acondicionamiento térmico de edificios: condiciones de habitabilidad en edificios: valores máximos de transmitancia térmica en cerramientos opacos.» Buenos Aires, 2001a.

—. «IRAM no 11.900 - Etiqueta de eficiencia energética de calefacción para edificios.» Buenos Aires, 2010.

-. IRAM no 11.900 - Prestaciones energéticas en viviendas. Método de cálculo. Buenos Aires: Reemplaza a IRAM 11900/2010, 2017.

Instituto de la Construcción. «Manual evaluación y calificación. Sistema Nacional de Certificación de Calidad Ambiental y Eficiencia Energética para Edificios de Uso Público. Versión 1.» Certificación edificio sustentable . 2014. http://certificacionsustentable.cl/descarga-de-documentos (accès le 04 04, 2018).

Instituto de Normas Técnicas de Costa Rica. «Requisitos para Edificaciones Sostenibles en el Trópico RESET.» 2012. http://www.arquitecturatropical.org/docs/RESET2017.pdf (accès le 04 04, 2018).

Instituto Nacional de Meteorologia. «Normais Climatológicas do Brasil 1961-1990.» 2009. http://www.inmet.gov.br/portal/index.php?r=clima/normaisClimatologicas (accès le 02 24, 2018).

Instituto Nacional de Normalización. «NCh n 1079 - Arquitectura y construcción. Zonificación climático habitacional para Chile y recomendaciones para el diseño arquitectónico.» 1997. http://tipbook.iapp.cl/ak/a871a9028e2d17e03ecbc8b26cef7a6b0b0b13b5/embed/view/minvunch01079-2008-049 (accès le 04 04, 2018).

Instituto Nacional de Tecnología, Normalización y Metrología. «Norma Paraguaya NP 4901715 sobre Instalaciones de aire acondicionado. Sistemas centrales y unitarios. Parámetros de confort térmico.» 2015b. http://www.faiar.net/wp-content/uploads/2018/03/NP-49-017-15-AA-Par\%C3\%A1metros-deconfort-t\%C3\%A9rmico.pdf (accès le 08 15, 2018). 
Instituto para la Diversificación y Ahorro de la Energía. «Escala de calificación energética para edificios de nueva construcción.»

2009. http://www.idae.es/uploads/documentos/documentos_CALENER_07_Escala_Calif_Energetica_A2009_A _5c0316ea.pdf (accès le 11 13, 2018).

Intendencia de Montevideo. «Resolución N²928/09 sobre reducción de la demanda de energía para acondicionamiento térmico.»

2009. http://www.montevideo.gub.uy/aplicacion/resolucion?parametro=2928-09 (accès le 08 15, 2018).

Intergovernmental Panel on Climate Change. «Guidelines for National Greenhouse Gas Inventories.» 2006. https://www.ipcc-nggip.iges.or.jp/public/2006gl/index.html (accès le 09 26, 2018).

International Energy Agency. «25 Energy efficiency policy recommentations.» 2011. https://www.iea.org/publications/freepublications/publication/25recom_2011.pdf (accès le 02 05, 2018).

-. "Final Report Annex 53: Total energy use in buildings. Analysis and evaluation methods.» $\begin{array}{llll}\text { International Energy } & \text { Agency. } & 2013 . & \mathrm{http} / / / \mathrm{www} . \text { iea- }\end{array}$ ebc.org/Data/publications/EBC_Annex_53_Main_Report.pdf (accès le 07 15, 2018).

International Standarization Organization. «ISO/IEC Guide 98 - 3: 2008. Uncertainty of measurement Part 3: Guide to the expression of uncertainty in measurement (GUM:1995).» International Organization for Standardization. 2008. https://www.iso.org/standard/50461.html (accès le 06 18, 2018).

Janda, K. B. «Worldwide status of energy standards for buildings: a 2009 update. Presentation at European Council for an Energy Efficient Economy - ECEEE 2009 Summer Study.» 2009. https://proceedings.eceee.org/vispanel.php?event=7 (accès le 02 05, 2018).

Korolija, I., Y. Zhang, L. Marjanovic-Halburd, et V. Hanby. «Regression models for predicting UK office building energy consumption from heating and cooling demands.» Energy and Buildings, 2013: 214-227.

Laboratório de Eficiência Energética em Edificações. «Proposta de revisão do zoneamento bioclimático do Brasil. Classificação de clima do Brasil - Versão 3.0.» 2014. http://www.labeee.ufsc.br/projetos/proposta-de-revisao-do-zoneamento-bioclimatico-brasileiro (accès le 1125,2018$)$.

Lange, P. Sustainability Governance. Exploring the Potential of Governance Modes to Promote Sustainable Development. Primera edición. Baden-Baden: Nomos, 2017.

Li, B., C. Du, R. Yao, W. Yu, et V. Costanzo. «Indoor thermal environments in Chinese residential buildings responding to the diversity of climates.» Applied Thermal Engineering, 2018: 693-708.

Li, J., et B. Shui. «A comprehensive analysis of building energy efficiency policies in China: status quo and development perspective.» Journal of Cleaner Production 90 (2015): 326-344.

López-Roldán, P., et S. Fachelli. «Metodología de la investigación social cuantitativa.» Dipòsit Digital de Documents, Universitat Autònoma de Barcelona. 2015. https://ddd.uab.cat/record/129382 (accès le 02 $22,2018)$. 
Marrero Meléndez, M., L. Martínez Escobar, P. Mercader Moyano, et C. Leiva Fernández. «Minimización del impacto ambiental en la ejecución de fachadas mediante el empleo de materiales reciclados.» Informes de la Construcción, 2013: 89-97.

Melo, A. P. «Desenvolvimento de um método para estimar o consumo de energia de edificações comerciais através da aplicação de redes neurais.» Tese de doutorado em Engenharia Civil pela Universidade Federal de Santa Catarina. Florianópolis: http://www.labeee.ufsc.br/sites/default/files/publicacoes/teses/TESE_AnaPaulaMelo.pdf, 2012.

Melo, A.P., D. Cóstola, R. Lamberts, et J. L. M. Hensen. «Assessing the accuracy of a simplified building energy simulation model using BESTEST: The case study of Brazilian regulation.» Energy and Buildings, 2012: 219-228.

Mercader Moyano, P., M. Olivares Santiago, et A. Ramirez de Arellano Agudo. «Modelo de cuantificación del consumo energético en edificación.» Materiales de Construcción, 2012: 567-582.

Mercader-Moyano, P., et J. Claro-Ponce. «Sistemas de Certificación en Clima Templado.» ARQUISUR Revista, 2017: 62-77.

Ministério da Economia e da Inovação. «Decreto - Lei $n^{\circ}$ 78/2006 sobre Sistema Nacional de Certificação Energética e da Qualidade do Ar Interior nos Edifícios. Diário da República n 67.» 2006. https://dre.pt/application/file/a/672552 (accès le 02 05, 2018).

Ministério das Obras Públicas, Transportes e Comunicações. «Decreto - Lei n 80/2006 sobre Regulamento das Características de Comportamento Térmico dos Edifícios. Diário da República de Portugal n 60.» 2006a. https://dre.pt/application/file/a/672550 (accès le 02 07, 2018).

Ministerio de Fomento. «Documento Básico HE Ahorro de energía.» 2017. https://www.codigotecnico.org/ (accès le 11 13, 2018).

Ministerio de la Presidencia. «Real Decreto 47/2007, de 19 de enero, por el que se aprueba el Procedimiento básico para la certificación de eficiencia energética de edificios de nueva construcción.» 2007. https://www.boe.es/boe/dias/2007/01/31/pdfs/A04499-04507.pdf (accès le 02 09, 2018).

Ministerio de la Vivienda. «Documento Básico HE Ahorro de Energía. Código Técnico de la Edificación.» junio 2007. https://www.codigotecnico.org/index.html (accès le 01 30, 2018).

- . «Real Decreto 314/2006, de 17 de marzo, por el que se aprueba el Código Técnico de la Edificación.» 2006. https://www.boe.es/buscar/doc.php?id=BOE-A-2006-5515 (accès le 04 04, 2018).

Ministerio de Vivienda y Urbanismo. «Resolución Exenta $n^{\circ} 7.250$ - Manual de procedimientos para viviendas nuevas del sistema de Calificación Energética de Viviendas en Chile.» 2016. https://www.leychile.cl/Navegar?idNorma=1096856 (accès le 04 04, 2018).

Ministerio de Vivienda, Ciudad y Territorio. «Resolución no 0549 - Parámetros y lineamientos de construcción sostenible - Guía para el ahorro de agua y energía en edificaciones. Reglamento del Capítulo 1 del Título 7 de la parte 2, del libro 2 del Decreto 1.077 de 2015.» Ministerio de Vivienda del Gobierno de 
Colombia. 2015b. http://www.minvivienda.gov.co/ResolucionesVivienda/0549\%20-\%202015.pdf (accès le 0404,2018$)$.

Ministerio de Vivienda, Construcción y Saneamiento. «Decreto Supremo n 006 - 2014 - Vivienda del 13 de mayo de 2014 sobre modificación del Título III del Reglamento Nacional de Edificaciones.» El peruano, 2014.

Ministério Do Planejamento, Orçamento e Gestão. «Instrução normativa no 2, de 4 de junho de 2014.» Brasília, 2014.

Ministerios de Desarrollo Urbano y Vivienda. «Norma Ecuatoriana de la Construcción, NEC-11, Capitulo 13: Eficiencia Energética en la Construcción en Ecuador, Capitulo 14: Energías Renovables.» Cámara de la Construcción de Quito, 2011.

Ministry of Business, Innovation and Employment. «Acceptable Solutions and Verification Methods for New Zealand Building Code Clause H1 Energy Efficiency.» 2016. https://www.building.govt.nz/assets/Uploads/building-code-compliance/h1-energy-efficiency/asvm/h1energy-efficiency-4th-edition-amendment3.pdf (accès le 09 04, 2018).

Ministry of construction. «Design and Construction Guidelines on the Rationalization of Energy Use for Houses - DCGREUH.» The energy conservation center Japan. 1990. https://www.eccj.or.jp/law/jutaku2_e.html (accès le 11 01, 2017).

Miranda Enríquez, R. «Evaluación energética experimental de edificios en condiciones reales de uso mediante el ajuste de modelos de simulación con aplicaciones al control predictivo.» Tesis inédita de la Universidad Complutense de Madrid, Facultad de Ciencias Físicas, Departamento de Física Atómica, Molecular y Nuclear. 2013. http://eprints.ucm.es/21523/ (accès le 06 10, 2018).

Municipalidad de Rosario. «Decreto no 985.» Rosario, 2013.

-. «Ordenanza № 8.757 - Aspectos Higrotérmicos y Eficiencia Energética en las construcciones.» 2011.

https://www.rosario.gov.ar/normativa/ver/visualExterna.do?accion=verNormativa\&idNormativa=75004 (accès le 04 04, 2018).

Nath Lopes, M., et R. Lamberts. «Development of a metamodel to predict cooling energy consumption of HVAC systems in office different climates.» Sustainability, 2018: 4718.

Palomo, E. del B., et G. Guyon. «Application of parameters space analysis tools for empirical model validation.» Energy and Buildings. Vol. 36. 2004. 23-33 https://doi.org/10.1016/S0378-7788(03)00039-2.

Pearson, K. «Notes on the history of correlation.» Biometrika, 1920: 25.45.

Peel, M. C., B. L. Finlayson, et T. A. McMahon. «Updated world map of the Koppen-Geiger climate classification.» Hydrology and Earth System Sciences 11 (2007): 1633-1644.

Pérez Fargallo, A., J. A. Pulido Arcas, C. Rubio Bellido, M. Trebilcock, B. Piderit, et S. Attia. "Development of a new adaptive comfort model for low income housing in the central-south of chile.» Energy and Buildings, 2018: 94-106. 
Pérez-Lombard, L., J. Ortiz, R. González, et I. R. Maes. «A review of benchmarking, rating and labelling concepts within the framework of building energy certification schemes.» Energy and Buildings, 2009 : 272-278.

Petersdorff, C., T. Boermans, et J. Harnisch. «Mitigation of CO2 emissions from the EU-15 building stock: beyond the EU Directive on the Energy Performance of Buildings.» Environmental Science and Pollution Research, 2006: 350-358.

Presidente della repubblica. «Comitato Termotecnico Italiano. Attuazione della direttiva 2002/91/CE $\begin{array}{llll}\text { relativa al nell'edilizia.» } & 2005 .\end{array}$ https://www.cti2000.it/index.php?controller=legislazione\&action=show\&id=21306 (accès le 08 24, 2018).

Reus Netto, G. «Sistemas de calificación edilicia en Latinoamérica. Master's Thesis, Architecture and Urbanism Department, National University of La Plata.» SEDICI Repositorio Intitutcional de la UNLP. 2017. http://sedici.unlp.edu.ar/handle/10915/62912 (accès le 04 04, 2018).

Ribas Portella, J. M. «Bottom-up description of the French building stock, including archetype buildings and energy demand.» Department of Energy and Environment. Division of Energy Technology. Chalmers University Of Technology, ${ }^{\circ}$ https://core.ac.uk/download/pdf/41813716.pdf (2012).

Rijal, H. B., M. Honjo, R. Kobayashi, et T. Nakaya. «Investigation of comfort temperature, adaptive model and the window-opening behaviour in Japanese houses.» Architectural Science Review, 2013: 5469.

Roriz, M. «Classificação de climas do Brasil - Versão 2. ANTAC: Associação Nacional de Tecnologia do Ambiente Construído. Grupo de Trabalho sobre Conforto Ambiental e Eficiência Energética de Edificações.» São Carlos, 2013.

Roriz, M., E. Ghisi, et R. Lamberts. «Bioclimatic zoning of Brazil: a proposal based on the Givoni and Mahoney methods, in: The 16th International Conference on Passive and Low Energy Architecture.» Centro de referencia e informação em habitação. 1999. http://www.infohab.org.br/acervos/advancedsearch (accès le 06 18, 2018).

Ruiz, M. A., et E. N. Correa. «Adaptive model for outdoor thermal comfort assessment in an Oasis city of arid climate.» Building and Environment, 2015: 40-51.

Secretaría de Economía. «NMX-AA-164-SCFI-2013 - Edificación Sustentable - Criterios y requerimientos ambientales mínimos.» Distrito Federal, 2013.

Secretaría de Energía. «Norma Oficial Mexicana NOM020ENER2011 - Eficiencia Energética en Edificaciones. Envolvente de Edificios para Uso Habitacional.» 2011. (accès le 04 04, 2018).

Secretaría del Medio Ambiente. «Programa de Certificación de Edificaciones Sustentables.» 2012. http://martha.org.mx/una-politica-con-causa/wp-content/uploads/2013/09/15-CertificacionEdificaciones-Sustentables.pdf (accès le 04 04, 2018).

Senado y Cámara de Diputados. "Ley n 13.059 - Condiciones de Acondicionamiento Térmico.» La Plata, 2003. 
Servicio Meteorológico Nacional. «Estadística Climática Básica - período 1981 - 2010.» 2017. https://www.smn.gob.ar/descarga-de-datos (accès le 02 24, 2018).

—. «Normales Climatológicas.» 2018. http://smn.cna.gob.mx/es/climatologia/informacionclimatologica (accès le 02 24, 2018).

South African Bureau of Standards. SANS 204 - Energy efficiency in buildings. Pretoria: SABS Standards Division, 2011.

Swiss Society of Engineers and Architects. "SIA 380/1 Thermische Energie im Hochbau.» 2009. https://awel.zh.ch/internet/baudirektion/awel/de/energie_radioaktive_abfaelle/energienachweis/sia_38 0_1_thermischeenergieimhochbau/_cr_content/contentPar/downloadlist/downloaditems/186_135461 3964863.spooler.download.1354613422063.pdf/AnfoPro+2009+V1-3-ge (accès le 01 12, 2018).

The Energy and Resources Institute. «Green rating integrated habitat - GRIHA for existing buildings. Version 1.» 2017. http://www.grihaindia.org/files/GRIHA_EB-Manual.pdf (accès le 02 09, 2018).

Trebilcock, M., J. Soto Muñoz, M. Yañez, et R. Figueroa San Martin. «The right to comfort: a field study on adaptive thermal comfort in free-running primary schools in Chile.» Building and Environment, 2017: 455-469.

Triana, M. A., R. Lamberts, et P. Sassi. «Should we consider climate change for Brazilian social housing? Assessment of energy efficiency adaptation measures.» Energy and Buildings, 2018: 1379-1392.

Turkish Standards Institute. «TS825 Thermal insulation requirements for buildings.» 2008.

U.S. Energy Information Administration. «Energy Statistics.» 2017. https://www.eia.gov/beta/international/ (accès le 09 11, 2018).

-. «Total Electricity Net Generation in 2015 - Billion Kwh.» 2015. https://www.eia.gov/beta/international/ (accès le 09 27, 2018).

$\begin{array}{lllll}\text { United Kingdom. } & \text { "Housing }\end{array}$ http://www.legislation.gov.uk/ukpga/2004/34/pdfs/ukpga_20040034_en.pdf (accès le 02 07, 2018).

United Nations Development Programme Turkey. «United Nations Development Programme Turkey. $\begin{array}{lllll}\text { Promoting Energy } & \text { Efficiency }\end{array}$ http://www.tr.undp.org/content/dam/turkey/docs/projectdocuments/EnvSust/project_00074059/EEbuil dings.pdf (accès le 25 08, 2018).

Ürge Vorsatz, D., et A. Novikova. «Potentials and costs of carbon dioxide mitigation.» Energy Policy 36 (2008): 642-661.

US Green Building Council. «LEED Green Building Rating System 2.0.» San Francisco, 2000.

USAID ECO-III. Energy Conservation Building Code User Guide - ECBD. New Delhi: Bureau of Energy Efficiency, 2009.

Walsh, A., D. Cóstola, et L. Chebel Labaki. «Review of methods for climatic zoning for building energy efficiency programs.» Building and Environment, 2017: 337-350. 
Wong, S. L., K. Wan, et T. Lam. «Artificial neural networks for energy analysis of office buildings with daylighting.» Applied Energy, 2010: 551-557.

Yoon, Y. R., et H. J. Moon. «Energy consumption model with energy use factors of tenants in commercial buildings using Gaussian process regression.» Energy and Buildings, 2018: 215-224. 


\section{Lista de figuras}

Figura 1: Metodología propuesta para el desarrollo del objetivo principal propuesto. Elaboración propia.

Figura 2: Relación entre las características del clima, de la envolvente, de uso y ocupación, y de las instalaciones en la determinación del consumo energético y del impacto ambiental de la edificación. Elaboración propia.

Figura 3: Países con presencia de clima templado analizados. Elaboración propia adaptada de la clasificación climática Köppen-Geiger (Ministerio de Vivienda y Urbanismo 2016).

Figura 4: Criterios de evaluación de regulaciones y certificaciones en países con presencia de clima templado. Elaboración propia.

Figura 5: Frecuencia de los criterios requeridos por las iniciativas analizadas. Elaboración propia.

Figura 6: Evolución del modelo predictivo edilicio y de los sistemas de calificación edilicia en clima templado. Elaboración propia. 38

Figura 7: Ámbito de aplicación de los modelos de predicción revisados. Elaboración propia. 38

Figura 8: Variables de entrada utilizadas para la construcción de modelos de predicción de consumo energético. Elaboración propia.

Figura 9: Técnicas utilizadas para el agrupamiento de datos en modelos de predicción. Elaboración propia.

Figura 10: Frecuencia de las técnicas de agrupamiento de datos empleadas en los modelos de predicción revisados. Elaboración propia.

Figura 11: Construcción del objetivo de la investigación. Elaboración propia. 
Figura 12: Jerarquía para la estructuración de los objetivos de la investigación. Elaboración propia.

Figura 13: Metodología propuesta para el desarrollo del método de cálculo simplificado.

Elaboración propia.

Figura 14: Esquema metodológico Parte I - Delimitación del ámbito de la cuestión. Elaboración propia.

Figura 15: Reestructuración de los requerimientos establecidos en los sistemas de calificación edilicia estudiados. Modelo de ejemplo: caso Ley n 13.059/03. Elaboración propia.

Figura 16: Selección de los sistemas de calificación y definición de sus indicadores. Elaboración propia.

Figura 17: Unidades habitacionales contratadas por el Programa MCMV (en millares). Elaboración propia.

Figura 18: Estimativa de la población asistida por el MCMV en Brasil x la población de cada país Latinoamericano. Elaboración propia.

Figura 19: Tipologías de edificios residenciales adoptadas inicialmente. Elaboración propia........ 73

Figura 20: Caso I: vivienda unifamiliar - sin escala. Elaboración propia.

Figura 21: Caso II: vivienda multifamiliar. Planta tipo en los doce niveles - sin escala. Elaboración propia.

Figura 22: Edificios de vivienda en Argentina. Fuente: Emaco, Credil y Grupo Nisen. 75

Figura 23: Edificios de vivienda en Chile. Fuente: Portal tu vivienda del Ministerio de Vivienda y Urbanismo.

Figura 24: Edificios de vivienda en México. Fuente: Portal Infonavit.

Figura 25: Edificios de vivienda en España. Fuente (Mercader Moyano, Olivares Santiago e Ramirez de Arellano Agudo 2012).

Figura 26: Muro exterior y cubierta tradicional en Latinoamérica. Elaboración propia.

Figura 27: Muro y cubierta tradicional en España. Elaboración propia adaptada de (Marrero Meléndez, et al. 2013)

Figura 28: Mapa bioambiental de Argentina. Fuente: (Instituto Argentino de Normalización y Certificación 2012).

Figura 29: Mapa bioambiental de Brasil. Fuente: (Associação Brasileira de Normas Técnicas 2008).

Figura 30: Mapa bioambiental de Chile. Fuente: (Instituto Nacional de Normalización 1997). ..... 81

Figura 31: Mapa bioambiental de España. Fuente: (Ministerio de la Vivienda, 2007).

Figura 32: Valores de transmitancia térmica $U$ de muros y techos para cada escenario de cálculo. 
Figura 33: Análisis de riesgo de condensación en los cerramientos opacos de los diferentes escenarios. Fuente: Design Builder ......

Figura 34: Localidades de Argentina, Brasil, Chile, España y México con clima templado.

Elaboración propia

Figura 35: Campos de observación. Elaboración propia.

Figura 36: Sección 3 - Percepción del confort con el empleo de estrategias pasivas. Elaboración propia.

Figura 37: Sección 3 - Percepción del confort con el empleo de artefactos de climatización. Elaboración propia.

Figura 38: Sección 4 - Estructura familiar por hogar. Elaboración propia. 106

Figura 39: Sección 4 - Ocupación de la vivienda según usuario. Elaboración propia. .................... 107

Figura 40: Sección 4 - Actividades desempeñadas según usuario. Elaboración propia.................. 107

Figura 41: Sección 4 - Preferencia de vestimenta según usuario. Elaboración propia................... 108

Figura 42: Sección 4 - Ocupación de los ambientes. Elaboración propia. ..................................... 108

Figura 43: Sección 5 - Equipos de climatización y ventilación. Elaboración propia........................ 109

Figura 44: Sección 5 - Empleo de estrategias pasivas por hogar. Elaboración propia...................... 110

Figura 45: Sección 6 - Modificación de materiales de la envolvente por hogar. Elaboración propia.

Figura 46: Ubicación de Criciúma en Santa Catarina. Fuente: Mapa de Santa Catarina - Wikipedia. Mapa de Criciúma - elaboración propia.

Figura 47: Implantación de la parcela de estudio. Elaboración propia adaptada de Google Maps.

Figura 48: Ubicación de Criciúma en la zona Il del mapa bioambiental de Brasil. Elaboración propia adaptada de (Associação Brasileira de Normas Técnicas 2008).

Figura 49: Temperaturas anuales. Fuente: Climat Consultant.

Figura 50: Humedad relativa mensual. Fuente: Climat Consultant. 113

Figura 51: Radiación anual. Fuente: Climat Consultant. 113

Figura 52: Nubosidad anual. Fuente: Climat Consultant. 114

Figura 53: Velocidad del viento anual. Fuente: Climat Consultant. 114

Figura 54: Esquema de las unidades habitacionales monitoreadas - planta y corte. Elaboración propia.

Figura 55: Ubicación de los sensores en planta - unidad funcional 303. Elaboración propia. ....... 116

Figura 56: Registro de temperatura y humedad medido en el cuadro bioclimático adaptado.

Elaboración propia adaptada de (Roriz, Ghisi e Lamberts 1999).

Figura 57: Esquema metodológico Parte II - Cuantificación del consumo energético. Elaboración propia. 
Figura 58: Etapas realizadas en el proceso de construcción del modelo teórico. Elaboración propia.

Figura 59: Variación de la temperatura interior medida y estimada para verano. Elaboración propia.

Figura 60: Variación de la temperatura interior medida y estimada para invierno. Elaboración propia.

Figura 61: Ubicación de sensores para medir la heterogeneidad espacial de la temperatura del aire. Elaboración propia.

Figura 62: Registro de la temperatura a distintas alturas en el estar comedor - condición de verano. Elaboración propia.

Figura 63: Registro de la temperatura a distintas alturas en el estar comedor - condición de invierno. Elaboración propia.

Figura 64: Balance térmico para la unidad funcional analizada. Fuente Design Builder. 133

Figura 65: Variación de la temperatura interior medida y estimada mejorada para la condición de verano. Elaboración propia.

Figura 66: Variación de la temperatura interior medida y estimada mejorada para la condición de invierno. Elaboración propia. 134

Figura 67: Esquema metodológico Parte III - Definición de la ecuación. Elaboración propia. 140

Figura 68: Consumo estimado por simulación energética x modelo estadístico ( $\mathrm{kWh} / \mathrm{m} 2 . a n ̃ o)$. Elaboración propia.

Figura 69: Consumo estimado por el modelo creado y por los sistemas de Brasil, Chile y España en relación con los grados días de las 42 localidades analizadas - Caso 1.

Figura 70: Relación entre los valores de U para muros y techos con los grados día de refrigeración y calefacción para localidades de Argentina, Brasil, Chile, España y México. Elaboración propia..... 160

Figura 71: Esquema de la zonificación climática propuesta en (Reus Netto 2017). Elaboración propia.

Figura 72: Etapas para la construcción del modelo de eficiencia energética. Elaboración propia.167

Figura 73: Ahorro potencial en calefacción y refrigeración de una vivienda tradicional en relación a una vivienda que atienda el estándar óptimo de Argentina, Brasil, Chile, España y México.

Elaboración propia.

Figura 74: Ahorro potencial en emisiones de $\mathrm{CO} 2$ de una vivienda tradicional en relación a una vivienda que atienda el estándar óptimo de Argentina, Brasil, Chile, España y México. Elaboración propia. 


\section{Lista de tablas}

Tabla 1: Sistemas de calificación edilicia implementados en países con clima templado ( ${ }^{*}$ Ver leyenda). Elaboración propia.

Tabla 2: Frecuencia de los criterios requeridos por las iniciativas analizadas (* Ver leyenda). Elaboración propia.

Tabla 3: Criterios de evaluación de la Etiqueta de eficiencia energética de calefacción para edificios. Elaboración propia adaptada de (Instituto Argentino de Normalización y Certificación 2010).

Tabla 4: Criterios de evaluación de la Ley sobre Condiciones de Acondicionamiento Térmico.

Elaboración propia adaptada de (Senado y Cámara de Diputados, 2003).

Tabla 5: Criterios de evaluación de la Ordenanza sobre Aspectos Higrotérmicos y Demanda Energética de las Construcciones. Elaboración propia adaptada de (Municipalidad de Rosario 2011).

Tabla 6: Criterios de evaluación del PBE Edifica para edificaciones residenciales. Elaboración propia adaptada de (Eletrobras 2013).

Tabla 7: Criterios de evaluación del Proceso de Alta Calidad Ambiental. Elaboración propia adaptada de (FCAV 2013)

Tabla 8: Categorías de evaluación del Sello Casa Azul. El * indica los criterios obligatorios. Elaboración propia adaptada de (CAIXA 2010).

Tabla 9: Criterios de evaluación de la CEV. Elaboración propia adaptada de (Ministerio de Vivienda y Urbanismo 2016).

Tabla 10: Criterios de evaluación de la Certificación de Calidad Ambiental y Eficiencia Energética para Edificios. Elaboración propia adaptada de (Instituto de la Construcción 2014).

Tabla 11: Categorías y criterios de evaluación de la norma mexicana de edificación sustentable. Determinados criterios establecen más de un requisito. Elaboración propia adaptada de (Secretaría de Economía 2013). 
Tabla 12: Criterios de evaluación del PCES. Elaboración propia adaptada de (Secretaría del Medio

Ambiente 2012).

Tabla 13: Indicadores de la envolvente edilicia considerados por cada sistema analizado.

Elaboración propia. 70

Tabla 14: Composición del muro exterior y de la cubierta tradicional en Latinoamérica.

Elaboración propia.

Tabla 15: Composición del muro exterior y de la cubierta tradicional en España. Elaboración propia.

Tabla 16: Características de las zonas bioclimáticas de Argentina. Elaboración propia adaptada de (Instituto Argentino de Normalización y Certificación 2012). 78

Tabla 17: Valores máximos de transmitancia térmica $U$ (W/m2.K) para condiciones de verano.

Elaboración propia adaptada de (Instituto Argentino de Normalización y Certificación, 2001a). 79

Tabla 18: Valores máximos de transmitancia térmica $\mathrm{U}(\mathrm{W} / \mathrm{m} 2 . \mathrm{K})$ para condiciones de invierno. Elaboración propia adaptada de (Instituto Argentino de Normalización y Certificación, 2001a). 79

Tabla 19: Temperatura interior de diseño para niveles de confort A, B y C. Elaboración propia adaptada de (Instituto Argentino de Normalización y Certificación, 2001a).

Tabla 20: Valores de Transmitancia Térmica (W/m3.K), Capacidad térmica $(\mathrm{kJ} / \mathrm{m} 2 . \mathrm{K})$ y Absorción a la radiación para muros y techos. Elaboración propia adaptada de (Associação Brasileira de Normas Técnicas 2013). 80

Tabla 21: Características de las zonas bioclimáticas de Brasil. Elaboración propia adaptada de (Associação Brasileira de Normas Técnicas 2008). 80

Tabla 22: Valores de transmitancia térmica (W/m2.K). Elaboración propia adaptada de (Instituto Nacional de Normalización 1997).

Tabla 23: Características de las zonas bioclimáticas de Chile. Elaboración propia adaptada de (Instituto Nacional de Normalización 1997).

Tabla 24: Valores admisibles para transmitancia térmica $(\mathrm{W} / \mathrm{m} 2 \mathrm{~K})$ de elementos opacos. Elaboración propia adaptada de (Ministerio de la Vivienda, 2007).

Tabla 25: Valores admisibles para transmitancia térmica $(\mathrm{W} / \mathrm{m} 2 \mathrm{~K})$ de elementos vidriados considerando un porcentaje de $10 \%$ a $20 \%$ en relación la superficie de la envolvente opaca. Elaboración propia adaptada de (Ministerio de la Vivienda, 2007).

Tabla 26: Valores de severidad climática de invierno. Elaboración propia adaptada de (Ministerio de la Vivienda, 2007).

Tabla 27: Valores de severidad climática de verano. Elaboración propia adaptada de (Ministerio de la Vivienda, 2007). 83

Tabla 28: Zonas climáticas según diferencia de altitud en relación a la capital de la provincia. Elaboración propia adaptada de (Ministerio de la Vivienda, 2007). 
Tabla 29: Valores de transmitancia térmica (W/m2.K). Elaboración propia adaptada de (Secretaría de Energía 2011).

Tabla 30: Valores de transmitancia de muros y techos en función del código normativo del país. Elaboración propia.

Tabla 31: Composición de los cuatro modelos de muros exteriores. Elaboración propia. 88

Tabla 32: Composición de los cuatro modelos de cubiertas. Elaboración propia.

Tabla 33: Ciudades de aplicación seleccionadas en función de la densidad poblacional, de los valores de grados día para acondicionamiento y la disponibilidad de archivo climático con extensión EPW. Elaboración propia.

Tabla 34: Descripción de las variables climáticas analizadas. Elaboración propia. 99

Tabla 35: Configuración de las características de ocupación y sistemas HVAC. Elaboración propia.

Tabla 36: Definición de parámetros activos y no activos en relación a la temperatura del aire, temperatura superficial interna, y temperatura operativa del ambiente (*Ver leyenda). Elaboración propia.

Tabla 37: Correlación entre los parámetros activos para la temperatura operativa. Elaboración propia.

Tabla 38: Consumo en acondicionamiento térmico para el Caso I - condición tradicional x según norma (kWh/m2). Elaboración propia.

Tabla 39: Consumo en acondicionamiento térmico para el Caso II - condición tradicional x según norma $\left(\mathrm{kWh} / \mathrm{m}^{2}\right)$. Elaboración propia.

Tabla 40: Muestra empleada en el análisis de regresión múltiple - Parte I. Elaboración propia. . 143

Tabla 41: Muestra empleada en el análisis de regresión múltiple - Parte II. Elaboración propia. 144

Tabla 42: Muestra empleada en el análisis de regresión múltiple - Parte III. Elaboración propia. 145

Tabla 43: Muestra empleada en el análisis de regresión múltiple - Parte IV. Elaboración propia. 146

Tabla 44: Resumen de los modelos estadísticos con una variable principal - Caso I y Caso II, verano e invierno. Elaboración propia adaptada del SPSS

Tabla 45: Coeficientes para los modelos estadísticos con una variable principal - Caso I y Caso II, verano e invierno. Elaboración propia adaptada del SPSS.

Tabla 46: Relación de las variables climáticas empleadas en los sistemas de calificación estudiados. Elaboración propia.

Tabla 47: Resumen de los modelos estadísticos para el Caso I - verano. Elaboración propia adaptada del SPSS.

Tabla 48: Coeficientes para los modelos estadísticos para el Caso I - verano. Elaboración propia adaptada del SPSS. 
Tabla 49: Resumen de los modelos estadísticos para el Caso I - invierno. Elaboración propia adaptada del SPSS. 150

Tabla 50: Coeficientes para los modelos estadísticos para el Caso I - invierno. Elaboración propia adaptada del SPSS.

Tabla 51: Resumen de los modelos estadísticos para el Caso II - verano. Elaboración propia adaptada del SPSS.

Tabla 52: Coeficientes para los modelos estadísticos para el Caso II - verano. Elaboración propia adaptada del SPSS.

Tabla 53: Resumen de los modelos estadísticos para el Caso II - invierno. Elaboración propia adaptada del SPSS.

Tabla 54: Coeficientes para los modelos estadísticos para el Caso II - invierno. Elaboración propia adaptada del SPSS.

Tabla 55: Comparación entre los consumos estimados con el método propuesto y los consumos estimados con las herramientas de cálculo del PBE de Brasil, la CEV de Chile y del CEE de España. Elaboración propia.

Tabla 56: Matriz eléctrica de Argentina, Brasil, Chile, México y España para 2015, según fuente de energía. (Billones kWh) (U.S. Energy Information Administration 2015). Elaboración propia. 170

Tabla 57: Emisiones de CO2 en la generación eléctrica según el combustible y el factor de conversión (kg CO2/GJ electricidad). Elaboración propia. 


\section{Lista de ecuaciones}

Ecuación 1: Indicador Tau. Fuente: (Instituto Argentino de Normalización y Certificación 2010).. 55 Ecuación 2: Cálculo de la incertidumbre asociada a la medición de la temperatura interna. Fuente:

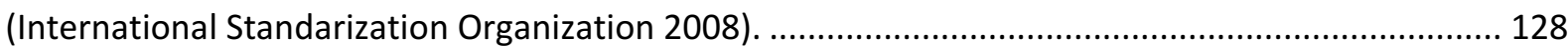

Ecuación 3: Consumo estival para el Caso I - vivienda unifamiliar. Elaboración propia................. 152

Ecuación 4: Consumo invernal para el Caso I - vivienda unifamiliar. Elaboración propia. ............ 152

Ecuación 5: Consumo estival para el Caso II - edificio multifamiliar. Elaboración propia. ............ 153

Ecuación 6: Consumo invernal para el Caso II - edificio multifamiliar. Elaboración propia........... 153

Ecuación 7: Consumo invernal para el Caso II - edificio multifamiliar. Fuente: (Instituto para la

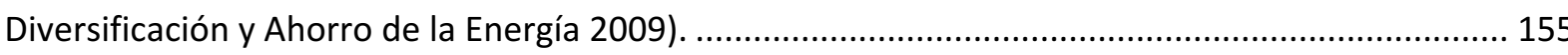


